\title{
Geophysical and Petrological Constraints on Ocean Plate Dynamics
}

\author{
by \\ Emily Kathryn Sarafian \\ B.Sc., Brown University, 2011 \\ Submitted in partial fulfillment of the requirements for the degree of \\ Doctor of Philosophy \\ at the \\ MASSACHUSETTS INSTITUTE OF TECHNOLOGY \\ and the \\ WOODS HOLE OCEANOGRAPHIC INSTITUTION \\ June 2017 \\ (C) 2017 Emily Kathryn Sarafian. All rights reserved. \\ The author hereby grants to MIT and WHOI permission to reproduce and \\ to distribute publicly paper and electronic copies of this thesis document \\ in whole or in part in any medium now known or hereafter created.
}

Signature of Author

Joint Program in Oceanography/Applied Ocean Science and Engineering Massachusetts Institute of Technology and Woods Hole Oceanographic Institution

May 4, 2017

Certified by

Rob L. Evans

Senior Scientist, Department of Geology and Geophysics, WHOI

Thesis Supervisor

Certified by

Glenn A. Gaetani

Associate Scientist, Department of Geology and Geophysics, WHOI

Thesis Supervisor

Accepted by

Mark D. Behn

Senior Scientist, Department of Geology and Geophysics, WHOI

Chairman, Joint Committee for Marine Geology and Geophysics 


\title{
Geophysical and Petrological Constraints on Ocean Plate Dynamics
}

\author{
by \\ Emily Kathryn Sarafian

\begin{abstract}
Submitted to the Department of Marine Geology and Geophysics, MIT/WHOI Joint Program in Oceanography/Applied Ocean Science and Engineering on May 4, 2017 in partial fulfillment of the requirements

for the degree of Doctor of Philosophy
\end{abstract}

\begin{abstract}
This thesis investigates the formation and subsequent motion of oceanic lithospheric plates through geophysical and petrological methods. Ocean crust and lithosphere forms at mid-ocean ridges as the underlying asthenosphere rises, melts, and flows away from the ridge axis. In Chapters 2 and 3, I present the results from partial melting experiments of mantle peridotite that were conducted in order to examine the mantle melting point, or solidus, beneath a mid-ocean ridge. Chapter 2 determines the peridotite solidus at a single pressure of $1.5 \mathrm{GPa}$ and concludes that the oceanic mantle potential temperature must be $\sim 60{ }^{\circ} \mathrm{C}$ hotter than current estimates. Chapter 3 goes further to provide a more accurate parameterization of the anhydrous mantle solidus from experiments over a range of pressures. This chapter concludes that the range of potential temperatures of the mantle beneath mid-ocean ridges and plumes is smaller than currently estimated. Once formed, the oceanic plate moves atop the underlying asthenosphere away from the ridge axis. Chapter 4 uses seafloor magnetotelluric data to investigate the mechanism responsible for plate motion at the lithosphere-asthenosphere boundary. The resulting two dimensional conductivity model shows a simple layered structure. By applying petrological constraints, I conclude that the upper asthenosphere does not contain substantial melt, which suggests that either a thermal or hydration mechanism supports plate motion. Oceanic plate motion has dramatically changed the surface of the Earth over time, and evidence for ancient plate motion is obvious from detailed studies of the longer lived continental lithosphere. In Chapter 5, I investigate past plate motion by inverting magnetotelluric data collected over eastern Zambia. The conductivity model probes the Zambian lithosphere and reveals an ancient subduction zone previously suspected from surface studies. This chapter elucidates the complex lithospheric structure of eastern Zambia and the geometry of the tectonic elements in the region, which collided as a result of past oceanic plate motion. Combined, the chapters of this thesis provide critical constraints on ocean plate dynamics.
\end{abstract}

Thesis Supervisors:

Rob L. Evans

Title: Senior Scientist, Department of Geology and Geophysics, WHOI

Glenn A. Gaetani

Title: Associate Scientist, Department of Geology and Geophysics, WHOI 


\section{Acknowledgments}

This thesis is highly misleading. The first page presents my name as though I were the mastermind - a genius singlehandedly writing manuscript after manuscript, solving every problem in a clear, succinct fashion. Every page appears polished and orderly. I would like to take this opportunity to make things perfectly clear - if I were the sole contributor to this thesis, there would be 50 pages of repetitive arguments followed by large jumps in logic and some nice looking figures. This thesis is the work of many, and the result of many, many drafts. I am very thankful to everyone who contributed to this thesis and to my graduate school experience.

None of this would exist if it were not for my advisors: Rob Evans and Glenn Gaetani. Thank you for keeping your office doors open, for your patience, and for listening to my crazy ideas. My committee members, Dan Lizarralde, Greg Hirth, and Tim Grove, provided phenomenal guidance and support. Thank you for always taking the time to meet and for providing the encouragement I needed. And thank you to my chair, Veronique Le Roux, for stepping up to save me.

There are so many WHOI scientists and staff that helped keep me going day in and day out - it is impossible to list them all. Thank you Meg Tivey, Veronique Le Roux, Sune Nielsen, Frieder Klein, Horst Marschall, Angela Helbling, Mark Behn, Henry Dick, Brian Monteleone, Lea Fraser, Julia Westwater, Andrew Daly, Kim Deisher, Kelly Servant, Eilean Kozak, and many others. Really, everyone at WHOI is pretty amazing. I also need to thank every JP student, all of the visiting students to the ExPet lab over the years, and all of the guest students I came across you all were true allies. In particular, thank you Alex Mitchell, Alec Bogdanoff, Izi Le Bras, Sophie Chu, Ben Urann, and Charlotte Wiman. And if there is one person I am forever indebted to, it's Jimmy Elsenbeck.

Without a doubt, I need to thank my family and my friends who are so close I call them family. I know my parents would be insanely proud of me. If it were not for my mother noticing my odd attachment to rocks as a child, I would not be getting my PhD in geology today. Even though he never understood what I was doing, my father always tried to be supportive. When I started in the program, he would listen to me explain my conductivity data, look at the colorful models, and say, "So that's the inside of the Earth..." He had no idea what to make of any of it. My parents were rare gems, and I owe them everything. My siblings, George, Jess, and Allison are all amazing human beings. I am so grateful that they always have my back even though I am pretty sure they consider me "the weird one". I also need to thank my in-laws (not just mom and dad, but the whole lot) for taking me in as one of their own. And to my friends: thank you so, so, so much for housing me, listening to my rants, thousands, if not millions, of texts, going along with my crazy life plans, propping me up, and keeping me grounded. Alex, all I can say is \#addiedontcare, \#wooo, \#pocketfriend, \#poppa, \#cookiebearworld. The Doug - your statistical insight is significant. Taryn, AKA Bat-ryn, thanks for practically keeping my child alive and teaching me how to be a mother. William, Willard, Wilhelm, Will - thank you for showing me what life would be like if I were male and British. 
Most importantly, thank you Adam and Adeline. Adam - you carried me, sometimes kicking and screaming. You are the best husband, partner, and coauthor. Adeline - you gave me the inspiration, drive, and necessary distractions I needed in order to finish. You are my sunshine.

Funding for this research was provided by the National Science Foundation Division of Earth Sciences (EAR) grant number 1010432, Division of Ocean Sciences (OCE) grant numbers 1459649 and 0928663, WHOI Deep Ocean Exploration Institute, and the WHOI Academic Programs Office. 


\section{Table of Contents}

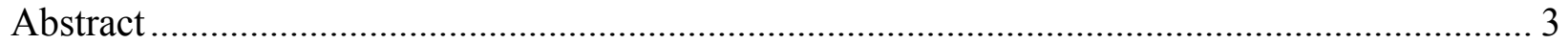

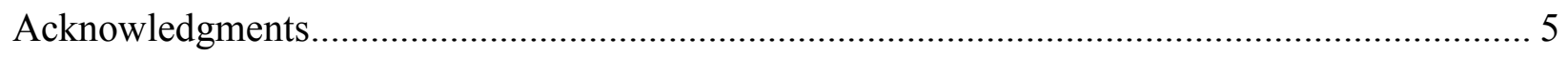

Chapter 1

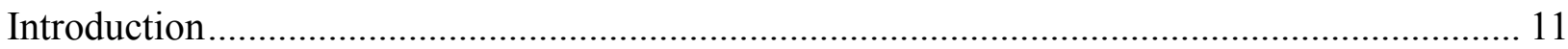

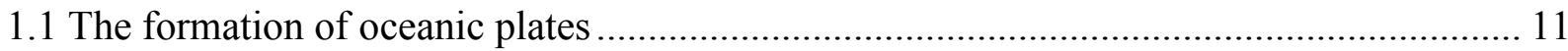

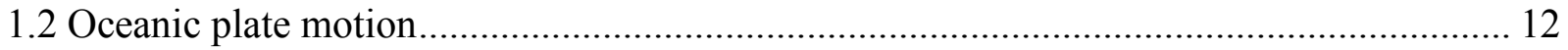

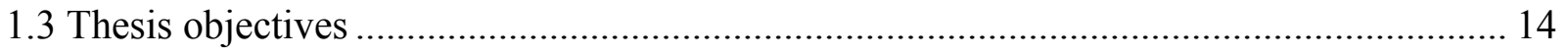

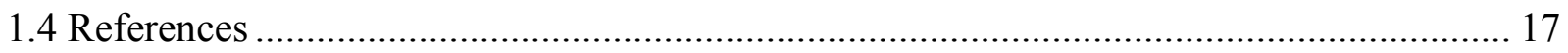

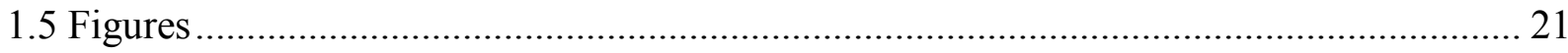

Chapter 2

Experimental constraints on the damp peridotite solidus and oceanic mantle potential

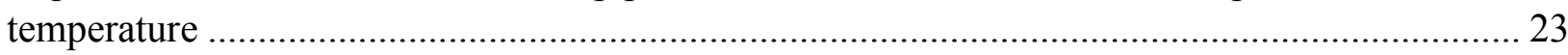

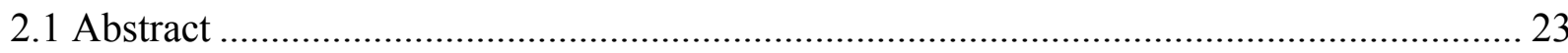

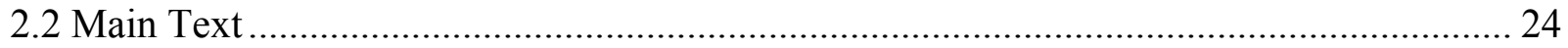

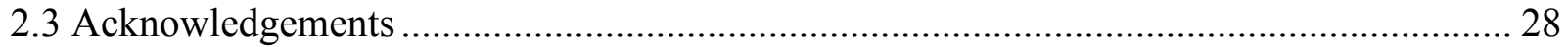

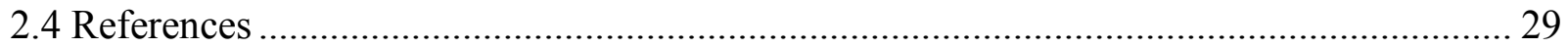

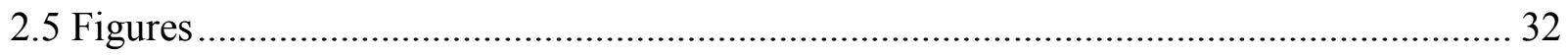

Chapter 3

Experimental determination of the $\mathrm{H}_{2} \mathrm{O}$-undersaturated peridotite solidus from 1.0 to $2.5 \mathrm{GPa} .37$

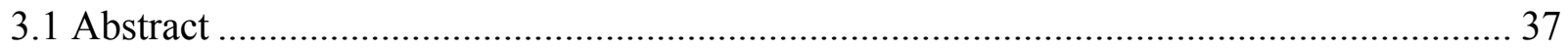

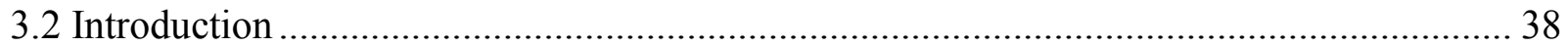

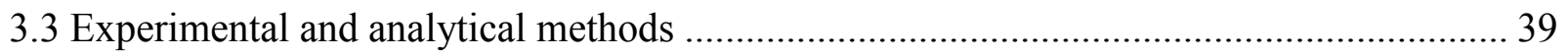

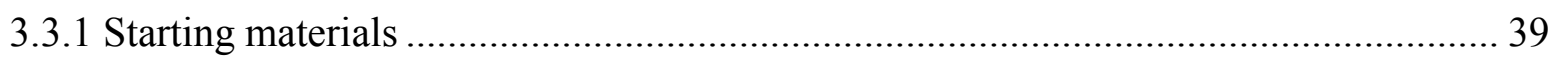

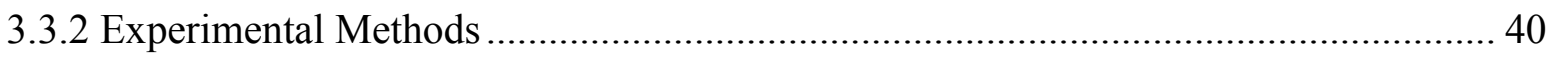

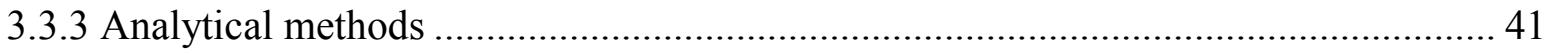

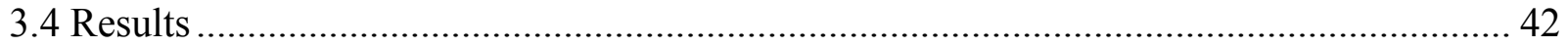

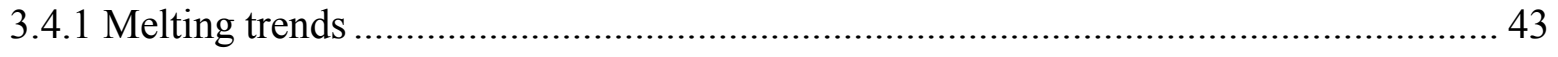

3.4.2 Capsule $\mathrm{H}_{2} \mathrm{O}$ Content .............................................................................. 44

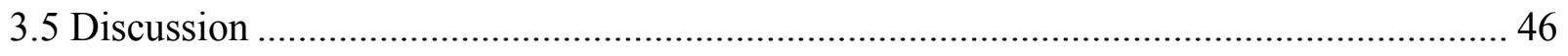

3.5.1 Comparison with Previous Work ....................................................................... 46

3.5.2 Parameterization of the Anhydrous Spinel Lherzolite Solidus ................................. 48 


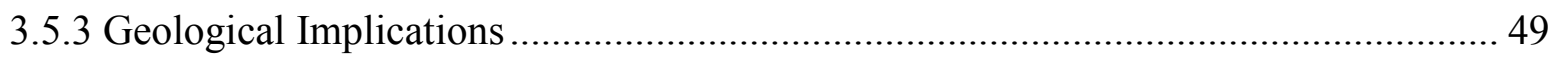

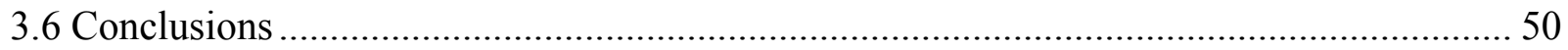

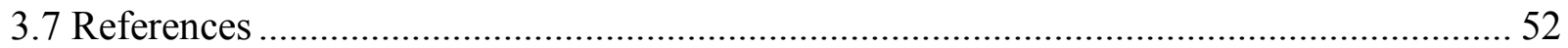

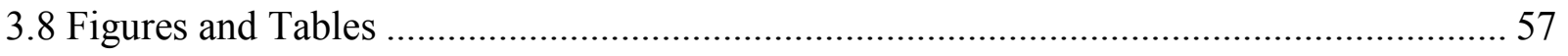

Chapter 4

The electrical structure of the central Pacific upper mantle constrained by the NoMelt

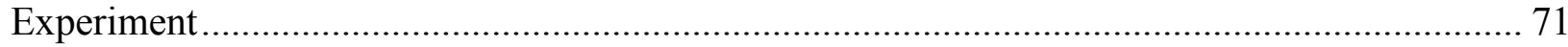

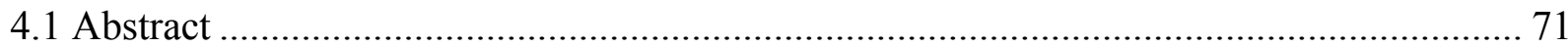

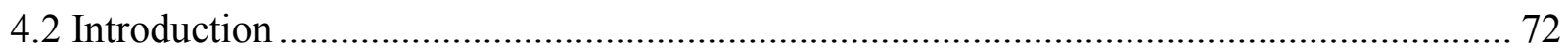

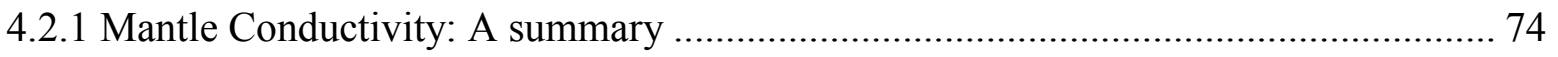

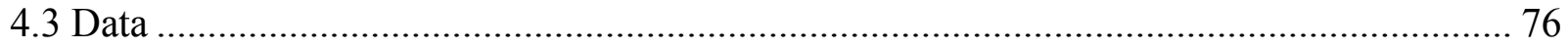

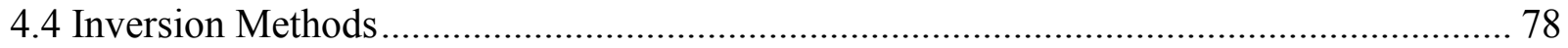

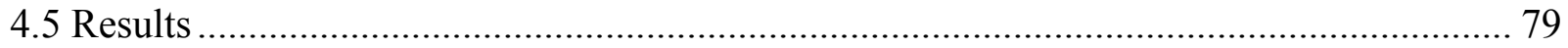

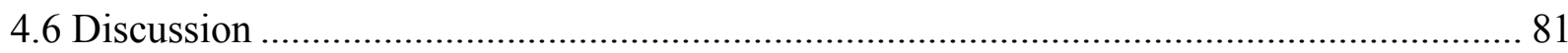

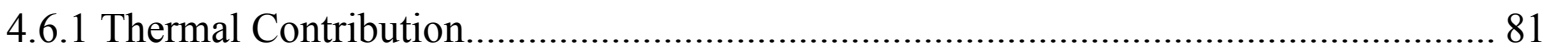

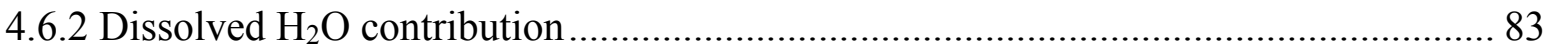

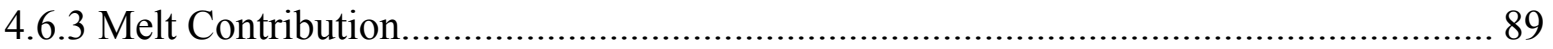

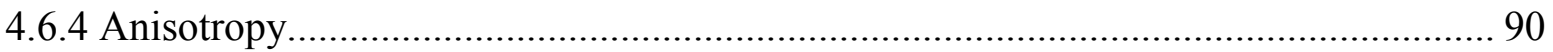

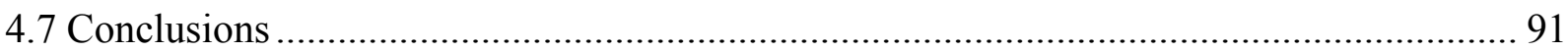

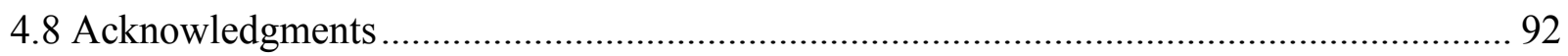

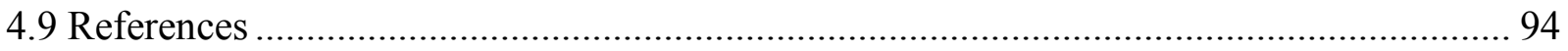

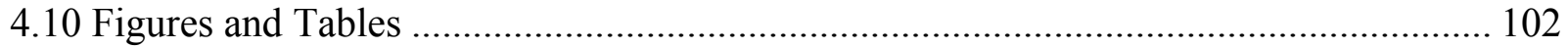

Chapter 5

Imaging Precambrian lithospheric structure in Zambia using electromagnetic methods ........... 111

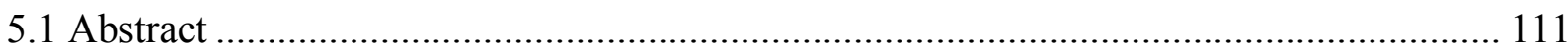

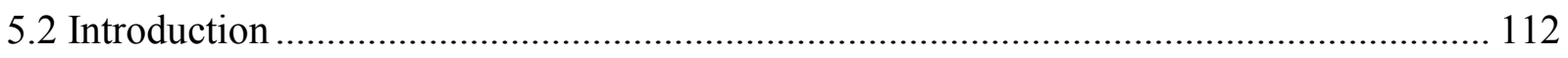

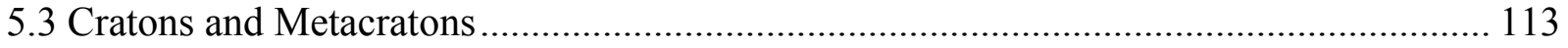

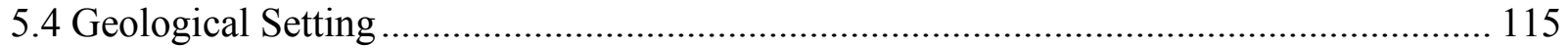

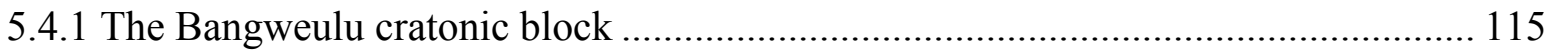

5.4.2 The Irumide and Southern Irumide Belt ............................................................. 116

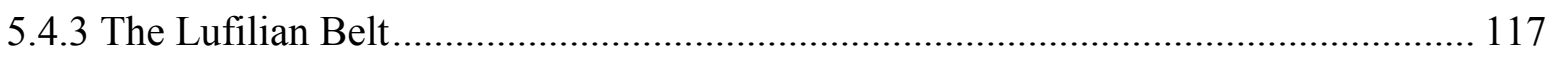

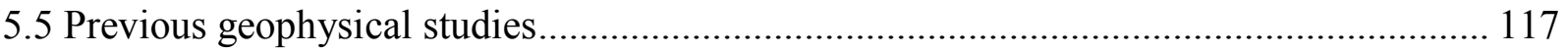

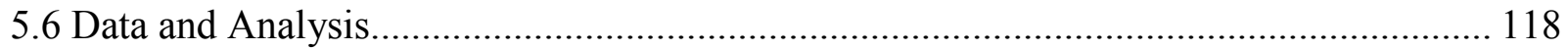




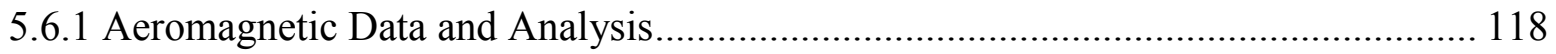

5.6.2 Magnetotelluric Data and Analysis...................................................................... 118

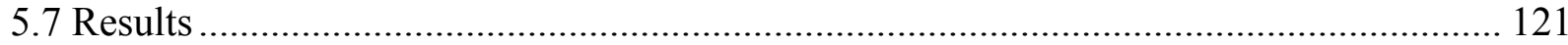

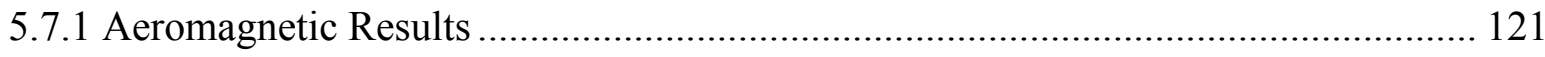

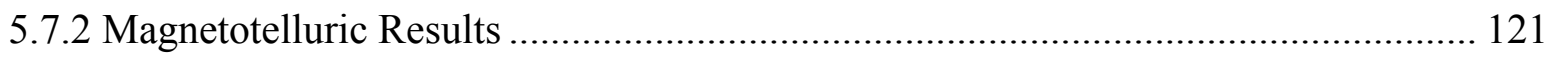

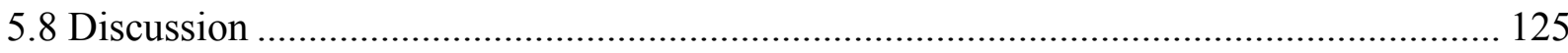

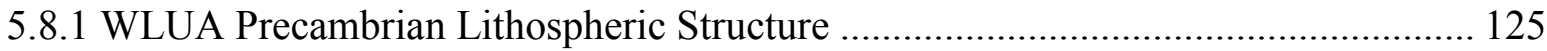

5.8.2 ELUA Precambrian Lithospheric Structure ……………........................................ 126

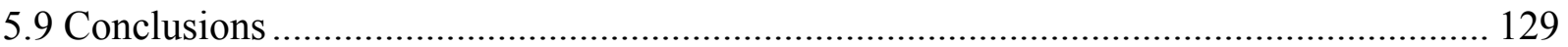

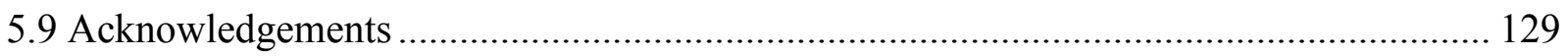

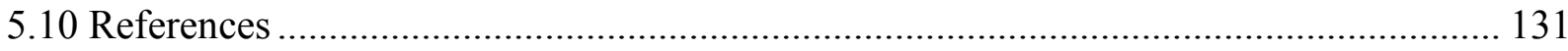

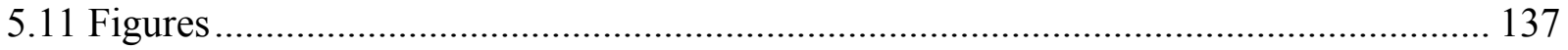

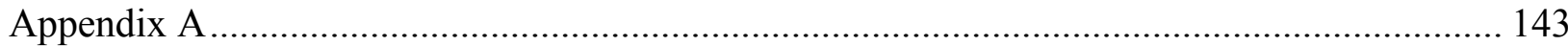

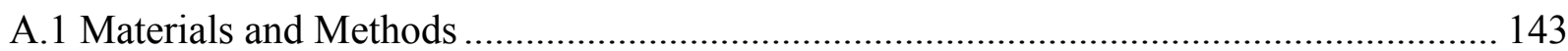

A.1.1. Experimental Design ......................................................................................... 143

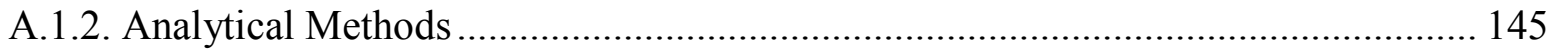

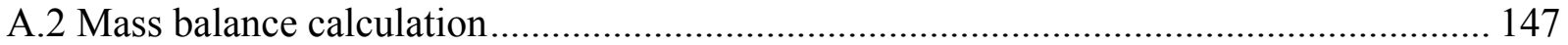

A.3 Solidus crossing calculations ................................................................................... 147

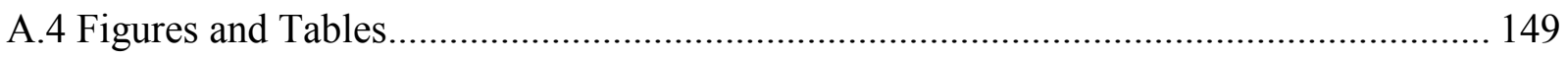

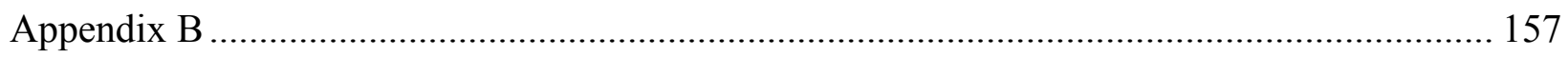

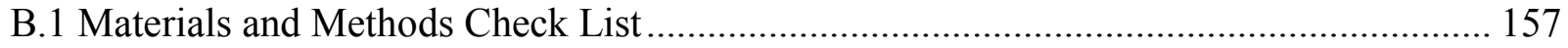

B.2 Figures and Tables................................................................................................... 163 


\section{Chapter 1}

\section{Introduction}

"While the thought of a highly mobile sea floor may seem alarming at first, it does little violence to geological history."

Robert S. Dietz [1961]

The concept of seafloor spreading [Hess, 1960] led to the modern understanding of plate tectonics where discrete rigid lithospheric plates move with respect to one another over the weaker, convecting asthenosphere [McKenzie and Parker, 1967]. New oceanic crust and lithosphere are produced along mid-ocean ridges (MORs) as tectonic plates diverge and the upwelling asthenosphere melts [Cann, 1970]. Old oceanic plates are recycled into the mantle at subduction zones where tectonic plates converge [Dickinson, 1974]. The formation and subduction of oceanic plates dramatically changes the face of the Earth by creating and destroying ocean basins, as well as reorganizing the stable, longer-lived continents. This thesis focuses on the formation and subsequent motion of oceanic plates.

\subsection{The formation of oceanic plates}

The global MOR system produces oceanic crust as a result of decompression partial melting of the asthenospheric mantle. As oceanic plates diverge, the underlying asthenosphere experiences passive adiabatic upwelling and begins to melt upon exceeding the pressure dependent solidus temperature. The melt produced migrates through the mantle and aggregates before erupting along the ridge axis [Cann, 1970; Klein and Langmuir, 1987; Langmuir et al., 1992; Plank and Langmuir, 1992; Smith and Cann, 1993] to form crust 6-7 km thick [Raitt, 1963].

The pressure and temperature at which the ascending asthenosphere exceeds the solidus is dependent on the composition of the asthenospheric mantle and the mantle potential temperature - the temperature of the mantle at the surface if it continued to rise adiabatically without experiencing partial melting [McKenzie and Bickle, 1988]. Mantle with high potential 
temperatures, or mantle compositions enriched in volatiles (e.g., $\mathrm{H}_{2} \mathrm{O}$ and $\mathrm{CO}_{2}$ ) and alkali components $\left(\mathrm{Na}_{2} \mathrm{O}\right.$ and $\left.\mathrm{K}_{2} \mathrm{O}\right)$ will begin to melt at a greater depth and will therefore sample a larger portion of the mantle [Asimow and Langmuir, 2003; Hirschmann, 2000; Plank and Langmuir, 1992]. Higher potential temperatures lead to greater mean extents of partial melting and thicker oceanic crust. On the other hand, enriched mantle generates low degree melts at depth, decreasing the mean extent of melting and only slightly increases the crustal thickness [e.g., Asimow and Langmuir, 2003; Klein and Langmuir, 1987; McKenzie and Bickle, 1988]. It is assumed that the upwelling mantle directly beneath a ridge is uniform in temperature and the residual mantle flows away from the ridge resulting in a triangular geometry of the melting regime [McKenzie and Bickle, 1988].

After melting, the residual mantle is depleted in incompatible elements, such as volatiles (e.g., $\mathrm{H}_{2} \mathrm{O}$ and $\mathrm{CO}_{2}$ ) [Hirth and Kohlstedt, 1996]. The depleted mantle conductively cools as it flows away from the ridge axis forming a rigid lithospheric plate that thickens with age. In a simple cooling plate model, the base of the lithosphere is defined by an isotherm [Parsons and Sclater, 1977; Stein and Stein, 1992]. However, in reality the transition between the oceanic lithosphere and asthenosphere, known as the lithosphere-asthenoshere boundary (LAB), has a complex structure. The LAB is a global feature assumed to occur at variable depths depending on tectonic setting [Plomerová et al., 2002] and is a critical boundary in determining plate motion [Bunge et al., 1996; Richards et al., 2002; Hoinkand Lenardic, 2008].

\subsection{Oceanic plate motion}

Oceanic plates are known to move in relation to other plates as well as the underlying convecting asthenosphere, but the mechanism enabling plate motion is still highly debated. Thermal [Stixrude and Lithgow-Bertelloni, 2005], hydration [Evans et al., 2005; Karato, 1990; Karato

and Jung, 1998], and melt mechanisms [Anderson and Spetzler, 1970; Kawakatsu et al., 2009; Lambert and Wyllie, 1970; Schmerr, 2012] have been used to explain the observed behavior at the LAB and the presence of a seismic low velocity zone (LVZ). The thermal mechanism requires that the temperature gradient of the upper asthenosphere results in a region of low viscosity at the LAB allowing the rigid plate to slide above the underlying mantle. While studies 
have shown that the pressure and temperature conditions at the LAB may result in the observed LVZ, it is uncertain whether a thermal mechanism would result in decreased viscosity [MacDonald and Ness, 1961; Stixrude and Lithgow-Bertelloni, 2005]. Additionally, the thermal mechanism may not be able to produce the sharp seismic velocity and attenuation discontinuities observed at the LAB [Anderson and Sammis, 1970; Karato and Jung, 1998].

Alternatively, the LAB may represent the boundary between a dehydrated lithosphere and a hydrated asthenosphere. The increase in mantle water content within the asthenosphere could directly influence the seismic properties of the mantle minerals [Karato and Jung, 1998], or change the microscopic viscosity of mantle minerals [Olugboji et al., 2013] resulting in a low viscosity layer to support plate motion. However, it remains uncertain if water is capable of causing the observed seismic signatures at the LAB [Fei et al., 2013].

The melt mechanism relies on the $\mathrm{LAB}$ to be impermeable to partial melt present in the asthenosphere. Melt present in the upper asthenosphere would provide a sharp decrease in mantle seismic velocity and viscosity at the LAB, effectively decoupling the lithosphere and asthenosphere. While various melts are thought to be stable within the LVZ in the upper asthenosphere [Gaillard et al., 2008; Hirschmann, 2010; Ni et al., 2011], it is unclear if enough melt is present and interconnected to generate the necessary decreases in velocity and viscosity [Takei, 2002].

Regardless of the mechanism deemed responsible for plate behavior, observations have shown that oceanic plate motion has had a huge impact on surface geology throughout geologic history. The evolution of ocean basins due to moving oceanic plates led to collision and rifting of continental masses, forming and subsequently destroying ancient supercontinents [Stern, 2008]. Evidence for these historic tectonic events is recorded in the surviving complex continental crust and lithosphere. Reconstructions of past plate motion come from surface geological mapping, geochemical, geochronological, and geophysical studies [Abdelsalam et al., 2011; Begg et al., 2009; De Waele et al., 2009; Johnson et al., 2006; Pasyanos and Nyblade, 2007; Ritsema et al., 1998; Ritsema and van Heijst, 2000]. However, substantial uncertainties in reconstructing continents over geologic timescales exist as continental tectonic elements experienced heavy 
structural alteration, high degrees of metamorphism, erosion and sedimentary cover [Abdelsalam et al., 2002; Artemieva and Mooney, 2001; Daly, 1986; De Waele et al., 2008; Johnson et al., 2005; Liégeois et al., 2013].

\subsection{Thesis objectives}

This thesis employs geophysical and petrological methods to examine the formation of oceanic plates along the mid-ocean ridge system, as well as the current and past movement of oceanic plates over the underlying asthenosphere. The combination of geophysics, specifically magnetotellurics, and petrology leads to a more accurate description of the mantle. Briefly, the chapters of this thesis investigate (Fig. 1):

Chapter 2 and 3: Solidus and potential temperature constraints of the mantle beneath a mid-ocean ridge, which impact melt generation and plate formation.

Chapter 4: The mechanism controlling oceanic plate motion over the underlying asthenosphere.

Chapter 5: Evidence of past oceanic plate motion in current continental settings.

Chapters 2 and 3 present a study to experimentally determine the damp peridotite solidus. Peridotite is thought to be the main component of the ambient upper mantle. Therefore, understanding the pressure and temperature path of the peridotite solidus is a critical constraint on mantle melting at a mid-ocean ridge. In this study, I performed partial melting experiments of a peridotite composition with a controlled amount of $\mathrm{H}_{2} \mathrm{O}$ using long-established experimental methods, but with a slight modification. By including large grains of olivine $(\sim 300 \mu \mathrm{m}$ in diameter) within my peridotite experiments, I was able to measure the $\mathrm{H}_{2} \mathrm{O}$ content of the olivine grains and quantify the total $\mathrm{H}_{2} \mathrm{O}$ content of my experimental capsules - something that was often deemed unattainable in previous studies due to run-produced minerals being too small to measure [Hirschmann, 2000; Hirschmann et al., 2009]. By conducting partial melting experiments over a range of pressures, I found that current estimates of the peridotite solidus are too low. Reconciling my results with geophysical constraints on the depth of melting beneath MORs, I was able to determine that the ambient mantle potential temperature must be $\sim 60{ }^{\circ} \mathrm{C}$ hotter. This study provides important new constraints on mantle melting, which dictates the formation of oceanic plates along the mid-ocean ridge system. In addition, the hotter mantle 
potential temperature could have important implications for how oceanic plates move in relation to the underlying asthenosphere - a topic that is further explored in the next chapter.

Chapter 4 focuses on magnetotelluric data collected over the intermediate-aged Pacific plate between the Clarion and Clipperton fracture zones from the NoMelt Experiment. The NoMelt Experiment aimed to understand the structure of the LAB and shed light on the mechanism for plate motion at this boundary. The study region is far from the mid-ocean ridge at which the plate formed, and is devoid of off axis magmatism and rugged bathymetry. At this plate age, the thickness of the lithosphere is expected to be relatively constant at $\sim 90 \mathrm{~km}$ as described in the cooling plate model [Parsons and Sclater, 1977; Stein and Stein, 1992]. With all things considered, it was anticipated that the oceanic upper mantle structure in the NoMelt region was simple. Inverse modeling of the magnetotelluric data did not disappoint. The preferred electrical model for the region resulted in a simple isotropic layered model of $80 \mathrm{~km}$ thick resistive lithosphere over a less resistive asthenosphere. I found that temperature alone could explain the observed conductivity structure if an adiabatic gradient of $0.5^{\circ} \mathrm{C} / \mathrm{km}$ was assumed for the upper mantle. A lower gradient of $0.3{ }^{\circ} \mathrm{C} / \mathrm{km}$ could also explain the observed conductivity but would require dissolved $\mathrm{H}_{2} \mathrm{O}$ in the asthenosphere. Our results did not support the presence of melt at the LAB and instead suggest that temperature alone, or a combination of temperature and dissolved $\mathrm{H}_{2} \mathrm{O}$ is the mechanism that sustains plate motion, at least in the central Pacific oceanic plate.

Regardless of the mechanism, oceanic plates have been moving throughout the course of geologic history. In Chapter 5, I look at the upper mantle structure of eastern Zambia as evidence for such past plate motion. Zambia is known to have very complex Precambrian geology due to multiple episodes of rifting and collision during the formation and breakup of supercontinents. By inverting magnetotelluric data that I collected across eastern Zambia to eastern Malawi, I was able to image the lithospheric structure in detail and shed light on the extent and structure of the Precambrian tectonic elements. As one might expect, the lithospheric structure of Zambia rivals the complexity of the surface geology. My magnetotelluric models showed that six tectonic elements are present in the defined region of study - two of which (the Mwembeshi Suture Zone and the Niassa Craton) previous studies could only speculate and not explicitly map. The 
Mwembeshi Suture Zone, as imaged in my magnetotelluric model, most likely represents a Mesoproterozoic subduction zone where a young, hot oceanic plate subducted beneath the Irumide Belt forcing the collision of two continental masses [Johnson et al., 2007], and providing clear evidence for ancient oceanic plate motion. 


\subsection{References}

Abdelsalam, M. G., S. S. Gao, and J.-P. Liégeois (2011), Upper mantle structure of the Saharan Metacraton, Journal of African Earth Sciences, 60(5), 328-336, doi:10.1016/j.jafrearsci.2011.03.009.

Abdelsalam, M. G., J.-P. Liégeois, and R. J. Stern (2002), The saharan metacraton, Journal of African Earth Sciences, 34(3), 119-136, doi:10.1016/S0899-5362(02)00013-1.

Anderson, D. L., and C. Sammis (1970), Partial melting in the upper mantle, Physics of the Earth and Planetary Interiors, 3, 41-50, doi:10.1016/0031-9201(70)90042-7.

Anderson, D. L., and H. Spetzler (1970), Partial melting and the low-velocity zone, Physics of the Earth and Planetary Interiors, 4(1), 62-64, doi:10.1016/0031-9201(70)90030-0.

Artemieva, I. M., and W. D. Mooney (2001), Thermal thickness and evolution of Precambrian lithosphere: a global study, Journal of Geophysical Research: Solid Earth, 106(B8), 1638716414, doi:10.1029/2000JB900439.

Asimow, P. D., and C. Langmuir (2003), The importance of water to oceanic mantle melting regimes, Nature, 421(6925), 815-820, doi:10.1038/nature01429.

Begg, G., W. Griffin, L. Natapov, S. Y. O'Reilly, S. Grand, C. O'Neill, J. Hronsky, Y. P. Djomani, C. Swain, and T. Deen (2009), The lithospheric architecture of Africa: Seismic tomography, mantle petrology, and tectonic evolution, Geosphere, 5(1), 23-50, doi:10.1130/GES00179.1.

Bunge H.P., Richards M.A., Baumgardner J.R. (1996) Effect of depth-dependent viscosity on the planform of mantle convection. Nature 379: 436-438.

Cann, J. (1970), New model for the structure of the ocean crust, Nature, 226, 928-930.

Daly, M. (1986), The intracratonic Irumide belt of Zambia and its bearing on collision orogeny during the Proterozoic of Africa, Geological Society, London, Special Publications, 19(1), $321-328$.

De Waele, B., I. Fitzsimons, M. Wingate, F. Tembo, B. Mapani, and E. Belousova (2009), The geochronological framework of the Irumide Belt: a prolonged crustal history along the margin of the Bangweulu Craton, American Journal of Science, 309(2), 132-187, doi: $10.2475 / 02.2009 .03$.

De Waele, B., S. Johnson, and S. Pisarevsky (2008), Palaeoproterozoic to Neoproterozoic growth and evolution of the eastern Congo Craton: its role in the Rodinia puzzle, Precambrian Research, 160(1), 127-141, doi:10.1016/j.precamres.2007.04.020.

Dickinson, W. R. (1974), Plate tectonics and sedimentation.

Dietz, R. S. (1961), Continent and ocean basin evolution by spreading of the sea floor, Nature, 190(4779), 854-857. 
Evans, R. L., G. Hirth, K. Baba, D. Forsyth, A. Chave, and R. Mackie (2005), Geophysical evidence from the MELT area for compositional controls on oceanic plates, Nature, 437(7056), 249-252, doi:10.1038/nature04014.

Fei H, Wiedenbeck M, Yamazake D, Katsura T (2013), Small effect of water on upper-mantle rheology based on silicon self-diffusion coefficients, Nature, 498, 213-215, doi: 10.1038/nature12193.

Gaillard, F., M. Malki, G. Iacono-Marziano, M. Pichavant, and B. Scaillet (2008), Carbonatite melts and electrical conductivity in the asthenosphere, Science, 322(5906), 1363-1365, doi:10.1126/science.1164446.

Hess, H. H. (1960), Evolution of ocean basins, Princeton University, Department of Geology.

Hirschmann, M. M. (2000), Mantle solidus: experimental constraints and the effects of peridotite composition, Geochemistry, Geophysics, Geosystems, 1(10), doi:10.1029/2000GC000070.

Hirschmann, M. M. (2010), Partial melt in the oceanic low velocity zone, Physics of the Earth and Planetary Interiors, 179(1-2), 60-71, doi:10.1016/j.pepi.2009.12.003.

Hirschmann, M. M., T. Tenner, C. Aubaud, and A. C. Withers (2009), Dehydration melting of nominally anhydrous mantle: The primacy of partitioning, Physics of the Earth and Planetary Interiors, 176(1-2), 54-68, doi:10.1016/j.pepi.2009.04.001.

Hirth, G., and D. L. Kohlstedt (1996), Water in the oceanic upper mantle: implications for rheology, melt extraction and the evolution of the lithosphere, Earth and Planetary Science Letters, 144(1), 93-108, doi:10.1016/0012-821X(96)00154-9.

Hoink T., Lenardic A. (2008) Three-dimensional mantle convection simulations with a lowviscosity asthenosphere and the relationship between heat flow and the horizontal length scale of convection. Geophys. Res. Lett. 35: doi:10.1029/2008GL033854.

Johnson, S., B. De Waele, and K. Liyungu (2006), U-Pb sensitive high-resolution ion microprobe (SHRIMP) zircon geochronology of granitoid rocks in eastern Zambia: Terrane subdivision of the Mesoproterozoic Southern Irumide Belt, Tectonics, 25(6), doi:10.1029/2006TC001977.

Johnson, S. P., B. De Waele, F. Tembo, C. Katongo, K. Tani, Q. Chang, T. Iizuka, and D. Dunkley (2007), Geochemistry, geochronology and isotopic evolution of the CheworeRufunsa Terrane, Southern Irumide Belt: a Mesoproterozoic continental margin arc, Journal of Petrology, doi:10.1093/petrology/egm025.

Johnson, S. P., T. Rivers, and B. De Waele (2005), A review of the Mesoproterozoic to early Palaeozoic magmatic and tectonothermal history of south-central Africa: implications for Rodinia and Gondwana, Journal of the Geological Society, 162(3), 433-450, doi:10.1144/0016-764904-028.

Karato, S.-I. (1990), The role of hydrogen in the electrical conductivity of the upper mantle, Nature, 347, 272-273, doi:10.1038/347272a0. 
Karato, S.-i., and H. Jung (1998), Water, partial melting and the origin of the seismic low velocity and high attenuation zone in the upper mantle, Earth and Planetary Science Letters, 157(3-4), 193-207, doi:10.1016/S0012-821X(98)00034-X.

Kawakatsu, H., P. Kumar, Y. Takei, M. Shinohara, T. Kanazawa, E. Araki, and K. Suyehiro (2009), Seismic evidence for sharp lithosphere-asthenosphere boundaries of oceanic plates, Science, 324(5926), 499-502, doi:10.1126/science.1169499.

Klein, E. M., and C. H. Langmuir (1987), Global correlations of ocean ridge basalt chemistry with axial depth and crustal thickness, Journal of Geophysical Research: Solid Earth (19782012), 92(B8), 8089-8115, doi:10.1029/JB092iB08p08089.

Lambert, I. B., and P. J. Wyllie (1970), Low-velocity zone of the Earth's mantle: incipient melting caused by water, Science, 169(3947), 764-766, doi:10.1126/science.169.3947.764.

Langmuir, C. H., E. M. Klein, and T. Plank (1992), Petrological systematics of mid-ocean ridge basalts: constraints on melt generation beneath ocean ridges, in Mantle Flow and Melt Generation at Mid-Ocean Ridges, edited by J. Phipps Morgan, D. K. Blackman and J. M. Sinton, pp. 183-280, AGU, Washington D.C.

Liégeois, J.-P., M. G. Abdelsalam, N. Ennih, and A. Ouabadi (2013), Metacraton: nature, genesis and behavior, Gondwana Research, 23(1), 220-237, doi:10.1016/j.gr.2012.02.016.

MacDonald, G. J., and N. F. Ness (1961), A study of the free oscillations of the earth, Journal of Geophysical Research, 66(6), 1865-1911, doi:10.1029/JZ066i006p01865.

McKenzie, D., and M. Bickle (1988), The volume and composition of melt generated by extension of the lithosphere, Journal of petrology, 29(3), 625-679, doi:10.1093/petrology/29.3.625.

McKenzie, D. P., and R. L. Parker (1967), The North Pacific: an example of tectonics on a sphere, Nature, 216, 1276-1280.

Ni, H., H. Keppler, and H. Behrens (2011), Electrical conductivity of hydrous basaltic melts: implications for partial melting in the upper mantle, Contributions to Mineralogy and Petrology, 162(3), 637-650, doi:10.1007/s00410-011-0617-4.

Olugboji, T. M., S. Karato, and J. Park (2013), Structures of the oceanic lithosphereasthenosphere boundary: mineral-physics modeling and seismological signatures, Geochemistry, Geophysics, Geosystems, n/a-n/a, doi:10.1002/ggge.20086.

Parsons, B., and J. G. Sclater (1977), An analysis of the variation of ocean floor bathymetry and heat flow with age, Journal of geophysical research, 82(5), 803-827, doi:10.1029/JB082i005p00803.

Pasyanos, M. E., and A. A. Nyblade (2007), A top to bottom lithospheric study of Africa and Arabia, Tectonophysics, 444(1), 27-44, doi:10.1016/j.tecto.2007.07.008. 
Plank, T., and C. H. Langmuir (1992), Effects of the melting regime on the composition of the oceanic crust, Journal of Geophysical Research: Solid Earth (1978-2012), 97(B13), 1974919770, doi:10.1029/92JB01769.

Plomerová, J., D. Kouba, and V. Babuška (2002), Mapping the lithosphere-asthenosphere boundary through changes in surface-wave anisotropy, Tectonophysics, 358(1), 175-185, doi:10.1016/S0040-1951(02)00423-7.

Raitt, M. (1963), The crustal rocks, The sea, 3, 85-102.

Richards MA, Yang WS, Baumgardner JR, Bunge HP (2002), Role of a low-viscosity zone in stabilizing place tectonics: Implications for comparative terrestrial planetology, Geochem. Geophys. Geosyst., 2, 1040, doi: 10.1029/2000GC000115.

Ritsema, J., A. A. Nyblade, T. J. Owens, C. A. Langston, and J. C. VanDecar (1998), Upper mantle seismic velocity structure beneath Tanzania, east Africa: Implications for the stability of cratonic lithosphere, Journal of Geophysical Research: Solid Earth, 103(B9), 2120121213, doi:10.1029/98JB01274.

Ritsema, J., and H. van Heijst (2000), New seismic model of the upper mantle beneath Africa, Geology, 28(1), 63-66.

Schmerr, N. (2012), The Gutenberg discontinuity: melt at the lithosphere-asthenosphere boundary, Science, 335(6075), 1480-1483, doi:10.1126/science.1215433.

Smith, D. K., and J. R. Cann (1993), Building the crust at the Mid-Atlantic Ridge, Nature, 365, 707-715.

Stein, C. A., and S. Stein (1992), A model for the global variation in oceanic depth and heat flow with lithospheric age, Nature, 359(6391), 123-129.

Stern, R. J. (2008), Neoproterozoic crustal growth: the solid Earth system during a critical episode of Earth history, Gondwana research, 14(1), 33-50, doi:10.1016/j.gr.2007.08.006.

Stixrude, L., and C. Lithgow-Bertelloni (2005), Mineralogy and elasticity of the oceanic upper mantle: Origin of the low-velocity zone, Journal of Geophysical Research, 110(B3), doi:10.1029/2004jb002965.

Takei, Y. (2002), Effect of pore geometry onVP/VS: From equilibrium geometry to crack, Journal of Geophysical Research, 107(B2), doi:10.1029/2001jb000522. 


\subsection{Figures}

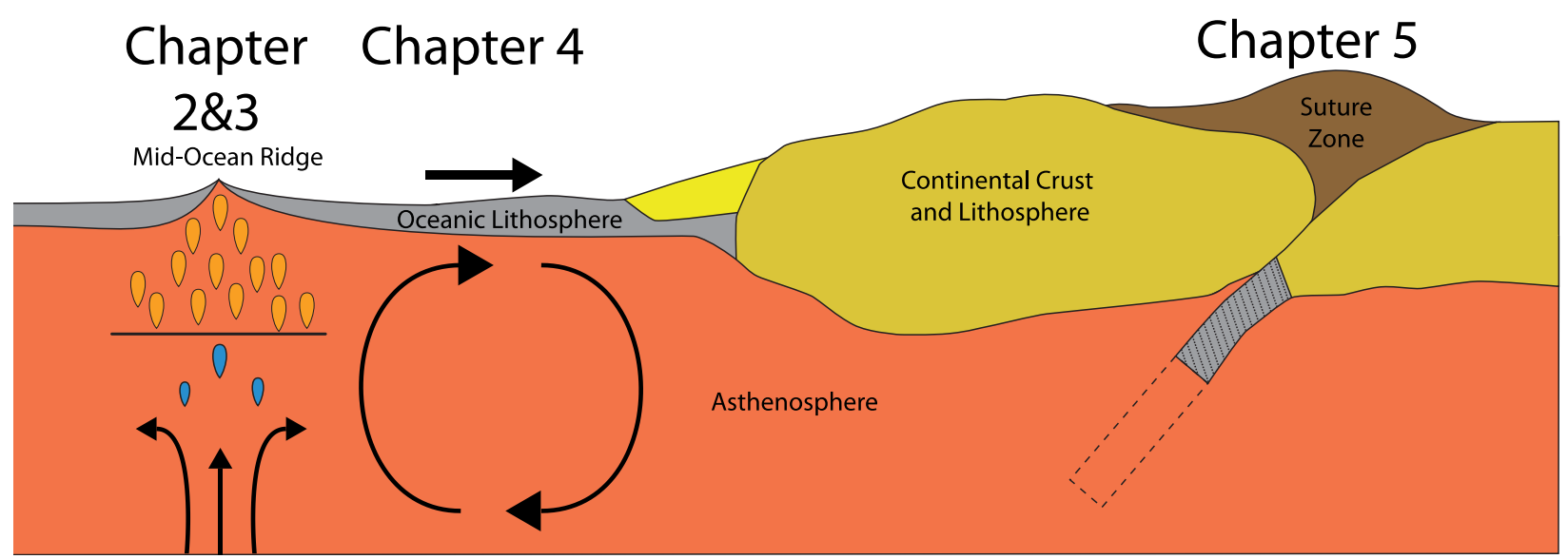

\section{Figure 1}

A cartoon of the regions investigated in each thesis chapter. Chapters 2 and 3 examine mantle melting beneath a mid-ocean ridge by conducting partial melting experiments. Chapter 4 uses seafloor magnetotelluric data to examine the mechanism responsible for plate motion at the boundary between the oceanic lithospheric plate and the underlying asthenosphere. Chapter 5 presents an electromagnetic model of continental lithospheric structure and reveals an ancient suture zone formed from past plate motion. 


\section{Chapter 2}

\section{Experimental constraints on the damp peridotite solidus and oceanic}

mantle potential temperature

\subsection{Abstract}

Decompression of hot mantle rock upwelling beneath oceanic spreading centers causes it to exceed the melting point (solidus), producing magmas that ascend to form basaltic crust $\sim 6-7 \mathrm{~km}$ thick. The oceanic upper mantle contains $\sim 50-200 \mu \mathrm{g} / \mathrm{g} \mathrm{H} \mathrm{H}_{2} \mathrm{O}$ dissolved in nominally anhydrous minerals, which - relative to its low concentration - has a disproportionate effect on the solidus that has not been quantified experimentally. Here we present results from an experimental determination of the peridotite solidus containing known amounts of dissolved hydrogen. Our data reveal that the $\mathrm{H}_{2} \mathrm{O}$-undersaturated peridotite solidus is hotter than previously thought. Reconciling geophysical observations of the melting regime beneath the East Pacific Rise with our experimental results requires that existing estimates for the oceanic upper mantle potential temperature be adjusted upward by $\sim 60^{\circ} \mathrm{C}$.

This chapter is published as: Emily Sarafian, Glenn A. Gaetani, Erik H. Hauri, and Adam R. Sarafian, 2017. Experimental constraints on the damp peridotite solidus and oceanic mantle potential temperature. Science, doi: 10.1126/scienceaaj2165. The final publication is available at Science via http://dx.doi.org/10.1126/scienceaaj2165, and this article is reprinted as accepted with permission granted in the original copyright agreement. 


\subsection{Main Text}

New ocean crust is formed by basaltic magmatism along $65,000 \mathrm{~km}$ of divergent plate boundaries - known as mid-ocean ridges - that are characterized by elevated topography, shallow seismicity, and high heat flow [Searle, 2013]. Mid-ocean ridge basalts (MORB) are produced by decompression partial melting of mantle rock as it ascends adiabatically beneath the ridge [Cann, 1970; Langmuir et al., 1992; Plank and Langmuir, 1992]. The depth at which mantle rock (peridotite, pyroxenite, eclogite, etc.) begins to melt is controlled by a combination of mantle potential temperature and the solidus [McKenzie and Bickle, 1988]. The potential temperature of any parcel of mantle is the temperature it would have upon ascending adiabatically to the surface without undergoing partial melting, and has important implications for mantle dynamics. A recent estimate for the range of potential temperatures in the oceanic upper mantle is 1314 to $1464{ }^{\circ} \mathrm{C}$ [Dalton et al., 2014]. It is generally accepted that the bulk of the upper mantle source of MORB consists of peridotite, so knowledge of its solidus combined with geophysical observations indicating the presence of partial melt can be used to constrain potential temperature. However, the peridotite solidus is sensitive to the presence of small amounts of hydrogen dissolved in the nominally anhydrous minerals (NAMs) that comprise the rock. At $\mathrm{H}_{2} \mathrm{O}$-undersaturated ("damp") conditions, the melting temperature of peridotite is dramatically lower at any given pressure relative to the anhydrous solidus, thereby increasing the depth at which partial melting begins for any potential temperature [Hirth and Kohlstedt, 1996]. Partial melting that begins beneath a ridge at the "damp" solidus involves a larger volume of peridotite and produces a higher mean pressure of melting combined with lower mean extent of melting [Asimow and Langmuir, 2003]. The bulk oceanic upper mantle is estimated to contain 50 to 200 $\mu \mathrm{g} / \mathrm{g} \mathrm{H}_{2} \mathrm{O}$ [Michael, 1988; Saal et al., 2002], but its influence on the onset of peridotite melting has proven challenging to quantify experimentally.

An experimental determination of the "damp" peridotite solidus requires controlling and characterizing the amount of $\mathrm{H}_{2} \mathrm{O}$ dissolved in NAMs. Despite meticulous drying protocols, a small amount of $\mathrm{H}_{2} \mathrm{O}$ is present in most high-pressure melting experiments due to adsorption onto starting materials (usually powders) [Hirschmann, 2000]. We are generally hindered from measuring the concentrations of $\mathrm{H}_{2} \mathrm{O}$ in NAMs that grow during partial melting experiments conducted near the peridotite solidus because of small grain sizes [Hirschmann et al., 2009]. 
Here, we developed an experimental approach that overcomes this difficulty and used it to quantify the solidus temperature for peridotite containing $140 \mu \mathrm{g} / \mathrm{g}$ dissolved $\mathrm{H}_{2} \mathrm{O}$ at $1.5 \mathrm{GPa}$ near the center of the spinel lherzolite stability field (see Supplement). Our approach takes advantage of the consistent, low concentration of adsorbed $\mathrm{H}_{2} \mathrm{O}$, rapid $\mathrm{H}$ diffusion through olivine [Kohlstedt and Mackwell, 1998; Demouchy and Mackwell, 2006], and strong partitioning of $\mathrm{H}_{2} \mathrm{O}$ into silicate melt [Aubaud et al., 2004; Hauri et al., 2006].

To determine the "damp" peridotite solidus, we conducted partial melting experiments at 1.5 GPa using a piston cylinder device [Boyd and England, 1960]. We added $\sim 300 \mu \mathrm{m}$ in diameter spheres of San Carlos olivine in 5:95 proportion by weight to a synthetic depleted MORB mantle (DMM) peridotite (Table S1) [Workman and Hart, 2005]. The rapid diffusivity of $\mathrm{H}$ in olivine [Kohlstedt and Mackwell, 1998; Demouchy and Mackwell, 2006] allows a sphere $500 \mu \mathrm{m}$ in diameter to diffusively equilibrate with the $\mathrm{H}_{2} \mathrm{O}$ fugacity imposed by the fine-grained peridotite matrix within a few hours (Fig S1) (see Supplement). This allowed the San Carlos spheres in our experiments to act as hygrometers with a $\mathrm{H}$ content we analyzed using secondary ion mass spectrometry (SIMS) (Fig 1; Table S2). Once we measured the H concentration of the spheres, we calculated the bulk $\mathrm{H}_{2} \mathrm{O}$ content of the peridotite using experimentally determined intermineral partition coefficients [Hirschmann et al., 2009; Aubaud et al., 2004; Hauri et al., 2006; O'Leary et al., 2010] (see Supplement). All San Carlos olivine spheres we measured within each capsule contained the same $\mathrm{H}_{2} \mathrm{O}$ content and are homogenous (see Table S2), indicating experimental equilibrium.

The initial $\mathrm{H}_{2} \mathrm{O}$ content of the San Carlos olivine spheres was $6.7 \pm 0.1 \mu \mathrm{g} / \mathrm{g}(\mathrm{n}=3)$ [Gaetani et al., 2014] (all errors reported as 2 SE). Our analyses of the post-experiment spheres indicate an average $\mathrm{H}_{2} \mathrm{O}$ concentration of $32 \pm 3 \mu \mathrm{g} / \mathrm{g}(\mathrm{n}=7)$ at temperatures below $1320^{\circ} \mathrm{C}$. We interpreted these experiments to be below the solidus as they did not contain any discernable partial melt. We used mass balance calculations based on the major element compositions of the phases (Database $\mathrm{S} 1$ ) and the $\mathrm{H}_{2} \mathrm{O}$ content of the olivine spheres to determine that the bulk peridotite had a $\mathrm{H}_{2} \mathrm{O}$ content of $140 \pm 20 \mu \mathrm{g} / \mathrm{g} \mathrm{H}_{2} \mathrm{O}(\mathrm{n}=5)$ (Table S3). Water is incompatible in the residual solid during peridotite partial melting with a bulk partition coefficient similar to that of the light rare earth element Ce [Saal et al., 2002; Hauri et al., 2006]. Therefore, upon crossing the 
"damp" solidus $\mathrm{H}_{2} \mathrm{O}$ should be strongly concentrated into the melt and the amount of $\mathrm{H}_{2} \mathrm{O}$ in the olivine spheres is expected to drop. We see this in spheres from experiments conducted above $1320{ }^{\circ} \mathrm{C}$, where $\mathrm{H}_{2} \mathrm{O}$ decreases systematically with increasing temperature (Fig. 2). We interpret these experiments to be above the solidus as they contain partial melt. We conclude from our experiments that the $140 \mu \mathrm{g} / \mathrm{g} \mathrm{H}_{2} \mathrm{O}$ peridotite solidus is between 1310 and $1330{ }^{\circ} \mathrm{C}$ (i.e. $\sim 1320$ $\left.{ }^{\circ} \mathrm{C}\right)$. For comparison, the parameterization of Hirschmann [2000] of the nominally anhydrous solidus (referred to as nominally anhydrous as it is based on experiments with unknown $\mathrm{H}_{2} \mathrm{O}$ contents) places the initiation of melting at $1.5 \mathrm{GPa}$ and $1308{ }^{\circ} \mathrm{C}$ (Fig 2). Our experimentally derived solidus of $1320{ }^{\circ} \mathrm{C}$ at $1.5 \mathrm{GPa}$ is in agreement with the nominally anhydrous solidus, given the $\pm 10{ }^{\circ} \mathrm{C}$ temperature uncertainty typically associated with piston cylinder experiments. This level of agreement suggests that $\sim 140 \mu \mathrm{g} / \mathrm{g}$ is a reasonable estimate for the bulk $\mathrm{H}_{2} \mathrm{O}$ content of previous experiments (Fig 3). A cryoscopic calculation [Hirschmann et al., 2009] based on our experimentally determined $140 \mu \mathrm{g} / \mathrm{g} \mathrm{H}_{2} \mathrm{O}$ peridotite solidus places the $1.5 \mathrm{GPa}$ truly anhydrous $\left(0 \mu \mathrm{g} / \mathrm{g} \mathrm{H}_{2} \mathrm{O}\right)$ peridotite solidus at $\sim 1370{ }^{\circ} \mathrm{C}$ (Fig 2) (see Supplement).

Magnetotelluric (MT) observations indicate the presence of a highly conductive region at 20-90 $\mathrm{km}$ depth beneath the ridge crest along the $8-11^{\circ} \mathrm{N}$ segment of the East Pacific Rise (EPR), which has been interpreted as the portion of the ascending mantle undergoing substantial partial melting in response to passive upwelling. The conductivity of partial melt is orders of magnitude higher than that of residual peridotite, so that MT is a sensitive tool for identifying the presence of melt in the oceanic upper mantle [Key et al., 2013]. If, as in previous studies, we assume that the nominally anhydrous peridotite solidus represents the $0 \mu \mathrm{g} / \mathrm{g} \mathrm{H}_{2} \mathrm{O}$ solidus an adiabat with a potential temperature of $1350{ }^{\circ} \mathrm{C}$ would cross the anhydrous solidus at $70 \mathrm{~km}$ depth [Hirschmann, 2000], $\sim 20 \mathrm{~km}$ from the base of the observed conductive region. The presence of $200 \mu \mathrm{g} / \mathrm{g} \mathrm{H}_{2} \mathrm{O}$ thought to be in the MORB source would lower this (assumed $0 \mu \mathrm{g} / \mathrm{g} \mathrm{H}_{2} \mathrm{O}$ ) peridotite solidus such that melting at the same potential temperature would begin at $86 \mathrm{~km}$ depth [O'Leary et al., 2010], near the base of the conductive anomaly (Fig 4A and 4B). This suggests that the main region of partial melting under the EPR identified by the mantle conductivity structure occurs when the mantle adiabat crosses the damp solidus. 
Our new experimental results can be used to reevaluate this potential temperature estimate. If we cryoscopically calculate the $0 \mu \mathrm{g} / \mathrm{g} \mathrm{H}_{2} \mathrm{O}$ peridotite solidus on the basis of results from our experiments containing $\sim 140 \mu \mathrm{g} / \mathrm{g} \mathrm{H}_{2} \mathrm{O}$ (Fig 2), $0 \mu \mathrm{g} / \mathrm{g} \mathrm{H}_{2} \mathrm{O}$ peridotite ascending along a $1350{ }^{\circ} \mathrm{C}$ potential temperature adiabat would begin to melt at a depth of $52 \mathrm{~km}$ beneath the EPR, well within the most conductive (highest melt fraction) region indicated by the MT data [Key et al., 2013]. In order to lower the solidus temperature such that the initiation of partial melt is at $86 \mathrm{~km}$ depth along the lower edge of the observed region of partial melting requires $\sim 450 \mu \mathrm{g} / \mathrm{g} \mathrm{H}_{2} \mathrm{O}$ dissolved in the oceanic upper mantle (Fig 4A and 4B). While there is evidence for an enriched mantle component in the Pacific upper mantle containing up to $\sim 660 \mu \mathrm{g} / \mathrm{g} \mathrm{H}_{2} \mathrm{O}$ [Shimizu et al., 2016], MORB glasses from the $9-10^{\circ} \mathrm{N}$ portion of the EPR indicate a mantle source containing $\sim 130 \mu \mathrm{g} / \mathrm{g} \mathrm{H}_{2} \mathrm{O}$ [le Roux et al., 2006]. Therefore, reconciling our experimental results with the MT observations for a potential temperature of $1350{ }^{\circ} \mathrm{C}$ requires unrealistically high $\mathrm{H}_{2} \mathrm{O}$ contents for the depleted oceanic upper mantle if partial melts formed beneath the ridge are quantitatively aggregated to the ridge axis [Saal et al., 2002].

Our study suggests that the temperature of the $0 \mu \mathrm{g} / \mathrm{g} \mathrm{H}_{2} \mathrm{O}$ peridotite solidus is $\sim 60{ }^{\circ} \mathrm{C}$ higher than previously thought, so that current estimates of potential temperature and $\mathrm{H}_{2} \mathrm{O}$ content of the oceanic upper mantle are unable to explain the geophysical observations along this portion of the EPR. In order to match the conductivity anomaly given the solidus determined in this study, the mantle adiabatic potential temperature beneath the northern EPR must be $1410{ }^{\circ} \mathrm{C}$ (Fig 4A and 4B) (see Supplement). This increase in mantle potential temperature is based on the assumption that deep melting in the observed melt region from MT imaging is due solely to mantle peridotite crossing the "damp" solidus. If an enriched material, such as pyroxenite, is a major mantle component, the deeper melting signal in the MT data could be a result of the enriched material melting [Shimizu et al., 2016] and the mantle potential temperature required to match the observed conductivity would be lower. The depth at which pyroxenite partial melting begins (and ends) is strongly dependent on composition with some pyroxenites melting at depths equal to or shallower than peridotite. Further, for a given combination of crustal thickness and potential temperature there is a tradeoff between amount of pyroxenite in the oceanic mantle and its composition [Lambart et al., 2016]. Therefore, it is difficult to assess the potential contribution of pyroxenite to the observed deep melting signal. 
More broadly, our experimental results indicate that mantle potential temperatures along all ocean spreading centers are hotter than existing estimates. The highest temperatures found at the Reykjanes Ridge may potentially require an increase up to $1530{ }^{\circ} \mathrm{C}$ [Dalton et al., 2014]. A hotter interior has important implications for key mantle dynamic parameters such as viscosity [Rudolph et al., 2015]. Higher mantle potential temperatures reduce mantle viscosity and may provide the weakening of the asthenosphere necessary to explain plate motion at the lithosphereasthenosphere boundary (LAB) - the boundary between the rigid tectonic plate and the convecting mantle. The LAB structure is known to be complex, containing discontinuities associated with the seismic low velocity zone and the Gutenberg discontinuity, making it difficult to discern the global mechanism controlling plate behavior. Two mechanisms often invoked are $\mathrm{H}_{2} \mathrm{O}$ dissolved in the peridotite [Hirth and Kohlstedt, 1996] or the presence of partial melt [Anderson and Spetzler, 1970] in the upper asthenosphere. However, while additional mechanisms may be at work at the local scale, an increase in mantle potential temperature based on our experimental findings may show that global plate motion has a simple thermal origin as recent basin-wide seismic waveform studies [Rychert et al., 2012] and localized conductivity measurements [Sarafian et al., 2015] in the Pacific suggest.

\subsection{Acknowledgements}

Funding for this research was provided by the National Science Foundation, grant number OCE1459649, and WHOI Deep Ocean Exploration Institute. We thank K. Key for use of the magnetotelluric data. We are grateful to three anonymous reviewers for providing constructive suggestions that improved the paper. The data reported in this study can be found in the Supplementary Materials. E. Sarafian and G. Gaetani initiated the project and designed the experiments. E. Sarafian performed the experiments. E. Sarafian and A. Sarafian performed and E. Hauri oversaw the SIMS analyses. All authors contributed to developing the ideas and writing the manuscript. 


\subsection{References}

Anderson, D. L., and H. Spetzler (1970), Partial melting and the low-velocity zone, Physics of the Earth and Planetary Interiors, 4(1), 62-64, doi:10.1016/0031-9201(70)90030-0.

Asimow, P. D., and C. Langmuir (2003), The importance of water to oceanic mantle melting regimes, Nature, 421(6925), 815-820, doi:10.1038/nature01429.

Aubaud, C., E. H. Hauri, and M. M. Hirschmann (2004), Hydrogen partition coefficients between nominally anhydrous minerals and basaltic melts, Geophysical Research Letters, 31(20), doi:10.1029/2004GL021341.

Boyd, F., and J. England (1960), Apparatus for phase-equilibrium measurements at pressures up to 50 kilobars and temperatures up to $1750^{\circ} \mathrm{C}$, Journal of Geophysical Research, 65(2), 741748.

Cann, J. R. (1970), New model for the structure of the ocean crust, Nature, 226, 928-930.

Dalton, C. A., C. H. Langmuir, and A. Gale (2014), Geophysical and geochemical evidence for deep temperature variations beneath mid-ocean ridges, Science, 344(6179), 80-83, doi:10.1126/science.1249466.

Demouchy, S., and S. J. Mackwell (2006), Mechanisms of hydrogen incorporation and diffusion in iron-bearing olivine, Phys Chem Miner, 33(5), 347-355, doi:DOI 10.1007/s00269-0060081-2.

Gaetani, G. A., J. A. O’Leary, K. T. Koga, E. H. Hauri, E. F. Rose-Koga, and B. D. Monteleone (2014), Hydration of mantle olivine under variable water and oxygen fugacity conditions, Contributions to Mineralogy and Petrology, 167(2), 1-14, doi:10.1007/s00410-014-0965-y.

Hauri, E., G. Gaetani, and T. Green (2006), Partitioning of water during melting of the Earth's upper mantle at H2O-undersaturated conditions, Earth and Planetary Science Letters, 248(34), 715-734, doi:10.1016/j.eps1.2006.06.014.

Hauri, E., J. Wang, J. E. Dixon, P. L. King, C. Mandeville, and S. Newman (2002), SIMS analysis of volatiles in silicate glasses: 1 . Calibration, matrix effects and comparisons with FTIR, Chemical Geology, 183(1), 99-114, doi:10.1016/S0009-2541(01)00375-8.

Hays, J. F. (1966), Lime-alumina-silica, Carnegie Institution of Washington Yearbook, 65, 234239.

Hirschmann, M. M. (2000), Mantle solidus: experimental constraints and the effects of peridotite composition, Geochemistry, Geophysics, Geosystems, 1(10), doi:10.1029/2000GC000070.

Hirschmann, M. M., T. Tenner, C. Aubaud, and A. C. Withers (2009), Dehydration melting of nominally anhydrous mantle: The primacy of partitioning, Physics of the Earth and Planetary Interiors, 176(1-2), 54-68, doi:10.1016/j.pepi.2009.04.001. 
Hirth, G., and D. L. Kohlstedt (1996), Water in the oceanic upper mantle: implications for rheology, melt extraction and the evolution of the lithosphere, Earth and Planetary Science Letters, 144(1-2), 93-108, doi:Doi 10.1016/0012-821x(96)00154-9.

Johannes, W., P. Bell, H. K. Mao, A. L. Boettcher, D. W. Chipman, J. F. Hays, R. C. Newton, and F. Seifert (1971), An interlaboratory comparison of piston-cylinder pressure calibration using the albite-breakdown reaction, Contrib Mineral Petr, 32, 24-38.

Key, K., S. Constable, L. Liu, and A. Pommier (2013), Electrical image of passive mantle upwelling beneath the northern East Pacific Rise, Nature, 495(7442), 499-502, doi:10.1038/nature11932.

Kohlstedt, D. L., and S. J. Mackwell (1998), Diffusion of hydrogen and intrinsic point defects in olivine, Zeitschrift für physikalische Chemie, 207(Part_1_2), 147-162, doi:10.1524/zpch.1998.207.Part_1_2.147.

Lambart, S., M. B. Baker, and E. M. Stolper (2016), The role of pyroxentie in basalt genesis: Melt-PX, a melting parameterization for mantle pyroxenites between 0.9 and $5 \mathrm{GPa}$, Journal of Geophysical Research: Solid Earth, 121, 5708-5735, doi:10.1002/2015JB012762.

Langmuir, C. H., E. M. Klein, and T. Plank (1992), Petrological systematics of mid-ocean ridge basalts: constraints on melt generation beneath ocean ridges, in Mantle Flow and Melt Generation at Mid-Ocean Ridges, edited by J. Phipps Morgan, D. K. Blackman and J. M. Sinton, pp. 183-280, AGU, Washington D.C.

le Roux, P. J., S. B. Shirey, E. H. Hauri, M. R. Perfit, and J. F. Bender (2006), The effects of variable sources, processes and contaminants on the composition of northern EPR MORB (8$10^{\circ} \mathrm{N}$ and $\left.12-14^{\circ} \mathrm{N}\right)$ : Evidence from volatiles $\left(\mathrm{H}_{2} \mathrm{O}, \mathrm{CO}_{2}, \mathrm{~S}\right)$ and halogens $(\mathrm{F}, \mathrm{Cl})$, Earth and Planetary Science Letters, 251, 209-231, doi:10.1016/j.epsl.2006.09.012.

McKenzie, D. P., and M. J. Bickle (1988), The volume and composition of melt generated by extension of the lithosphere, J Petrol, 29(3), 625-679.

Michael, P. J. (1988), The concentration, behavior and storage of $\mathrm{H}_{2} \mathrm{O}$ in the suboceanic upper mantle: implications for mantle metasomatism, Geochimica et Cosmochimica Acta, 52(2), 555-566.

O'Leary, J. A., G. A. Gaetani, and E. H. Hauri (2010), The effect of tetrahedral Al3+ on the partitioning of water between clinopyroxene and silicate melt, Earth and Planetary Science Letters, 297(1-2), 111-120, doi:10.1016/j.eps1.2010.06.011.

Plank, T., and C. H. Langmuir (1992), Effects of the melting regime on the composition of the oceanic crust, Journal of Geophysical Research: Solid Earth (1978-2012), 97(B13), 1974919770, doi:10.1029/92JB01769.

Rychert, C. A., N. Schmerr, and N. Harmon (2012), The Pacific lithosphere-asthenosphere boundary: Seismic imaging and anisotropic constraints from SS waveforms, Geochemistry, Geophysics, Geosystems, 13(9), doi:10.1029/2012GC004194. 
Rudolph, M. L., V. Lekić, and C. Lithgow-Bertelloni (2015), Viscosity jump in Earth's midmantle. Science, 350, 1349-1352, doi:10.1126/science.aad1929.

Saal, A. E., E. H. Hauri, C. H. Langmuir, and M. R. Perfit (2002), Vapour undersaturation in primitive mid-ocean-ridge basalt and the volatile content of Earth's upper mantle, Nature, 419(6906), 451-455, doi:10.1038/nature01073.

Sarafian, E., R. Evans, J. A. Collins, J. Elsenbeck, G. A. Gaetani, J. B. Gaherty, G. Hirth, and D. Lizarralde (2015), The electrical structure of the central Pacific upper mantle constrained by the NoMelt experiment, Geochemistry, Geophysics, Geosystems, 16(4), 1115-1132, doi:10.1002/2014GC005709.

Searle, R. (2013), Mid-Ocean Ridges, 330 pp., Cambridge University Press, New York.

Shimizu, K., A. E. Saal, C. E. Myers, A. N. Nagle, E. H. Hauri, D. W. Forsyth, V. S. Kamenetsky, and Y. Niu (2016), Two-component mantle melting-mixing model for the generation of mid-ocean ridge basalts: Implications for the volatile content of the Pacific upper mantle, Geochimica et Cosmochimica Acta, 176, 44-80, doi:10.1016/j.gca.2015.10.033.

Workman, R. K., and S. R. Hart (2005), Major and trace element composition of the depleted MORB mantle (DMM), Earth and Planetary Science Letters, 231(1-2), 53-72, doi:10.1016/j.eps1.2004.12.005. 


\subsection{Figures}

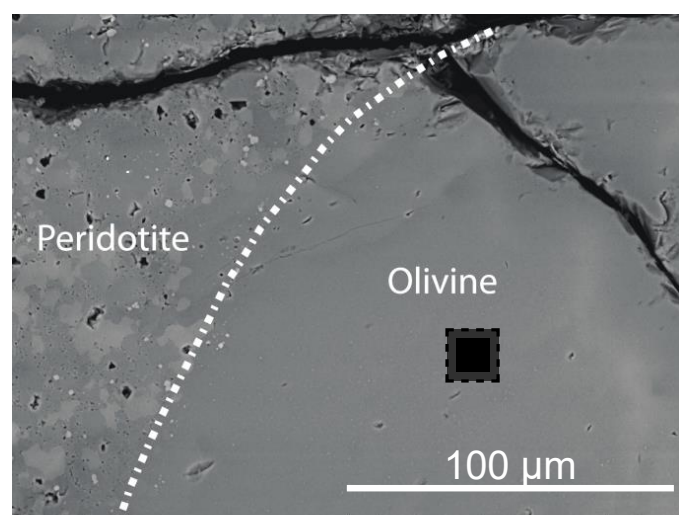

\section{Figure 1.}

Backscattered electron image of experimentally produced peridotite mineral grains and a San Carlos olivine sphere. The dashed white line marks the edge of the San Carlos olivine sphere. The black box illustrates the approximate size of a NanoSIMS analysis showing that the peridotite is too fine grained for measurement, but the olivine sphere is large enough to conduct multiple measurements and determine the $\mathrm{H}_{2} \mathrm{O}$ content of the experiment. Brightness is proportional to mean atomic number. 


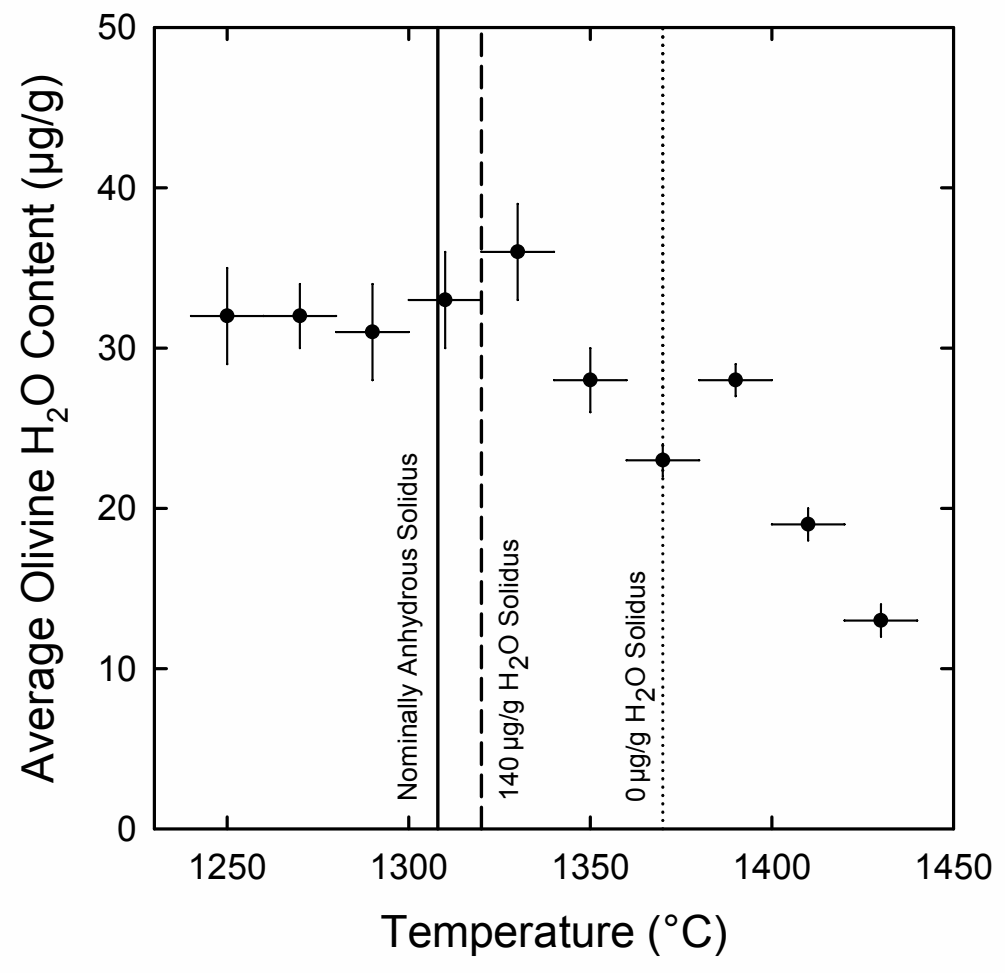

Figure 2.

Average $\mathrm{H}_{2} \mathrm{O}$ content of San Carlos olivine spheres with temperature at 1.5 GPa. Subsolidus experiments contain on average $32 \pm 3 \mu \mathrm{g} / \mathrm{g} \mathrm{H}_{2} \mathrm{O}$ and experiments above the solidus show a general trend of decreasing $\mathrm{H}_{2} \mathrm{O}$ content with increasing temperature. Error bars are 2 standard error in $\mathrm{H}_{2} \mathrm{O}$ content and $\pm 10{ }^{\circ} \mathrm{C}$ in temperature. The nominally anhydrous solidus (dotted line) [Hirschmann, 2000], the $140 \mu \mathrm{g} / \mathrm{g} \mathrm{H}_{2} \mathrm{O}$ solidus determined experimentally in this study (dashed line), and the calculated $0 \mu \mathrm{g} / \mathrm{g} \mathrm{H}_{2} \mathrm{O}$ (truly anhydrous) solidus (solid line) are shown. 


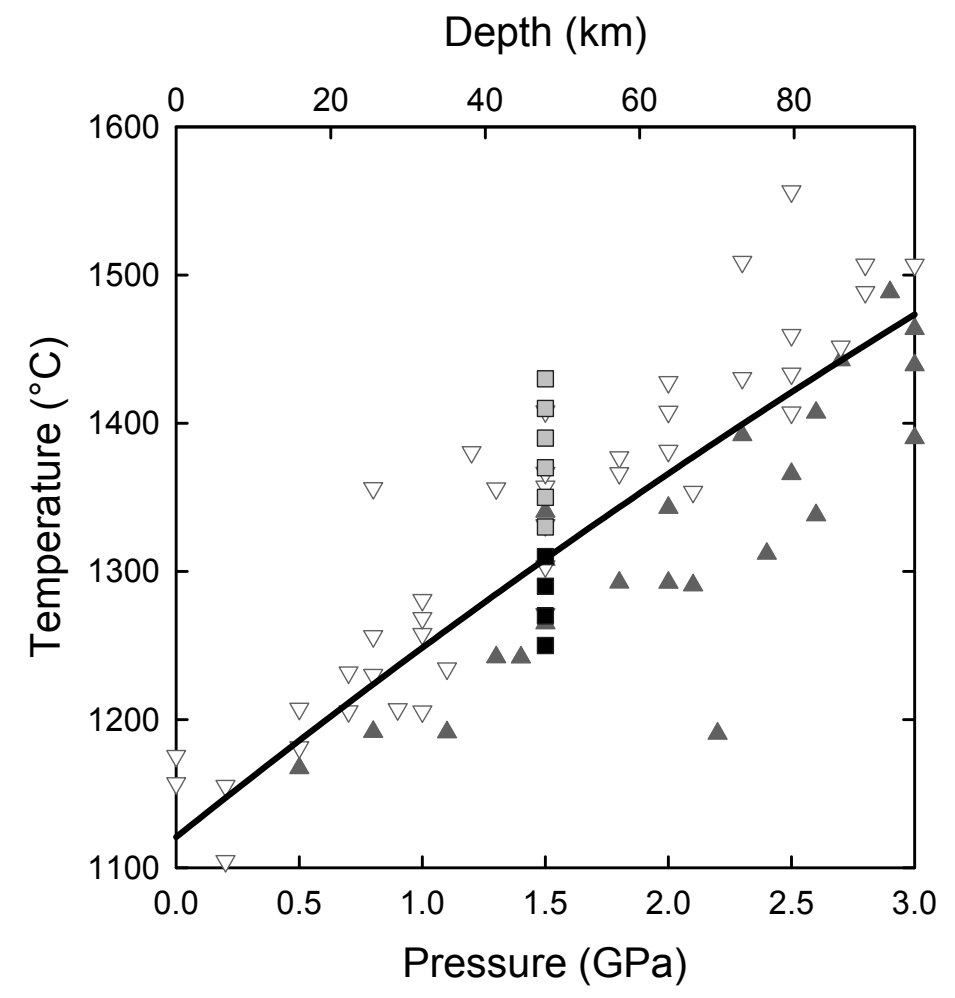

\section{Figure 3.}

Comparison of our experimental results with the nominally anhydrous solidus parameterized from earlier partial melting experiments. The nominally anhydrous solidus (bold line) was parameterized based on the presence (inverted triangles) and absence (filled triangles) of melt in experiments containing unknown concentrations of $\mathrm{H}_{2} \mathrm{O}$ [Hirschmann, 2000]. Experiments from this study conducted at $1.5 \mathrm{GPa}$ and containing $140 \mu \mathrm{g} / \mathrm{g} \mathrm{H}_{2} \mathrm{O}$ (gray squares are experiments that contain melt; black squares are melt-free experiments) show a strong agreement with the nominally anhydrous solidus, indicating that it is actually damp. Figure adapted from [Hirschmann, 2000]. 

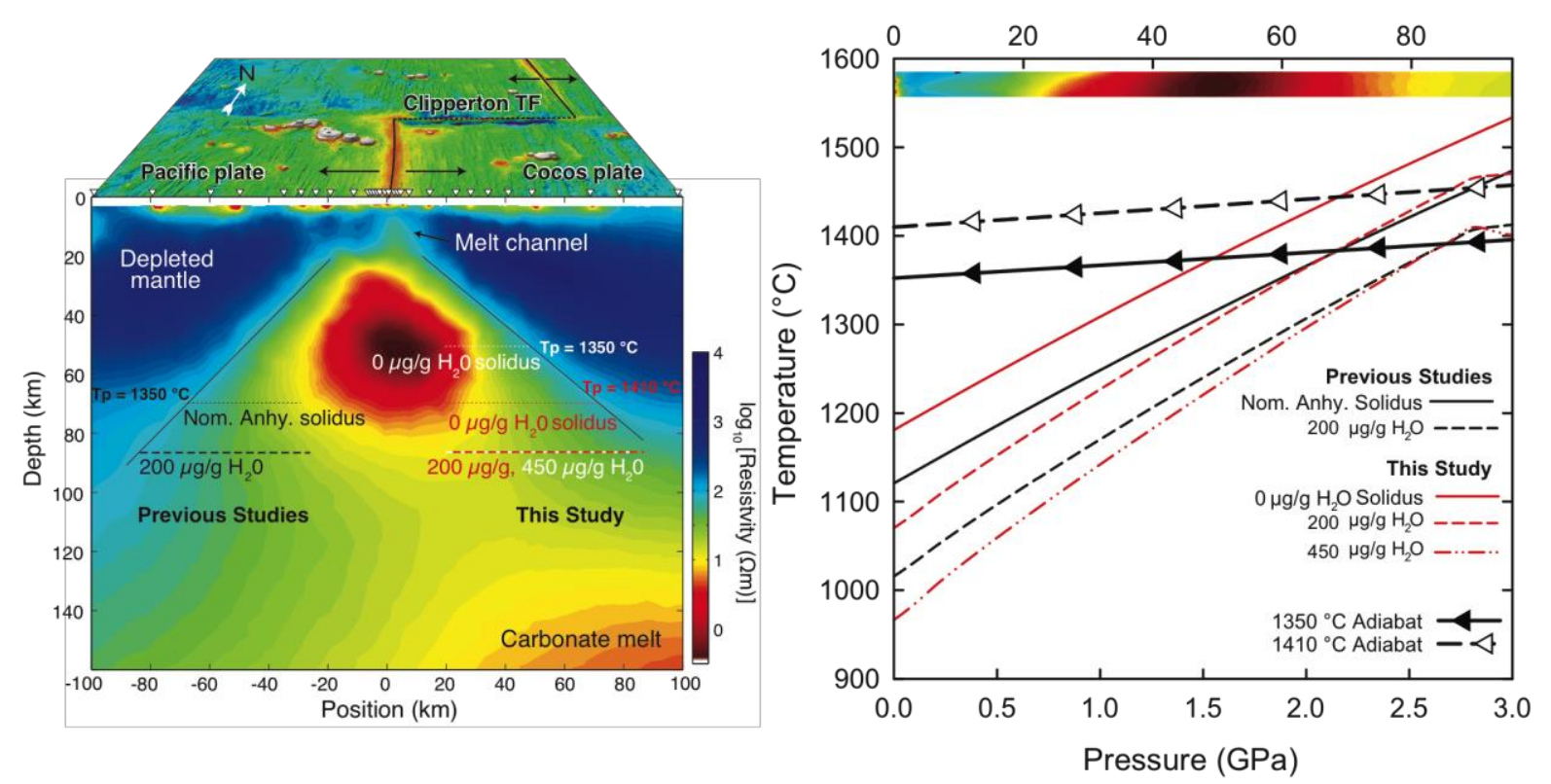

Figure 4.

Reconciling magnetotelluric observations with the experimental results. (A) The conductivity structure of the Northern East Pacific Rise. Warm colors show the melting regime under the ridge. Black lines show the nominally anhydrous solidus (dot-dashed) and $200 \mu \mathrm{g} / \mathrm{g}$ $\mathrm{H}_{2} \mathrm{O}$ solidus (dashed) of previous studies (left side) [Hirschmann, 2000; Hirschmann et al., 2009] corresponding to a mantle potential temperature $\left(\mathrm{T}_{\mathrm{p}}\right)$ of $1350{ }^{\circ} \mathrm{C}$. White lines show the 0 $\mu \mathrm{g} / \mathrm{g} \mathrm{H}_{2} \mathrm{O}$ (dot-dashed) and $450 \mu \mathrm{g} / \mathrm{g} \mathrm{H}_{2} \mathrm{O}$ solidi (dashed) from this study (right side) at the same $\mathrm{T}_{\mathrm{p}}$. Red lines are the $0 \mu \mathrm{g} / \mathrm{g} \mathrm{H}_{2} \mathrm{O}$ (dot-dashed) and $200 \mu \mathrm{g} / \mathrm{g} \mathrm{H}_{2} \mathrm{O}$ solidi (dashed) from this study corresponding to a mantle $\mathrm{T}_{\mathrm{p}}$ of $1410^{\circ} \mathrm{C}$. Figure adapted from [Key et al., 2013]. (B) The solidi and conductivity structure with depth beneath the ridge from (A), and the corresponding 1350 (bold black) and $1410{ }^{\circ} \mathrm{C}$ (bold dashed black) mantle adiabats. Black lines are the nominally anhydrous (solid) and corresponding $200 \mu \mathrm{g} / \mathrm{g} \mathrm{H}_{2} \mathrm{O}$ (dashed) solidi from previous studies [Hirschmann, 2000; Hirschmann et al., 2009]. Red lines are the $0 \mu \mathrm{g} / \mathrm{g} \mathrm{H}_{2} \mathrm{O}$ (solid), and corresponding 200 (dashed) and $450 \mu \mathrm{g} / \mathrm{g} \mathrm{H}_{2} \mathrm{O}$ (dot-dashed) solidi based on this study. The kink in the solidi at $2.8 \mathrm{GPa}$ represents the spinel to garnet transition. The adiabat-solidi intersections illustrate depth where melting begins. 


\section{Chapter 3}

\section{Experimental determination of the $\mathrm{H}_{2} \mathrm{O}$-undersaturated peridotite solidus}

\section{from 1.0 to $2.5 \mathrm{GPa}$}

\subsection{Abstract}

This study presents an experimental determination of the solidus for peridotite containing $\sim 140$ $\mu \mathrm{g} / \mathrm{g} \mathrm{H}_{2} \mathrm{O}$ at pressures from 1.0 to $2.5 \mathrm{GPa}$ and a parameterization of the truly anhydrous, or 0 $\mu \mathrm{g} / \mathrm{g} \mathrm{H}_{2} \mathrm{O}$, spinel lherzolite solidus. Our experimental starting material consists of a synthetic peridotite containing a small proportion of San Carlos olivine spheres $\sim 300 \mu \mathrm{m}$ in diameter. By analyzing the $\mathrm{H}_{2} \mathrm{O}$ content of the San Carlos olivine spheres, we are able to monitor the $\mathrm{H}_{2} \mathrm{O}$ content of our experimental charges. Our data reveal that the $\mathrm{H}_{2} \mathrm{O}$-undersaturated peridotite solidus is in good agreement with a previous parameterization of the nominally anhydrous solidus, an indication that the $0 \mu \mathrm{g} / \mathrm{g} \mathrm{H}_{2} \mathrm{O}$ solidus is hotter than previously thought. By performing a reverse cryoscopic calculation, we find that the $0 \mu \mathrm{g} / \mathrm{g} \mathrm{H}_{2} \mathrm{O}$ peridotite solidus is up to $86{ }^{\circ} \mathrm{C}$ hotter on average than previous estimates between 0.8 and $2.8 \mathrm{GPa}$. Increasing the peridotite solidus temperature provides further constraints on the range of ambient oceanic mantle potential temperatures. 


\subsection{Introduction}

The ambient oceanic upper mantle is thought to contain $\sim 50-200 \mu \mathrm{g} / \mathrm{g} \mathrm{H}_{2} \mathrm{O}$ [e.g., le Roux et al., 2006; Michael, 1988; Saal et al., 2002; Shimizu et al., 2016] dissolved in nominally anhydrous minerals (NAMs) as point defects. The presence of small amounts of $\mathrm{H}_{2} \mathrm{O}$ strongly influences the temperature at which upper mantle peridotite begins to melt at a given pressure - the solidus and thereby the depth at which partial melting begins beneath oceanic spreading centers [e.g., Asimow and Langmuir, 2003; Hirth and Kohlstedt, 1996]. Knowledge of the mantle solidus helps to constrain the relationship between the depth at which partial melting begins and mantle potential temperature (the mantle adiabat extrapolated to the Earth's surface exclusive of partial melting). However, the effect of small concentrations of $\mathrm{H}_{2} \mathrm{O}$ on the solidus temperature of peridotite is challenging to quantify experimentally because it requires identifying the presence of a small proportion of partial melt and characterizing the amount of $\mathrm{H}_{2} \mathrm{O}$ dissolved in an experimental charge [Hirschmann et al., 2009]. Experimental starting materials (usually powders) are known to adsorb $\mathrm{H}_{2} \mathrm{O}$ that is difficult to remove despite meticulous drying protocols [Hirschmann, 2000; Medard et al., 2008]. The utility of existing experimental data on the temperature of the peridotite solidus is, therefore, limited by the presence of an unknown amount of $\mathrm{H}_{2} \mathrm{O}$ dissolved in the peridotite.

Here, we present results from an experimental determination of the temperature of the $\mathrm{H}_{2} \mathrm{O}$ undersaturated peridotite solidus at pressures from 1.0 to 2.5 GPa. This work expands upon the recent study of Sarafian et al. [2017], who presented a new experimental approach to accurately determine the initiation of melting for $\mathrm{H}_{2} \mathrm{O}$-undersaturated peridotite and quantify the amount of $\mathrm{H}_{2} \mathrm{O}$ in the experimental charge. They exploited the rapid volume diffusion of $\mathrm{H}$ through olivine and the incompatible behavior of $\mathrm{H}_{2} \mathrm{O}$ during peridotite partial melting to determine the solidus temperature of spinel lherzolite containing $\sim 140 \mu \mathrm{g} / \mathrm{g} \mathrm{H}_{2} \mathrm{O}$ at $1.5 \mathrm{GPa}$. Volume diffusion of $\mathrm{H}_{2} \mathrm{O}$ - or more specifically protons $(\mathrm{H})$ - in olivine is rapid enough that spheres of natural San Carlos olivine, a few hundred microns in diameter, embedded in a matrix of fine-grained peridotite will diffusively equilibrate with the $f_{\mathrm{H} 2 \mathrm{O}}$ imposed by the peridotite on short timescales at upper mantle temperatures [Demouchy and Mackwell, 2003; Demouchy and Mackwell, 2006; Gaetani et al., 2014; Kohlstedt and Mackwell, 1998]. Therefore, the addition of a small proportion of these 
spheres ( $\sim 5 \%$ by weight) to the starting peridotite does not significantly perturb the solidus temperature and provides a means to monitor the concentration of $\mathrm{H}_{2} \mathrm{O}$ in the experimental charge via secondary ion mass spectrometry (SIMS) analysis, even though the experimentally grown grains are too small to analyze (Fig. 1). Further, crossing the solidus is marked by a decrease in the $\mathrm{H}_{2} \mathrm{O}$ concentration of the San Carlos olivine spheres due to its incompatible behavior during peridotite partial melting [Hauri et al., 2006; Michael, 1988; Saal et al., 2002]. As equilibrium (or batch) partial melting proceeds with increasing temperature, $\mathrm{H}_{2} \mathrm{O}$ is progressively sequestered in the melt and the concentration of $\mathrm{H}_{2} \mathrm{O}$ in the San Carlos olivine spheres systematically decreases, a behavior that can be modeled on the basis of experimentally determined mineral-melt partitioning data [Aubaud et al., 2004; E. Hauri et al., 2006; Tenner et al., 2012].

Results from SIMS analyses of the San Carlos olivine spheres in our experiments reveals that the charges consistently contain $\sim 140 \mu \mathrm{g} / \mathrm{g} \mathrm{H}_{2} \mathrm{O}$ - within the range predicted for the ambient oceanic upper mantle. Therefore, our experimentally determined $\mathrm{H}_{2} \mathrm{O}$-undersaturated peridotite solidus is directly relevant to melt generation in the mantle beneath oceanic spreading centers. On the basis of these experimental results, we use a reverse cryoscopic calculation to estimate the temperature of the $0 \mu \mathrm{g} / \mathrm{g} \mathrm{H}_{2} \mathrm{O}$ (anhydrous) peridotite solidus between 0.8 and $2.8 \mathrm{GPa}$ in the spinel peridotite stability field [Borghini et al., 2009; Robinson and Wood, 1998]. We compare our data and our calculated $0 \mu \mathrm{g} / \mathrm{g} \mathrm{H}_{2} \mathrm{O}$ peridotite solidus to two previous estimates of the anhydrous peridotite solidus [Hirschmann, 2000; Katz et al., 2003] and show that our $0 \mu \mathrm{g} / \mathrm{g} \mathrm{H}_{2} \mathrm{O}$ peridotite solidus is hotter than current models of the anhydrous solidus across the spinel stability field. Our results suggests a smaller range of mantle potential temperatures.

\subsection{Experimental and analytical methods}

\subsubsection{Starting materials}

The starting composition used in our experiments is based on the depleted MORB mantle (DMM) of Workman and Hart [2005], excluding $\mathrm{P}_{2} \mathrm{O}_{5}$ (Table 1). The peridotite was synthesized from a mixture of high-purity oxides, Ca-metasilicate $\left(\mathrm{CaSiO}_{3}\right)$, synthetic fayalite, Amelia albite and natural orthoclase. Individual components were first dried for 1 to 480 hours at 800 to 1000 
${ }^{\circ} \mathrm{C}$ to remove adsorbed $\mathrm{H}_{2} \mathrm{O}$ before being weighed. The components were combined and then ground in an agate mortar and pestle under ethanol for 6 hours to produce a homogeneous powder. The synthetic DMM mixture was reacted at $1050{ }^{\circ} \mathrm{C}$ and $0.1 \mathrm{MPa}$ for 72 hours in vertical gas mixing furnace with the fugacity of oxygen controlled at the fayalite-magnetitequartz (FMQ) buffer using $\mathrm{CO}_{2}$ and $\mathrm{CO}$ gases. Following the reaction step, the mix formed a solid cylinder that was subsequently crushed to a fine powder. San Carlos olivine spheres 250$500 \mu \mathrm{m}$ in diameter were fabricated from large single crystals of San Carlos olivine. San Carlos

olivine spheres were generated by hand-picking inclusion-free and optically clear, semi-round San Carlos olivine pieces approximately $500 \mu \mathrm{m}$ in diameter. The San Carlos olivine was then placed in an air abrasion chamber under 2.25 PSI for 15 hours. Afterward, the spheres were cleaned with distilled $\mathrm{H}_{2} \mathrm{O}$ and ethanol, and the most spherical grains were hand-picked. The olivine spheres were then vigorously mixed with the synthetic peridotite in $\sim 5: 95$ proportions by weight in a Wig-L-Bug apparatus. The homogenized mix (olivine spheres + synthetic peridotite) was stored under vacuum at $120{ }^{\circ} \mathrm{C}$ to minimize $\mathrm{H}_{2} \mathrm{O}$ adsorption (see Appendix B).

\subsubsection{Experimental Methods}

Experiments were performed as follows. An aliquot of the starting material was packed into a capsule - fabricated from a $10 \mathrm{~mm}$ length of $\mathrm{Au}_{80} \mathrm{Pd}_{20}$ tubing - that had been pre-conditioned to minimize Fe loss following the procedures of Gaetani and Grove [1998]. Once packed, the top of the capsule was triple crimped and it was held under vacuum at $120^{\circ} \mathrm{C}$ to eliminate as much adsorbed $\mathrm{H}_{2} \mathrm{O}$ as possible. After drying, the experimental capsules were immediately welded shut to ensure that the experimental powder was exposed to minimal atmospheric $\mathrm{H}_{2} \mathrm{O}$. The sealed capsule was placed into an $\mathrm{MgO}$ sleeve and positioned in the hot spot of a straight-walled graphite furnace using crushable $\mathrm{MgO}$ spacers that had been dried for at least 24 hours at $1000^{\circ} \mathrm{C}$. The furnace assembly was placed in a sintered $\mathrm{CaF}_{2}$ sleeve, which served as the pressure medium (see Appendix B).

Experiments were performed at pressures of 1.0, 2.0, and $2.5 \mathrm{GPa}$ and temperatures of 1210 to $1490{ }^{\circ} \mathrm{C}$ (Table 2) in an end-loaded piston cylinder device [Boyd and England, 1960] with 12.7 
mm assemblies using the cold-piston-in technique [Johannes et al., 1971]. The friction correction was determined at 1.2 to $1.4 \mathrm{GPa}$ and $1300{ }^{\circ} \mathrm{C}$ using the breakdown of $\mathrm{Ca}$ Tschermakite to the assemblage anorthite, gehlenite, and corundum [Hays, 1966] and is within the pressure uncertainty. Therefore, no friction correction was applied to reported pressures. The temperature was measured and controlled using $\mathrm{W}_{97} \mathrm{Re}_{3}-\mathrm{W}_{75} \mathrm{Re}_{25}$ thermocouples with no correction for the effect of pressure on thermocouple electromotive force. The accuracy for pressure is within $\pm 50 \mathrm{MPa}$ and for temperature is within $\pm 10^{\circ} \mathrm{C}$. Experiments were pressurized at room temperature then brought to the experimental temperature at a rate of $60{ }^{\circ} \mathrm{C} / \mathrm{min}$. After $24 \mathrm{~h}$, experiments were quenched to room temperature by shutting off the power. Capsules were mounted in epoxy, sectioned longitudinally, and polished using $\mathrm{SiC}$ and water based diamond suspension down to $0.25 \mu \mathrm{m}$ such that multiple San Carlos olivine grains were exposed for analysis (see Appendix B).

\subsubsection{Analytical methods}

After each experiment, run produced minerals and San Carlos olivine spheres in polished experimental charges were first inspected using a Hitachi TM3000 scanning electron microscope (SEM) with an attached energy dispersive x-ray spectrometer (EDS) at the Woods Hole Oceanographic Institution. Sectioned and polished experiments were then removed from the epoxy and pressed into indium metal along with three secondary reference materials: 1) a low $\mathrm{H}_{2} \mathrm{O}$ reference to monitor machine background (Suprasil 3002 pure $\mathrm{SiO}_{2}$ glass, $1 \mu \mathrm{g} / \mathrm{g} \mathrm{H}_{2} \mathrm{O}$ provided by Heraeus Quarzglas, Switzerland), 2) a mid $\mathrm{H}_{2} \mathrm{O}$ reference to monitor reproducibility (Herasil 102 pure $\mathrm{SiO}_{2}$ glass, $55 \mu \mathrm{g} / \mathrm{g} \mathrm{H}_{2} \mathrm{O}$ provided by Heraeus Quarzglas, Switzerland), and 3) a high $\mathrm{H}_{2} \mathrm{O}$ reference to monitor instrumental drift (ALV 519-4-1 mid ocean ridge basalt glass, $1700 \mu \mathrm{g} / \mathrm{g} \mathrm{H} \mathrm{H}_{2} \mathrm{O}$ ).

The major element compositions of mineral phases were analyzed in select experiments using the JEOL JXA-8200 electron microprobe at the Massachusetts Institute of Technology. We used a focused electron beam (spot size $\sim 1 \mu \mathrm{m}$ ) with a $10 \mathrm{nA}$ beam current and an accelerating potential of $15 \mathrm{kV}$ for analyses. Elements were counted for 40 seconds. In house natural and 
synthetic standards were used for calibration. Mineral analyses with totals below $98 \%$ and above $102 \%$ were discarded (Table S1).

SIMS measurements of the San Carlos olivine spheres were conducted on the Cameca IMS 6F and NanoSIMS 50L ion microprobes at the Carnegie Institution of Washington, Department of Terrestrial Magnetism following previously established methods for volatile analyses [Hauri et al., 2002; Koga et al., 2003; O'Leary et al., 2010; Saal et al., 2008; Sarafian et al., 2017]. Briefly, a focused $\mathrm{Cs}^{+}$primary beam, $\sim 15 \mathrm{nA}(6 \mathrm{f})$ or $\sim 10 \mathrm{nA}$ (NanoSIMS), was rastered over a $20 \times 20 \mu \mathrm{m}^{2}$ (6f) or $15 \times 15 \mu \mathrm{m}^{2}$ (NanoSIMS) area. A field aperture (6f) or beam blanking (NanoSIMS) was used to measure ions from the central $10 \times 10 \mu \mathrm{m}^{2}$ (6f) or $4 \times 4 \mu^{2}$ (NanoSIMS) of the crater. Mass resolving power $(\mathrm{M} / \Delta \mathrm{M}$ at $10 \%$ peak height) was $\sim 4500$, sufficient to separate ${ }^{16} \mathrm{OH}$ from ${ }^{17} \mathrm{O}$. Measured masses, ${ }^{12} \mathrm{C},{ }^{16} \mathrm{O}{ }^{1} \mathrm{H},{ }^{19} \mathrm{~F},{ }^{31} \mathrm{P},{ }^{30} \mathrm{Si},{ }^{32} \mathrm{~S},{ }^{35} \mathrm{Cl}(6 \mathrm{f})$ and ${ }^{12} \mathrm{C},{ }^{16} \mathrm{O}{ }^{1} \mathrm{H},{ }^{19} \mathrm{~F}, \pm{ }^{31} \mathrm{P},{ }^{30} \mathrm{Si}, \pm{ }^{32} \mathrm{~S},{ }^{35} \mathrm{Cl}$ (NanoSIMS), were normalized using ${ }^{30} \mathrm{Si}$ as the reference mass. Measurements consisted of a 5 minute pre-sputter period and a 3 minute counting time. Ion imaging was used to identify small cracks or contamination within the craters, which were observed to have elevated signal. Following the methods of Sarafian et al. [2017], secondary standards were always measured before and after each experimental capsule in order to account for the instrumental background $\left(<5 \mu \mathrm{g} / \mathrm{g} \mathrm{H}_{2} \mathrm{O}\right)$ and instrumental drift throughout the analyses.

\subsection{Results}

Experimental conditions, the identity of experimentally produced phases, and the mean San Carlos olivine sphere $\mathrm{H}_{2} \mathrm{O}$ contents are listed in Table 2. Experimentally produced phases consisted of anhedral to subhedral grains of olivine $(\sim 5-20 \mu \mathrm{m}$ in diameter $)+$ orthopyroxene (opx; $\sim 5-15 \mu \mathrm{m}$ in diameter) + spinel $(\sim 1-4 \mu \mathrm{m}$ in diameter) \pm clinopyroxene (cpx; $\sim 5-10 \mu \mathrm{m}$ in diameter \pm glass. The molar $\mathrm{Mg} /(\mathrm{Mg}+\mathrm{Fe})$ ratio $(\mathrm{Mg} \#)$ of San Carlos and experimentally produced olivine ranged from 0.88 to 0.94 . The $\mathrm{Mg} \#$ of the opx range from 0.86 to 0.95 , and the cpx have $\mathrm{Mg} \#$ of 0.85 to 0.95 . The highest $\mathrm{Mg} \# \mathrm{~s}$ are found in the phases of the highest temperature experiments. The initial $\mathrm{H}_{2} \mathrm{O}$ content of the San Carlos olivine was $6.7 \pm 0.1 \mu \mathrm{g} / \mathrm{g}$ $(\mathrm{n}=3 ; 2$ SE) [Gaetani et al., 2014]. 


\subsubsection{Melting trends}

The measured $\mathrm{H}_{2} \mathrm{O}$ content of the San Carlos olivine spheres in experiments at each pressure follow the same general trend. In experiments interpreted as being below the solidus temperature, the concentrations of $\mathrm{H}_{2} \mathrm{O}$ in the olivine spheres are similar and independent of temperature. These experiments do not contain melt that is discernable via reflected light microscopy, backscattered electron imaging, or elemental mapping using EDS (see Appendix B). Whereas the $\mathrm{H}_{2} \mathrm{O}$ contents of the olivine spheres are independent of temperature below the solidus at a single pressure, the average $\mathrm{H}_{2} \mathrm{O}$ content of the subsolidus olivine spheres increases with increasing pressure. The average olivine sphere $\mathrm{H}_{2} \mathrm{O}$ contents from subsolidus experiments at 1.0, 2.0, and $2.5 \mathrm{GPa}$ are $22 \pm 2 \mu \mathrm{g} / \mathrm{g}(\mathrm{n}=4), 46 \pm 6 \mu \mathrm{g} / \mathrm{g}(\mathrm{n}=6)$, and $56 \pm 3 \mu \mathrm{g} / \mathrm{g}(\mathrm{n}=6)(2 \mathrm{SE})$, respectively. Sarafian et al. [2017] determined the average olivine sphere $\mathrm{H}_{2} \mathrm{O}$ contents from subsolidus experiments at $1.5 \mathrm{GPa}$ to be $32 \pm 3 \mu \mathrm{g} / \mathrm{g}(\mathrm{n}=7)$.

Experiments containing visible partial melt were interpreted to be at temperatures above the solidus (see Appendix B). In super solidus experiments at each pressure the measured $\mathrm{H}_{2} \mathrm{O}$ content of the olivine spheres drops systematically with increasing temperature and visually observed increasing melt fraction. We placed the solidus for our experimental $\mathrm{H}_{2} \mathrm{O}$ content midway between the highest temperature subsolidus experiment and the lowest temperature super solidus experiment at each pressure. With increasing pressure, the solidus temperature lies between 1250 and $1270{ }^{\circ} \mathrm{C}$ (i.e. $\sim 1260{ }^{\circ} \mathrm{C}$ at $1 \mathrm{GPa}$ ), 1350 and $1370{ }^{\circ} \mathrm{C}$ (i.e. $\sim 1360{ }^{\circ} \mathrm{C}$ at $2 \mathrm{GPa}$ ), and 1390 and $1410^{\circ} \mathrm{C}$ (i.e. $\sim 1400{ }^{\circ} \mathrm{C}$ at $2.5 \mathrm{GPa}$ ) (Fig. 2). Sarafian et al. [2017] identified the 1.5 GPa solidus between 1310 and $1330{ }^{\circ} \mathrm{C}$ (i.e. $\sim 1320{ }^{\circ} \mathrm{C}$ ). It should be noted that the identification of the solidus temperature at each pressure is based on the identification of incipient melt and not a decrease in the measured San Carlos olivine sphere $\mathrm{H}_{2} \mathrm{O}$ content. Identification of incipient melt in low $\mathrm{H}_{2} \mathrm{O}$ content experiments is very challenging due to the fine grain size of the peridotite material and quench growth. This could be a source of error, such as in previous experimental studies [Hirschmann, 2000]. Melt content of the experiments could not be estimated due to quench growth. 
The observed melting trends are expected on the basis of $\mathrm{H}_{2} \mathrm{O}$ compatibility during peridotite partial melting. Water is incompatible in the residual solid [Hauri et al., 2006; Saal et al., 2002], so as partial melting progresses with increasing temperature at a given pressure, the San Carlos olivine $\mathrm{H}_{2} \mathrm{O}$ content is expected to decrease with increasing melt fraction. However, the increasing average $\mathrm{H}_{2} \mathrm{O}$ content of the San Carlos olivine in subsolidus experiments suggests a pressure dependence on the partitioning of $\mathrm{H}_{2} \mathrm{O}$ among olivine, opx, and cpx, such that as pressure increases $\mathrm{H}_{2} \mathrm{O}$ partitions more strongly into olivine (spinel is assumed to contain no $\mathrm{H}_{2} \mathrm{O}$ ). Previous studies of Hirschmann et al. [2009] and O'Leary et al. [2010] predict the opposite trend in the pressure range of our study. They assume that the olivine-melt $\mathrm{H}_{2} \mathrm{O}$ partition coefficient remains constant with pressure and predict that the $\mathrm{Al}$ content of pyroxenes should increase as pressure increases, thus allowing $\mathrm{H}_{2} \mathrm{O}$ to be more compatible in pyroxenes due to a couple substitution with $\mathrm{Al}^{3+}$. However, experimental pyroxene data below $2.5 \mathrm{GPa}$ is largely scattered and does not fit the predicted trend of increasing Al content. Furthermore, olivine partitioning is known to have a pressure dependence [Novella et al., 2014]. Therefore, we must reevaluate the partitioning of $\mathrm{H}_{2} \mathrm{O}$ between olivine and pyroxenes when calculating our experimental $\mathrm{H}_{2} \mathrm{O}$ content.

\subsubsection{Capsule $\mathrm{H}_{2} \mathrm{O}$ Content}

We determined the total capsule $\mathrm{H}_{2} \mathrm{O}$ content by first calculating the modal proportions of the phases in the select subsolidus experiments measured by electron microprobe, and then applying mineral-mineral partition coefficients inferred from experimental data to calculate the amount of $\mathrm{H}_{2} \mathrm{O}$ in each phase. Phase proportions were calculated by minimizing the difference between the major element oxide abundances measured in select subsolidus experiments (Table S1) and the known bulk oxide abundances of the synthetic starting material (see Table 2).

We calculated the mineral-melt $\mathrm{H}_{2} \mathrm{O}$ partition coefficients, $D_{H}^{\text {mineral-melt }}$, for our experimentally produced opx and cpx from the composition dependent realtionships derived in Hirschmann et al. [2009] and O'Leary et al. [2010], respectively. We observed that the calculated

$D_{H}^{\text {Opx-melt }}$ and $D_{H}^{\text {Cpx-melt }}$ remained approximately constant over the experimental pressures and temperatures, with both the average $D_{H}^{O p x-m e l t}$ and $D_{H}^{C p x-m e l t}$ from all experiments equal to 
$0.018 \pm 0.002(\mathrm{n}=16 ; 2 \mathrm{SD})$. The constant $D_{H}^{\text {Pyroxene-melt }}$ value is due to the fact that our experimental pyroxene $\mathrm{Al}$ content remains relatively constant with temperature and pressure, and does not increase with increasing pressure as much as predicted by Hirschmann et al. [2009].

In a recent study, Novella et al. [2014] showed that olivine has a $\mathrm{H}$ partition coefficient that is highly dependent on pressure. In order to determine the $D_{H}^{\text {Olivine-melt }}$ for the San Carlos olivine and run produced olivine in our experiments, we compiled experimental $D_{H}^{\text {Olivine-melt }}$ data from previous experiments that contained olivine $+\mathrm{opx}+\mathrm{cpx}+$ glass \pm an aluminous phase and did not experience substantial Fe loss [Aubaud et al., 2004; Hauri et al., 2006; Novella et al., 2014; Tenner et al., 2012] to ensure the silica activity was buffered and experimental equilibrium could be achieved (Fig. 3). Our compilation shows that

$$
D_{H}^{\text {Olivine-melt }}=0.0006( \pm 0.0001) \times P+0.001( \pm 0.001)
$$

where $\mathrm{P}$ is pressure in $\mathrm{GPa}\left(\mathrm{R}^{2}=0.89\right)$. This relationship is similar to the pressure relationship determined in Novella et al. [2014]. From this relationship, we calculated the $D_{H}^{\text {Olivine-melt }}$ for our experimental pressures.

Using the average calculated $D_{H}^{\text {Pyroxene-melt }}$ and calculated $D_{H}^{\text {Olivine-melt }}$, we are able to determine how the intermineral partition coefficient, $D_{H}^{\text {Pyroxene-Olivine, }}$, varies as a function of pressure (Fig. 4). On the basis of this result, it is clear that pressure has a substantial effect on the partitioning of $\mathrm{H}$ among mantle minerals, and that $D_{H}^{\text {Pyroxene-olivine }}$ can be described by the following power law:

$$
D_{H}^{\text {Pyroxene-Olivine }}=15( \pm 2) \times P^{-1.0( \pm 0.2)}
$$

where $\mathrm{P}$ is pressure in GPa. In the spinel stability field, pyroxenes contain more $\mathrm{H}_{2} \mathrm{O}$ than olivine, but the Al content of the pyroxenes may remain constant or even start to decrease with increasing pressure resulting in constant or decreasing pyroxene $\mathrm{H}_{2} \mathrm{O}$ content. The pyroxene $\mathrm{Al}$ content (and therefore $\mathrm{H}_{2} \mathrm{O}$ compatibility) then substantially decreases at garnet-in and continues 
to decrease as the garnet modal proportion increases. At the same time, the olivine $\mathrm{H}_{2} \mathrm{O}$ compatibility continues to increase with pressure. As a result, pyroxenes contain substantially more $\mathrm{H}_{2} \mathrm{O}$ than olivine at $1 \mathrm{GPa}$, but contain roughly the same amount of $\mathrm{H}_{2} \mathrm{O}$ as olivine at much higher pressures $(\geq 12 \mathrm{GPa})$.

Given the calculated phase proportions and the measured San Carlos olivine sphere $\mathrm{H}_{2} \mathrm{O}$ contents, we were able to calculate the $\mathrm{H}_{2} \mathrm{O}$ content of each experiment using the pressure-

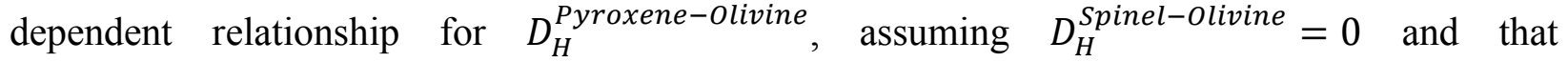
experimentally produced olivine $\mathrm{H}_{2} \mathrm{O}$ contents are the same as those measured in the San Carlos olivine (Table 3). In this way the mean $\mathrm{H}_{2} \mathrm{O}$ content for experiments ranging from 1.0 to $2.5 \mathrm{GPa}$ was determined to be $140 \pm 40 \mu \mathrm{g} / \mathrm{g}$ (2 SD n=17) (Fig. 5).

\subsection{Discussion}

\subsubsection{Comparison with Previous Work}

Many studies have focused on determining the initiation of melting in the upper mantle by using results from partial melting experiments of mantle material to map the peridotite solidus [e.g., Herzberg et al., 2000; Hirschmann, 2000; Iwamori et al., 1995; Langmuir et al., 1992; McKenzie and Bickle, 1988]. However, variations in experimental methods, starting compositions, and uncertainties in identifying small amounts of melt in an experimental charge leads to discrepancies between laboratories, which makes it challenging to produce an accurate solidus parameterization [e.g., Baker and Stolper, 1994; Hirschmann, 2000; Katz et al., 2003]. Figure 6 shows parameterizations of the anhydrous peridotite solidus from Hirschmann [2000], Herzberg et al. [2000], and Katz et al. [2003] (Table 4). Hirschmann [2000] constrained the anhydrous peridotite solidus by fitting subsolidus and super solidus experimental data for peridotite with compositions closest to the primitive upper mantle defined by McDonough and Rudnick [1998]. The results of this study indicated a general shift of the nominally anhydrous peridotite solidus to cooler temperatures relative to previous parameterizations [e.g., McKenzie and Bickle, 1998], though considerable interlaboratory discrepancies were noted. Hirschmann [2000] determined that the scatter is most likely due to compositional differences between experimental studies, 
such as alkali content and, to a lesser degree, Mg\#. On the other hand, Herzberg et al. [2000] experimentally studied the anhydrous solidus for a single peridotite composition (KLB-1) between pressures of 5.0 to $9.7 \mathrm{GPa}$. They determined the best peridotite solidus within the spinel lherzolite field by analyzing the solidi and the associated error for different peridotite compositions, and determined the solidus to be in agreement with that determined from the previous study of McKenzie and Bickle, 1998. Katz et al. [2003] used select anhydrous partial melting experiments with reliable melt fraction and modal cpx data to calibrate a model for the anhydrous peridotite solidus, allowing more fertile compositions than Hirschmann [2000]. Katz et al. [2003] derived a solidus temperature that is $\sim 35^{\circ} \mathrm{C}$ lower than that of Hirschmann [2000]. However, they discuss that there are substantial interlaboratory discrepancies in melt fractions present at a given pressure and temperature, which complicated the model calibration. An important confounding factor is that all nominally anhydrous experiments contain some unknown - but presumably small - amount of adsorbed $\mathrm{H}_{2} \mathrm{O}$, which will have a disproportionate influence on experimentally determined peridotite solidus. Despite this, the experimentally determined solidus is generally treated as the truly anhydrous $\left(0 \mu \mathrm{g} / \mathrm{g} \mathrm{H}_{2} \mathrm{O}\right)$ solidus and the influence of $\mathrm{H}_{2} \mathrm{O}$ on the initiation of melting is accounted for computationally [Hirschmann et al., 2009; Sarafian et al., 2017].

Our experiments use a single composition, consistent experimental methods, and employ a new approach to monitoring experimental $\mathrm{H}_{2} \mathrm{O}$ contents thereby minimizing the issues faced when comparing interlaboratory data on partial melting of peridotite containing an unknown amount of $\mathrm{H}_{2} \mathrm{O}$. Our experimentally determined solidus temperatures for peridotite containing $\sim 140 \mu \mathrm{g} / \mathrm{g}$ $\mathrm{H}_{2} \mathrm{O}$ are systematically higher than those predicted by the Katz et al. [2003] anhydrous model at all investigated pressures. The maximum offset $\left(+47^{\circ} \mathrm{C}\right)$ occurs at $1.0 \mathrm{GPa}$, and the mismatch decreases with increasing pressure $\left(+14{ }^{\circ} \mathrm{C}\right.$ at $\left.2.5 \mathrm{GPa}\right)$. On the other hand, our experimentally derived $140 \mu \mathrm{g} / \mathrm{g} \mathrm{H}_{2} \mathrm{O}$ solidus temperatures at 1.0 and $1.5 \mathrm{GPa}$ are higher than the Hirschmann [2000] and Herzberg et al. [2000] anhydrous solidus, but are cooler at 2.0 and $2.5 \mathrm{GPa}$. The maximum difference between the Hirschmann [2000] and Herzberg et al. [2000] anhydrous solidus and our $140 \mu \mathrm{g} / \mathrm{g} \mathrm{H}_{2} \mathrm{O}$ solidus is at $2.5 \mathrm{GPa}\left(-21^{\circ} \mathrm{C}\right.$ and $-32{ }^{\circ} \mathrm{C}$, respectively). Therefore, our solidus is in agreement with the nominally anhydrous solidus derived in Hirschmann [2000] given the $\pm 20{ }^{\circ} \mathrm{C}$ temperature uncertainty associated with the parameterization. This level of 
agreement suggests that $\sim 140 \mu \mathrm{g} / \mathrm{g} \mathrm{H}_{2} \mathrm{O}$ is a reasonable estimate for the average bulk $\mathrm{H}_{2} \mathrm{O}$ content of previous experiments used to constrain the nominally anhydrous solidus (Fig 6).

\subsubsection{Parameterization of the Anhydrous Spinel Lherzolite Solidus}

Knowledge of the anhydrous solidus provides an important constraint on melt generation in the mantle. Water lowers the mantle solidus allowing for deeper melting, but only supports low melt productivity. The majority of melt produced beneath a mid-ocean ridge is produced after the mantle crosses the anhydrous solidus [e.g., Asimow and Langmuir, 2003]. We used a "reverse cryoscopic" correction to determine the $0 \mu \mathrm{g} / \mathrm{g} \mathrm{H}_{2} \mathrm{O}$ peridotite solidus in the spinel stability field (0.8-2.8 GPa) on the basis of our experimental results of the $\sim 140 \mu \mathrm{g} / \mathrm{g} \mathrm{H} \mathrm{H}_{2} \mathrm{O}$ peridotite solidus at $1.0,1.5,2.0$, and $2.5 \mathrm{GPa}$. Our experimental results are limited to the spinel peridotite stability field without coexisting aluminous phases (i.e. plagioclase or garnet), which for simplicity is considered 0.8 to $2.8 \mathrm{GPa}$. The peridotite solidus is unlikely to follow a simple extrapolation of our parameterization in the plagioclase and garnet stability fields. Additional experiments at pressures below 1.0 $\mathrm{GPa}$ and above 2.5 $\mathrm{GPa}$ using the same experimental approach would constrain the peridotite solidus over a wider range of mantle pressures and may shed light on inflections where the solidus intersects aluminous phase stability boundaries.

Following the methods of Hirschmann et al. [2009], we used

$$
\mathrm{T}_{\text {anhydr }}=\mathrm{T}_{\text {hydr }}\left[1-(\mathrm{R} / \mathrm{M} \Delta \mathrm{S}) \ln \left(1-\mathrm{X}_{\mathrm{OH}}\right)\right]
$$

where $T_{\text {anhydr }}$ is the anhydrous solidus temperature, $T_{\text {hydr }}$ is the hydrated solidus temperature, $R$ is the gas constant in $\mathrm{J} \mathrm{K}^{-1} \mathrm{~mol}^{-1}, \mathrm{M}$ is the number of grams in one mole of silicate $\left(59 \mathrm{~g} \mathrm{~mol}^{-1}\right), \Delta \mathrm{S}$ is the entropy of fusion per unit mass $\left(0.4 \mathrm{~J} \mathrm{~K}^{-1} \mathrm{~g}^{-1}\right)$, and $\mathrm{X}_{\mathrm{OH}}$ is the mole fraction of dissolved $\mathrm{H}_{2} \mathrm{O}$ in the melt as dissociated hydroxyl. The $\mathrm{H}_{2} \mathrm{O}$ content of the melt was calculated using the pressure dependent $D_{H}^{\text {Olivine-Melt }}$ and $D_{H}^{\text {Pyroxene-Olivine }}$ as described in the results section of this study. We then fit a solidus from $0.8 \mathrm{GPa}$ to $2.8 \mathrm{GPa}$ using the same functional form used by Hirschmann [2000] and Katz et al. [2003] (Fig. 6; Table 4). Uncertainty in solidus temperature is estimated to be $\pm 20^{\circ} \mathrm{C}$ (2 SD) from our regression, whereas uncertainties in cryoscopically determined temperatures are insignificant. The $0 \mu \mathrm{g} / \mathrm{g} \mathrm{H}_{2} \mathrm{O}$ solidus based on our experimental 
determination of the $\sim 140 \mu \mathrm{g} / \mathrm{g} \mathrm{H}_{2} \mathrm{O}$ solidus is, on average, $61{ }^{\circ} \mathrm{C}$ hotter than the nominally anhydrous solidus of Hirschmann [2000] , $64^{\circ} \mathrm{C}$ hotter than the anhydrous solidus of Herzberg et al. [2000], and $96{ }^{\circ} \mathrm{C}$ hotter than that of Katz et al. [2003] over 0.8-2.8 GPa. In addition, the shape of the $0 \mu \mathrm{g} / \mathrm{g} \mathrm{H}_{2} \mathrm{O}$ solidus from this study is more curved than the earlier parameterizations. This results in the maximum difference between our $0 \mu \mathrm{g} / \mathrm{g} \mathrm{H}_{2} \mathrm{O}$ solidus and the previously determined solidi to occur at $1.5 \mathrm{GPa}\left(+68{ }^{\circ} \mathrm{C}\right.$ compared to Hirschmann, 2000; $+76{ }^{\circ} \mathrm{C}$ compared to Herzberg et al., 2000; $+103{ }^{\circ} \mathrm{C}$ compared to Katz et al., 2003) and the smallest difference to occur at $2.5 \mathrm{GPa}\left(+51{ }^{\circ} \mathrm{C}\right.$ compared to Hirschmann, $2000 ;+40{ }^{\circ} \mathrm{C}$ compared to Herzberg et al., 2000; $+86{ }^{\circ} \mathrm{C}$ compared to Katz et al., 2003) (Table 5). Solidi for any desired $\mathrm{H}_{2} \mathrm{O}$ content can be estimated from our $0 \mu \mathrm{g} / \mathrm{g} \mathrm{H}_{2} \mathrm{O}$ solidus using standard cryoscopic calculations (i.e. solving Equation 3 for $\mathrm{T}_{\text {Hydrous }}$ (Fig. 7).

\subsubsection{Geological Implications}

Peridotite partial melting is thought to initiate at depths ranging from $50 \mathrm{~km}$ to greater than 100 $\mathrm{km}$ depending on the mantle composition and temperature, with the deepest initiation of melting associated with mantle plumes [Asimow, 1999; Langmuir et al., 1993]. Peridotite containing $\sim 50-200 \mu \mathrm{g} / \mathrm{g}$ dissolved $\mathrm{H}_{2} \mathrm{O}$ is thought to be the principle mantle lithology and the primary source for mid-ocean ridge basalts. Therefore, the $0 \mu \mathrm{g} / \mathrm{g} \mathrm{H}_{2} \mathrm{O}$ and $\mathrm{H}_{2} \mathrm{O}$-undersaturated peridotite solidi determined in this study for the spinel peridotite stability field can provide critical constraints on the ambient mantle potential temperature.

Recent estimates for oceanic mantle potential temperatures far from the influence of plumes range from 1280 to $1450{ }^{\circ} \mathrm{C}$, a total variation of $170{ }^{\circ} \mathrm{C}$ [Behn and Grove, 2015; Dalton et al., 2014; Herzberg et al., 2007]. The lower limit of this range, $1280{ }^{\circ} \mathrm{C}$, would cross the Hirschmann [2000], Herzberg et al. [2000], and Katz et al. [2003] anhydrous solidi at 49 km, $\sim 52 \mathrm{~km}$, and $\sim 60 \mathrm{~km}$, respectively. Based on our experimental results, a mantle potential temperature of $1280{ }^{\circ} \mathrm{C}$ would require $\sim 165 \mu \mathrm{g} / \mathrm{g} \mathrm{H} 2 \mathrm{O}$ to initiate melting at $50 \mathrm{~km}$ depth beneath a ridge if we assume that $50 \mathrm{~km}$ is the shallowest depth for $\mathrm{H}_{2} \mathrm{O}$-undersaturated mantle melting (Fig. 7). However, this lowest potential temperature estimate would only produce small amounts of melt until $33 \mathrm{~km}$, when the anhydrous solidus is crossed and higher melt productivity is 
expected [Asimow and Langmuir, 2003]. This low mantle potential temperature would not generate enough melt for observed crustal thicknesses and may not produce normal MORB (NMORB) geochemical signatures, such as the predicted $\mathrm{Fe}$ and $\mathrm{Na}$ content. To illustrate this point, we can assume that the oceanic crust is generated from melting that occurs above the $\mathrm{H}_{2} \mathrm{O}$ undersaturated solidus with a constant melt productivity of $1 \%$ per $100 \mathrm{MPa}$ of decompression as an upper limit to calculate crustal thickness on the basis of the mean extent of melting, height of the residual mantle column, and the difference between melt and oceanic crust densities $(\sim 10 \%)$ [Langmuir et al., 1992]. Allowing melting to continue all the way to the surface, a mantle potential temperature of $1280{ }^{\circ} \mathrm{C}$ crosses the $165 \mu \mathrm{g} / \mathrm{g} \mathrm{H}_{2} \mathrm{O}$ solidus at $50 \mathrm{~km}$ depth producing only $\sim 4 \mathrm{~km}$ of crust. If instead we assume that $50 \mathrm{~km}$ is the shallowest depth for anhydrous mantle melting, our $0 \mu \mathrm{g} / \mathrm{g} \mathrm{H}_{2} \mathrm{O}$ peridotite solidus requires the lowest mantle potential temperature to be $1350{ }^{\circ} \mathrm{C}$ producing a mantle potential temperature range from 1350 to $1450{ }^{\circ} \mathrm{C}$ (Fig. 7). This decreases the range of mantle potential temperatures to produce NMORB from a $170{ }^{\circ} \mathrm{C}$ range to a $100{ }^{\circ} \mathrm{C}$ range.

Our spinel peridotite solidus is applicable to well-mixed mantle with peridotite being main component, such as in regions of the East Pacific Rise. Slow and ultraslow spreading ridges may have a more heterogeneous mantle source [Dick and Zhou, 2015; Zhou and Dick, 2013] and might not be described entirely by peridotite melting. In general, pyroxenites and enriched mantle components could generate melt deeper than the peridotite $\mathrm{H}_{2} \mathrm{O}$-undersaturated peridotite solidus, and recent studies have found these enriched components could be prevalent [Gale et al., 2013; Lambart et al., 2016; Shimizu et al., 2016]. Furthermore, carbon and other incompatible elements also influence the solidus and generate melt at greater depths [Dasgupta et al., 2007; Hirschmann, 2000].

\subsection{Conclusions}

By utilizing a new experimental approach to study the $\mathrm{H}_{2} \mathrm{O}$-undersaturated peridotite solidus, we are able to determine the $0 \mu \mathrm{g} / \mathrm{g} \mathrm{H}_{2} \mathrm{O}$ peridotite solidus within the spinel peridotite stability field between 0.8 and $2.8 \mathrm{GPa}$. The new experimental approach monitors experimental $\mathrm{H}_{2} \mathrm{O}$ content through large San Carlos olivine sphere embedded in the peridotite. Our experimental results 
suggest that the $0 \mu \mathrm{g} / \mathrm{g} \mathrm{H}_{2} \mathrm{O}$ peridotite solidus is substantially hotter than current estimates used to model melting beneath mid-ocean ridges (on average $+61{ }^{\circ} \mathrm{C}$ to $+96{ }^{\circ} \mathrm{C}$ over 0.8 to $2.8 \mathrm{GPa}$ ), with the largest difference occurring at $1.5 \mathrm{GPa}$ (between $+68{ }^{\circ} \mathrm{C}$ to $+103{ }^{\circ} \mathrm{C}$ ). This increase in peridotite solidus temperatures reduces the range of mantle potential temperatures beneath midocean ridges from $170{ }^{\circ} \mathrm{C}$ to $100{ }^{\circ} \mathrm{C}$ and reduces the thermal anomalies expected for mantle plumes. 


\subsection{References}

Ardia, P., M. M. Hirschmann, A. C. Withers, and T. J. Tenner (2012), H2O storage capacity of olivine at 5-8GPa and consequences for dehydration partial melting of the upper mantle, Earth and Planetary Science Letters, 345-348, 104-116, doi:10.1016/j.eps1.2012.05.038.

Asimow, P. D. (1999), Melting the mantle, Encyclopedia of Volcanoes, 55-68.

Asimow, P. D., J. Dixon, and C. Langmuir (2004), A hydrous melting and fractionation model for mid-ocean ridge basalts: Application to the Mid-Atlantic Ridge near the Azores, Geochemistry, Geophysics, Geosystems, 5(1), doi:10.1029/2003GC000568.

Asimow, P. D., and C. Langmuir (2003), The importance of water to oceanic mantle melting regimes, Nature, 421(6925), 815-820, doi:10.1038/nature01429.

Aubaud, C., E. H. Hauri, and M. M. Hirschmann (2004), Hydrogen partition coefficients between nominally anhydrous minerals and basaltic melts, Geophysical Research Letters, 31(20), doi:10.1029/2004GL021341.

Baker, M. B. and E. M. Stolper (1994), Determining the composition of high-pressure mantle melts using diamond aggregates, Geochimica et Cosmochimica Acta, 58(13), 2811-2827, doi: 10.1016/0016-7037(94)90116-3.

Behn, M. D., and T. L. Grove (2015), Melting systematics in mid-ocean ridge basalts: Application of a plagioclase-spinel melting model to global variations in major element chemistry and crustal thickness, Journal of Geophysical Research: Solid Earth, 120(7), 4863-4886, doi:10.1002/2015JB011885.

Borghini, G., P. Fumagalli, and E. Rampone (2009), The Stability of Plagioclase in the Upper Mantle: Subsolidus Experiments on Fertile and Depleted Lherzolite, J Petrol 51, 229-254, doi: 10.1093/petrology/egp079.

Boyd, F., and J. England (1960), Apparatus for phase-equilibrium measurements at pressures up to 50 kilobars and temperatures up to $1750^{\circ} \mathrm{C}$, Journal of Geophysical Research, 65(2), 741748.

Canales, J. P., G. Ito, R. S. Detrick, and J. Sinton (2002), Crustal thickness along the western Galápagos Spreading Center and the compensation of the Galápagos hotspot swell, Earth and Planetary Science Letters, 203(1), 311-327, doi:10.1016/S0012-821X(02)00843-9.

Cann, J. (1970), New model for the structure of the ocean crust, Nature, 226, 928-930.

Cushman, B., J. Sinton, G. Ito, and J. Eaby Dixon (2004), Glass compositions, plume-ridge interaction, and hydrous melting along the Galápagos Spreading Center, $90.5^{\circ} \mathrm{W}$ to $98^{\circ} \mathrm{W}$, Geochemistry, Geophysics, Geosystems, 5(8), doi:10.1029/2004GC000709. 
Dalton, C. A., C. H. Langmuir, and A. Gale (2014), Geophysical and geochemical evidence for deep temperature variations beneath mid-ocean ridges, Science, 344(6179), 80-83, doi:10.1126/science. 1249466.

Dasgupta, R., M. M. Hirschmann, and N. D. Smith (2007), Water follows carbon: CO2 incites deep silicate melting and dehydration beneath mid-ocean ridges, Geology, 35(2), 135, doi:10.1130/g22856a.1.

Dasgupta, R., A. Mallik, K. Tsuno, A. C. Withers, G. Hirth, and M. M. Hirschmann (2013), Carbon-dioxide-rich silicate melt in the Earth's upper mantle, Nature, 493(7431), 211-215, doi:10.1038/nature11731.

Demouchy, S., and S. Mackwell (2003), Water diffusion in synthetic iron-free forsterite, Physics and Chemistry of Minerals, 30(8), 486-494, doi:10.1007/s00269-003-0342-2.

Demouchy, S., and S. Mackwell (2006), Mechanisms of hydrogen incorporation and diffusion in iron-bearing olivine, Physics and Chemistry of Minerals, 33(5), 347-355, doi:10.1007/s00269-006-0081-2.

Dick, H. J., and H. Zhou (2015), Ocean rises are products of variable mantle composition, temperature and focused melting, Nature Geoscience, 8(1), 68-74, doi:10.1038/ngeo2318.

Gaetani, G. A., and T. L. Grove (1998), The influence of water on melting of mantle peridotite, Contributions to Mineralogy and Petrology, 131(4), 323-346, doi:10.1007/s004100050396.

Gaetani, G. A., J. A. O'Leary, K. T. Koga, E. H. Hauri, E. F. Rose-Koga, and B. D. Monteleone (2014), Hydration of mantle olivine under variable water and oxygen fugacity conditions, Contributions to Mineralogy and Petrology, 167(2), 1-14, doi:10.1007/s00410-014-0965-y.

Gale, A., C. A. Dalton, C. H. Langmuir, Y. Su, and J. G. Schilling (2013), The mean composition of ocean ridge basalts, Geochemistry, Geophysics, Geosystems, 14(3), 489-518, doi:10.1029/2012GC004334.

Hauri, E., G. Gaetani, and T. Green (2006), Partitioning of water during melting of the Earth's upper mantle at H2O-undersaturated conditions, Earth and Planetary Science Letters, 248(34), 715-734, doi:10.1016/j.eps1.2006.06.014.

Hauri, E., J. Wang, J. E. Dixon, P. L. King, C. Mandeville, and S. Newman (2002), SIMS analysis of volatiles in silicate glasses: 1. Calibration, matrix effects and comparisons with FTIR, Chemical Geology, 183(1), 99-114, doi:10.1016/S0009-2541(01)00375-8.

Hays, J.F. (1966), Lime-alumina-silica, Carnegie Institution of Washington Yearbook, 65, 234239.

Herzberg, C., P. D. Asimow, N. Arndt, Y. Niu, C. Lesher, J. Fitton, M. Cheadle, and A. Saunders (2007), Temperatures in ambient mantle and plumes: Constraints from basalts, picrites, and komatiites, Geochemistry, Geophysics, Geosystems, 8(2), doi:10.1029/2006GC001390. 
Herzberg, C., P. Raterron, and J. Zhang (2000), New experimental observations on the anhydrous solidus for peridotite KLB-1, Geochemistry, Geophysics, Geosystems, 1(11), doi:10.1029/2000gc000089.

Hirschmann, M. M. (2000), Mantle solidus: experimental constraints and the effects of peridotite composition, Geochemistry, Geophysics, Geosystems, 1(10), doi:10.1029/2000GC000070.

Hirschmann, M. M., C. Aubaud, and A. C. Withers (2005), Storage capacity of H2O in nominally anhydrous minerals in the upper mantle, Earth and Planetary Science Letters, 236(1-2), 167-181, doi:10.1016/j.eps1.2005.04.022.

Hirschmann, M. M., T. Tenner, C. Aubaud, and A. C. Withers (2009), Dehydration melting of nominally anhydrous mantle: The primacy of partitioning, Physics of the Earth and Planetary Interiors, 176(1-2), 54-68, doi:10.1016/j.pepi.2009.04.001.

Hirth, G., and D. L. Kohlstedt (1996), Water in the oceanic upper mantle: implications for rheology, melt extraction and the evolution of the lithosphere, Earth and Planetary Science Letters, 144(1), 93-108, doi:10.1016/0012-821X(96)00154-9.

Iwamori, H., D. McKenzie, and E. Takahashi (1995), Melt generation by isentropic mantle upwelling, Earth and Planetary Science Letters, 134(3), 253-266, doi: 10.1016/0012$821 \mathrm{X}(95) 00122-\mathrm{S}$.

Johannes, W., P. M. Bell, H. K. Mao, A. L. Boettcher, D. W. Chipman, J. F. Hays, R. C. Newton, and F. Seifert (1971), An interlaboratory comparison of piston-cylinder pressure calibration using the albite-breakdown reaction, Contrib Mineral Petr, 32, 24-38, doi:10.1007/BF00372231.

Katz, R. F., M. Spiegelman, and C. H. Langmuir (2003), A new parameterization of hydrous mantle melting, Geochemistry, Geophysics, Geosystems, 4(9), n/a-n/a, doi:10.1029/2002gc000433.

Klein, E. M., and C. H. Langmuir (1987), Global correlations of ocean ridge basalt chemistry with axial depth and crustal thickness, Journal of Geophysical Research: Solid Earth (19782012), 92(B8), 8089-8115, doi:10.1029/JB092iB08p08089.

Koga, K., E. Hauri, M. Hirschmann, and D. Bell (2003), Hydrogen concentration analyses using SIMS and FTIR: Comparison and calibration for nominally anhydrous minerals, Geochemistry, Geophysics, Geosystems, 4(2), n/a-n/a, doi:10.1029/2002gc000378.

Kohlstedt, D. L., and S. J. Mackwell (1998), Diffusion of hydrogen and intrinsic point defects in olivine, Zeitschrift für physikalische Chemie, 207(Part_1_2), 147-162, doi:10.1524/zpch.1998.207.Part_1_2.147.

Lambart, S., M. B. Baker, and E. M. Stolper (2016), The role of pyroxenite in basalt genesis: Melt-PX, a melting parameterization for mantle pyroxenites between 0.9 and $5 \mathrm{GPa}$, Journal of Geophysical Research: Solid Earth, 121(8), 5708-5735, doi:10.1002/2015JB012762. 
Langmuir, C. H., E. M. Klein, and T. Plank (1992), Petrological systematics of mid-ocean ridge basalts: constraints on melt generation beneath ocean ridges, in Mantle Flow and Melt Generation at Mid-Ocean Ridges, edited by J. Phipps Morgan, D. K. Blackman and J. M. Sinton, pp. 183-280, AGU, Washington D.C.

Langmuir, C. H., E. M. Klein, and T. Plank (1993), Petrological systematics of mid-ocean ridge basalts: Constraints on melt generation beneath ocean ridges, Mantle flow and melt generation at mid-ocean ridges, 183-280, doi:10.1029/GM071p0183.

le Roux, P. J., S. B. Shirey, E. H. Hauri, M. R. Perfit, and J. F. Bender (2006), The effects of variable sources, processes and contaminants on the composition of northern EPR MORB (8-10 N and 12-14 N): Evidence from volatiles (H 2 O, CO 2, S) and halogens (F, Cl), Earth and Planetary Science Letters, 251(3), 209-231, doi:10.1016/j.epsl.2006.09.012.

McDonough, W. F., and R. L. Rudnick (1998), Mineralogy and composition of the upper mantle, Reviews in mineralogy, 37, 139-164.

McKenzie, D., and M. Bickle (1988), The volume and composition of melt generated by extension of the lithosphere, Journal of petrology, 29(3), 625-679, doi:10.1093/petrology/29.3.625.

Médard, E., and T. L. Grove (2007), The effect of $\mathrm{H} 2 \mathrm{O}$ on the olivine liquidus of basaltic melts: experiments and thermodynamic models, Contributions to Mineralogy and Petrology, 155(4), 417-432, doi:10.1007/s00410-007-0250-4.

Medard, E., C. A. McCammon, J. A. Barr, and T. L. Grove (2008), Oxygen fugacity, temperature reproducibility, and $\mathrm{H} 2 \mathrm{O}$ contents of nominally anhydrous piston-cylinder experiments using graphite capsules, American Mineralogist, 93(11-12), 1838-1844, doi:10.2138/am.2008.2842.

Michael, P. J. (1988), The concentration, behavior and storage of $\mathrm{H} 2 \mathrm{O}$ in the suboceanic upper mantle: Implications for mantle metasomatism, Geochimica et Cosmochimica Acta, 52(2), 555-566, doi:10.1016/0016-7037(88)90110-X.

Novella, D., D. J. Frost, E. H. Hauri, H. Bureau, C. Raepsaet, and M. Roberge (2014), The distribution of $\mathrm{H} 2 \mathrm{O}$ between silicate melt and nominally anhydrous peridotite and the onset of hydrous melting in the deep upper mantle, Earth and Planetary Science Letters, 400, 1-13, doi:10.1016/j.epsl.2014.05.006.

O'Leary, J. A., G. A. Gaetani, and E. H. Hauri (2010), The effect of tetrahedral Al3+ on the partitioning of water between clinopyroxene and silicate melt, Earth and Planetary Science Letters, 297(1-2), 111-120, doi:10.1016/j.eps1.2010.06.011.

Plank, T., and C. H. Langmuir (1992), Effects of the melting regime on the composition of the oceanic crust, Journal of Geophysical Research: Solid Earth (1978-2012), 97(B13), 1974919770, doi:10.1029/92JB01769. 
Robinson, J.A.C. and B. J. Wood (1998), The depth of the spinel to garnet transition at the peridotite solidus, Earth and Planetary Science Letters 164, 277-284, doi: 10.1016/S0012821X(98)00213-1.

Saal, A. E., E. H. Hauri, C. H. Langmuir, and M. R. Perfit (2002), Vapour undersaturation in primitive mid-ocean-ridge basalt and the volatile content of Earth's upper mantle, Nature, 419(6906), 451-455, doi:10.1038/nature01073.

Saal, A. E., E. H. Hauri, M. L. Cascio, J. A. Van Orman, M. C. Rutherford, and R. F. Cooper (2008), Volatile content of lunar volcanic glasses and the presence of water in the Moon's interior, Nature, 454(7201), 192-195, doi:10.1038/nature07047.

Sarafian, E., G. A. Gaetani, E. H. Hauri, and A. R. Sarafian (2017), Experimental constraints on the damp peridotite solidus and oceanic mantle potential temperature, Science, 355(6328), 942-945, doi:10.1126/science.aaj2165.

Shen, Y., and D. W. Forsyth (1995), Geochemical constraints on initial and final depths of melting beneath mid-ocean ridges, Journal of Geophysical Research: Solid Earth, 100(B2), 2211-2237, doi:10.1029/94JB02768.

Shimizu, K., A. E. Saal, C. E. Myers, A. N. Nagle, E. H. Hauri, D. W. Forsyth, V. S. Kamenetsky, and Y. Niu (2016), Two-component mantle melting-mixing model for the generation of mid-ocean ridge basalts: Implications for the volatile content of the Pacific upper mantle, Geochimica et Cosmochimica Acta, 176, 44-80, doi:10.1016/j.gca.2015.10.033.

Smith, D. K., and J. R. Cann (1993), Building the crust at the Mid-Atlantic Ridge, Nature, 365, 707-715.

Tenner, T. J., M. M. Hirschmann, A. C. Withers, and P. Ardia (2012), H2O storage capacity of olivine and low-Ca pyroxene from 10 to $13 \mathrm{GPa}$ : consequences for dehydration melting above the transition zone, Contributions to Mineralogy and Petrology, 163(2), 297-316.

Workman, R. K., and S. R. Hart (2005), Major and trace element composition of the depleted MORB mantle (DMM), Earth and Planetary Science Letters, 231(1-2), 53-72, doi:10.1016/j.eps1.2004.12.005.

Zhou, H., and H. J. Dick (2013), Thin crust as evidence for depleted mantle supporting the Marion Rise, Nature, 494(7436), 195-200, doi:10.1038/nature11842. 


\subsection{Figures and Tables}

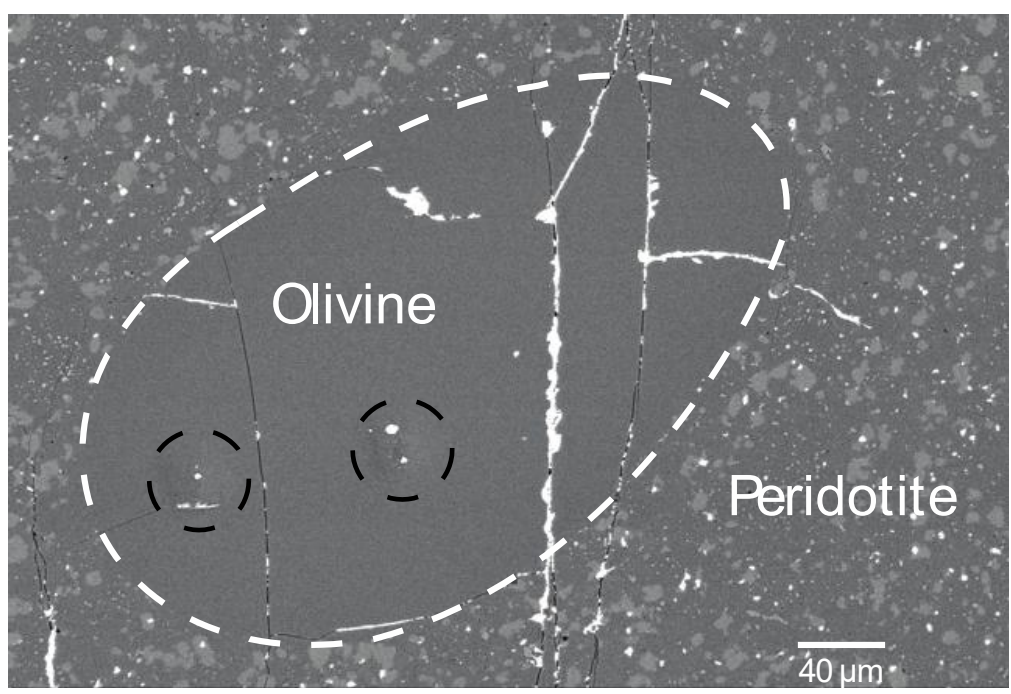

\section{Figure 1}

A backscattered electron image of the run-produced peridotite mineral grains and an embedded San Carlos olivine sphere. Two 6f SIMS analyses are visible in the San Carlos olivine spheres. The San Carlos olivine provides a target for multiple measurements by SIMS, whereas the matrix is too fine-grained. 


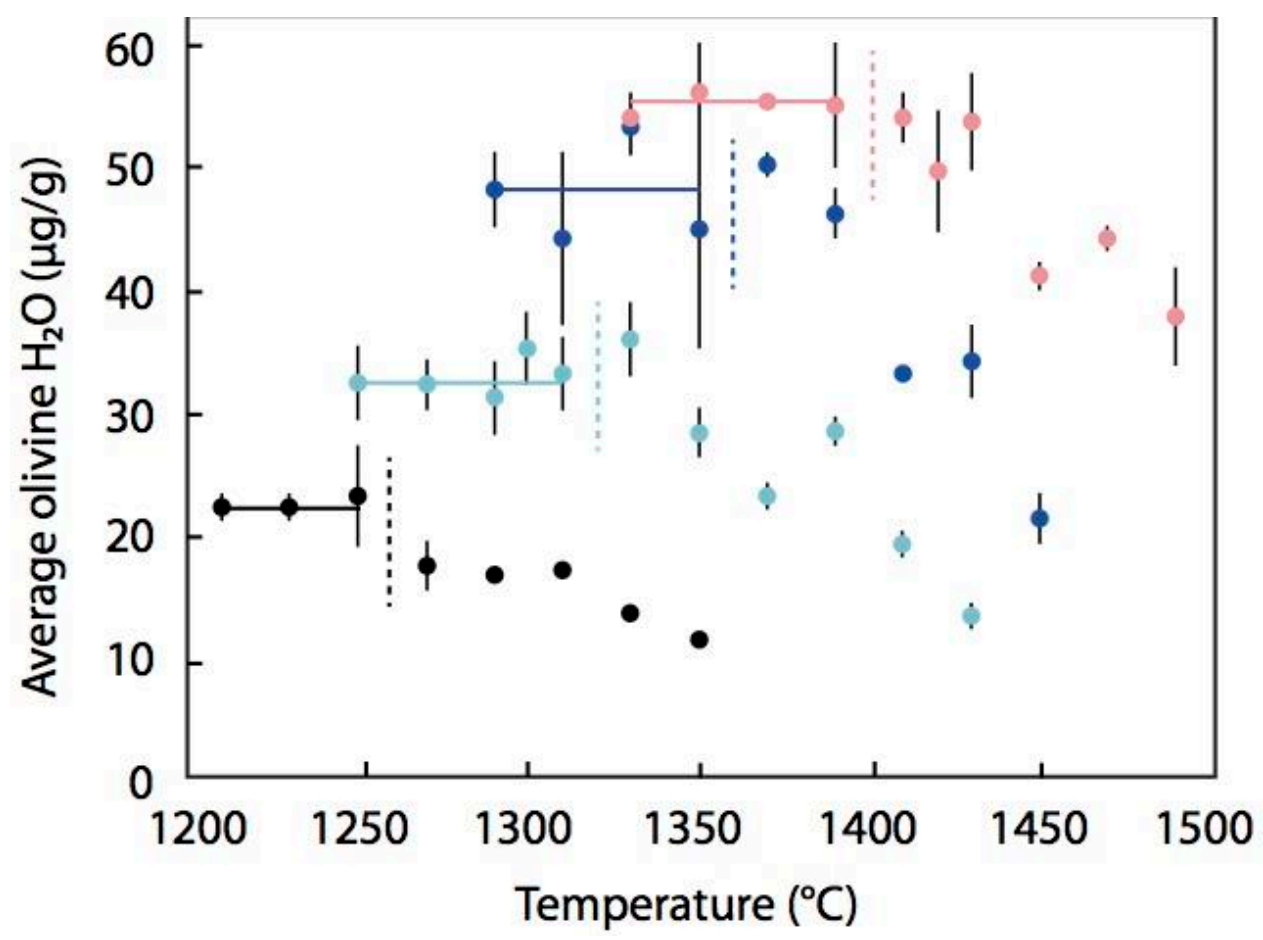

\section{Figure 2}

The average $\mathrm{H}_{2} \mathrm{O}$ content of the San Carlos olivine spheres with temperature and pressure. Black data are from $1 \mathrm{GPa}$ experiments, light blue are $1.5 \mathrm{GPa}$, dark blue are $2 \mathrm{GPa}$, and pink are 2.5 GPa experiments. The solid lines show the average subsolidus $\mathrm{H}_{2} \mathrm{O}$ content and the dashed lines show the solidus temperature at each pressure. The San Carlos olivine sphere $\mathrm{H}_{2} \mathrm{O}$ content follows a similar melting trend at each pressure. Error bars are 2 standard error in $\mathrm{H}_{2} \mathrm{O}$ content. Temperature uncertainty is $\pm 10^{\circ} \mathrm{C}$. 


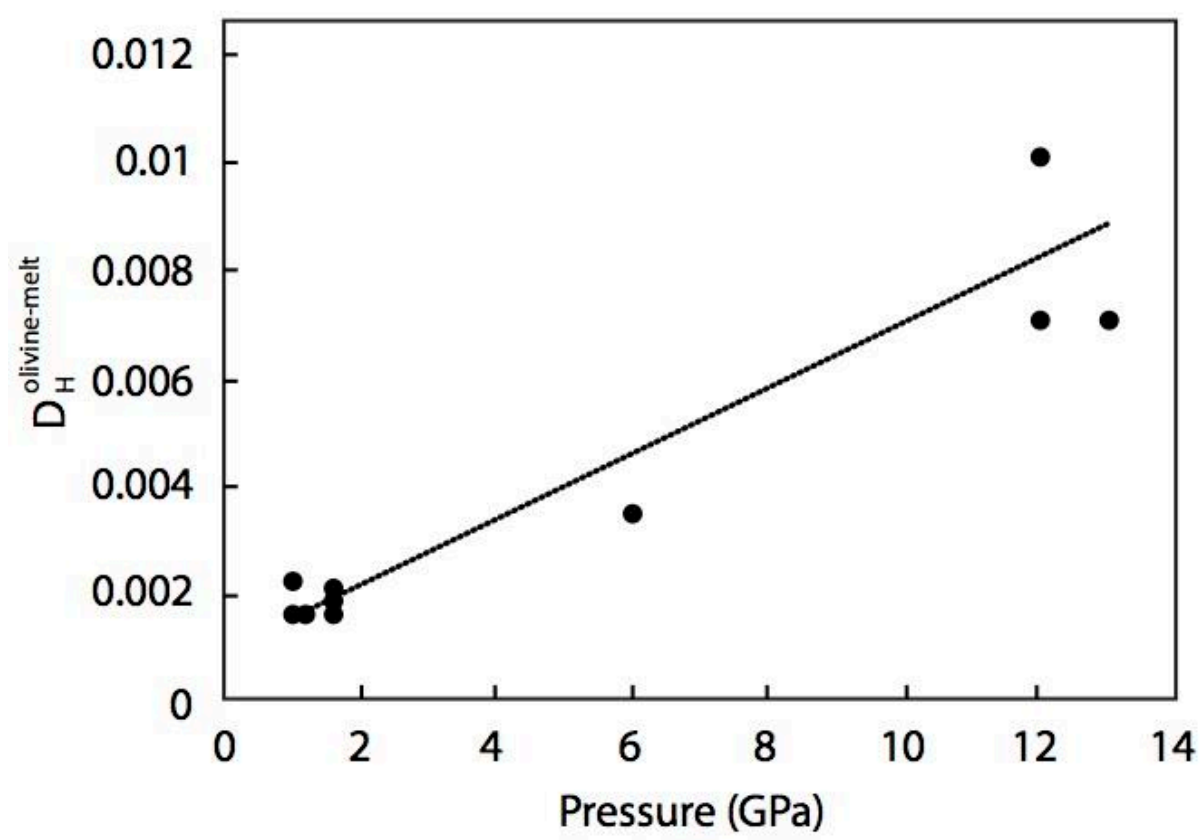

Figure 3

Experimental $D_{H}^{\text {Olivine-melt }}$ data from experiments that contained olivine $+\mathrm{opx}+\mathrm{cpx}+\mathrm{glass} \pm$ an aluminous phase over a range of pressures. Low pressure data are from Aubaud et al. [2004] and Hauri et al. [2006]. The datum at $6 \mathrm{GPa}$ is from Novella et al. [2014] and higher pressure data are from Tenner et al. [2012]. The data show a positive correlation between $D_{H}^{\text {Olivine-melt }}$ and pressure. 


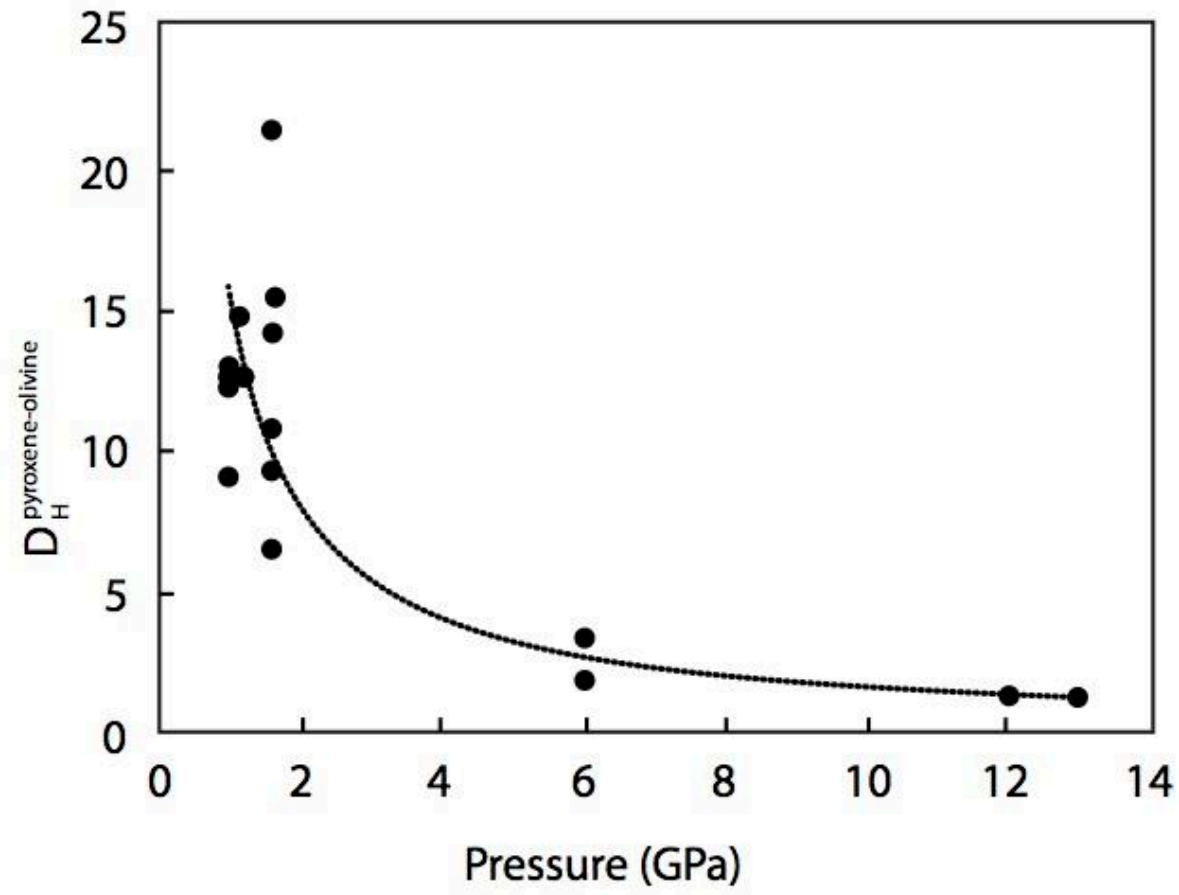

Figure 4

Experimental $D_{H}^{\text {Pyroxene-Olivine }}$ data from the same experiments as Fig. 3 and including the $D_{H}^{\text {Pyroxene-Olivine }}$ calculated in this study. The data show a power trend between $D_{H}^{\text {Pyroxene-Olivine }}$ and pressure. 


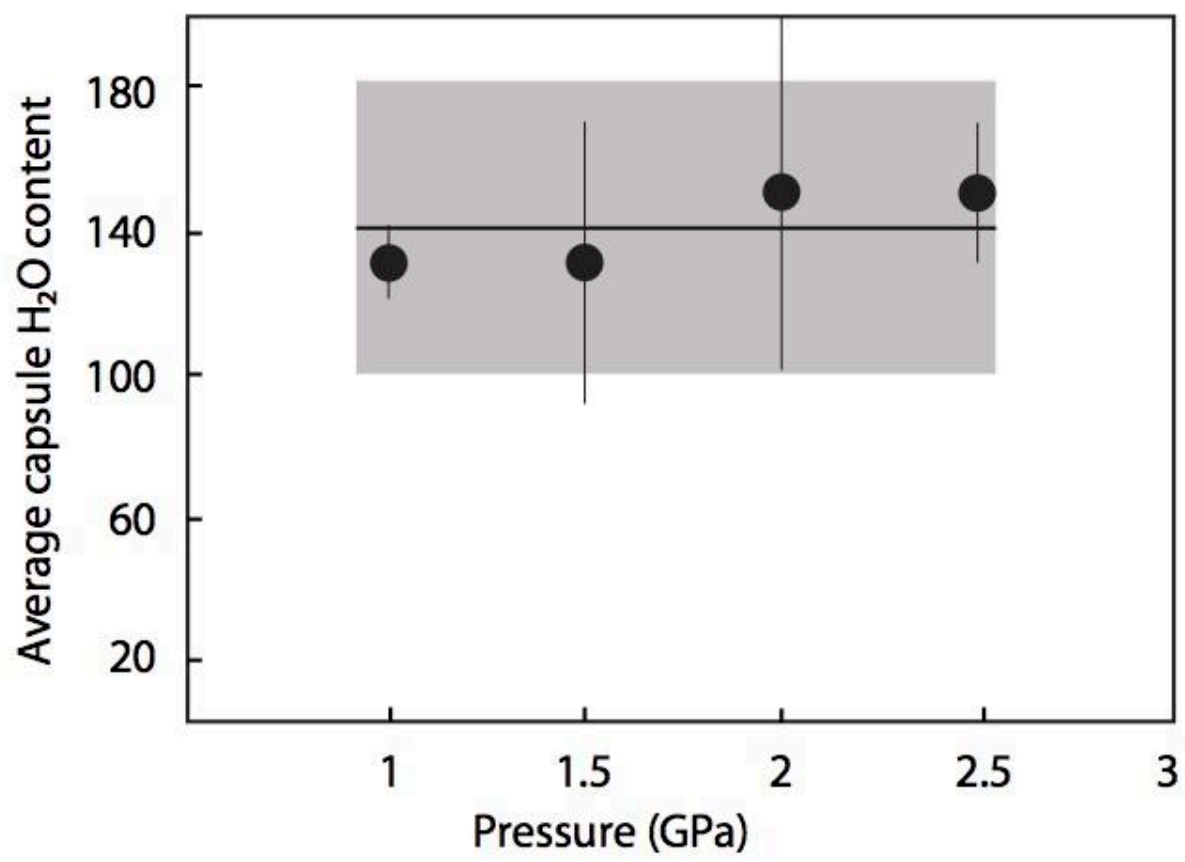

\section{Figure 5}

The average $\mathrm{H}_{2} \mathrm{O}$ content of the experimental capsules at each pressure in this study calculated from mass balance. The bold line shows the average $\mathrm{H}_{2} \mathrm{O}$ content of all experiments over every pressure and the gray region shows the corresponding uncertainty (2 SD). 


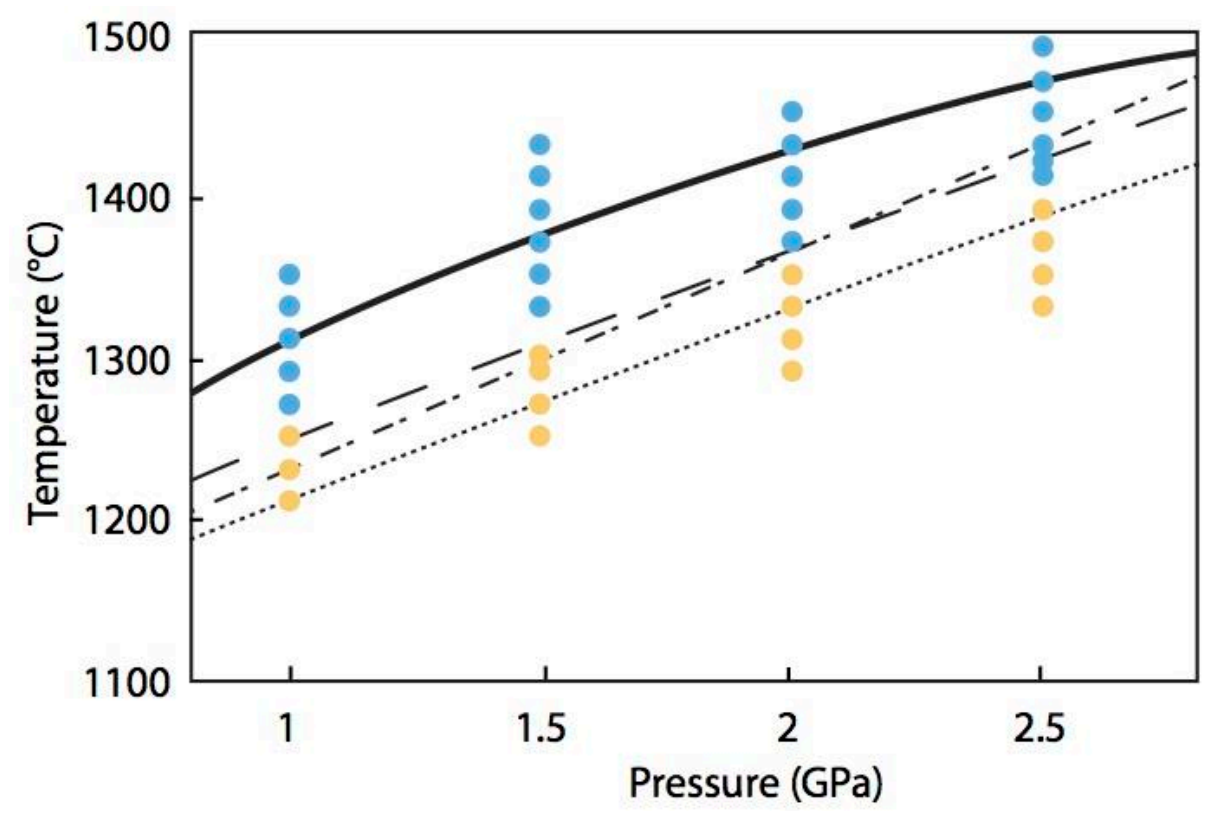

\section{Figure 6}

A comparison of our experimental results with two previous models for the anhydrous peridotite solidus: Hirschmann [2000] in dashed, Herzberg et al. [2000] in dash-dot, and Katz et al. [2003] in dotted. Our experiments containing $140 \mu \mathrm{g} / \mathrm{g} \mathrm{H}_{2} \mathrm{O}$ (blue circles are experiments that contain melt; yellow circles are melt-free experiments) show a strong agreement with the nominally anhydrous solidus from Hirschmann [2000]. The solid bold line shows the $0 \mu \mathrm{g} / \mathrm{g} \mathrm{H}_{2} \mathrm{O}$ peridotite solidus calculated from our experimental results. 


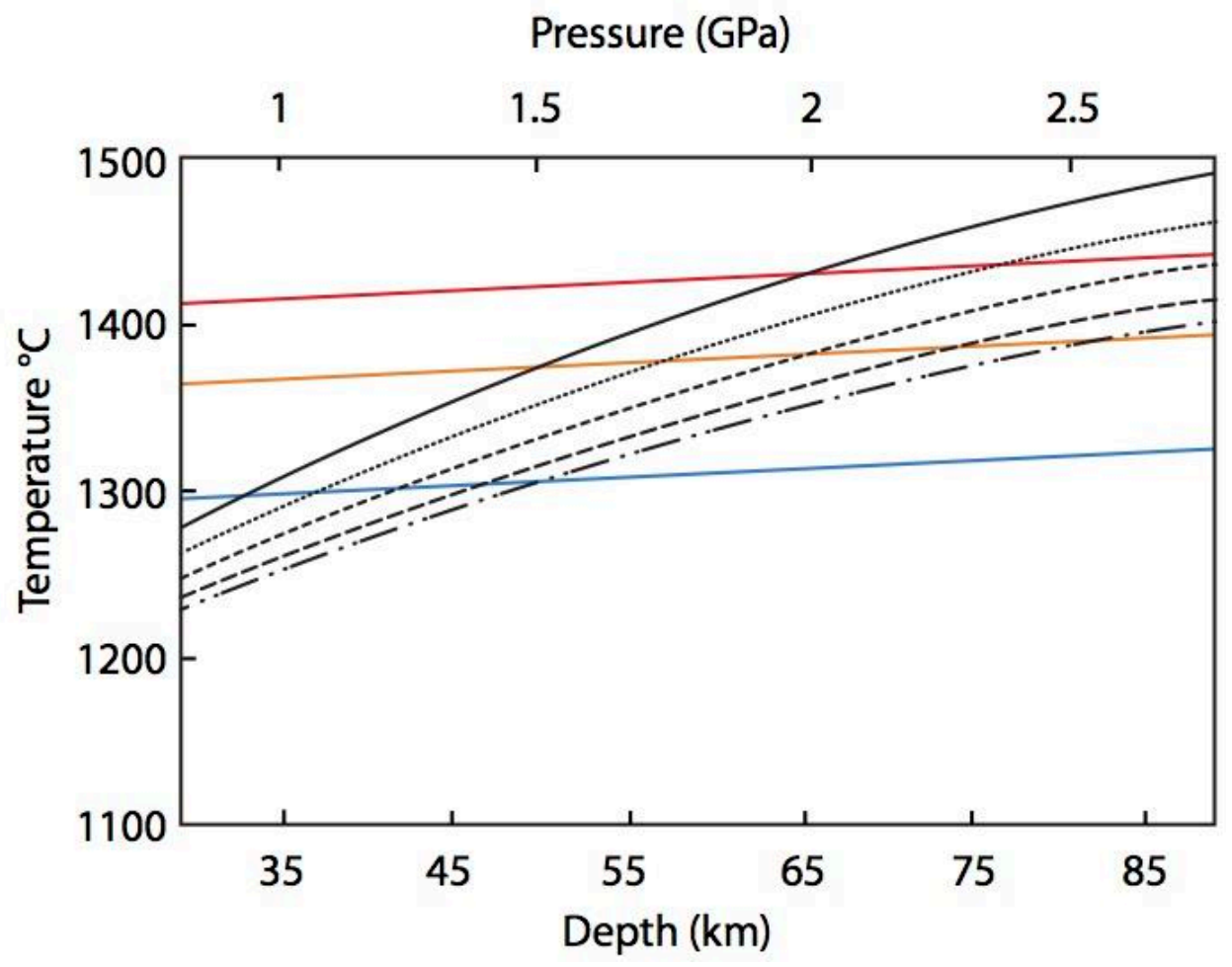

\section{Figure 7}

The $0 \mu \mathrm{g} / \mathrm{g} \mathrm{H}_{2} \mathrm{O}$ peridotite solidus calculated in this study and the corresponding $\mathrm{H}_{2} \mathrm{O}$ undersaturated solidi for mantle $\mathrm{H}_{2} \mathrm{O}$ contents of 50 (dotted), 100 (short dashed), 150 (long dashed), and $180 \mu \mathrm{g} / \mathrm{g} \mathrm{H}_{2} \mathrm{O}$ (dash dot). Also shown are mantle adiabats with a potential temperature of 1280 (blue line), 1350 (orange line), and $1397{ }^{\circ} \mathrm{C}$ (red line). The mantle will begin to melt where the adiabat intersects the solidus. 


\section{Table 1}

Oxides and corresponding components for starting composition, and component dehydration conditions

\begin{tabular}{|c|c|c|c|c|c|}
\hline Oxide & $\begin{array}{l}\mathrm{DMM}^{\mathrm{a}} \\
(\mathrm{wt} \%)\end{array}$ & Component & $\begin{array}{c}\text { DMM } \\
\text { Component } \\
(w t \%)\end{array}$ & $\begin{array}{c}\text { Dehydration } \\
\text { Temperature } \\
\left({ }^{\circ} \mathrm{C}\right)\end{array}$ & $\begin{array}{c}\text { Dehydration } \\
\text { Time } \\
(\mathrm{hrs})\end{array}$ \\
\hline $\mathrm{SiO}_{2}$ & 44.62 & $\mathrm{SiO}_{2}$ & 36.04 & 1000 & 240 \\
\hline $\mathrm{Al}_{2} \mathrm{O}_{3}$ & 3.98 & $\mathrm{Al}_{2} \mathrm{O}_{3}$ & 3.47 & 1000 & 480 \\
\hline $\mathrm{FeO}^{\mathrm{b}}$ & 8.17 & $\mathrm{Fe}_{2} \mathrm{SiO}_{4}{ }^{\mathrm{c}}$ & 11.58 & 800 & 18 \\
\hline $\mathrm{MnO}$ & 0.14 & $\mathrm{MnO}$ & 0.14 & 800 & 18 \\
\hline $\mathrm{MgO}$ & 38.65 & $\mathrm{MgO}$ & 38.65 & 800 & 1 \\
\hline $\mathrm{CaO}$ & 3.17 & $\mathrm{CaSiO}_{3}{ }^{\mathrm{d}}$ & 6.56 & 800 & 2 \\
\hline $\mathrm{Na}_{2} \mathrm{O}$ & 0.29 & $\mathrm{NaAlSi}_{3} \mathrm{O}_{8}{ }^{\mathrm{e}}$ & 2.53 & 800 & 28 \\
\hline $\mathrm{Cr}_{2} \mathrm{O}_{3}$ & 0.58 & $\mathrm{Cr}_{2} \mathrm{O}_{3}$ & 0.58 & 1000 & 18 \\
\hline $\mathrm{TiO}_{2}$ & 0.14 & $\mathrm{TiO}_{2}$ & 0.14 & 800 & 28 \\
\hline $\mathrm{NiO}$ & 0.25 & $\mathrm{NiO}$ & 0.25 & 800 & 28 \\
\hline $\mathrm{K}_{2} \mathrm{O}$ & 0.014 & $\mathrm{KAlSi}_{3} \mathrm{O}_{8}{ }^{\mathrm{f}}$ & 0.063 & 800 & 28 \\
\hline $\mathrm{H}_{2} \mathrm{O}$ & 0 & $\mathrm{H}_{2} \mathrm{O}$ & 0 & - & - \\
\hline Total & 99.98 & - & 100.00 & - & - \\
\hline
\end{tabular}

a. Based on Workman and Hart [2005]

b. Total $\mathrm{Fe}$ as $\mathrm{FeO}$

c. Pure fayalite synthesized from $\mathrm{SiO}_{2}$ and $\mathrm{FeO}$

d. Pure $\mathrm{Ca}$ metasilicate synthesized from $\mathrm{CaO}$ and $\mathrm{SiO}_{2}$

e. Amelia albite standard

f. Research grade orthoclase. Electron microprobe verified homogeneity.

g. No $\mathrm{H}_{2} \mathrm{O}$ was added to the mixture 
Table 2

Run conditions, average San Carlos olivine $\mathrm{H}_{2} \mathrm{O}$ content and number of SIMS analyses, and experimental run products. Modal abundance of phases is listed in subsolidus experiments.

\begin{tabular}{|c|c|c|c|c|c|c|c|}
\hline Experiment & $\begin{array}{l}\text { Drying } \\
\text { Time } \\
\text { (h) }\end{array}$ & $\begin{array}{c}\mathrm{P} \\
(\mathrm{GPa})\end{array}$ & $\begin{array}{c}\mathrm{T} \\
\left({ }^{\circ} \mathrm{C}\right)\end{array}$ & $\begin{array}{l}\text { Duration } \\
\text { (h) }\end{array}$ & $\begin{array}{c}\text { Average San } \\
\text { Carlos } \mathrm{H}_{2} \mathrm{O} \\
\text { Content }{ }^{\mathrm{a}} \\
(\mu \mathrm{g} / \mathrm{g})\end{array}$ & $\begin{array}{c}\text { \# of } \\
\text { Analyses }\end{array}$ & Run products ${ }^{\mathrm{b}, \mathrm{c}}$ \\
\hline $\begin{array}{c}\text { ETDMM } \\
102\end{array}$ & 48 & 1.0 & 1210 & 24 & $22(1)$ & 8 & $\begin{array}{c}\mathrm{Ol}(58)+\mathrm{Opx}(23)+\mathrm{Cpx} \\
(12)+\mathrm{Sp}(2)\end{array}$ \\
\hline $\begin{array}{c}\text { ETDMM } \\
103\end{array}$ & 48 & 1.0 & 1230 & 24 & $22(1)$ & 7 & $\begin{array}{c}\mathrm{Ol}(58)+\mathrm{Opx}(24)+\mathrm{Cpx} \\
(11)+\mathrm{Sp}(2)\end{array}$ \\
\hline $\begin{array}{l}\text { ETDMM } \\
104\end{array}$ & 48 & 1.0 & 1250 & 24 & $24.6(6)$ & 7 & $\mathrm{Ol}+\mathrm{Opx}+\mathrm{Cpx}+\mathrm{Sp}$ \\
\hline $\begin{array}{c}\text { ETDMM } \\
104 \mathrm{~b}\end{array}$ & 48 & 1.0 & 1250 & 24 & $21(2)$ & 6 & $\begin{array}{c}\mathrm{Ol}(59)+\mathrm{Opx}(24)+\mathrm{Cpx} \\
(10)+\mathrm{Sp}(2)\end{array}$ \\
\hline $\begin{array}{l}\text { ETDMM } \\
105\end{array}$ & 24 & 1.0 & 1270 & 24 & $17(2)$ & 8 & $\mathrm{Ol}+\mathrm{Opx}+\mathrm{Cpx}+\mathrm{Sp}+\mathrm{Gl}$ \\
\hline $\begin{array}{l}\text { ETDMM } \\
106\end{array}$ & 48 & 1.0 & 1290 & 24 & $16.4(2)$ & 8 & $\mathrm{Ol}+\mathrm{Opx}+\mathrm{Cpx}+\mathrm{Sp}+\mathrm{Gl}$ \\
\hline $\begin{array}{c}\text { ETDMM } \\
107\end{array}$ & 24 & 1.0 & 1310 & 24 & $16.9(4)$ & 8 & $\mathrm{Ol}+\mathrm{Opx}+\mathrm{Cpx}+\mathrm{Sp}+\mathrm{Gl}$ \\
\hline $\begin{array}{c}\text { ETDMM } \\
108\end{array}$ & 48 & 1.0 & 1330 & 24 & $13.4(7)$ & 8 & $\mathrm{Ol}+\mathrm{Opx}+\mathrm{Cpx}+\mathrm{Sp}+\mathrm{Gl}$ \\
\hline $\begin{array}{c}\text { ETDMM } \\
109\end{array}$ & 48 & 1.0 & 1350 & 24 & $10.9(6)$ & 7 & $\mathrm{O} 1+\mathrm{Opx}+\mathrm{Sp}+\mathrm{Gl}$ \\
\hline $\begin{array}{l}\text { ETDMM } \\
200\end{array}$ & 24 & 2.0 & 1290 & 24 & $48(3)$ & 6 & $\begin{array}{c}\mathrm{Ol}(57)+\mathrm{Opx}(24)+\mathrm{Cpx} \\
(11)+\mathrm{Sp}(2)\end{array}$ \\
\hline $\begin{array}{l}\text { ETDMM } \\
201\end{array}$ & 24 & 2.0 & 1310 & 24 & $50(2)$ & 8 & $\begin{array}{c}\mathrm{Ol}(62)+\mathrm{Opx}(17)+\mathrm{Cpx} \\
(16)+\mathrm{Sp}(2)\end{array}$ \\
\hline $\begin{array}{l}\text { ETDMM } \\
201 \mathrm{~b}\end{array}$ & 24 & 2.0 & 1310 & 24 & $37(3)$ & 6 & $\begin{array}{c}\mathrm{Ol}(58)+\mathrm{Opx}(20)+\mathrm{Cpx} \\
(14)+\mathrm{Sp}(2)\end{array}$ \\
\hline $\begin{array}{l}\text { ETDMM } \\
202\end{array}$ & 24 & 2.0 & 1330 & 24 & $53(2)$ & 8 & $\begin{array}{c}\mathrm{Ol}(57)+\mathrm{Opx}(20)+\mathrm{Cpx} \\
(15)+\mathrm{Sp}(2)\end{array}$ \\
\hline $\begin{array}{l}\text { ETDMM } \\
203\end{array}$ & 24 & 2.0 & 1350 & 24 & $56(8)$ & 5 & $\mathrm{Ol}+\mathrm{Opx}+\mathrm{Cpx}+\mathrm{Sp}$ \\
\hline $\begin{array}{l}\text { ETDMM } \\
203 b\end{array}$ & 24 & 2.0 & 1350 & 24 & $34(2)$ & 8 & $\mathrm{O} 1+\mathrm{Opx}+\mathrm{Cpx}+\mathrm{Sp}$ \\
\hline $\begin{array}{l}\text { ETDMM } \\
204\end{array}$ & 24 & 2.0 & 1370 & 24 & $50(1)$ & 6 & $\mathrm{Ol}+\mathrm{Opx}+\mathrm{Cpx}+\mathrm{Sp}+\mathrm{Gl}$ \\
\hline $\begin{array}{l}\text { ETDMM } \\
205\end{array}$ & 24 & 2.0 & 1390 & 24 & $46(2)$ & 8 & $\mathrm{Ol}+\mathrm{Opx}+\mathrm{Cpx}+\mathrm{Sp}+\mathrm{Gl}$ \\
\hline $\begin{array}{l}\text { ETDMM } \\
206\end{array}$ & 24 & 2.0 & 1410 & 24 & $32.9(7)$ & 8 & $\mathrm{Ol}+\mathrm{Opx}+\mathrm{Cpx}+\mathrm{Sp}+\mathrm{Gl}$ \\
\hline $\begin{array}{l}\text { ETDMM } \\
207\end{array}$ & 24 & 2.0 & 1430 & 24 & $35(1)$ & 7 & $\mathrm{O} 1+\mathrm{Opx}+\mathrm{Sp}+\mathrm{Gl}$ \\
\hline $\begin{array}{c}\text { ETDMM } \\
207 \mathrm{~b}\end{array}$ & 24 & 2.0 & 1430 & 24 & $32(2)$ & 5 & $\mathrm{O} 1+\mathrm{Opx}+\mathrm{Sp}+\mathrm{Gl}$ \\
\hline
\end{tabular}


Table 2 (continued)

\begin{tabular}{|c|c|c|c|c|c|c|c|}
\hline Experiment & $\begin{array}{l}\text { Drying } \\
\text { Time } \\
\text { (h) }\end{array}$ & $\begin{array}{c}\mathrm{P} \\
(\mathrm{GPa})\end{array}$ & $\begin{array}{c}\mathrm{T} \\
\left({ }^{\circ} \mathrm{C}\right)\end{array}$ & $\begin{array}{l}\text { Duration } \\
\text { (h) }\end{array}$ & $\begin{array}{c}\text { Average San } \\
\text { Carlos } \mathrm{H}_{2} \mathrm{O} \\
\text { Content }^{\mathrm{a}} \\
(\mu \mathrm{g} / \mathrm{g})\end{array}$ & $\begin{array}{c}\text { \# of } \\
\text { Analyses }\end{array}$ & Run products ${ }^{\mathrm{b}, \mathrm{c}}$ \\
\hline $\begin{array}{l}\text { ETDMM } \\
208\end{array}$ & 24 & 2.0 & 1450 & 24 & $21(2)$ & 4 & $\mathrm{Ol}+\mathrm{Opx}+\mathrm{Sp}+\mathrm{Gl}$ \\
\hline $\begin{array}{l}\text { ETDMM } \\
208 b\end{array}$ & 24 & 2.0 & 1450 & 24 & $19(1)$ & 7 & $\mathrm{Ol}+\mathrm{Opx}+\mathrm{Sp}+\mathrm{Gl}$ \\
\hline $\begin{array}{l}\text { ETDMM } \\
208 \mathrm{c}\end{array}$ & 24 & 2.0 & 1450 & 24 & $24(1)$ & 7 & $\mathrm{Ol}+\mathrm{Opx}+\mathrm{Sp}+\mathrm{Gl}$ \\
\hline $\begin{array}{l}\text { ETDMM } \\
250\end{array}$ & 24 & 2.5 & 1330 & 24 & $54(3)$ & 5 & $\begin{array}{c}\mathrm{O} 1(56)+\mathrm{Opx}(21)+\mathrm{Cpx} \\
(15)+\mathrm{Sp}(2)\end{array}$ \\
\hline $\begin{array}{l}\text { ETDMM } \\
259\end{array}$ & 24 & 2.5 & 1350 & 24 & $56(4)$ & 6 & $\begin{array}{c}\mathrm{Ol}(58)+\mathrm{Opx}(19)+\mathrm{Cpx} \\
(16)+\mathrm{Sp}(2)\end{array}$ \\
\hline $\begin{array}{l}\text { ETDMM } \\
259 b\end{array}$ & 24 & 2.5 & 1350 & 24 & $60(2)$ & 5 & $\mathrm{Ol}+\mathrm{Opx}+\mathrm{Cpx}+\mathrm{Sp}$ \\
\hline $\begin{array}{l}\text { ETDMM } \\
2510\end{array}$ & 24 & 2.5 & 1370 & 24 & $55(1)$ & 8 & $\begin{array}{c}\mathrm{Ol}(56)+\mathrm{Opx}(22)+\mathrm{Cpx} \\
(15)+\mathrm{Sp}(2)\end{array}$ \\
\hline $\begin{array}{l}\text { ETDMM } \\
251\end{array}$ & 0 & 2.5 & 1390 & 24 & $50(2)$ & 7 & $\begin{array}{c}\mathrm{Ol}(60)+\mathrm{Opx}(17)+\mathrm{Cpx} \\
(16)+\mathrm{Sp}(2)\end{array}$ \\
\hline $\begin{array}{l}\text { ETDMM } \\
251 b\end{array}$ & 24 & 2.5 & 1390 & 24 & $59(3)$ & 5 & $\begin{array}{c}\mathrm{Ol}(57)+\mathrm{Opx}(20)+\mathrm{Cpx} \\
(16)+\mathrm{Sp}(2)\end{array}$ \\
\hline $\begin{array}{l}\text { ETDMM } \\
252\end{array}$ & 24 & 2.5 & 1410 & 24 & $54(2)$ & 8 & $\mathrm{Ol}+\mathrm{Opx}+\mathrm{Cpx}+\mathrm{Sp}+\mathrm{Gl}$ \\
\hline $\begin{array}{l}\text { ETDMM } \\
2511\end{array}$ & 24 & 2.5 & 1420 & 24 & $44.9(5)$ & 8 & $\mathrm{Ol}+\mathrm{Opx}+\mathrm{Cpx}+\mathrm{Sp}+\mathrm{Gl}$ \\
\hline $\begin{array}{l}\text { ETDMM } \\
2511 \mathrm{~b}\end{array}$ & 24 & 2.5 & 1420 & 24 & $55(2)$ & 7 & $\mathrm{Ol}+\mathrm{Opx}+\mathrm{Cpx}+\mathrm{Sp}+\mathrm{Gl}$ \\
\hline $\begin{array}{l}\text { ETDMM } \\
253\end{array}$ & 24 & 2.5 & 1430 & 24 & $52(1)$ & 7 & $\mathrm{Ol}+\mathrm{Opx}+\mathrm{Cpx}+\mathrm{Sp}+\mathrm{Gl}$ \\
\hline $\begin{array}{l}\text { ETDMM } \\
253 \mathrm{~b}\end{array}$ & 24 & 2.5 & 1430 & 24 & $56(1)$ & 7 & $\mathrm{Ol}+\mathrm{Opx}+\mathrm{Cpx}+\mathrm{Sp}+\mathrm{Gl}$ \\
\hline $\begin{array}{l}\text { ETDMM } \\
254\end{array}$ & 24 & 2.5 & 1450 & 24 & $41(1)$ & 7 & $\mathrm{Ol}+\mathrm{Opx}+\mathrm{Cpx}+\mathrm{Sp}+\mathrm{Gl}$ \\
\hline $\begin{array}{l}\text { ETDMM } \\
255\end{array}$ & 24 & 2.5 & 1470 & 24 & $44(1)$ & 7 & $\mathrm{Ol}+\mathrm{Opx}+\mathrm{Cpx}+\mathrm{Sp}+\mathrm{Gl}$ \\
\hline $\begin{array}{l}\text { ETDMM } \\
256\end{array}$ & 24 & 2.5 & 1490 & 24 & $36(1)$ & 7 & $\mathrm{Ol}+\mathrm{Opx}+\mathrm{Cpx}+\mathrm{Sp}+\mathrm{Gl}$ \\
\hline $\begin{array}{l}\text { ETDMM } \\
256 \mathrm{~b}\end{array}$ & 24 & 2.5 & 1490 & 24 & $40(1)$ & 6 & $\mathrm{Ol}+\mathrm{Opx}+\mathrm{Cpx}+\mathrm{Sp}+\mathrm{Gl}$ \\
\hline
\end{tabular}

a. Number in parentheses are 2 standard error uncertainties.

b. Run products are olivine (ol), orthopyroxene (opx), clinopyroxene (cpx), spinel (sp), and optically identified glass (gl). All experiments also included San Carlos olivine spheres.

c. Modal proportions (in \%) are listed in parentheses. All experiments also contained 5\% San Carlos olivine. 
Table 3

An example mass balance calculation for experiment ETDMM18: $\mathrm{T}=1250^{\circ} \mathrm{C}$.

\begin{tabular}{lccc}
\hline \multicolumn{1}{c}{ Phase } & $\begin{array}{c}\text { Phase } \\
\text { proportion }^{\mathrm{a}}(\%)\end{array}$ & $\begin{array}{c}\text { Phase } \mathrm{H}_{2} \mathrm{O} \\
\text { content } \\
(\mu \mathrm{g} / \mathrm{g})\end{array}$ & $\begin{array}{c}\text { Total DMM } \\
\mathrm{H}_{2} \mathrm{O} \text { content } \\
(\mu \mathrm{g} / \mathrm{g})\end{array}$ \\
\hline San Carlos & 5 & 32 & 2 \\
olivine & & & 18 \\
Olivine & 56 & 32 & 67 \\
Orthopyroxene & 21 & 320 & 46 \\
Clinopyroxene & 15 & 320 & 0 \\
Spinel & 3 & 0 & 133 \\
Total & 100 & - & \\
\hline
\end{tabular}




\section{Table 4}

The parameterizations of the anhydrous peridotite solidi where $\mathrm{P}$ is pressure in GPa.

$\begin{array}{ll}\text { Katz et al. [2003] } & \mathrm{T}=-5.1 \mathrm{P}^{2}+132.9 \mathrm{P}+1085.7 \\ \text { Hirschmann [2000] } & \mathrm{T}=-5.104 \mathrm{P}^{2}+132.899 \mathrm{P}+1120.661 \\ \text { Herzberg et al. }[2000] & \mathrm{T}=132 \mathrm{P}+1102 \\ \text { This Study } & \mathrm{T}=-27 \mathrm{P}^{2}+201.7 \mathrm{P}+1133.7(\mathrm{Rs}=.998)\end{array}$




\section{Table 5}

The values of the anhydrous and $140 \mu \mathrm{g} / \mathrm{g} \mathrm{H}_{2} \mathrm{O}$ solidi at each pressure studied.

\begin{tabular}{|c|c|c|c|c|c|}
\hline $\begin{array}{l}\text { Pressure } \\
(\mathrm{GPa})\end{array}$ & $\begin{array}{l}\text { Hirschmann } \\
\text { [2000] Nom. } \\
\text { Anhydrous }\end{array}$ & $\begin{array}{l}\text { Herzberg et } \\
\text { al. [2000] } \\
\text { Anhydrous }\end{array}$ & $\begin{array}{l}\text { Katz et al., } \\
\text { [2003] } \\
\text { Anhydrous }\end{array}$ & $\begin{array}{l}\text { My } 140 \\
\text { ppm }\end{array}$ & $\begin{array}{l}\text { My } 0 \text { ppm } \\
\text { (diff. } \\
\text { Hirschmann; } \\
\text { Herzberg; } \\
\text { Katz) }\end{array}$ \\
\hline 1.0 & 1248 & 1234 & 1213 & 1260 & $\begin{array}{l}1308(60 ; 75 ; \\
95)\end{array}$ \\
\hline 1.5 & 1309 & 1300 & 1274 & 1320 & $\begin{array}{l}1380(68 ; 76 ; \\
103)\end{array}$ \\
\hline 2.0 & 1366 & 1366 & 1332 & 1360 & $\begin{array}{l}1427(65 ; 65 ; \\
100)\end{array}$ \\
\hline 2.5 & 1421 & 1432 & 1386 & 1400 & $\begin{array}{l}1473(51 ; 40 ; \\
86)\end{array}$ \\
\hline
\end{tabular}




\section{Chapter 4}

\section{The electrical structure of the central Pacific upper mantle constrained by the NoMelt Experiment}

\subsection{Abstract}

The NoMelt Experiment imaged the mantle beneath 70 Ma Pacific seafloor with the aim of understanding the transition from the lithosphere to the underlying convecting asthenosphere. Seafloor magnetotelluric data from four stations were analyzed using 2-D regularized inverse modeling. The preferred electrical model for the region contains an $80 \mathrm{~km}$ thick resistive $\left(>10^{3}\right.$ $\Omega \mathrm{m})$ lithosphere with a less resistive $(\sim 50 \Omega \mathrm{m})$ underlying asthenosphere. The preferred model is isotropic and lacks a highly conductive $(\leq 10 \Omega \mathrm{m})$ layer under the resistive lithosphere that would be indicative of partial melt. We first examine temperature profiles that are consistent with the observed conductivity profile. Our profile is consistent with a mantle adiabat ranging from $0.3^{\circ} \mathrm{C} / \mathrm{km}-0.5^{\circ} \mathrm{C} / \mathrm{km}$. A choice of the higher adiabatic gradient means that the observed conductivity can be explained solely by temperature. In contrast, a $0.3^{\circ} \mathrm{C} / \mathrm{km}$ adiabat requires an additional mechanism to explain the observed conductivity profile. Of the plausible mechanisms, $\mathrm{H}_{2} \mathrm{O}$, in the form of hydrogen dissolved in olivine, is the most likely explanation for this additional conductivity. Our profile is consistent with a mostly dry lithosphere to $80 \mathrm{~km}$ depth, with bulk $\mathrm{H}_{2} \mathrm{O}$ contents increasing to between 25 and $400 \mathrm{ppm}$ by weight in the asthenosphere with specific values dependent on the choice of laboratory dataset of hydrous olivine conductivity and the value of mantle oxygen fugacity. The estimated $\mathrm{H}_{2} \mathrm{O}$ contents support the theory that the rheological lithosphere is a result of dehydration during melting at a mid-ocean ridge with the asthenosphere remaining partially hydrated and weakened as a result.

This chapter is published as: Emily Sarafian, Rob L. Evans, John Collins, Jimmy Elsenbeck, Glenn A. Gaetani, James B. Gaherty, Greg Hirth, and Daniel Lizarralde, 2015. The electrical structure of the central Pacific upper mantle constrained by the NoMelt Experiment. Geochemistry, Geophysics, Geosystems, doi: 10.1002/2014GC005709. The final publication is available at American Geophysical Union Publications via http://dx.doi.org/10.1002/2014GC005709, and this article is reprinted as published with permission granted in the original copyright agreement. 


\subsection{Introduction}

The theory of plate tectonics divides Earth's upper mantle into rigid lithospheric plates that move over a weaker, convecting asthenosphere. The transition from a rigid plate to the underlying asthenosphere occurs at variable depths in the mantle depending on tectonic setting [Plomerová et al., 2002] and is a critical boundary in determining plate behavior [Bunge et al., 1996; Richards et al., 2002; Hoink and Lenardic, 2008]. Researchers have long debated the rheology of the upper mantle and the lithosphere-asthenosphere boundary (LAB), particularly the mechanisms needed to weaken the asthenosphere to account for observed plate behavior. Early interpretations of geophysical measurements included the presence of melt in the upper oceanic asthenosphere [e.g., Anderson and Sammis, 1970; Anderson and Spetzler, 1970; Lambert and Wyllie, 1970]. New geophysical models along with a host of recent laboratory conductivity measurements have added to the debate, particularly over whether the uppermost asthenosphere immediately below the LAB is weakened as a result of the presence of hydrogen [e.g., Gaherty et al., 1995; Hirth and Kohlstedt, 1996; Phipps Morgan, 1997; Karato and Jung, 1998], melt [Anderson and Sammis, 1970; Anderson and Spetzler, 1970; Lambert and Wyllie, 1970; Kawakatsu et al., 2009; Schmerr, 2012] or a combination of the two.

In the oceans, the evolution of the mantle is arguably more straightforward than in continental settings as lithospheric plates cool and grow as they move away from mid-ocean-ridges, yet the difficulty of making detailed localized measurements in the oceans means that we still know surprisingly little of its structure and evolution. Decades of global seismic studies provide some insight into the evolution of the oceanic lithosphere [e.g., Ritzwoller et al., 2004; Nettles et al., 2005; Priestley and McKenzie, 2006]. However, such analyses have generally used data sets that span ocean basins and thus do not well constrain critical, more subtle features that are diagnostic of composition and evolutionary processes. Constraints on the depth dependence of shearvelocity structure in the oceanic lithosphere and across the LAB come primarily from regional surface- and body-wave studies [Nishimura and Forsyth, 1989; Gaherty et al., 1996; Gu et al., 2005; Tan and Helmberger, 2007], studies of mantle reflectivity from old Pacific lithosphere [Revenaugh and Jordan, 1991; Collins et al., 2002; Bagley and Revenaugh, 2008], receiver function studies [Rychert and Shearer, 2009; Kawakatsu et al., 2009], as well as from analysis of seismic phase SS precursors [Schmerr, 2012]. These studies showed that the transition from the 
lithosphere to the asthenosphere is complex with multiple seismic discontinuities observed within the transitional region at various oceanic plate ages. Observations include a seismic discontinuity mapped by SS waveforms, the depth of which increases with plate age [Rychert and Shearer, 2011]. This SS Lithospheric Profiling (SSLIP) reflector has been interpreted as the $\mathrm{LAB}$ with its depth dependent on a critical temperature of $\sim 950^{\circ} \mathrm{C}$ in the uppermost asthenosphere. Observations from the western Pacific and the Philippine Sea, over a range of seafloor ages ( $40-130 \mathrm{Ma})$, further identify a sharp LAB with the suggestion that the underlying asthenosphere contains some degree of partial melt [Kawakatsu et al., 2009]. Another observed seismic feature is an abrupt drop in seismic velocity (the so-called $\mathrm{G}$ discontinuity) at depths of $\sim 70-80 \mathrm{~km}$ independent of plate age, which is too sharp to be thermal in origin [e.g., Bagley and Revenaugh, 2008], and has been interpreted variously in terms of partial melt, decreased grain size, a change in anisotropy, and/or the presence of a hydrous asthenosphere. A self-consistent quantitative explanation for the observed LAB structure has yet to be determined, leaving the relationship between the $\mathrm{G}$ discontinuity and the LAB unclear. Recent Pacific basin-wide observations suggest that the LAB is a thermal boundary whereas the G discontinuity remains more elusive and is related to changes in mantle seismic anisotropy either due to a compositional or dynamical variation, such as hydration or melt [Rychert et al., 2012; Beghein et al., 2014].

The NoMelt Experiment set out to image the structure of intermediate-age oceanic upper mantle in order to better understand the mechanisms responsible for the transition between the lithosphere and asthenosphere. The experiment took place on 70 Ma Pacific seafloor between the Clarion and Clipperton fracture zones (Figure 1). At this age, the thermal lithosphere is expected to be deeper than the $\mathrm{G}$ discontinuity and to have overgrown shallow conductive features seen elsewhere [e.g., Evans et al., 2005; Naif et al., 2013]. A combination of seismic and magnetotelluric (MT) techniques were used to image the upper mantle. This paper focuses on the inversion and interpretation of the seafloor MT data collected. MT maps the subsurface conductivity structure, which is sensitive to temperature, amount of dissolved hydrogen, and interconnected conductors such as melt or fluid. As a result, electromagnetic methods offer considerable insight into the debate over the nature of the LAB transition [e.g., Eaton et al., 2009]. Two-dimensional isotropic and anisotropic inversion techniques were used to obtain the electrical structure of the upper mantle. The resulting electrical model is then averaged into a 1-D 
profile and compared with recent laboratory data to determine the influence of temperature, $\mathrm{H}_{2} \mathrm{O}$ content, and the possibility of partial melt through the LAB and in the uppermost asthenosphere.

\subsubsection{Mantle Conductivity: A summary}

Mantle conductivity models, particularly those related to $\mathrm{H}_{2} \mathrm{O}$ and partial melting, have been evolving over the last few years due to progress in laboratory conductivity measurements. In this paper, two of the most recent hydrous olivine conductivity models and a recent melt conductivity model are used to evaluate the dominant mechanism operative in the study area. This section provides a brief overview of the models used for interpretation.

Mantle nominally anhydrous minerals (NAMs), such as olivine, orthopyroxene (opx), clinopyroxene (cpx), and spinel or garnet, can accommodate various amounts of dissolved $\mathrm{H}_{2} \mathrm{O}$ (hydrogen) at upper mantle conditions. In the $\mathrm{H}_{2} \mathrm{O}$ model for the $\mathrm{LAB}$, a dehydrated lithosphere sits above a more hydrous asthenosphere of lower viscosity [e.g., Hirth and Kohlstedt, 1996]. The increase in mantle $\mathrm{H}_{2} \mathrm{O}$ content may influence the seismic velocity of the mantle rocks via its influence on seismic attenuation [e.g., Karato and Jung, 1998; Karato, 2006; Olugboji et al., 2013] consistent with the observed LAB seismic properties, though recent work suggests that the effect of $\mathrm{H}_{2} \mathrm{O}$ may not be enough to account for rheological changes [Fei et al., 2013]. In addition, dissolved $\mathrm{H}_{2} \mathrm{O}$ can enhance the electrical conductivity of mantle minerals [Wang et al., 2006; Yoshino et al., 2009; Poe et al., 2010; Dai and Karato, 2014], yet there is still considerable disagreement between the various laboratories reporting conductivity measurements on hydrous olivine (see discussion in Evans [2012] and Jones et al. [2012]). A recent analysis has attempted to reconcile the published data with a reanalysis of all data sets resulting in a single "unified hydrous olivine" model (UHO) [Gardes et al., 2014]. Nonetheless, subsequent studies have reopened the controversy, with results apparently suggesting that two conduction mechanisms are operative, one at low temperatures expected in the lithosphere and one at asthenospheric temperatures [Dai and Karato, 2014]. At higher temperatures, conductivity is enhanced by dissolved $\mathrm{H}_{2} \mathrm{O}$ to a greater degree than predicted by the UHO model. Also at issue is whether conductivity in hydrous olivine is anisotropic, with higher conductivity along the a-axis, as expected from laboratory measurements of hydrogen diffusion [Mackwell and Kohlstedt, 1990; Kohlstedt and Mackwell, 1998]. Some published conductivity data [e.g., Yoshino et al., 2006] do 
not support a model in which a damp mantle with an a-axis aligned olivine fabric would exhibit electrical anisotropy as suggested by Evans et al., [2005], but again, more recent data appear to place this model back into contention [Dai and Karato, 2014].

Another mechanism to enhance conductivity is partial melt. Shankland and Waff [1977] showed that silicate melt is a semiconductor with conductivity dependent on temperature and weakly on pressure. Partial melts of mantle materials have conductivities in the range of 1-10 S/m, substantially higher than anhydrous subsolidus olivine, although the conductivity of a particular melt depends on composition $\left(\mathrm{H}_{2} \mathrm{O}\right.$ and $\mathrm{CO}_{2}$ in particular) [Yoshino et al., 2012; Sifre et al., 2014], temperature, and pressure [Roberts and Tyburczy, 1999; Toffelmier and Tyburczy, 2007; Yoshino et al., 2012; Sifre et al., 2014]. For example, at constant pressure the addition of $\mathrm{H}_{2} \mathrm{O}$ to melt promotes an increase in conductivity [e.g., Ni et al., 2011; Pommier et al., 2008]. Furthermore, for a given temperature and melt fraction, order of magnitude variations in electrical conductivity can also result from relatively minor changes in the melt interconnection geometry or texture [Schmeling, 1986; Roberts and Tyburczy, 1999; ten Grotenhuis et al., 2005]. Other effects on melt conductivity are $\mathrm{Na}$ content, which can increase conductivity at the incipient stages of melting [Pommier and Garnero, 2014] and $\mathrm{CO}_{2}$ content, which at the very early stages of melting can dramatically increase conductivity [Sifre et al., 2014]. The above studies indicate the effect of melt on conductivity is greater than previously thought when interpreting field results [Pommier and Garnero, 2014; Sifre et al., 2014]. This means that MT is in fact able to detect very small silicate melt fractions (typically on the order of 0.1-0.2 vol\%) at the onset of melting where $\mathrm{CO}_{2}$ is concentrated in the melt. That said, a critical requirement for a partial melt distribution to impact bulk conductivity is that the melt be well connected through the host rock. Evidence that partial melt in the mantle is well interconnected, even at low melt fractions, comes from laboratory simulations [e.g., Toramaru and Fujii, 1986; Riley et al., 1990; Zhu et al., 2011].

Carbonatite melts are at least 2 orders of magnitude more conductive than silicate melts [Gaillard et al., 2008; Yoshino et al., 2010]. Carbonatite melts can form in trace amounts deep in the mantle [Dasgupta and Hirschmann, 2006] and are thought to be stable in the upper asthenosphere beneath seafloor older than about $45 \mathrm{Ma}$ [Hirschmann, 2010]. Because of their 
high conductivity, volume fractions as small as $0.01 \%$ have the potential to impact bulk conductivity at measurable levels, and carbonate melt is interconnected to fractions as low as $0.05 \mathrm{wt} \%$ [Minarik and Watson, 1995]. Silicate, carbonated silicate, carbonatite melts [Hirschmann, 2010; Gaillard et al., 2008], and hydrous silicate melts [Ni et al., 2011] could be stable in the LVZ depending on the pressure and temperature. Estimated melt fractions range from $0.05-0.1 \%$ if the melt is carbonatite [Gaillard et al., 2008; Yoshino et al., 2010; 2012], $\sim 0.3 \%$ if carbonated silicate melt [Hirschmann, 2010], and $0.3-1 \%$ if hydrous silicate melt [Ni et al., 2011]. At higher melt fraction the melt interconnectivity increases, which in combination with the melt buoyancy can provide pathways for melt to migrate [Karato, 2012]. Yet at the very low melt fractions at which $\mathrm{CO}_{2}$ bearing or carbonatite melts can impact bulk mantle conductivity, it has been argued that melt networks could be stable against upward buoyancy driven migration [Sifre et al., 2014], thereby removing one of the major arguments against widespread melt distributions in the upper asthenosphere.

\subsection{Data}

The MT component of the NoMelt experiment measured natural electric and magnetic field variations during a year-long deployment between December 4, 2011 and January 7, 2013. A linear array of six stations was deployed in a profile roughly parallel to the plate spreading direction (Table 1; Figure 1), coincident with an array of ocean bottom seismographs. The region of study did not contain rugged or anomalous bathymetry such as seen at a mid-ocean ridge [Baba et al., 2006], nor any active volcanism, and therefore was expected to have a simple 2-D electrical structure (see Figure 1). Four out of six stations provided useful data with sufficient period range to constrain mantle structure at depths well beyond that predicted for the LAB in the studied region. Electromagnetic time series from each site were cleaned by removing obvious noise such as variations due to instrument settling or collection, data spikes, and steps in the field magnitude, and corrected for clock drift using magnetic field data from the INTErnational Realtime MAGnetic observatory NETwork (INTERMAGNET) Hawaiian station. These observatory data also served as a reference for instrument rotation, and as a remote reference for robust processing carried out with the bounded influence code, BIRRP [Chave and Thomson, 2003; 2004]. 
The final apparent resistivity and phase curves for all sites used during inversion are shown in Figure 2. Useful periods contained in the response function range from $\sim 800 \mathrm{~s}$ out to $100,000 \mathrm{~s}$, sufficiently long to probe through the upper-mantle and down as far as the $410 \mathrm{~km}$ discontinuity. The calculated response functions from the four stations show dominantly 2-D characteristics, with significantly smaller diagonal elements relative to the off-diagonal elements in the impedance tensors $(\mathbf{Z})$, regardless of the orientation of the tensor. The strong off-diagonal elements of the $\mathbf{Z}$ tensor describe the two modes of the 2-D MT response. $Z_{x y}$ is the transverse electric (TE) mode corresponding to electric current flowing parallel to the regional electrical strike. $Z_{\mathrm{yx}}$ is the transverse magnetic (TM) mode, corresponding to the electric current flowing perpendicular to the electrical strike. The data were processed in a reference frame such that the $\mathrm{X}$-axis (the assumed electric strike) is perpendicular to the spreading direction. This particular rotation direction was chosen because the dominant seafloor fabric is aligned with the spreading ridge. Numerous seismic anisotropy studies using a variety of methodologies indicate that lithospheric fabric is aligned with fast wave speeds parallel to spreading direction [Raitt et al., 1969; Nishimura and Forsyth, 1989; Montagner and Tanimoto, 1991; Wolfe and Solomon, 1998; Gaherty et al., 2004]. The anisotropic inversion requires orthogonality between the primary conductivity axes. If conductivity is enhanced in the direction of plate-spreading, then this fabric would be orthogonal to our principal strike direction and would be identifiable by the inversion.

The NoMelt survey area was specifically chosen to be devoid of seamounts and large topographic features to ensure a limited amount of melt in the upper mantle. Variations in depth between each usable site was $<60 \mathrm{~m}$. Because the NoMelt region does not have significant bathymetric variation, which distorts the measured electric and magnetic fields, topographic corrections as described by Baba and Chave [2005] were not considered. A flat ocean floor was assumed and the shortest periods were masked prior to inverting which is where topographic effects are most significant [Baba and Chave, 2005; Matsuno et al., 2010]. The two modes show nearly identical phase trends and decreasing resistivity with increasing period, confirming the presence of a simple electrical structure and justifying our 2-D approach to inverting the responses. 


\subsection{Inversion Methods}

MT resistivity and phase data were inverted for both isotropic and anisotropic electrical structure. Isotropic electrical models of the NoMelt mantle were derived using a 2-D regularized inversion scheme [Rodi and Mackie, 2001] implemented within the WinGLink software package. Previous MT investigations of the Pacific detected anisotropic conductivity distributions, in which the conductivity of the upper asthenosphere was greater in the (horizontal) direction of plate motion [Evans et al., 2005; Baba et al., 2006]. Anisotropy can lead to distorted structure if inverted using an isotropic code, therefore a 2-D anisotropic inversion scheme [Baba et al., 2006] was used to verify that the observed structure from isotropic inversions is accurate, or if electrically anisotropic features are present within the lithosphere-asthenosphere transition zone. The isotropic inversions result in a single resistivity model, whereas the anisotropic inversions solved for three separate models showing resistivity in the strike direction $\left(\rho_{\mathrm{xx}}\right)$ parallel to plate motion $\left(\rho_{\mathrm{yy}}\right)$ and in the vertical direction $\left(\rho_{\mathrm{zz}}\right)$. The anisotropic inversions of the NoMelt data resulted in the same structure as in the isotropic inversion and the difference between the horizontal directions $\left(\rho_{\mathrm{xx}}-\rho_{\mathrm{yy}}\right)$ indicate that there is no significant electrical anisotropy required in the region to explain our data (Figure 3b.). As a result, only the isotropic inversion is discussed for the remainder of this paper.

A variety of starting models and regularization parameters were used to explore model space during the inversion process. Starting models varied from uniform half-space models to layered models with structure introduced from assumed a-priori knowledge or for hypothesis testing. In some cases the starting resistivity of the layers was simply varied, while in other cases the resistivity was locked, or a tear (relaxation of model smoothness) was placed at various depths to allow for sharper boundaries. Inversions with starting models containing tears were run to ensure that if a thin layer of high conductivity were present it was not being entirely smoothed out between the resistive lithosphere and conductive asthenosphere by the regularization scheme. Data error values were maintained at 10\% for the apparent resistivity and 5\% for the phase. Error floors on the apparent resistivity and phase of both modes were held at $5 \%$ during initial inversions. Generally, the two modes were inverted jointly because the two modes contain complementary information - the TE mode is most sensitive to continuous conductive structures in the strike (x) direction, and the TM mode is most sensitive to the regional structure and 
resistivity boundaries [e.g., Wannamaker et al., 1989]. Single-mode inversions were also completed and revealed that the TE mode was insensitive to the resistive lithosphere resulting in high conductivities at lithospheric depths. Therefore, in order to constrain lithospheric resistivities, later inversions had an increased error floor of $20 \%$ for the TE mode apparent resistivity. The smoothness regularization parameter, $\tau$, was varied between 100 (smooth) and 0.01 (rough) to find the best fitting model that did not contain spurious structure. Models generated with large $\tau$ values (smooth models with poorer fits to the data) damped the uppermost lithospheric resistivity, potentially smoothing out important features. On the other hand, at small $\tau$ values (rough models with good data fit), the model became geologically implausible with oscillatory conductivity variations. Inversions were completed to investigate the data sensitivity to the lithospheric resistivity, the conductance of a possible high conductivity layer at the LAB, and the resistivity of the asthenosphere. Models were evaluated through RMS misfit values, smoothness, and geological plausibility. The RMS misfit of the preferred isotropic model at the various tau values ranged from $1.05(\tau=0.01)$ to $2.49(\tau=100)$, a small variation which further suggests that the NoMelt data are consistent with a moderately 2-D structure. Given that the resulting models showed very little lateral variability, the preferred isotropic 2-D conductivity model was averaged (in log domain) into a 1-D conductivity profile with depth (Figure 3c).

\subsection{Results}

The preferred 2-D isotropic conductivity model of the NoMelt region was derived from a layered starting model with a high resistivity lithosphere $\left(10^{4} \Omega \mathrm{m}\right)$ underlain by a $100 \Omega \mathrm{m}$ halfspace. The inverted model contains a $2-30 \Omega \mathrm{m}$ conductive layer of variable thickness above the lithosphere. The electrical lithosphere extends to $80 \mathrm{~km}$ depth and high resistivities are maintained, although the final resistivity in the lithosphere was slightly reduced from the starting values $\left(10^{2}-10^{3} \Omega \mathrm{m}\right)$. Asthenospheric (>80 km depth) resistivities decreased to $25-75 \Omega \mathrm{m}$ (Figure 3a). After hundreds of iterations, the preferred model achieved an RMS misfit value of 1.21 (see Figure 4). The same general structure was achieved throughout all inversions, regardless of starting model. 
In all cases, the resistivity within the cool lithosphere is not as high as might be expected, but this is a resolution issue inherent to the MT technique. Inversions of synthetic data generated from a model with a highly resistive lithosphere overlying a range of lower-lithosphere and asthenospheric structures show that the resistivity within the lithosphere is always reduced as a result of the combined effects of a lack of sensitivity and regularization, with no loss of fit between the model and the data [Evans et al., 2011].

No models were obtained from our field data that contained a layer of low $(<10 \Omega \mathrm{m})$ resistivity in the upper electrical asthenosphere or within the LAB region, and the inversion algorithm removed any such layer when imposed in starting models. Synthetic tests suggest that MT data can have sensitivity to such a feature. When a melt layer was forced under the resistive lithosphere, the model RMS misfit increased to values greater than 5 and resulted in a poorer fit to the data (see Figure 4). Starting models that contained tears resulted in oscillatory structure that lead to a highly resistive asthenosphere, suggesting that the relaxation of regularization in this case was equivalent to lowering the $\tau$ value and the data were likely overfit in these examples.

The 1-D conductivity profile of the NoMelt model captures the characteristics of the 2-D structure and shows a smooth transition from a resistive lithosphere to an increasingly conductive asthenosphere (Figure 3c). This lack of a conductive layer in the LAB transition zone is in contrast to profiles from the MELT area [Evans et al., 2005], SERPENT experiment [Naif et al., 2013] and the Philippine Sea [Baba et al.,2010] (see Figure 5). Observations at the Southern East Pacific Rise highlight an electrically conductive and anisotropic layer in the asthenosphere beneath a resistive (anhydrous) upper plate [Evans et al., 2005; Baba et al., 2006]. The conductivity of the asthenosphere in the MELT region can be explained by a damp composition, but could also be explained by a small amount of partial melt. In contrast, an anisotropic conductor seen off Nicaragua [Naif et al., 2013] is sufficiently conductive to require the presence of melt in the upper electrical asthenosphere, although for melting to occur the mantle must also be damp. One further observation, which is supportive of a damp and possibly melt bearing upper asthenosphere comes from $\sim 30 \mathrm{Ma}$ lithosphere in the Phillipine Sea [Baba et al., 2010] where a conductive upper asthenosphere is consistent with a small silicate melt 
fraction. Thus, to date, we have three observations of an electrically conductive layer in the upper mantle in relatively young oceanic lithosphere that are each consistent with the presence of melt and $\mathrm{H}_{2} \mathrm{O}$ (dissolved hydrogen) at asthenospheric depths to aid with the interpretation of the NoMelt data.

The next section discusses the possible thermal, dissolved $\mathrm{H}_{2} \mathrm{O}$, and partial melt contributions to the observed conductivity structure in the NoMelt region and clarifies which mechanism is most likely responsible for the weakening of the asthenosphere based on our MT observations. The comparison of the NoMelt profile with profiles from other surveys (Figure 5) seems to suggest that dissolved $\mathrm{H}_{2} \mathrm{O}$ and partial melt mechanisms are not as influential in the NoMelt region as in other regions.

\subsection{Discussion}

The observed conductivity in the NoMelt region shows a simple upper mantle electrical structure under the 70 Ma Pacific Plate. The 1-D profile generated allows for a quick conversion of the model into temperature, dissolved $\mathrm{H}_{2} \mathrm{O}$, and interconnected partial melt - three major mechanisms influencing mantle conductivity. As these components have strong interdependency and influence the observed conductivity in a complex manner, we chose to interpret the model in a sequential manner starting with the simplest, first order control, a direct conversion of conductivity to temperature, then examine potential effects of added dissolved $\mathrm{H}_{2} \mathrm{O}$, and finally for an additional interconnected partial melt component.

\subsubsection{Thermal Contribution}

We first converted the conductivity profile directly to a temperature profile between 50 and 300 $\mathrm{km}$ depth (Table 2, Figure 6), using the SEO3 at quartz-magnetite-fayalite buffer (QFM) model for anhydrous olivine conductivity [Constable, 2006]. Previous studies [e.g. Evans et al., 2005] have used the SO2 model [Constable et al., 1992] for the background anhydrous olivine conductivity. SO2 is appreciably less conductive than SEO3 (QFM), and a similar direct conversion to temperature using $\mathrm{SO} 2$ would predict temperatures that are hotter by roughly $200^{\circ} \mathrm{C}$ at $200 \mathrm{~km}$ depth, which seems unreasonably hot. Similarly, if the anhydrous olivine conductivity is calculated using SEO3 at a more reducing buffer such as iron-wustite (IW), 
predicted temperatures would also be hotter, but in this case only by about $60^{\circ} \mathrm{C}$ at $200 \mathrm{~km}$. Thus, there is some variability in the estimation of temperature within the asthenosphere based on the choice of oxygen fugacity and the dry olivine conductivity model.

The thermal adiabatic gradient of our temperature profile calculated from SEO3 (QFM) was determined by calculating the slope of the temperature profile well within the convecting asthenosphere between depths of 150 and $300 \mathrm{~km}$. The resulting adiabat has a thermal gradient of $0.5^{\circ} \mathrm{C} / \mathrm{km}$ and a potential temperature of $1374^{\circ} \mathrm{C}$. Deviation of our temperature profile from the calculated adiabat suggests upper limits on plate thickness and basal temperature in the NoMelt region of $110 \mathrm{~km}$ and $1424^{\circ} \mathrm{C}$, respectively. These values are within the realm of likely mantle temperatures, but it is not clear if they are consistent with other constraints on mantle structure. Following Crosby et al. [2006], we define the base of the lithospheric plate by the intersection of the conductive plate geotherm with the mantle adiabat. To obtain this estimate and provide a better constraint on plate thickness, we calculated the conductive plate geotherm of the NoMelt mantle from the temperatures within the resistive lithosphere of the 2-D electrical model at depths between 50 and $80 \mathrm{~km}$. This resulted in a plate geotherm that intersected the adiabat at a depth of $91 \mathrm{~km}$ with a corresponding basal temperature of $1415^{\circ} \mathrm{C}$ (see Figure 6).

Depth-age relationships of oceanic plates are useful in determining asymptotic plate thicknesses [Parsons and Sclater, 1977; Stein and Stein, 1992; Crosby et al., 2006], and with a carefully chosen dataset, can help verify our calculated mantle plate thickness and basal temperature. Previous plate cooling studies have determined that the asymptotic Pacific plate thickness is between 90 and $125 \mathrm{~km}$ [Parsons and Sclater, 1977; McKenzie and Bickle, 1988; Stein and Stein, 1992; Crosby et al., 2006]. Our next step, therefore, was to investigate the depth-age relationship following the procedure of Crosby et al. [2006] for the segment of the Pacific Plate between the Clarion and Clipperton fracture zones from $70 \mathrm{Ma}$ to the East Pacific Rise to determine if our plate model derived from an unconstrained conversion of our NoMelt model was consistent with the seafloor subsidence. Seafloor older than about $80 \mathrm{Ma}$ shows anomalous bathymetry and was not considered in our analysis [Crosby et al., 2006]. The segment bathymetry is consistent with a suite of possible basal temperature-asymptotic plate thickness pairs ranging from a hot, thin plate with a basal temperature of $1500^{\circ} \mathrm{C}$ and a plate thickness of 
$75 \mathrm{~km}$, to a colder, thicker plate with a basal temperature of $1250^{\circ} \mathrm{C}$ and a $125 \mathrm{~km}$ thick plate. The plate thickness and basal temperature that best predict bathymetric variations, and which generate a thermal profile most consistent with our observations from our 2-D inverse model, are $86 \mathrm{~km}$ and $1412^{\circ} \mathrm{C}$ respectively. This result is very close to the plate thickness and basal temperature that we predicted by only considering the converted temperature profile.

From these analyses we derive a plate cooling mantle geotherm that results in a conductivitydepth profile that matches the observed NoMelt profile except in the lowermost lithosphere where the geotherm predicts slightly more resistive structure (Table 2; Figure 6). However, while a mantle thermal gradient of $0.5^{\circ} \mathrm{C} / \mathrm{km}$ is consistent with the range of estimated adiabatic gradients [Katsura et al., 2010, and references therein; Stixrude and Lithgow-Bertelloni, 2005], other estimates suggest a lower mantle gradient of $0.3^{\circ} \mathrm{C} / \mathrm{km}$ [e.g. Turcotte and Schubert, 2002]. Therefore, we also constructed a background thermal model from the plate geotherm derived from bathymetry, but with a mantle adiabatic gradient of $0.3^{\circ} \mathrm{C} / \mathrm{km}$. This lower gradient background thermal model has the same plate thickness and basal temperature as the previous model, but a slightly higher potential temperature of $1386^{\circ} \mathrm{C}$ and a conductivity depth profile that is slightly more resistive than the observed NoMelt profile in both the lower lithosphere and asthenosphere (Table 2; Figure 6). Forward modeling of our preferred electrical model with a $0.3^{\circ} \mathrm{C} / \mathrm{km}$ thermal gradient showed a poorer fit to the data (see Figure 4), which indicates that our data is sensitive to the adiabatic thermal gradient. As a result, conductivities at depths below $50 \mathrm{~km}$ are under-predicted by the $0.3^{\circ} \mathrm{C} / \mathrm{km}$ mantle gradient thermal model and an additional solid state or melt mechanism is needed to explain the observed conductivity profile.

\subsubsection{Dissolved $\mathrm{H}_{2} \mathrm{O}$ contribution}

The first mechanism we considered to enhance the background thermal conductivity profile to match our observed profile was the solid state contribution of dissolved $\mathrm{H}_{2} \mathrm{O}$ in mantle minerals. Current knowledge of mantle mineral conductivity with dissolved hydrogen is focused on olivine - the major phase $(60 \%)$ in the upper mantle - due to a lack of compelling data on the conductivity of other nominally anhydrous phases, such as pyroxenes, for upper mantle conditions [Dai and Karato, 2009]. Such focus limits most MT studies to assume that hydrous olivine is the dominant conducting phase when considering a subsolidus mechanism. Thus we 
used two of the most recent models for how dissolved $\mathrm{H}_{2} \mathrm{O}$ in olivine enhances the measured conductivity: the UHO model [Gardes et al., 2014] and a model that includes high temperature conductivity measurements made at temperatures appropriate for the asthenosphere from Dai and Karato [2014] (referred to as the DK model).

The UHO model re-analyzes previously published conductivity measurements to form a single Arrhenius relationship that satisfies all the data. The relationship involves anhydrous and hydrous conductivity mechanisms that relate the conductivity of olivine to its $\mathrm{H}_{2} \mathrm{O}$ content such that

$\sigma_{\mathrm{SHO}}=\sigma_{0}^{\mathrm{V}} \exp \left(-\Delta \mathrm{H}^{\mathrm{V}} / \mathrm{RT}\right)+\sigma_{0}^{\mathrm{P}} \exp \left(-\Delta \mathrm{H}^{\mathrm{P}} / \mathrm{RT}\right)+\sigma_{0}^{\mathrm{H}} \mathrm{C}_{\mathrm{H}_{2} \mathrm{O}} \exp \left[\left(-\Delta \mathrm{H}^{\mathrm{H}}-\alpha \mathrm{C}_{\mathrm{H}_{2} \mathrm{O}}^{1 / 3}\right) / \mathrm{RT}\right](1)$

where $\sigma_{S H O}$ is the conductivity of hydrous olivine, $\sigma_{0}^{V}, \sigma_{0}^{P}$, and $\sigma_{0}^{H}$ are the pre-exponential factors for the anhydrous vacancy and polaron terms, and the hydrous conductive process respectively, $\Delta H^{V}, \Delta H^{P}$, and $\Delta H^{H}$ are the corresponding activation enthalpies, $\mathrm{R}$ is the gas constant, $\mathrm{T}$ is the absolute temperature, and $\mathrm{C}_{\mathrm{H}_{2} \mathrm{O}}$ is the concentration of $\mathrm{H}_{2} \mathrm{O}$ dissolved in olivine. The DK model produces a similar relationship to that found for previous conductivity measurements but adds new measurements made at higher temperatures that capture a distinct high temperature conduction mechanism in olivine. The resulting conductivity equation is

$$
\sigma_{\mathrm{DK}}=\mathrm{C}_{\mathrm{w}}\left[\sigma_{0}^{1} \exp \left(-\Delta \mathrm{H}^{1} / \mathrm{RT}\right)+\sigma_{0}^{2} \exp \left(-\Delta \mathrm{H}^{2} / \mathrm{RT}\right)\right]+\sigma_{\mathrm{SEO} 3}
$$

where $\sigma_{D K}$ is the hydrous olivine conductivity, $\sigma_{0}^{1}$ and $\sigma_{0}^{2}$ are fitted pre-exponential terms, and $\Delta H^{1}$ and $\Delta H^{2}$ are the corresponding activation enthalpies. The $\sigma_{S E O 3}$ term accounts for a parallel anhydrous conductivity that is needed to fully describe the mantle conductivity and which is important when conductivities suggest small mantle $\mathrm{H}_{2} \mathrm{O}$ contents. Dai and Karato [2014] developed a separate relationship for each olivine axis (a, b, and c) from which we calculated the geometric mean in order to get a relationship applicable to a bulk isotropic mantle as observed in the NoMelt region. 
Using these two hydrous olivine models and our background thermal model, we varied olivine $\mathrm{H}_{2} \mathrm{O}$ content from $0 \mathrm{ppm}$ to $1000 \mathrm{ppm}$ in $1 \mathrm{ppm}$ intervals then compared the calculated hydrous conductivity profiles to our observed conductivity model for the NoMelt region. By minimizing the difference between our observed profile and the hydrous conductivity profiles, we estimate the $\mathrm{H}_{2} \mathrm{O}$ content of olivine starting in the lower lithosphere at $50 \mathrm{~km}$ down to $300 \mathrm{~km}$ depth in 10 $\mathrm{km}$ intervals (Table 2; Figure 7a.). Both models predict variable olivine $\mathrm{H}_{2} \mathrm{O}$ contents with depth, but both models agree that while our background thermal model is slightly more resistive than the observed profile in the lithosphere $(<80 \mathrm{~km})$ there should be little to no $\mathrm{H}_{2} \mathrm{O}$ in this region otherwise the hydrated olivine conductivity is more conductive than the NoMelt profile. Outside of the lithosphere, the two models predict different $\mathrm{H}_{2} \mathrm{O}$ contents with DK predicting between only trace amounts between 0-7 ppm and UHO predicting between 0-118 ppm.

While many MT studies go on to discuss whether the calculated $\mathrm{H}_{2} \mathrm{O}$ content of the olivine grains is consistent with the predicted oceanic upper mantle bulk $\mathrm{H}_{2} \mathrm{O}$ contents of 50-200 ppm [Saal et al., 2002; Simons et al., 2002; Workman and Hart, 2005], most fail to consider the corresponding $\mathrm{H}_{2} \mathrm{O}$ content of the other upper mantle minerals (orthopyroxene, clinopyroxene, and spinel or garnet). While these minerals may not greatly influence the measured conductivity, they do impact the total dissolved $\mathrm{H}_{2} \mathrm{O}$ in the mantle. In order to determine the corresponding bulk mantle $\mathrm{H}_{2} \mathrm{O}$ contents from the calculated olivine $\mathrm{H}_{2} \mathrm{O}$ contents, we conducted a mass balance calculation dependent on the mineral modal proportions and mineral/mineral partition coefficients for $\mathrm{H}_{2} \mathrm{O}$.

The mineral modal proportions $\left(\Phi^{\text {min }}\right)$ and the partition coefficients for $\mathrm{H}_{2} \mathrm{O}$ between opx and melt $\left(D_{H}^{o p x / m e l t}\right)$, olivine and melt $\left(D_{H}^{\text {ol/melt }}\right)$, spinel and melt $\left(D_{H}^{\text {sp/melt }}\right)$, and garnet and melt $\left(D_{H}^{g t / m e l t}\right)$ are based on the work by Hirschmann et al. [2009] who determined the partition coefficients for olivine, spinel, and garnet and melt in the upper mantle to be $0.0017,0$, and 0.003 respectively. The partition coefficient for opx is dependent on the Al content of the pyroxene. Pyroxene composition changes with pressure such that increasing pressure increases the $\mathrm{Al}$ content until the garnet stability field where $\mathrm{Al}$ goes into the garnet phase. Using the relationships described in Hirschmann et al. [2009] our $D_{H}^{\text {opx } / \text { melt }}$ ranges from 0.01 to 0.02 
where $D_{H}^{o p x / m e l t}$ increases with depth until spinel-to-garnet transition is reached. The partition coefficient of $\mathrm{H}_{2} \mathrm{O}$ between cpx and melt was taken from the work of O'Leary et al. [2010] which considers the effect of varying cpx composition along a mantle adiabat, particularly tetrahedral $\mathrm{Al}\left({ }^{\mathrm{IV}} \mathrm{Al}^{3+}\right)$, on $\mathrm{H}_{2} \mathrm{O}$ partitioning. The majority of $\mathrm{H}^{+}$within the cpx structure is incorporated through a coupled substitution with ${ }^{\mathrm{IV}} \mathrm{Al}^{3+}$ that is sensitive to the phase composition, but not to pressure and temperature. At pressures less than 5-7 GPa, the $\mathrm{Al}$ content of cpx is similar to that of opx, thus we were able to use the same relations described in Hirschmann et al. [2009] to calculate the Al content of cpx. From this Al content, we were able to prescribe a conservative (upper) estimate of 0.02 for $D_{H}^{c p x} /$ melt based on O'Leary et al. [2010] (their Figure 6 and equation 11).

We then calculated the bulk mantle $\mathrm{H}_{2} \mathrm{O}$ content from the inferred olivine $\mathrm{H}_{2} \mathrm{O}$ content and partition coefficients using the following equation:

$$
\begin{aligned}
& \text { Bulk Mantle } \mathrm{H}_{2} \mathrm{O}=\Phi^{\mathrm{ol}} \mathrm{C}_{\mathrm{w}}+\Phi^{\mathrm{opx}} \mathrm{C}_{\mathrm{w}} \mathrm{D}_{\mathrm{H}}^{\mathrm{opx} / \mathrm{melt}} / \mathrm{D}_{\mathrm{H}}^{\text {ol } / \text { melt }}+\Phi^{\mathrm{cpx}} \mathrm{C}_{\mathrm{w}} \mathrm{D}_{\mathrm{H}}^{\mathrm{cpx} / \mathrm{melt}} / \mathrm{D}_{\mathrm{H}}^{\text {ol } / \text { melt }} \\
& +\Phi^{\mathrm{gt}} \mathrm{C}_{\mathrm{w}} \mathrm{D}_{\mathrm{H}}^{\mathrm{gt} / \mathrm{melt}} / \mathrm{D}_{\mathrm{H}}^{\mathrm{ol} / \mathrm{melt}}
\end{aligned}
$$

where the garnet (gt) contribution is added at pressures greater than $2.8 \mathrm{GPa}$. Based on thermodynamic considerations, the olivine-melt and garnet-melt partition coefficients should also be dependent on pressure, but current experimental data do not capture significant changes at pressures below 5-7 GPa [Hirschmann et al., 2009]. Our considered depths reach pressures up to $10 \mathrm{GPa}$, therefore the determined partition coefficients represent minimums.

The resulting bulk mantle $\mathrm{H}_{2} \mathrm{O}$ content estimated from both hydrous olivine models over the depth range investigated are listed in Table 2 and shown in Figure 7b. The lower lithosphere requires some $\mathrm{H}_{2} \mathrm{O}$ to enhance the conductivity from that of anhydrous olivine to the observed profile. The accuracy of this $\mathrm{H}_{2} \mathrm{O}$ estimate is uncertain because of uncertainties in $D_{H}^{\mathrm{min} / \text { melt }}$ values, phase compositions, phase proportions [see Hirschmann et al., 2009], and because the regularization used during inversion generates smooth models with gradual conductivity variations rather than sharp boundaries. This smoothing could bring the conductivity of the lower 
lithosphere to higher values than reality due to the influence of the conductive asthenosphere immediately below.

As expected the UHO model predicts much higher olivine and bulk mantle $\mathrm{H}_{2} \mathrm{O}$ contents (see Figure 7b.). This difference is due to two major differences between the DK and UHO conductivity models. First, each model has different conduction mechanisms operative at high temperature, with the DK model requiring significantly lower $\mathrm{H}_{2} \mathrm{O}$ contents to achieve higher conductivities. This high-temperature conduction mechanism has been previously hypothesized [Karato, 2013], but never before measured due to the difficulty in conducting high temperature experiments with constant $\mathrm{H}_{2} \mathrm{O}$ contents. Second, our DK hydrated olivine conductivity model includes the same anhydrous term used to derive our background thermal model whereas the UHO model uses different anhydrous terms based on a data set that is somewhat less conductive than SEO3 (QFM) and asthenospheric temperatures [Xu et al., 2000]. The less conductive UHO anhydrous terms result in higher estimates of $\mathrm{H}_{2} \mathrm{O}$ contents in order to match the observed NoMelt conductivity. The SEO3 (QFM) model is considerably more conductive than other published models of anhydrous olivine conductivity [Constable et al., 1992; Xu et al., 2000] and the reasons behind this are discussed in the original article [Constable, 2006]. If instead of the SEO3 (QFM) model we used the SO2 anhydrous olivine model [Constable et al., 1992] to calculate our anhydrous thermal conductivity and $\mathrm{DK} \mathrm{H}_{2} \mathrm{O}$ content, then either temperatures are $\sim 200^{\circ} \mathrm{C}$ hotter or, for the thermal profile on a $0.3^{\circ} \mathrm{C} / \mathrm{km}$ adiabat used above, the conductivity of the geotherm drops by almost a full order of magnitude in the asthenosphere. While this change does not impact the $\mathrm{H}_{2} \mathrm{O}$ contents predicted by the UHO model, it drastically changes the $\mathrm{H}_{2} \mathrm{O}$ contents predicted by the DK model to unreasonably large amounts such that the entire NoMelt thermal profile lies above the $\mathrm{H}_{2} \mathrm{O}$-undersaturated solidus and pervasive melting must occur - a feature not seen in the NoMelt data. On the other hand, the SEO3 (IW) model either requires that the mantle temperatures are $\sim 60^{\circ} \mathrm{C}$ hotter, or the conductivity of the geotherm on a $0.3^{\circ} \mathrm{C} / \mathrm{km}$ adiabat drops by half an order of magnitude. In this case, the predicted bulk mantle $\mathrm{H}_{2} \mathrm{O}$ contents from the DK model increase from the predictions of SEO3 (QFM) by $20 \mathrm{ppm}$ at $300 \mathrm{~km}$ depth, which is insufficient to lower the $\mathrm{H}_{2} \mathrm{O}$-undersaturated solidus to the point where it crosses the NoMelt thermal profile. Therefore, we conclude that, since the SEO3 (QFM) model resulted in the lowest $\mathrm{H}_{2} \mathrm{O}$ contents from the DK model and the UHO model (with separate anhydrous 
terms) predicted the highest $\mathrm{H}_{2} \mathrm{O}$ contents, these options provide the most conservative estimates of the olivine and bulk mantle $\mathrm{H}_{2} \mathrm{O}$ content.

Petrologic constraints suggest that the source mantle $\mathrm{H}_{2} \mathrm{O}$ content for oceanic basalts is between 50-200 ppm [Michael, 1988; Saal et al., 2002; Simons et al., 2002; Workman and Hart, 2005]. In addition, experimental storage capacity data suggest that upper mantle peridotite can hold up to $\sim 700$ ppm at $8 \mathrm{GPa}$ [Ardia et al., 2012], though $\mathrm{CO}_{2}$ may decrease this capacity by a factor of 2 [Yang et al., 2014]. Estimated bulk $\mathrm{H}_{2} \mathrm{O}$ contents from the DK model remain below these constraints throughout the mantle based on the SEO3 (QFM) anhydrous model, while the UHO model predicts $\mathrm{H}_{2} \mathrm{O}$ contents within the independently constrained ranges until a depth of 210 $\mathrm{km}$, where $\mathrm{H}_{2} \mathrm{O}$ contents reach over 200 ppm and rise to almost 400 ppm by $300 \mathrm{~km}$. The peridotite storage capacity may very well be exceeded by $300 \mathrm{~km}$ dependent on the partitioning of $\mathrm{H}_{2} \mathrm{O}$ between garnet and olivine [Ardia et al., 2012], which would suggest that melt or a fluid could be stable at greater depths and higher temperatures. In order to investigate whether our observed conductivities are below the estimated partially hydrated solidus, our next step was to calculate the solidi corresponding to both the $\mathrm{UHO}$ and DK estimated mantle $\mathrm{H}_{2} \mathrm{O}$ contents to compare to the NoMelt thermal profile.

We modeled the anhydrous peridotite solidus using the parameterization from Hirschmann [2000].We then calculated the peridotite partition coefficient $D_{H}^{\text {perid/melt }}$ based on the mineral abundances and $D_{H}^{\text {min/melt }}$ values previously described. $D_{H}^{\text {perid/melt }}$ increases from 0.007 to 0.009 until the onset of garnet stability when the opx abundance and pyroxene aluminum content decreases. At higher pressures, the $D_{H}^{\text {perid/melt }}$ decreases to 0.005 . These values match the values determined by Hirschmann et al. [2009] who verified the peridotite partition coefficient values through a Monte Carlo simulation to minimize the influence of the uncertainties in $D_{H}^{\text {min/melt }}$, and mineral abundances. The $D_{H}^{\text {perid/melt }}$ values were then used to calculate the fraction of $\mathrm{H}_{2} \mathrm{O}$ in the melt phase at the solidus based on the parameterization of Katz et al. [2003] where the decrease in solidus temperature is proportional to the dissolved bulk $\mathrm{H}_{2} \mathrm{O}$ content from each model. 
At no point does our preferred NoMelt thermal profile cross either $\mathrm{H}_{2} \mathrm{O}$-undersaturated peridotite solidus (Figure 7c.). Taken at face value, this suggests that melting is unlikely at any depth in the NoMelt asthenosphere and that $\mathrm{H}_{2} \mathrm{O}$ dissolved in olivine is solely responsible for the observed conductivity.

\subsubsection{Melt Contribution}

While the combination of a hydrous mantle and a plate cooling model with a low adiabatic thermal gradient offer a self-consistent, solid-state explanation for the observed mantle conductivity in the NoMelt region, the presence of $\mathrm{CO}_{2}$ may provide a means to induce melting even at low temperatures, so we place constraints on how much melt could be consistent with our observed profile. Recent melt fraction estimates in the asthenosphere from MT studies range from 0.5 to $\sim 2 \mathrm{vol} \%$ dependent on whether silicate, hydrous silicate, or carbonatite melt compositions are considered [Naif et al., 2013; Baba et al., 2010]. These melt fractions were estimated by using observed conductivity profiles and simultaneously assuming a background conductivity and a melt conductivity at a certain pressure, temperature, and $\mathrm{H}_{2} \mathrm{O}$ content, but we have found that our predicted $\mathrm{H}_{2} \mathrm{O}$ contents should not be enough to lower the solidus for melting.

Recent laboratory work has shown that $\mathrm{CO}_{2}$ drastically influences the melt conductivity at the initial stages of melting [Sifre et al., 2014], and stabilizes carbonated silicate melt in the upper asthenosphere [Hirschmann, 2010]. The oceanic mantle is thought to contain 25-100 ppm $\mathrm{CO}_{2}$ [Hirschmann and Dasgupta, 2009], but some estimates range to hundreds of ppm [e.g., Sifre et al., 2014]. Mantle $\mathrm{CO}_{2}$ content will vary with degree of melting and oxidation [Dasgupta et al., 2013], as well as the stability of a $\mathrm{CO}_{2}$ phase. For this study we assume that the combination of the $\mathrm{H}_{2} \mathrm{O}$ contents calculated previously and a certain defined bulk $\mathrm{CO}_{2}$ is sufficient to lower the $\mathrm{H}_{2} \mathrm{O}$-undersaturated peridotite solidus temperature so that some melt is stable in the NoMelt mantle (see Figure 7c). We assumed what we believe to be a conservative bulk mantle $\mathrm{CO}_{2}$ content of 100 ppm based on the above predictions.

Melt conductivity depends strongly on the $\mathrm{CO}_{2}$ content of the melt, which depends strongly on melt fraction, since $\mathrm{CO}_{2}$ is essentially perfectly incompatible in the solid [Sifre et al., 2014]. This 
behavior means that the melt conductivity, melt $\mathrm{CO}_{2}$ content, and melt fraction are all unknown parameters that vary as melting progresses, and they cannot be simultaneously determined using MT data alone. In order to solve for the possible melt fractions in the NoMelt asthenosphere, we assumed the same volatile mantle partitioning as Sifre et al. [2014] and determined the melt conductivity at a range of melt fractions. Although there is no strong evidence for a highly conductive layer within the LAB region of the NoMelt profile, we chose to vary melt fractions between 0 and 5 vol\% - a larger range than Utada and Baba's [2014] determination for old oceanic mantle (100 Ma).

The background mantle conductivity was determined by the amount of $\mathrm{H}_{2} \mathrm{O}$ that remains in the residual peridotite based on $\mathrm{H}_{2} \mathrm{O}$ partitioning. Combined with the corresponding carbonated silicate melt conductivity, we were able to calculate the bulk peridotite conductivity at each melt fraction considered from the Hashin-Shtrikman (HS) upper bound mixing law [Hashin and Shtrikman, 1962]. The resulting bulk conductivities were directly compared to the observed NoMelt profile, and the best fitting melt fractions at each depth in the asthenosphere were chosen by minimizing the difference between the observed and calculated bulk conductivities.

Regardless of whether UHO or DK bulk $\mathrm{H}_{2} \mathrm{O}$ contents are used for the calculation of melt conductivities, melt fractions required to explain the observed NoMelt electrical conductivity remain at or below $1 \mathrm{vol} \%$ (Table 2). The DK model predicts a maximum melt fraction of 0.075 vol\% at $80 \mathrm{~km}$ showing the potential for a small amount of carbonated hydrous silicate melt at our observed electrical LAB depth. On the other hand, the UHO model predicts a maximum melt fraction of $1.0 \mathrm{vol} \%$ at $300 \mathrm{~km}$, but again predicts only a melt fraction of $0.075 \mathrm{vol} \%$ at the electrical LAB. Therefore, if a mantle $\mathrm{CO}_{2}$ content of $100 \mathrm{ppm}$ is accurate and is able to decrease the solidus enough for melting to occur, only trace amounts of melt would be present at the NoMelt electrical LAB. The lack of significant melt at the depths corresponding to the LAB further support a hydrous mechanism explanation for the observed conductivity.

\subsubsection{Anisotropy}

In contrast to two recent oceanic studies [Evans et al., 2005; Naif et al., 2013], our data do not require electrical anisotropy. Furthermore, a possible interpretation of the MT model for the 
NoMelt upper mantle uses dissolved $\mathrm{H}_{2} \mathrm{O}$ to explain slightly elevated conductivities. Initial interpretations of the southern portion of the MELT Experiment also invoked dissolved $\mathrm{H}_{2} \mathrm{O}$ to explain the observed conductivity, but these studies suggested higher $\mathrm{H}_{2} \mathrm{O}$ contents than for the NoMelt region [Evans et al., 2005; Baba et al., 2006]. Anisotropy in the MELT area showed that conductivities differed by about a factor of 4-5 between the plate spreading and strike directions (see Figure 5). This result is consistent with predictions of conductivity based on diffusion of hydrogen, which is significantly faster along the olivine a-axis [Kohlstedt and Mackwell, 1998]. Although subsequent published conductivity measurements are less conclusive on whether hydrous olivine conductivity is anisotropic [Yoshino et al., 2006; Poe et al., 2010], recent data do show evidence for higher conductivity along the a-axis [Dai and Karato, 2014], with a factor of 2-3 possible for a mantle aggregate. While dissolved $\mathrm{H}_{2} \mathrm{O}$ may be influencing the NoMelt mantle conductivity, we do not observe any electrical anisotropy. The most likely explanation is that the $\mathrm{H}_{2} \mathrm{O}$ contents are sufficiently low as to not induce detectable electrical anisotropy in an imperfectly aligned mantle fabric [e.g. Yang, 2012].

\subsection{Conclusions}

The NoMelt Experiment set out to image the structure of the central Pacific plate lithosphere and the LAB transition. Electrical conductivity is sensitive to temperature, dissolved $\mathrm{H}_{2} \mathrm{O}$, and interconnected melt giving electromagnetic data the ability to help determine the mechanisms responsible for the rheological transition from the rigid lithosphere to the weak asthenosphere. Results from 2-D isotropic and anisotropic inversions of MT data indicate that the electrical structure of the NoMelt region is isotropic and does not contain a highly conductive layer under the resistive electrical lithosphere. Therefore, based on first order interpretations of the modeled structure, the LAB does not contain significant amounts of interconnected partial melt. To determine the conductivity mechanisms operative at the LAB we compared a 1-D profile averaged from our preferred 2-D model to laboratory conductivity data of anhydrous and hydrous olivine and interpretations of the electrical structure from other oceanic settings.

Results from our analysis advocate for three separate interpretations. The first interpretation is a purely thermal explanation for the observed NoMelt conductivity where the mantle adiabat has a 
gradient of $0.5^{\circ} \mathrm{C} / \mathrm{km}$ and a potential temperature of $1374^{\circ} \mathrm{C}$. The intersection of the adiabat and the plate geotherm constrained by bathymetric data is at $86 \mathrm{~km}$ and $1412^{\circ} \mathrm{C}$. If instead a lower adiabatic thermal gradient of $0.3^{\circ} \mathrm{C} / \mathrm{km}$ is preferred, in keeping with other constraints on mantle properties [e.g., Turcotte and Schubert, 2002], the potential temperature of the mantle increases to $1386^{\circ} \mathrm{C}$ but plate thickness and basal temperature remains the same. However, this choice of adiabat underpredicts asthenospheric conductivity assuming a dry olivine composition, suggesting that another mechanism is needed to explain the observed NoMelt mantle conductivity. We suggest that a small amount of $\mathrm{H}_{2} \mathrm{O}$ dissolved in olivine is a viable explanation, although the range of asthenospheric bulk $\mathrm{H}_{2} \mathrm{O}$ contents is highly dependent on the choice of conductive hydrous olivine model chosen, as well as the choice of dry olivine conductivity model. We estimate bulk mantle $\mathrm{H}_{2} \mathrm{O}$ contents between 25 and $400 \mathrm{ppm}$ at $300 \mathrm{~km}$ depth, broadly consistent with petrologic constraints on mantle $\mathrm{H}_{2} \mathrm{O}$ contents. These concentrations of $\mathrm{H}_{2} \mathrm{O}$ are insufficient, by themselves, to lower the mantle solidus for melting to occur.

We do not see strong evidence in the NoMelt electrical structure for melting of the asthenosphere and our observed profile does not appear to cross the anhydrous or hydrous solidi. However, we cannot rule out that the presence of $\mathrm{CO}_{2}$ in the mantle could lower the mantle solidus sufficiently to allow for mantle melting. The amount of $\mathrm{CO}_{2}$ in the mantle and the effects of $\mathrm{CO}_{2}$ content on the mantle solidus are not well constrained, but if it is assumed that $100 \mathrm{ppm} \mathrm{CO}_{2}$ is enough to initiate melting then small amounts of melt could be present throughout the NoMelt lower lithosphere and asthenosphere. Only trace amounts of melt $(<0.1 \mathrm{vol} \%)$ are necessary to explain our observed conductivity at LAB depths.

\subsection{Acknowledgments}

We would like to thank Nick Schmerr and two anonymous reviewers for providing comments that significantly improved our manuscript. The results presented in this paper rely on data collected at magnetic observatories. We thank the national institutes that support them and INTERMAGNET for promoting high standards of magnetic observatory practice (www.intermagnet.org). Magnetotelluric data from the NoMelt Experiment will be made freely accessible through the IRIS MT repository (http://ds.iris.edu/spud/emtf). Funding for the 
NoMELT Experiment was provided by the National Science Foundation. We would like to thank Chris Judge for his assistance in mobilizing the MT instruments and with their deployment and recovery at sea. 


\subsection{References}

Anderson, D.L. and C. Sammis (1970), Partial melting in the upper mantle, Earth Planet. Int., 3, 41-50, doi: 10.1016/0031-9201(70)90042-7.

Anderson, D.L. and H. Spetzler (1970), Partial melting and the low-velocity zone, Phys. Earth Planet. Int., 4, 62-64, doi: 10.1016/0031-9201(70)90030-0.

Ardia, P., M.M. Hirschmann, A.C. Withers, and T.J. Tenner (2012), $\mathrm{H}_{2} \mathrm{O}$ storage capacity of olivine at 5-8 GPa and consequences for dehydration partial melting of the upper mantle, Earth Planet. Sci. Lett., 345-348, 104-116, doi: 10.1016/j.epsl.2012.05.038.

Baba, K. and A.D. Chave (2005), Correction of seafloor magnetotelluric data for topographic effects during inversion, J. Geophys. Res. 110, doi:10.1029/2004JB003463.

Baba, K., A.D. Chave, R.L. Evans, G. Hirth, and R.L. Mackie (2006), Mantle dynamics beneath the East Pacific Rise at $17^{\circ} \mathrm{S}$ : Insights from the Mantle Electromagnetic and Tomography (MELT) experiment, J. Geophys. Res., 111, B02101, doi:10.1029/2004JB003598.

Baba, K., H. Utada, T. Goto, T. Kasaya, H. Shimizu, and N. Tada (2010), Electrical conductivity imagine of the Philippine Sea upper mantle using seafloor magnetotelluric data, Phys. Earth and Planet. Int., 183, 44-62, doi: 10.1016/j.pepi.2010.09.010.

Bagley, B. and J. Revenaugh (2008), Upper mantle seismic shear discontinuities of the Pacific, $J$. Geophys. Res., 113, doi:10.1029/2008JB005692.

Beghein, C., K. Yuan, N. Schmerr, and Z. Xing (2014), Changes in seismic anisotropy shed light on the nature of the Gutenberg Discontinuity, Science, 343, 1237-1240, doi: 10.1126/science. 1246724 .

Bunge, H.P., M.A. Richards, and J.R. Baumgardner (1996), Effect of depth-dependent viscosity on the planform of mantle convection, Nature, 379, 436-438.

Caricchi, L., F. Gaillard, J. Mecklenburgh, and E. Le Trong (2011), Experimental determination of electrical conductivity during deformation of melt-bearing olivine aggregates and electrical anisotropy in the oceanic low velocity zone, Earth Planet. Sci. Lett., 302, 81-94, doi: $\underline{10.1016 / \mathrm{j} . e p s 1.2010 .11 .041 .}$.

Chave, A.D. and J.T. Smith (1994), On electric and magnetic galvanic distortion tensor decompositions, J. Geophys. Res.: Solid Earth, 99, 4669-4682, DOI: 10.1029/93JB03368

Chave, A.D. and D.J. Thomson (2003), A bounded influence regression estimator based on the statistics of the hat matrix, J. R. Stat. Soc., Ser., C 52, 307-322, doi: 10.1111/14679876.00406 .

Chave, A.D. and D.J. Thomson (2004), Bounded influence magnetotelluric response function estimation, Geophys. J. Int., 157, 988-1006, doi: 10.1111/j.1365-246X.2004.02203.x.

Collins, J.A., F.L. Vernon, J.A. Orcutt, and R.A. Stephen (2002), Upper mantle structure beneath the Hawaiian swell: Constraints from the ocean seismic network pilot experiment, Geophys. Res. Lett., 29, doi:10.1029/2001GL013302. 
Constable, S. (2006), SEO3: A new model of olivine electrical conductivity, Geophys. J. Int., 166, 435-437, doi: 10.1111/j.1365-246X.2006.03041.x.

Constable, S., T.J. Shankland, and A. Duba (1992), The electrical conductivity of an isotropic olivine mantle, J. Geophys. Res., 97, 3397 3404, DOI: 10.1029/91JB02453.

Crosby, A.G., D. McKenzie, and J.G. Sclater (2006), The relationship between depth, age and gravity in the oceans, Geophys. J. Int., 166, 553-573, doi: 10.1111/j.1365246X.2006.03015x.

Dai, L. and S. Karato (2009), Electrical conductivity of wadsleyite at high temperatures and high pressures, Earth Planet. Sci. Lett., 287, 277-283, doi: 10.1016/j.epsl.2009.08.012.

Dai, L. and S. Karato (2014), High and highly anisotropic electrical conductivity of the asthenosphere due to hydrogen diffusion in olivine, Earth Planet. Sci. Lett., 408, 79-86, doi: 10.1016/j.epsl.2014.10.003.

Dasgupta, R. and M.M. Hirschmann (2006), Melting in the Earth's deep upper mantle caused by carbon dioxide, Nature, 440, 659-662, doi: 10.1038/nature04612.

Dasgupta, R., A. Mallik, K. Tsuno, A.C. Withers, G. Hirth, and M.M. Hirschmann (2013), Carbon-dioxide-rich silicate melt in the Earth's upper mantle, Nature, 493, 211-215, doi:10.1038/nature11731.

Dixon, J.E., L. Leist, C. Langmuir, and J.G. Schilling, (2002), Recycled dehydrated lithosphere observed in plume-influenced mid-ocean-ridge basalt, Nature, 420, 385-389, doi: 10.1038 /nature 01215 .

Eaton, D.W., F. Darbyshire, R.L. Evans, H. Grütter, A. Jones, and X. Yuan (2009), The elusive lithosphere-asthenosphere boundary (LAB) beneath cratons, Lithos., 109, 1-22, doi:10.1016/j.lithos.2008.05.009.

Evans, R.L., (2012), Chapter 3: Earth's Electromagnetic Environment. Part 1. Conductivity of Earth Materials, in A.D. Chave, and A.G. Jones (eds.), The Magnetotelluric Method: Theory and Practice, Cambridge University Press, ISBN 9780521819275.

Evans, R.L., G. Hirth, K. Baba, D. Forsyth, A.D. Chave, and R. Mackie (2005), Geophysical evidence from the MELT area for compositional controls on oceanic plates, Nature, 437, 249-252, doi: 10.1038/nature04014.

Evans, R.L., D. Lizarralde, J.A. Collins, J. Elsenbeck, E. Tursack, G. Hirth, J.B. Gaherty, A. Pommier, K. Baba, and T. Matsuno (2011), Electromagnetic constraints on the structure of the oceanic upper mantle: Consistencies and inconsistencies with other observations, Abstract DI34B-03 presented at 2011 Fall Meeting, AGU, San Francisco, Calif., 5-9 Dec.

Fei, H., M. Wiedenbeck, D., Yamazake, and T. Katsura (2013), Small effect of water on uppermantle rheology based on silicon self-diffusion coefficients, Nature, 498, 213-215, doi: 10.1038/nature12193.

Finlay, C.C., S. Maus, C.D. Beggan, T.N. Bondar, A. Chambodut, T.A. Chernova, A. Chulliat, V.P. Golovkov, B. Hamilton, M. Hamoudi, R. Holme, G. Hulot, W. Kuang, B. Langlais, F. 
Lesur, J. Lowes, H. Luhr, S. Macmillan, M. Mandea, S. McLean, C. Manoj, M. Menvielle, I. Michalis, N. Olsen, J. Rauberg, M. Rother, T.J. Sabaka, A. Tangborn, L. Toffner-Clausen, E. Thebault, A.W.P. Thomson, I. Wardinski, Z. Wei, and T.I. Zvereva (2010), International Geomagnetic Reference Field: the eleventh generation. International Association of Geomagnetism and Aeronomy, Working Group V-MOD, Geophys. J. Int. 183, 1216-1230, doi: $10.1111 / \mathrm{j} .1365-246 \mathrm{X} .2010 .04804 . \mathrm{x}$.

Gaherty, J.B., T.H. Jordan, and L.S. Gee (1996), Seismic structure of the upper mantle in a central Pacific corridor, J. Geophys. Res., DOI: 10.1029/96JB01882

Gaillard, F., M. Malki, G. Iacono-Marziano, M. Pichavant, and B. Scaillet (2008), Carbonatite melts and electrical conductivity in the asthenosphere, Science, 322, 1363-1365, doi: $10.1126 /$ science. 1164446 .

Gardes, E., F. Gaillard, and P. Tarits (2014), Toward a unified hydrous olivine electrical conductivity law, Geochem. Geophys. Geosyst., 15, 4984-5000, DOI: 10.1002/2014GC005496.

Gu, Y.J., A.L. Lerner-Lam, A.M. Dziewonski, and G. Ekstrom (2005), Deep structure and seismic anisotropy beneath the East Pacific Rise, Earth Planet. Sci. Lett., 232, 259-272, doi: 10.1016/j.eps1.2005.01.019.

Hashin, Z. and S. Shtrikman (1962), A variational approach to the theory of effective magnetic permeability of multiphase materials, J. Appl. Phys., 33, 3125-3131, doi: $10.1063 / 1.1728579$.

Hirschmann, M.M. (2000), Mantle solidus: Experimental constraints and the effects of peridotite composition, Geochem. Geophys. Geosyst., 1, DOI: 10.1029/2000GC000070.

Hirschmann, M.M. (2010), Partial melt in the oceanic low velocity zone, Phys. Earth Planet. Int., 179, 60-71, doi: 10.1016/j.pepi.2009.12.003.

Hirschmann, M.M. and R. Dasgupta (2009), The H/C ratios of Earth's near-surface and deep reservoirs, and consequences for deep Earth volatile cycles, Chem. Geology, 262, 4-16, doi 10.1016/j.chemgeo.2009.02.008:

Hirschmann, M.M., T. Tenner, C. Aubaud, and A.C. Withers (2009), Dehydration melting of nominally anhydrous mantle: The primacy of partitioning, Phys. Earth Planet. Int., 176, 5468, doi: 10.1016/j.pepi.2009.04.001.

Hirth, G. and D.L. Kohlstedt (1996), Water in the oceanic upper mantle: implications for rheology, melt extraction and the evolution of the lithosphere, Earth and Planet. Lett., 144, 93-108, doi: 10.1016/0012-821X(96)00154-9.

Hoink, T. and A. Lenardic (2008), Three-dimensional mantle convection simulations with a lowviscosity asthenosphere and the relationship between heat flow and the horizontal length scale of convection, Geophys. Res. Lett., 35, doi:10.1029/2008GL033854.

Jones, A.G., J. Fullea, R.L. Evans, and M.R. Muller (2012), Water in cratonic lithosphere: Calibrating laboratory-determined models of electrical conductivity of mantle minerals using 
geophysical and petrological observations, Geochem. Geophys. Geosyst., 13, doi: 10.1029/2012GC004055.

Karato, S. (1990), The role of hydrogen in the electrical conductivity of the upper mantle, Nature, 347, 272-273, doi: 10.1038/347272a0.

Karato, S. (2006), Remote sensing of hydrogen in Earth's mantle, Rev. Mineral. Geochem., 62, 343-375, doi: 10.2138/rmg.2006.62.15.

Karato, S. (2012), On the origin of the asthenosphere, Earth and Planet. Sci. Lett., 321-322, 95 103, doi: $10.1016 / \mathrm{j} . \mathrm{eps} 1.2012 .01 .001$.

Karato, S. (2013), Theory of isotope diffusion in a material with multiple species and its implications for hydrogen-enhanced electrical conductivity in olivine, Physics Earth Planet. Int., 219, 49-54, doi: 10.1016/j.pepi.2013.03.001.

Karato, S. and H. Jung (1998), Water, partial melting and the origin of the seismic low velocity and high attenuation zone in the upper mantle, Earth Planet Sci. Lett., 157, 193-207, doi: 10.1016/S0012-821X(98)00034-X.

Katsura, T., A. Yoneda, D. Yamazaki, T. Yoshino, and E. Ito (2010), Adiabatic temperature profile in the mantle, Phys. Earth Planet. Int., 183, 212-218, doi: 10.1016/j.pepi.2010.07.001.

Katz, R.F., M. Spiegelman, and C.H. Langmuir (2003), A new parameterization of hydrous mantle melting, Geochem. Geophys. Geosyst., 4(9), 1073, doi:10.1029/2002GC000433.

Kawakatsu, H., P. Kumar, Y. Takei, M. Shinohara, T. Kanazawa, E. Araki, and K. Suyehiro (2009), Seismic evidence for sharp lithosphere-asthenosphere boundaries of oceanic plates, Science, 324, 499-502, doi: 10.1126/science.1169499.

Kohlstedt, D.L. and S.J. Mackwell (1998), Diffusion of hydrogen and intrinsic point defects in olivine, Zeit. Phys. Chem., 207, 147-162, doi: 10.1524/zpch.1998.207.Part 1 2.147.

Lambert, I.B. and P.J. Wyllie (1970), Low-velocity zone of the Earth's mantle: incipient melting caused by water, Science, 169, 764-766, doi: 10.1126/science.169.3947.764.

Lizarralde, D., A.D. Chave, G. Hirth, and A. Schultz (1995), Northeastern Pacific mantle conductivity profile from long-period magnetotelluric sounding using Hawaii-to-California submarine cable data, J. Geophys. Res., 100, DOI: 10.1029/95JB01244.

Mackwell, S.J. and D.L. Kohlstedt (1990), Diffusion of hydrogen in olivine: Implications for water in the mantle, J. Geophys. Res., 95, DOI: 10.1029/JB095iB04p05079.

Matsuno, T., N. Seama, R.L. Evans, A.D. Chave, K. Baba, A. White, T. Goto, G. Heinson, G. Boren, A. Yoneda, and H. Utada (2010), Upper mantle electrical resistivity structure beneath the central Mariana subduction system, Geochem. Geophys. Geosys., 11, Q09003, doi:10.1029/2010GC003101.

McKenzie, D., J. Jackson, and K. Priestley (2005), Thermal structure of oceanic and continental lithosphere, Earth Planet. Sci. Lett., 233, 337-349, doi: 10.1016/j.epsl.2005.02.005.

Mei, S. and D.L. Kohlstedt (2000), Influence of water on plastic deformation of olivine aggregates 2. Dislocation creep regime, J. Geophys. Res., 105, DOI: 10.1029/2000JB900180. 
Michael, P.J. (1988), The concentration, behavior and storage of $\mathrm{H}_{2} \mathrm{O}$ in the suboceanic upper mantle: implications for mantle metasomatism, Geochim Cosmochim Acta, 52, 555-566, doi: 10.1016/0016-7037(88)90110-X.

Minarik, W.G. and E.B. Watson (1995), Interconnectivity of carbonate melt at low melt fraction, Earth Planet. Sci. Lett., 133, 423-437, doi: 10.1016/0012-821X(95)00085-Q.

Naif, S., K. Key, S. Constable, and R.L. Evans (2013), Melt-rich channel observed at the lithosphere-asthenosphere boundary, Nature, 495, 356-359, doi: 10.1038/nature11939.

Nettles, M., (2005), Anisotropic velocity structure of the mantle beneath North America, Ph.D. thesis, Harvard University, Cambridge, MA, USA.

Ni, H., H. Keppler, and H. Behrens, (2011), Electrical conductivity of hydrous basaltic melts: implications for partial melting in the upper mantle, Contrib. Mineral. Petrol., 162, 637-650, doi: 10.1007/s00410-011-0617-4.

Nishimura, C.E. and D.W. Forsyth (1989), The anisotropic structure of the upper mantle in the Pacific, Geophys. J., 96, 203-229, doi: 10.1111/j.1365-246X.1989.tb04446.x.

O'Leary, J.A., G.A. Gaetani, and E.H. Hauri (2010), The effect of tetrahedral $\mathrm{Al}^{3+}$ on the partitioning of water between clinopyroxene and silicate melt, Earth Planet. Sci. Lett., 297, 111-120, doi: 10.1016/j.epsl.2010.06.011.

Olugboji, T.M., S. Karato, and J. Park (2013), Structures of the oceanic lithosphereasthenosphere boundary: Mineral-physics modeling and seismological signatures, Geochem. Geophys. Geosyst., 14, 880-901, DOI: 10.1002/ggge.20086.

Parsons, B. and J.G. Sclater (1977), An analysis of the variation of ocean floor bathymetry and heat flow with age, J. Geophys. Res., 82, 803-827, DOI: 10.1029/JB082i005p00803.

Plomerová, J., D. Kouba, and V. Babuška (2002), Mapping the lithosphere-asthenosphere boundary through changes in surface-wave anisotropy, Tectonophys, 358, 175-185, doi: 10.1016/S0040-1951(02)00423-7.

Poe, B.T., C. Romano, F. Nestola, and J.R. Smyth (2010), Electrical conductivity anisotropy of dry and hydrous olivine at $8 \mathrm{GPa}$, Phys. Earth Planet. Int., 181, 103-111, doi: 10.1016/j.pepi.2010.05.003.

Pommier, A., F. Gaillard, M. Pichavant, and B. Scaillet (2008), Laboratory measurements of electrical conductivities of hydrous and dry Mount Vesuvius melts under pressure, $J$. Geophys. Res., 113, B05205, doi:10.1029/2007JB005269.

Pommier, A. and E.J. Garnero (2014), Petrology-based modeling of mantle melt electrical conductivity and joint interpretation of electromagnetic and seismic results, J. Geophys. Res. Solid Earth, 119, doi:10.1002/2013JB010449.

Priestley, K. and D. McKenzie (2006), The thermal structure of the lithosphere from shear wave velocities, Earth Planet. Sci. Lett., 244, 285-301, doi: 10.1016/j.eps1.2006.01.008. 
Revenaugh, J. and T.H. Jordan (1991), Mantle layering from ScS reverberations: 1. Waveform inversion of zeroth-order reverberations, J. Geophys. Res., 96, 19749-19762, DOI: $10.1029 / 91 \mathrm{JB} 01659$.

Richards, M.A., W.S. Yang, J.R. Baumgardner, and H.P. Bunge (2002), Role of a low-viscosity zone in stabilizing place tectonics: Implications for comparative terrestrial planetology, Geochem. Geophys. Geosyst., 2, 1040, DOI: 10.1029/2000GC000115.

Riley, G.N., D.L. Kohlstedt, and P.M. Richter (1990), Melt migration in a silicate liquid-olivine system: An experimental test of compaction theory, Geophys. Res. Lett., 17, 2101-2104, DOI: $10.1029 /$ GL017i012p02101.

Ritzwoller, M.H., N.M. Shapiro, and S. Zhong, (2004), Cooling history of the Pacific lithosphere, Earth. Planet Sci. Lett., 226, 69-84, doi: 10.1016/j.epsl.2004.07.032.

Roberts, J.J. and J.A. Tyburczy (1999), Partial-melt electrical conductivity: Influence of melt composition, J. Geophys. Res., 104, 7055-7065, DOI: 10.1029/1998JB900111.

Rodi, W. and R.L. Mackie (2001), Nonlinear conjugate gradients algorithm for 2-D magnetotelluric inversion, Geophysics, 66, 174-187, doi: 10.1190/1.1444893.

Rychert, C. A., N. Schmerr, and N. Harmon (2012), The Pacific lithosphere-asthenosphere boundary: Seismic imaging and anisotropic constraints from SSwaveforms. Geochemistry Geophysics Geosystems, 13, Q0AK10, doi:10.1029/2012GC004194.

Rychert, C. A. and P.M. Shearer (2009), A Global View of the Lithosphere-Asthenosphere Boundary, Science, 324(5926), 495-498, doi:10.1126/science.1169754.

Rychert, C.A. and P.M. Shearer (2011), Imaging the lithosphere-ashtenosphere boundary beneath the Pacific using SS waveform modeling, J. Geophys. Res., 116, doi:10.1029/2010JB008070.

Saal, A.E., E.H. Hauri, C.H. Langmuir, and M.R. Perfit (2002), Vapour undersaturation in primitive mid-ocean-ridge basalt and the volatile content of Earth's upper mantle, Nature, 419, 451-455, doi: 10.1038/nature01073.

Schmeling, H. (1986), Numerical models on the influence of partial melt on elastic, anelastic and electrical properties of rocks. Part II: electrical conductivity, Phys. Earth Planet. Int., 43, 123-136, doi: 10.1016/0031-9201(86)90080-4.

Schmerr, N. (2012), The Gutenberg discontinuity: melt at the lithosphere-asthenosphere boundary, Science, 335, 1480-1483, doi: 10.1126/science.1215433.

Shankland, T.J. and H.S. Waff (1977), Partial melting and electrical conductivity anomalies in the upper mantle, J. Geophys. Res., 82, 5409-5417.

Sifre, D., E. Gardes, M. Massuyeau, L. Hashim, S. Hier-Majumder, and F. Gaillard (2014), Electrical conductivity during incipient melting in the oceanic low-velocity zone, Nature, 509, 81-85, doi: 10.1038/nature13245.

Simons, K., J. Dixon, J-G Schilling, R. Kingsley, and R. Poreda (2002), Volatiles in basaltic glasses from the Easter-Salas y Gomez Seamount Chain and Easter Microplate: Implications 
for geochemical cycling of volatile elements, Geochem., Geophys., Geosyst., 3(7), 1-29, doi: 10.1029/2001GC000173.

Stagno, V., D.O. Ojwang, C.A. McCammon, and D.J. Frost (2013), The oxidation state of the mantle and the extraction of carbon from Earth's interior, Nature, 493, 84-88, DOI:10.1038/nature11679.

Stein, C. and S. Stein (1992), A model for the global variation in oceanic depth and heat flow with lithospheric age, Nature, 359, 123-129.

Stixrude, L. and C. Lithgow-Bertelloni (2005), Mineralogy and elasticity of the oceanic upper mantle: Origin of the low-velocity zone, J. Geophys. Res., 110, DOI: 10.1029/2004JB002965.

Takei, Y. (2002), Effect of pore geometry on Vp/Vs: From equilibrium geometry to crack, $J$. Geophys. Res., 107, doi:10.1029/2001JB005522.

Tan, Y. and D. Helmberger (2007), A new method for determining small earthquake source parameters using short-period $\mathrm{P}$ waves, Seism. Soc. America, 97, 1176-1195, Doi:10.1785/0120060251.

ten Grotenhuis, S.M., M.R. Drury, C.J. Spiers, and C.J. Peach (2005), Melt distribution in olivine rocks based on electrical conductivity measurements, J. Geophys. Res., 110, B12201, doi:10.1029/2004JB003462.

Toffelmier, D.A. and J.A. Tyburczy (2007), Electromagnetic detection of a 410-km-deep melt layer in the southwestern United States, Nature, 447, 991-994, doi: 10.1038/nature05922.

Toramaru, A. and N. Fujii (1986), Connectivity of melt phase in a partially molten peridotite, $J$. Geophys. Res., 91, 9239-9252, DOI: 10.1029/JB091iB09p09239.

Turcotte, D.L. and G. Schubert (2002), Geodynamics (second edition), Cambridge University Press, Cambridge.

Utada, H. and K. Baba (2014), Estimating the electrical conductivity of the melt phase of a partially molten asthenosphere from seafloor magnetotelluric sounding data, Phys. Earth Planet. Int., 227, 41-47, doi: 10.1016/j.pepi.2013.12.004.

Wang, D., M. Mookherjee, Y. Xu, and S. Karato (2006), The effect of water on the electrical conductivity of olivine, Nature, 443, 977-980, doi:10.1038/nature05256.

Wannamaker, P.E., J.R. Booker, A.G. Jones, A.D. Chave, J.H. Filloux, H.S. Waff, and L.K. Law (1989), Resistivity cross section through the Juan de Fuca subduction system and its tectonic implications, J. Geophys. Res., 94, 14127-14144, DOI: 10.1029/JB094iB10p14127.

Wolfe, C.J. and S.C. Solomon (1998), Shear-wave splitting and implications for mantle flow beneath the MELT region of the East Pacific Rise, Science, 280, 1230-1232, doi: $10.1126 /$ science. 280.5367 .1230 .

Workman, R.K., and S.R. Hart (2005), Major and trace element composition of the depleted MORB mantle (DMM), Earth Planet. Sci. Lett., 231, 53-72, doi: 10.1016/j.epsl.2004.12.005. 
Yang, X., (2012), Orientation-related electrical conductivity of hydrous olivine, clinopyroxene and plagioclase and implications for the structure of the lower continental crust and uppermost mantle, Earth Planet. Sci. Lett., 317-318, 241-250, doi: 10.1016/j.eps1.2011.11.011.

Yang, X., D. Liu, and Q. Xia, (2014), CO2-induced small water solubility in olivine and implications for properties of the shallow mantle, Earth and Planet. Sci. Letts., 403, 37-47, doi: $\underline{10.1016 / j . e p s 1.2014 .06 .025}$.

Yoshino, T., M. Laumonier, E. McIsaac, and T. Katsura (2010), Electrical conductivity of basaltic and carbonatite melt-bearing peridotites at high pressures: Implications for melt distribution and melt fraction in the upper mantle, Earth Planet. Sci. Lett., 295, 593-602, doi: 10.1016/j.eps1.2010.04.050.

Yoshino, T., T. Matsuzaki, A. Shatskiy, and T. Katsura (2009), The effect of water on the electrical conductivity of oliving aggregates and its implications for the electrical structure of the upper mantle, Earth Planet. Sci. Lett., 288, 291-300, doi: 10.1016/j.epsl.2009.09.032.

Yoshino, T., E. McIsaac, M. Laumonier, and T. Katsura (2012), Electrical conductivity of partial molten carbonate peridotite, Phys. Earth Planet. Int., 194-195, 1-9, doi: 10.1016/j.pepi.2012.01.005.

Zhu, W., G.A. Gaetani, F. Fusseis, L.G.J. Montesi, and F. De Carlo (2011), Microtomography of partially molten rocks: Three-Dimensional melt distribution in mantle peridotite, Science, 332, 88-91, doi:10.1126/science.1202221. 


\subsection{Figures and Tables}

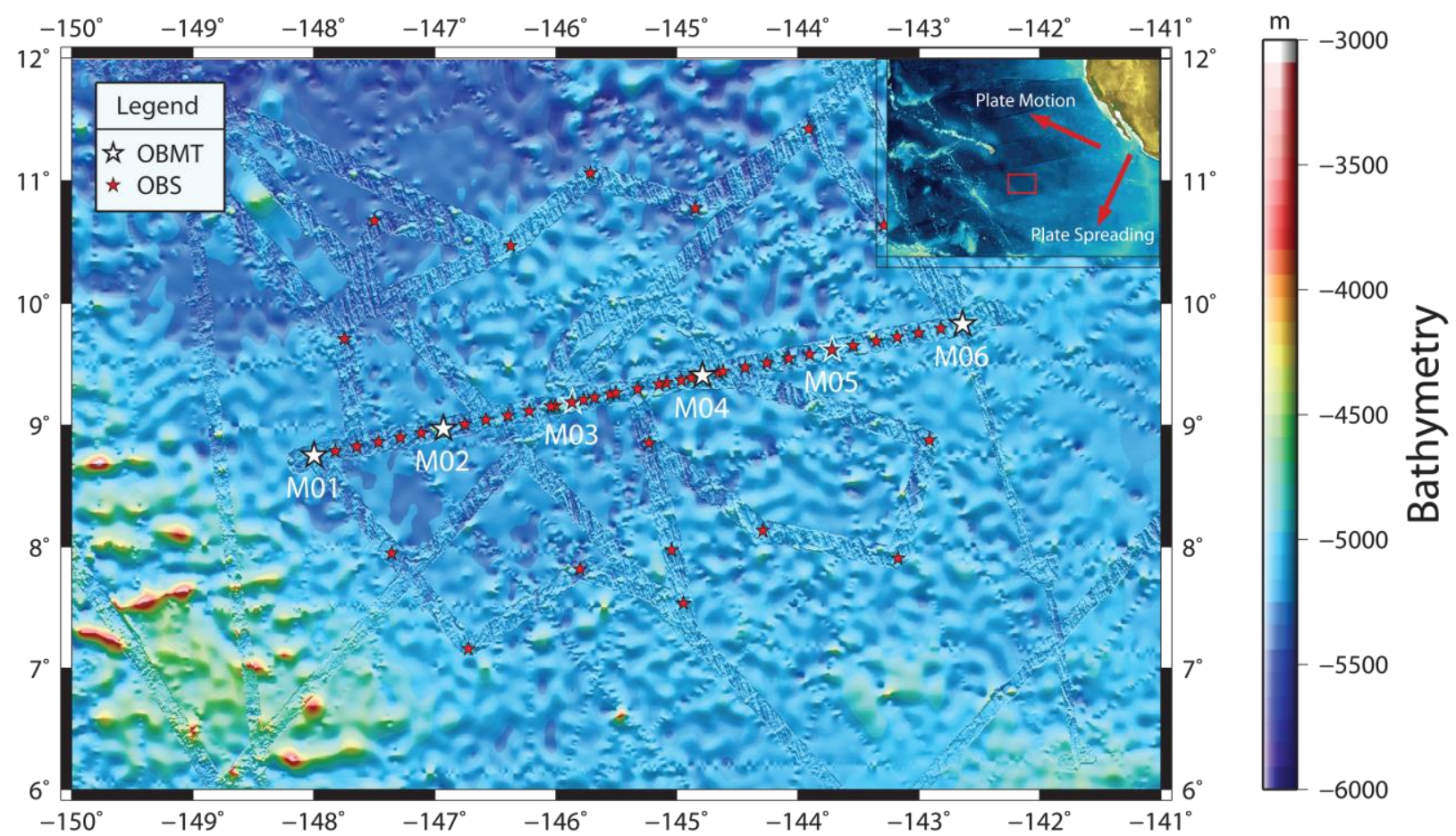

\section{Figure 1}

Shown is the region of the NoMelt Experiment. White stars indicate MT stations 1 through 6 along a linear array - filled stars are stations that provided useable data, unfilled stars were not used. Red stars indicate the locations of seismic stations. Figure insert shows the location of the region and the current plate motion and the plate spreading direction used during inversion. 

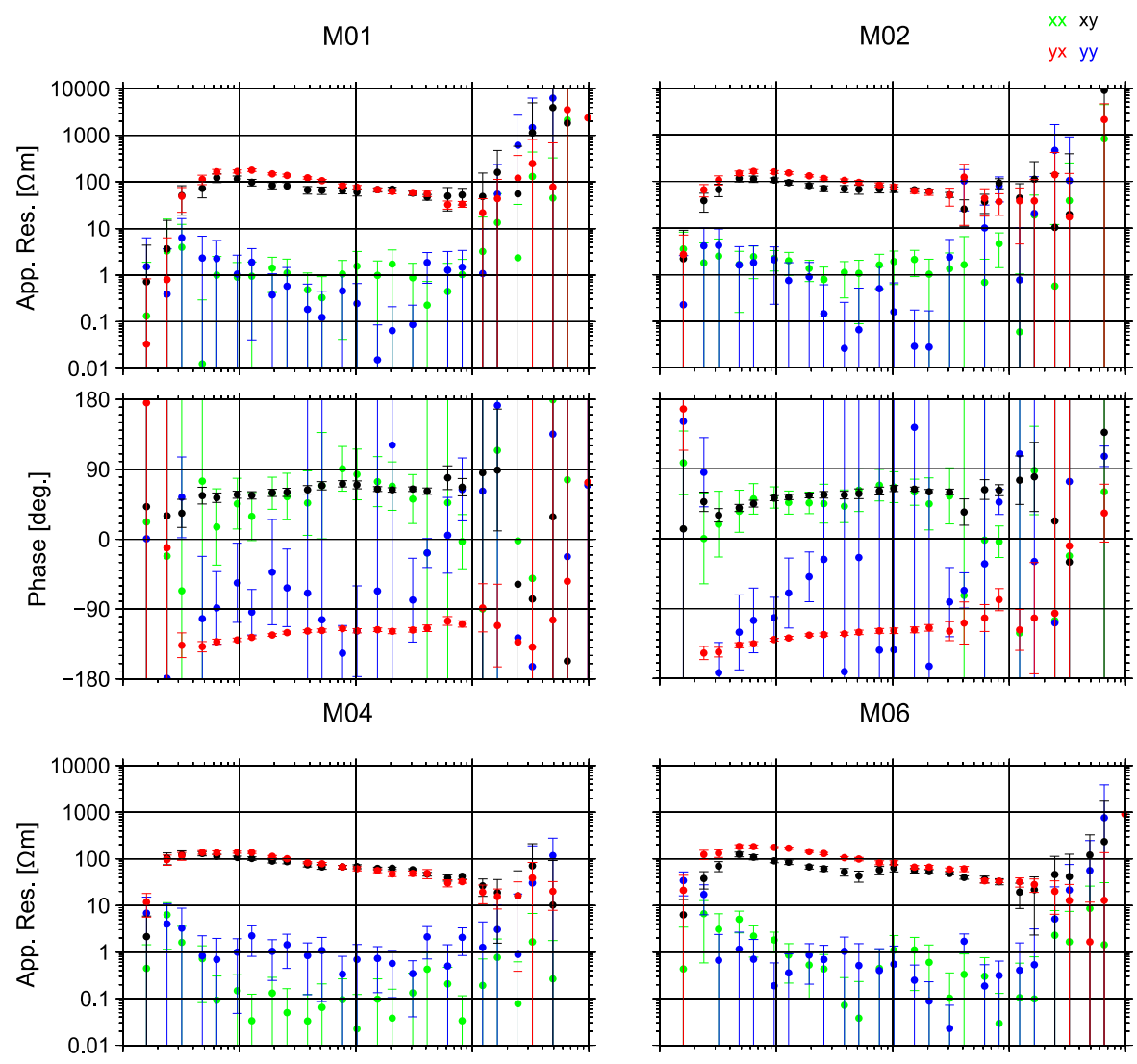

M06
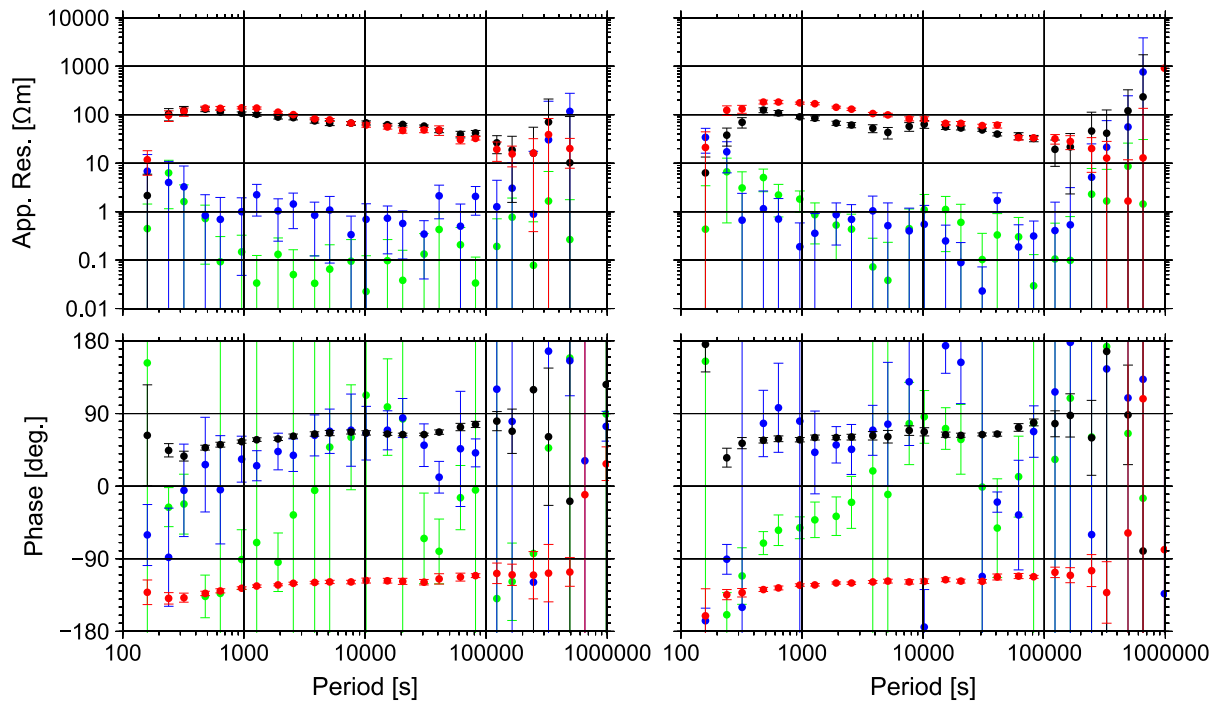

Figure 2

The apparent resistivity and phase curves vs. data period from the 4 used stations is shown. The TE mode $\left(Z_{x y}\right)$ and TM mode $\left(Z_{y x}\right)$ are the black and red dots, respectively. The off-diagonal elements (green and blue dots) have low apparent resistivities and large errors suggesting that the NoMelt electrical structure is 2-D (see text). 


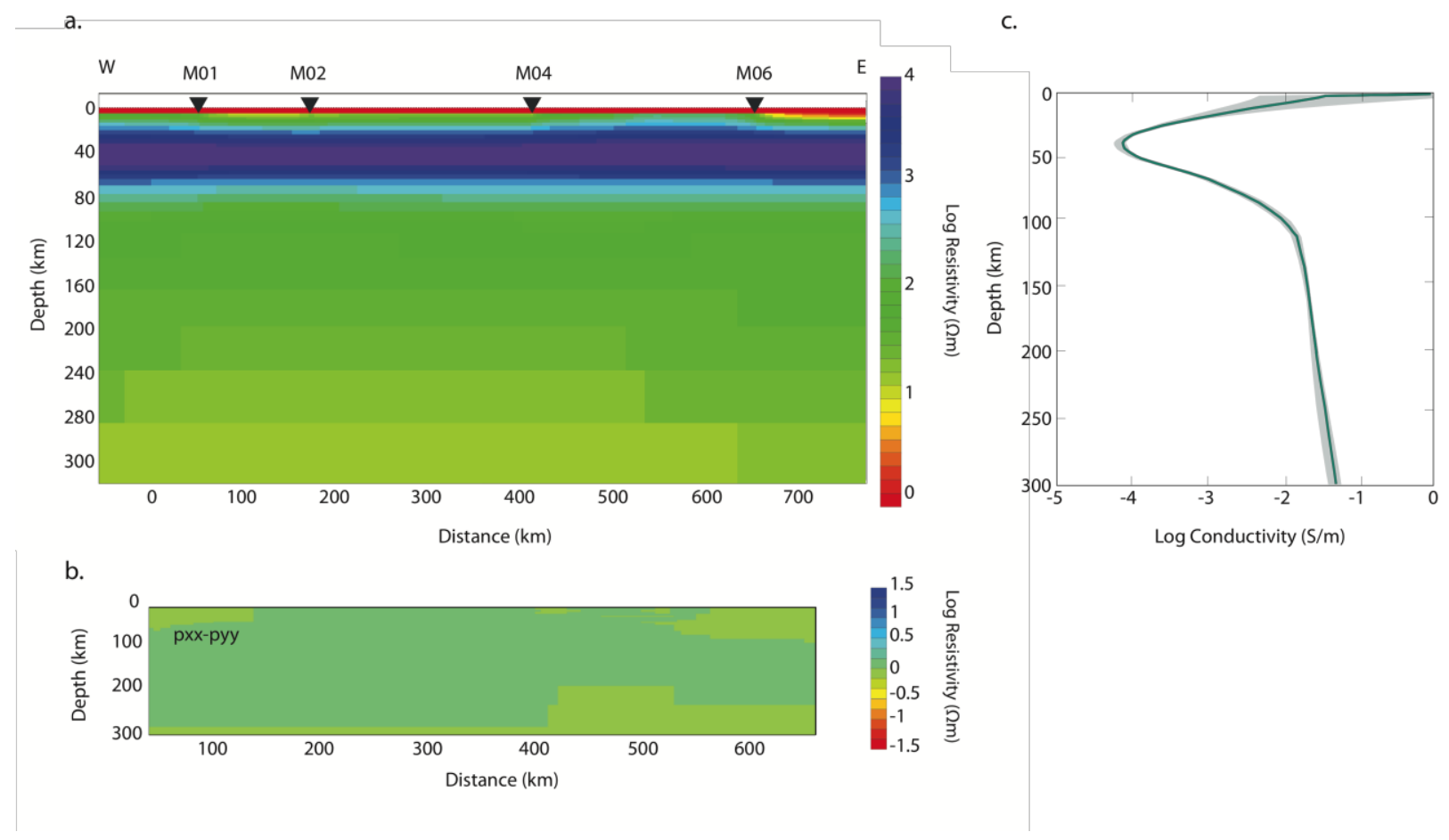

\section{Figure 3}

a. Our preferred 2-D isotropic resistivity model for the NoMelt region. b. The difference between resistivity in the horizontal directions $\left(\rho_{\mathrm{xx}}-\rho_{\mathrm{yy}}\right)$ of the 2-D anisotropy model. The log resistivity values indicate that there is no significant electrical anisotropy required in the region to explain our data. c. The corresponding 1-D model produced from averaging the 2-D model resistivities with depth (bold teal line) and the maximum and minimum resistivity values with depth (shaded range). 

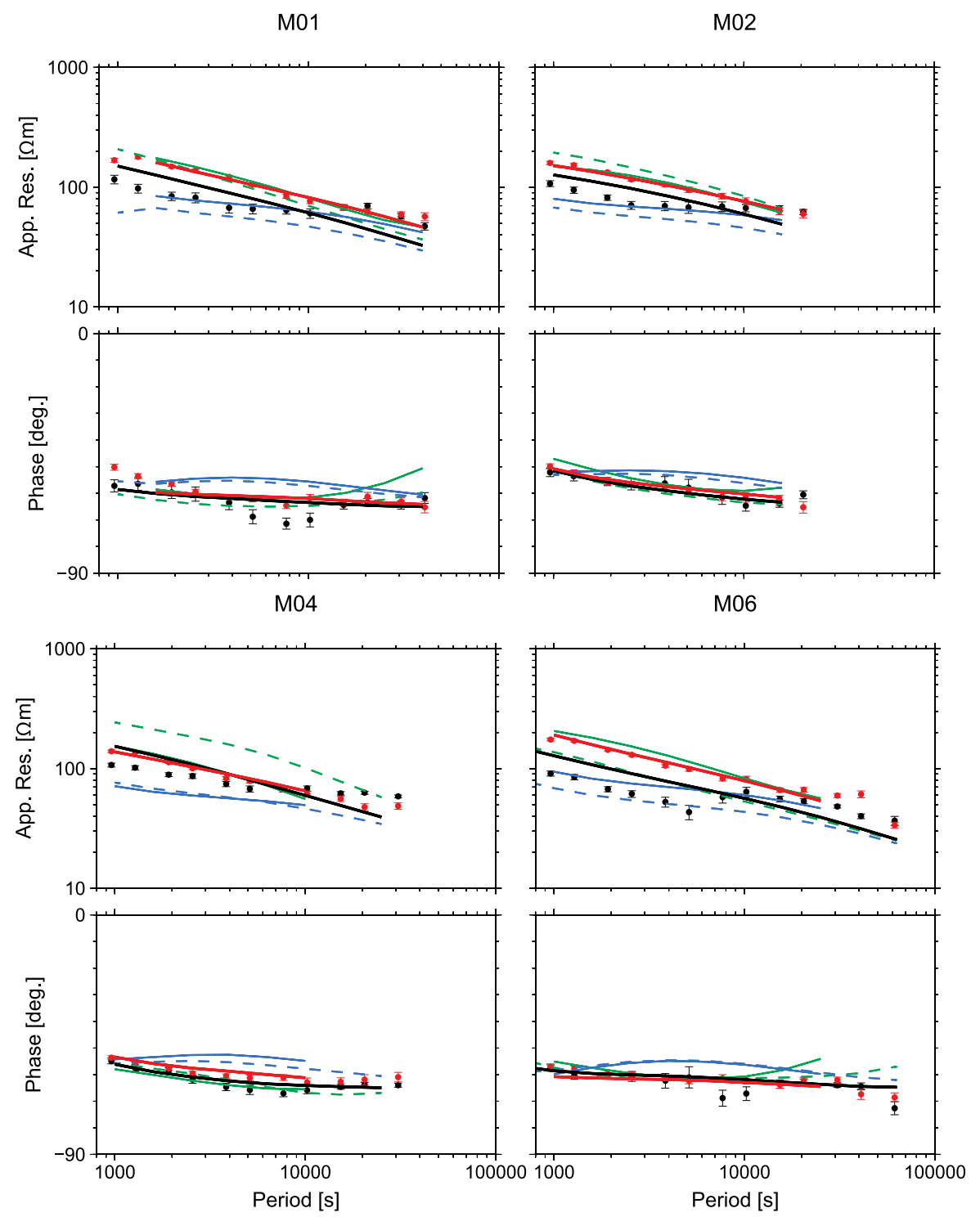

\section{Figure 4}

Inversion model responses for the preferred isotropic 2-D model (TM mode in bold red line; TE mode in bold black line), an isotropic 2-D model with a forced $15 \Omega \mathrm{m}$ melt layer at the base of the lithosphere (blue lines; TM mode solid, TE mode dashed), and an isotropic 2-D model with a $0.3^{\circ} \mathrm{C} / \mathrm{km}$ thermal gradient within the asthenosphere (green lines; TM mode solid, TE mode dashed). See section 4 for discussion. 


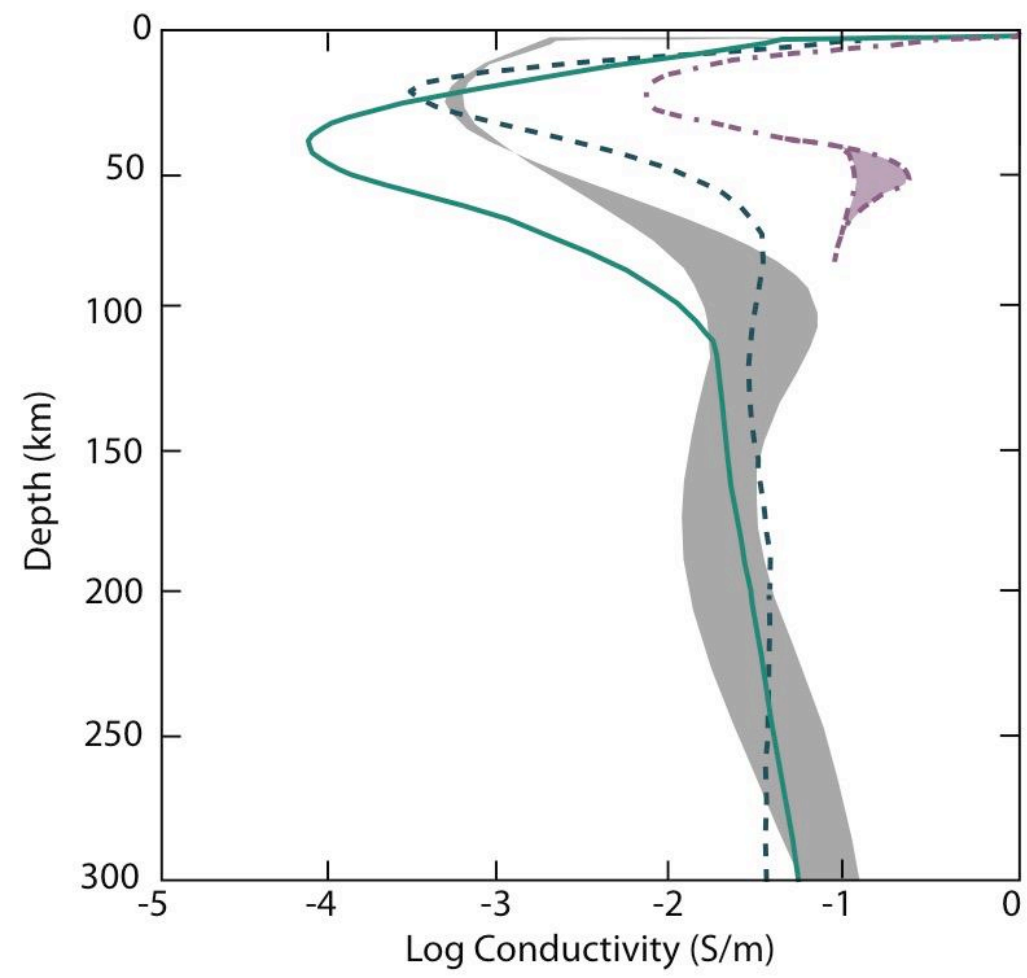

Figure 5

1-D log conductivity vs. depth profile of the averaged NoMelt 2-D model (teal) compared to MT models from other seafloor areas is shown. In general, the NoMelt LAB is less conductive than the MELT (gray region), SERPENT (purple dashed region), and Philippine Sea (teal dashed) LAB. The MELT and SERPENT regions indicate the amount of electrical anisotropy observed. 


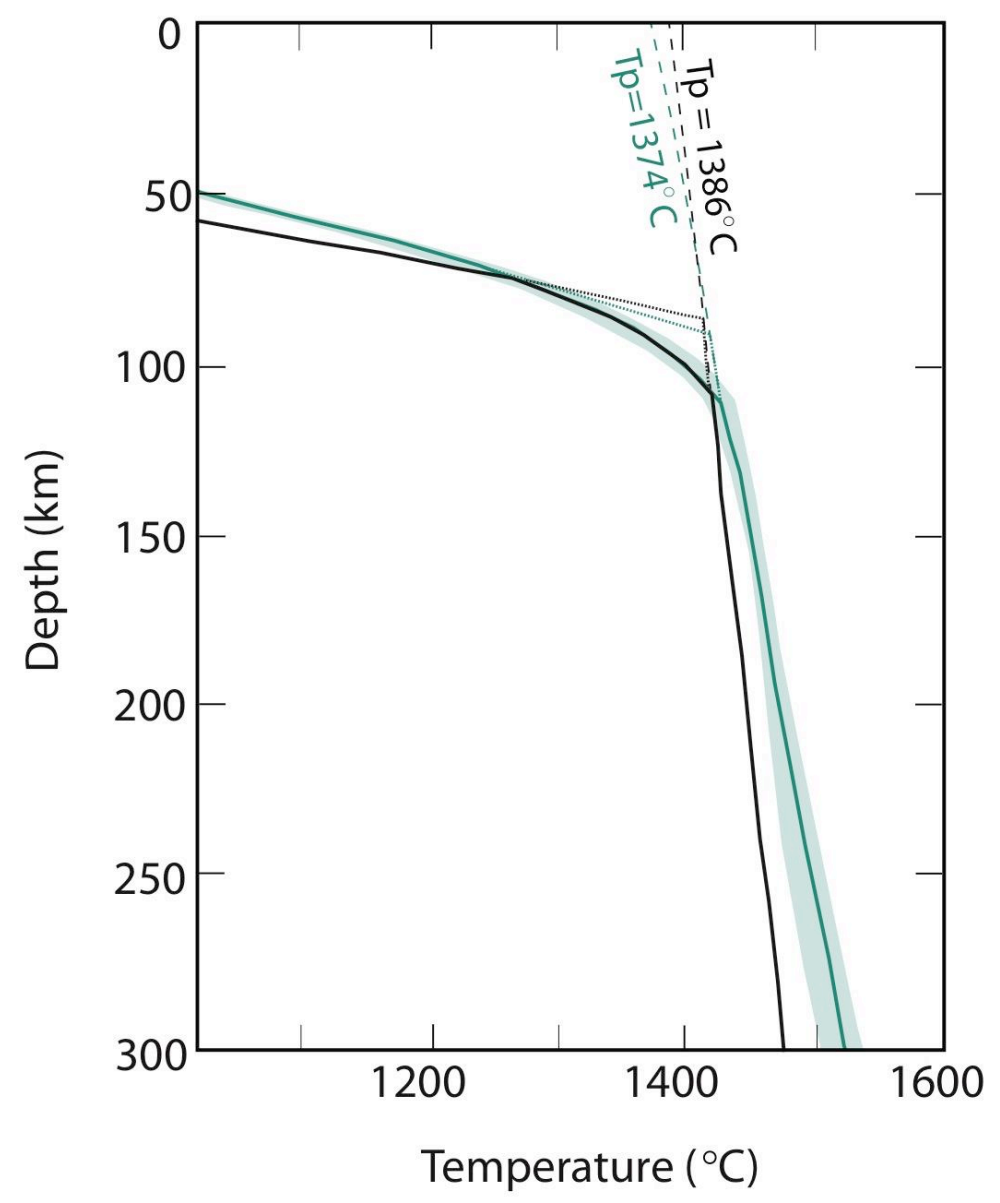

\section{Figure 6}

Shown is the direct temperature conversion of the observed NoMelt conductivity with depth (teal). The shaded region shows the maximum and minimum temperature converted from conductivity. This thermal profile was calculated to have an adiabatic thermal gradient of 0.5 ${ }^{\circ} \mathrm{C} / \mathrm{km}$, a potential temperature of $1374^{\circ} \mathrm{C}$ (dashed teal line), and a plate thickness of $91 \mathrm{~km}$ (dotted teal line). Also shown is the background plate cooling thermal model (black) with an adiabatic thermal gradient of $0.3{ }^{\circ} \mathrm{C} / \mathrm{km}$, a potential temperature of $1386^{\circ} \mathrm{C}$ (dashed black line), and a plate thickness of $86 \mathrm{~km}$ (dotted black line). The plate thickness and basal temperature from the background thermal model is determined by bathymetric variations (see section 5.1 for discussion). 

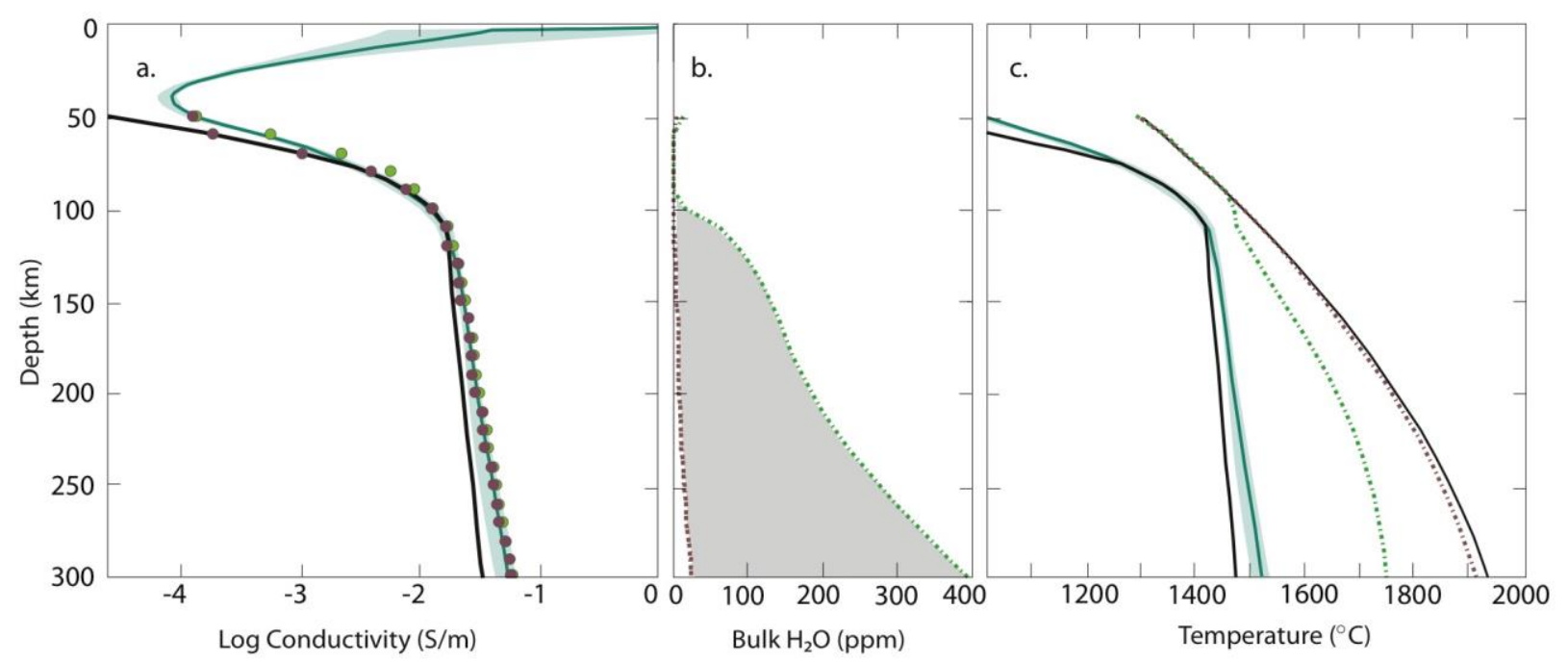

\section{Figure 7}

a. Shown is the observed NoMelt conductivity profile with depth (teal). The teal region indicates the maximum and minimum conductivity from the 2-D model (as in Figure 3). The conductivity calculated from the background thermal model (black), and the calculated conductivities of the two hydrated olivine models with depth in $10 \mathrm{~km}$ intervals (DK: purple dots; UHO: green dots). The plot shows how $\mathrm{H}_{2} \mathrm{O}$ increases the conductivity from the background thermal profile (black) to our observed profile (teal). b. The range of $\mathrm{H}_{2} \mathrm{O}$ estimates from both hydrous olivine models with depth for the NoMelt mantle (DK: purple dashed line; UHO: green dashed line; also see Table 2). The shaded region shows the possible bulk mantle $\mathrm{H}_{2} \mathrm{O}$. c. Shown are the thermal profiles as in Figure 6. Also shown are the nominally anhydrous solidus (solid thin black line) and the partially hydrated solidi calculated from the two hydration models (DK: purple dashed; UHO: green dashed). From the plot it is clear that our observed profile does not cross any solidus. Therefore for melt to be stable in the NoMelt mantle, $\mathrm{CO}_{2}$ would have to decrease the solidus temperature further than the partially hydrated solidi (see section 5.3 for explanation). 


\section{Table 1}

NoMelt MT station sites used in inversions and corresponding latitude, longitude, depth.

\begin{tabular}{cccc}
\hline Site & Latitude & Longitude & $\begin{array}{c}\text { Depth } \\
(\mathrm{m})\end{array}$ \\
\hline M01 & $8^{\circ} 45^{\prime} 03.630^{\prime \prime} \mathrm{N}$ & $147^{\circ} 59^{\prime} 44.687^{\prime \prime} \mathrm{W}$ & 5179 \\
M02 & $8^{\circ} 58^{\prime} 21.763^{\prime \prime} \mathrm{N}$ & $146^{\circ} 55^{\prime} 38.195^{\prime \prime} \mathrm{W}$ & 5226 \\
M04 & $9^{\circ} 24^{\prime} 30.586^{\prime \prime} \mathrm{N}$ & $144^{\circ} 47^{\prime} 16.039^{\prime \prime} \mathrm{W}$ & 5167 \\
M06 & $9^{\circ} 49^{\prime} 45.130^{\prime \prime} \mathrm{N}$ & $142^{\circ} 38^{\prime} 22.062^{\prime \prime} \mathrm{W}$ & 5181 \\
\hline
\end{tabular}




\section{Table 2}

Thermal, $\mathrm{H}_{2} \mathrm{O}$, and melt model results with depth

\begin{tabular}{|c|c|c|c|c|c|c|}
\hline $\begin{array}{c}\text { Depth } \\
(\mathrm{km})\end{array}$ & $\begin{array}{c}\text { Temperature } \\
\text { of Plate } \\
\text { Model with } \\
0.5^{\circ} \mathrm{C} / \mathrm{km} \\
\text { Gradient } \\
\left({ }^{\circ} \mathrm{C}\right)\end{array}$ & $\begin{array}{c}\text { Temperature } \\
\text { of Plate } \\
\text { Model with } \\
0.3^{\circ} \mathrm{C} / \mathrm{km} \\
\text { Gradient } \\
\left({ }^{\circ} \mathrm{C}\right)\end{array}$ & $\begin{array}{c}\text { Bulk Mantle } \\
\text { Water } \\
\text { Content } \\
\text { from DK } \\
\text { model } \\
(\mathrm{ppm})^{\mathrm{a}}\end{array}$ & $\begin{array}{l}\text { Bulk Mantle } \\
\text { Water } \\
\text { Content } \\
\text { from UHO } \\
\text { model } \\
(\mathrm{ppm})^{\mathrm{a}}\end{array}$ & $\begin{array}{c}\text { Melt Content } \\
\text { assuming DK } \\
\text { water content } \\
+100 \mathrm{ppm} \\
\mathrm{CO}_{2}(\mathrm{vol} \%)\end{array}$ & $\begin{array}{c}\text { Melt Content } \\
\text { assuming UHO } \\
\text { water content } \\
+100 \mathrm{ppm} \\
\mathrm{CO}_{2}(\mathrm{vol} \%)\end{array}$ \\
\hline 50 & 902 & 902 & $4(1)$ & $13(3)$ & 0.069 & 0.069 \\
\hline 60 & 1053 & 1053 & $0(0)$ & $0(0)$ & 0.073 & 0.073 \\
\hline 70 & 1196 & 1196 & $0(0)$ & $0(0)$ & 0.075 & 0.075 \\
\hline 80 & 1306 & 1306 & $0(0)$ & $0(0)$ & 0.075 & 0.075 \\
\hline 90 & 1360 & 1360 & $0(0)$ & $0(0)$ & 0.0096 & 0.0096 \\
\hline 100 & 1400 & 1400 & $0(0)$ & $16(4)$ & 0.065 & 0.015 \\
\hline 110 & 1424 & 1419 & $0(0)$ & $61(17)$ & 0.060 & 0.019 \\
\hline 120 & 1429 & 1422 & $0(0)$ & $84(24)$ & 0.058 & 0.058 \\
\hline 130 & 1434 & 1425 & $3(1)$ & $103(30)$ & 0.056 & 0.056 \\
\hline 140 & 1439 & 1428 & $3(1)$ & $118(35)$ & 0.054 & 0.024 \\
\hline 150 & 1444 & 1431 & $3(1)$ & $129(39)$ & 0.052 & 0.053 \\
\hline 160 & 1449 & 1434 & $7(2)$ & $141(43)$ & 0.052 & 0.028 \\
\hline 170 & 1454 & 1437 & $6(2)$ & $150(46)$ & 0.028 & 0.029 \\
\hline 180 & 1459 & 1440 & $6(2)$ & 159 (49) & 0.048 & 0.048 \\
\hline 190 & 1464 & 1443 & $6(2)$ & $172(53)$ & 0.045 & 0.045 \\
\hline 200 & 1469 & 1446 & $6(2)$ & $185(57)$ & 0.039 & 0.040 \\
\hline 210 & 1474 & 1449 & $10(3)$ & $199(61)$ & 0.039 & 0.040 \\
\hline 220 & 1479 & 1452 & $10(3)$ & $216(66)$ & 0.039 & 0.040 \\
\hline 230 & 1484 & 1455 & $10(3)$ & $234(71)$ & 0.039 & 0.040 \\
\hline 240 & 1489 & 1458 & $13(4)$ & $254(77)$ & 0.039 & 0.040 \\
\hline 250 & 1494 & 1461 & $13(4)$ & $276(83)$ & 0.039 & 0.040 \\
\hline 260 & 1499 & 1464 & $17(5)$ & $297(89)$ & 0.039 & 0.040 \\
\hline 270 & 1504 & 1467 & $17(5)$ & $321(96)$ & 0.039 & 0.040 \\
\hline 280 & 1509 & 1470 & $20(6)$ & 345 (103) & 0.039 & 0.040 \\
\hline 290 & 1514 & 1473 & $23(7)$ & $368(110)$ & 0.040 & 1.00 \\
\hline 300 & 1519 & 1476 & $23(7)$ & 394 (118) & 0.040 & 1.00 \\
\hline
\end{tabular}

a. Corresponding olivine water contents are listed in parentheses 


\section{Chapter 5}

\section{Imaging Precambrian lithospheric structure in Zambia using electromagnetic methods}

\subsection{Abstract}

The Precambrian geology of eastern Zambia and Malawi is highly complex due to multiple episodes of rifting and collision, particularly during the formation of Greater Gondwana as a product of the Neoproterozoic Pan-African Orogeny. The lithospheric structure and extent of known Precambrian tectonic entities of the region are poorly known as there have been to date few detailed geophysical studies to probe them. Herein, we present results from electromagnetic lithospheric imaging across Zambia into southern Malawi using the magnetotelluric method complemented by high-resolution aeromagnetic data of the upper crust in order to explore the extent and geometry of Precambrian structures in the region. We focus particularly on determining the extent of subcontinental lithospheric mantle (SCLM) beneath the ArcheanPaleoproterozoic cratonic Bangweulu Block, the Mesoproterozoic-Neoproterozoic Irumide and Southern Irumide Orogenic Belts, and the Neoproterozoic Lufilian Orogenic Belt. We also focus on imaging the boundaries between these tectonic entities, particularly the boundary between the Irumide and Southern Irumide Belts. The thickest and most resistive lithosphere is found beneath the Bangweulu Block as anticipated for stable cratonic lithosphere. Whereas the lithospheric thickness estimates beneath the Lufilian and Irumide Belts matches those determined for other orogenic belts, the Southern Irumide Belt lithosphere is substantially thicker rivaling that of the Bangweulu Block to the north. We interpret the thicker lithosphere beneath the Southern Irumide Belt as due to preservation of a cratonic nucleus (the pre-Mesoproterozoic Niassa Craton). A conductive mantle discontinuity is observed between the Irumide and Southern Irumide Belts directly beneath the Mwembeshi Shear Zone. We interpret this discontinuity as modified SCLM relating to a major suture zone. The lithospheric geometries determined from our study reveals tectonic features inferred from surficial studies and provide important details for the tectonothermal history of the region.

This chapter is submitted as: Emily Sarafian, Rob L. Evans, Mohamed G. Abdelsalam, Estella Atekwana, Jimmy Elsenbeck, Alan G. Jones, and Ezekiah Chikambwe, Imaging Precambrian lithospheric structure in Zambia using electromagnetic methods, Gondwana Research, March 19, 2017. 


\subsection{Introduction}

The assembly of the Greater Gondwana supercontinent at $\sim 600 \mathrm{Ma}$, following the breakup of Rodinia at $\sim 830 \mathrm{Ma}$, marks an important tectonic event in Earth history [Stern, 2008]. It is estimated that Neoproterozoic volcanism formed $\sim 20 \%$ of the continental crust that is currently preserved in the form of orogenic belts circling older cratonic fragments that collided to create Greater Gondwana [Maruyama and Liou, 1998]. Collision between different cratonic fragments at the end of the Neoproterozoic was accompanied by widespread remobilization (metacratonization) of either entire cratonic blocks or the cratonic margins [Abdelsalam et al., 2002; Liégeois et al., 2013].

There are substantial uncertainties in detailing the tectonic elements of the super-continent, especially the spatial distribution of cratonic fragments, the orogenic belts surrounding them, and the portions of the cratonic fragments that have been metacratonized. This is largely because many of the present-day fragments of Greater Gondwana are covered with Phanerozoic sedimentary rocks formed in large intra-continental sag basins [Artemieva and Mooney, 2001]. SCLM thickness varies between tectonic elements, with typical estimates of a few tens of kilometers beneath active rifts to $>250 \mathrm{~km}$ under certain cratons, though refertilization of old cratonic SCLM or cooling of young SCLM can cause delamination and thinning of the lithosphere [Begg et al., 2009; Khoza et al., 2013; Miensopust et al., 2011]. These lithospheric heterogeneities facilitated strain localization during Phanerozoic rifting [McConnell, 1972; Nyblade and Brazier, 2002], which further complicates the surface expression of the different Precambrian tectonic structures.

In Africa, which in many reconstructions is put as the heart of Greater Gondwana [Irving and Irving, 1982; Smith and Hallam, 1970], surface geological mapping, geochemical and geochronological studies together with low resolution seismic tomography [Abdelsalam et al., 2011; Begg et al., 2009; Deen et al., 2006; Lebedev et al., 2009; Pasyanos, 2010; Pasyanos and Nyblade, 2007; Ritsema and van Heijst, 2000; Shapiro and Ritzwoller, 2002] have resulted in establishing the extent of major cratons and orogenic belts of Greater Gondwana (Fig. 1A). However, identifying the geologic framework of Greater Gondwana is particularly difficult in the 
region between the Bangweulu Block in northern Zambia and the Zimbabwe craton to the south (Fig. 1B) because few detailed studies of lithospheric structure exist in this area.

In this paper, we present results from two-dimensional (2D) isotropic inversion of a NW-SE magnetotelluric (MT) regional profile collected across Zambia and southern Malawi (Figs. 1B and 2A). This regional profile crosses major Precambrian entities including the Bangweulu Block, the Irumide and Southern Irumide Orogenic Belts (separated by the Mwembeshi Shear Zone), and the Lufilian Orogenic Belt (Fig. 1B). MT maps the lateral and vertical subsurface resistivity structure, and is sensitive to variations in temperature, composition, and interconnected conductors, such as fluid, melt, or metals. As a result, MT is a powerful tool to investigate lithospheric structure [Evans et al., 2011; Alan G Jones, 1999; Khoza et al., 2013; Miensopust et al., 2011; Muller et al., 2009]. In addition to the mantle-probing MT data, we also use high-resolution aeromagnetic data over the Mwembeshi Shear Zone and surrounding Irumide and Southern Irumide Belts provided by the Geological Survey Department of Zambia to unveil the upper crustal structure (Fig. 3). The combination of electrical models derived from our MT data and high-resolution aeromagnetic data allows us to reveal the extent of the SCLM and improve our understanding of the Precambrian structures in the region - those obvious in surface geology, and those oblivious to surface geology as they are buried at depth. In particular, our work facilitates delineation between stable cratonic blocks with thick SCLM from those with thinned SCLM, possibly due to partial delamination and regional metacratonization, and provides detailed images of the lithospheric boundaries (suture zones) between different Precambrian entities. Before discussing the data, results, and geological implications of our study, we first define the key terms of craton and metacratons, and then briefly discuss the geological background and previous geophysical studies of the region of study.

\subsection{Cratons and Metacratons}

Cratons primarily occupy the interior of continental plates. They are Archean to Paleoproterozoic in age, and have been tectonically stable for long periods of time, possibly since the time of their formation, albeit with frequent modification in many cases due to influx of metasomatizing fluids. Such long-lasting stability is attributed to the presence of a thick, cold and mostly 
anhydrous SCLM beneath the cratonic continental crust [Peslier et al., 2010]. The thick, depleted nature of the SCLM makes it sufficiently buoyant to be isolated from the convecting mantle surrounding the cratonic keel [Arndt et al., 2009; Hirth et al., 2000; Pollack, 1986]. In Africa, examples of stable cratons (at least their interior portions) include the composite West African Craton, the composite Congo Craton, and the composite Kalahari Craton (Fig. 1A).

To explain the nature of the lithosphere in northern Africa, Abdelsalam et al. [2002] introduced the term Saharan 'metacraton' as 'a craton that has been remobilized during an orogenic event, but that is still recognizable predominantly through its rheological, geochronological, and isotopic characteristics'. In this definition, the prefix 'meta' abbreviates 'metamorphosis' in the general sense of the term and not in the restricted geological meaning of 'metamorphism'. Abdelsalam et al. [2011] proposed that partial SCLM delamination or convective removal of the cratonic root is the responsible mechanism for metacratonization. It has been suggested that metacratonization can also occur locally due to plate collision along the margins of cratons or the development of lithospheic-scale shear zones in the interior of cratons [De Waele et al., 2006b; Liégeois et al., 2013; Liégeois et al., 2003]. For example, De Waele et al. [2006b] and Liégeois et al. [2013] used the presence of Paleoproterozoic-Neoproterozoic high-K granitoids that intrude the Irumide Orogenic Belt in Zambia as evidence of multiple stages of metacratonization of the southern margin of the Archean-Paleoproterozoic cratonic Bangweulu Block. They determined that the Irumide represented the southern continuation of the Bangweulu Block before being metacratonized.

Liégeois et al. [2003] proposed that the development of major N-trending lithospheric-scale shear zones in the once intact cratonic block of the Hoggar in Algeria led to planar delamination of the SCLM resulting in zonal metacratonization leading to the present configuration of the Hoggar as interleaving $\mathrm{N}$-trending slivers of cratons and metacratons. This notion is further supported by MT imaging of part of the Tuageg Shield in southern Algeria where sub-vertical crustal-scale conductors were observed coincident with the surface exposure of major shear zones [Bouzid et al., 2015]. 


\subsection{Geological Setting}

The lithospheric structure beneath eastern Zambia and southern Malawi is poorly constrained, but surface geology indicates that the tectonic elements traversed by our MT profile include the Archean-Paleoproterozoic Bangweulu Block [De Waele et al., 2006b], the MesoproterozoicNeoproterozoic Irumide and Southern Irumide Orogenic Belts (separated by the Mwembeshi Shear Zone), and the Neoproterozoic Lufilian Orogenic Belt [De Waele et al., 2009; Johnson et al., 2006; Johnson et al., 2005; Westerhof et al., 2008]. In some publications, the central part of the Southern Irumide Orogenic Belt is shown to be occupied by a cratonic nucleus, referred to as the Niassa Craton (Fig. 1B) [Andreoli, 1984].

\subsubsection{The Bangweulu cratonic block}

The Bangweulu Block is a cratonic block to the SW of the Tanzania Craton that underlies most of northern Zambia (Fig. 1B). Early studies of the Bangweulu Block identified a crystalline basement of schist, metavolcanics, granitoids, and gneisses overlain by Neoproterozoic sedimentary cover. The metavolcanics and gneisses were dated to be Paleoproterozoic in age (1.84-1.72 Ga). However, the presence of $2.73 \mathrm{Ga}$ granites suggests that at least a portion of the Bangweulu Block is Neoarchean in age [Andersen and Unrug, 1984; Begg et al., 2009; Boniface and Schenk, 2012; De Waele et al., 2006b].

The Bangweulu Block is thus thought to be a Neoarchean microcontinent that was strongly affected by Paleoproterozoic tectonic events [Begg et al., 2009; De Waele et al., 2006b]. Prior to the Neoproteozoic Pan-African Orogeny, an ocean basin and magmatic arc separated the Tanzania Craton from the Bangweulu Block. Collision of the Bangweulu Block and Tanzania Craton at ca. 1.95 Ga formed the Ubendian Orogenic Belt (Fig. 1B) [Begg et al., 2009; Boniface

and Schenk, 2012]. Subsequently, at ca. $1.8 \mathrm{Ga}$, the Tanzania-Bangweulu Craton collided with the Congo Craton forming the composite Congo-Tanzania-Bangweulu Craton (CC in Fig. 1A). Towards the end of the formation of Greater Gondwana, the ocean basin separating the CongoTanzania-Bangweulu Craton and Kalahari Craton (the northern part of which is referred to as the Zimbabwe Craton; Fig. 1A and B) was subducted and the two cratons collided along the Damara-Lufilian-Zambezi Orogenic Belt (Fig. 1A) in the late Neoproterozoic - early Cambrian Damara-Lufilian-Zambezi Orogeny [Johnson et al., 2005]. 


\subsubsection{The Irumide and Southern Irumide Belt}

The Irumide and Southern Irumide Belts are thick-skinned fold and thrust belts (folding and thrusting involve both basement and cover) that lie to the SE of the Bangweulu Block and Lufilian Belt (Fig. 1) [Ackermann, 1950; Ackermann, 1960; Daly, 1986]. Detailed geochronological studies by De Waele et al. [2003; 2006a; 2006b; 2009] and [Johnson et al., 2005; 2006] established four lithotectonic units for the Irumide Belt. (1) Paleoproterozic (2.05$1.96 \mathrm{Ga})$ with minor Archean (2.7 Ga) crystalline granitic gneissic basement complex. (2) Paleoproterozoic (1.94 - $1.66 \mathrm{Ga})$ metasedimentary rocks (quartzites and meta-pelites. (3) Early Mesoproterozoic (1.66-1.52 Ga) granitoids. (4) Late Mesoproterozoic to early Neoproterozoic (1.05-0.95 Ga) granitoids. Similar geochemical and isotopic signature of different granitoid pulses in the southern edge of the Bangweulu Block and the Irumide Belt (2.05-1.95; 1.88-1.85; 1.65-1.55; and 1.05-0.95 Ga) and lack of juvenile subduction-related rocks in the Irumide Belt may indicate that the Irumide Belt is the southern margin of the Bangweulu Block that was metacratonized at 2.0, 1.85; 1.6 and $1.0 \mathrm{Ga}$ [De Waele et al., 2006a].

Johnson et al. [2005; 2006] determined that the Irumide and Southern Irumide Belt experienced different magmatic histories reflected by the lack of early Mesoproterozoic granitoids in the Southern Irumide Belt. They concluded that the crust underlying the Southern Irumide Belt is not the southward continuation of the crust of the Irumide Belt. Rather, it represents allochthonous continental arc terranes that collided with the Irumide Belt during the Mesoproterozoic Irumide Orogeny and was later reworked during the late Neoproterozoic - early Cambrian DamaraLufilian-Zambezi Orogeny (Fig. 1A and B). Johnson et al. [2006] suggested that the Irumide Belt and the Southern Irumide Belt are separated by a suture zone, possibly represented by the ENE-trending Mwembeshi Shear Zone (also referred to as the Mwembeshi dislocation, MSZ, Fig. 1B) that has segments buried beneath the Paleozoic-Mesozoic Luangwa Rift Zone. Johnson et al. [2007] go further to suggest that this suture zone formed as a result of a young, hot oceanic slab subducting beneath the Irumide Belt during the Irumide Orogeny. Additionally, the Southern Irumide Belt is thought to contain an elusive cratonic nucleus known as the Niassa Craton (Fig. 1B) [Andreoli, 1984; Daly, 1986]. This cratonic nucleus is believed to be Archean in age and covered by Paleoproterozoic sedimentary rocks and is therefore considered "lost" [De Waele et al., 2006a]. 


\subsubsection{The Lufilian Belt}

The Neoproterozoic Lufilian Belt is a fold and thrust belt that lies between the Bangweulu Block and Irumide Belt in our study region (Fig. 1B), but is a part of a network of orogenic belts in central Africa that includes the Zambezi and Damara Belts [Begg et al., 2009; Katongo et al., 2004; Porada and Berhorst, 2000]. The major units consist of a Paleoproterozoic basement (granite, schist, gneiss) overlain by mafic volcanics (730-770 Ma), granites/rhyolites (530-560 Ma), and a thick folded sedimentary cover [Johnson et al., 2005]. The Lufilian Belt formed during continental rifting at ca. $880 \mathrm{Ma}$, followed by subsequent collision of the CongoTanzania-Bangweulu Craton and Kalahari Craton at ca. 550 Ma. Neoproterozoic Pan-African deformation resulted in a major fault separating the Bangweulu Block and Lufilian Belt [Andersen and Unrug, 1984] with peak metamorphism occurring at 550-520 Ma [Johnson et al., $2005]$.

\subsection{Previous geophysical studies}

Few geophysical studies have focused directly on our study region resulting in poor resolution imaging of the lithospheric structure and uncertainties in the delineation of tectonic elements. In recent seismic work, O'Donnell et al. [2013] resolved the lithospheric shear-velocity structure in the region around the Tanzania Craton, including Zambia and Malawi, using a large teleseismic dataset from the AfricaArray East African stations. They found a high-velocity region in eastern Zambia coincident with the known Bangweulu Block, as well as low velocity regions in the northern and southern areas of the Lake Malawi Rift thought to be related to active rifting along the Western Branch of the East African Rift System (EARS). At depths less than $100 \mathrm{~km}$, the Bangweulu Block is the dominant high-velocity feature in Zambia. At greater depths, the dominant seismically fast feature migrates to the southeast into the Southern Irumide Belt. The deep, high velocity region in the Southern Irumide Belt is interpreted to be a subsurface extension of the Archean Bangweulu Block, with upwards of $200 \mathrm{~km}$ thick lithosphere [O'Donnell et al., 2013], which may be the expression of the inferred Niassa Craton. However, the lateral and particularly vertical resolution of this model is not high within Zambia and decreases with depth limiting the interpretation of lithospheric structure in the region and calling into question the true extent of the high velocity anomaly within the Southern Irumide Belt. 


\subsection{Data and Analysis}

\subsubsection{Aeromagnetic Data and Analysis}

The aeromagnetic data used in this study were acquired by Geometrics Inc. for the Geological Survey Department of Zambia between 1973-1976 with a mean terrain clearance of $150 \mathrm{~m}$ and mean line spacing of $800 \mathrm{~m}-1000 \mathrm{~m}$ in the N-S direction. The International Geomagnetic Reference Field (IGRF) [Thébault et al., 2015] was removed from the data. We applied the vertical derivative (vertical gradient) filter to the total magnetic field data to highlight the trends of the Precambrian regional structures in the Irumide and Southern Irumide Orogenic Belts, the Mwembeshi Shear Zone, and the southeastern extension of the Lufilian Orogenic Belt (Figs. 3A5A). Vertical derivative maps accentuate short-wavelength anomalies while attenuating the longwavelengths such that breaks, discontinuities, and rock fabric are highlighted.

Additionally, to enhance the ability to interpret the Precambrian structures, we also applied the tilt derivative filter developed by Miller and Singh [1994], Thurston and Smith [1997], Verduzco et al. [2004], Smith and Salem [2005], and Salem et al. [2007]. We derived the tilt derivative images by computing the ratio between the vertical derivative and horizontal derivative of the total field magnetic data (Figs. 3B-5B). In these images, the tilt angle defines the contacts between geological materials that have alternating high and low magnetic susceptibilities [Salem et al., 2007]. The calculated tilt angles range between $+90^{\circ}$ and $-90^{\circ}$ with the angle values with $(+)$ sign the steeper features (in this case the high features in Precambrian fabric) (Figs. 3C-5C). The angle values with (-) sign indicate the shallower structural features (Figs. 3D-5D). The tilt derivative has its zero values close to the edges of the body and is positive over the source and can resolve subtle deeper structures [Miller and Singh, 1994]. Therefore, the spatial images of the tilt map can be used to determine the approximate horizontal and lateral extent of features such as faults, geologic contacts, and edges of basins and uplifts.

\subsubsection{Magnetotelluric Data and Analysis}

MT data were collected in a profile of 36 broadband MT sites from northern Zambia into southern Malawi in 2012, with usable data provided from 32 stations (Figs. 1B and 2A). Stations 
were spaced $\sim 20 \mathrm{~km}$ apart in a roughly NW-SE trending profile, but were limited to existing roads and tracks, causing minor variability in station spacing. The MT traverse extends from the Bangweulu flats in northwestern Zambia (underlain by the Bangweulu Block and the Lufilian Orogenic Belt) across the Muchinga Mountains (where the Irumide Orogenic Belt is exposed on the northwestern footwall of the Luangwa Rift Valley), the Luangwa Rift Valley, and the flexural zone of the Luangwa Rift Valley (where the Mwembeshi Shear Zone and the Southern Irumide Orogenic Belt are exposed) to the Malawi Rift (Fig. 6A). Five component time series magnetotelluric data were recorded by a Phoenix Geophysics V5 System for 2-3 days over a period range of $\sim 0.003 \mathrm{~s}(384 \mathrm{~Hz})$ to several thousand seconds, yielding high quality responses that facilitates good resolution of lithospheric structure. At each site were measured naturally occurring two horizontal electric and three magnetic field variations in orthogonal components: $\mathrm{Hx}, \mathrm{Hy}, \mathrm{Hz}$, and Ex and Ey.

The MT time series were first processed by applying the robust techniques of Jones and Jödicke [1984] (Method 6 in Jones et al. [1989]) in the Phoenix Geophysics SSMT2000 processing software, and converted to apparent resistivities and phases. The approach employs the Least Trimmed Squares robust approach independently developed by Rousseeuw [1984]. Sites deployed simultaneously served as remote references during processing to reduce bias in the calculated response. The dimensionality of the data with depth was qualitatively determined using phase tensor analysis [Caldwell et al., 2004] at all period bands (Fig. 2B) and at four different period bands. Short periods sampling shallow depths indicate a 3D structure, and longer periods (deeper depths) suggest a less complex 2D mantle structure. The dominant geo-electric strike direction for each profile segment was determined using Groom-Bailey galvanic distortion decomposition [Groom and Bailey, 1989] using the multi-site, multi-frequency STRIKE software package [McNeice and Jones, 2001]. MT responses from sites along the western end of the profile were decomposed to a dominant geo-electric azimuth of $30 \mathrm{E}$ of N. Sites along the eastern end of the profile had a dominant strike perpendicular to the acquisition geometry (Fig. 2B).

Based on the strike and dimensionality analysis, the array was split into two profile segments in order to perform 2D inverse modeling of the electrical structure: the western Luangwa profile 
(WLUA) and the eastern Luangwa profile (ELUA) (Fig. 2A). Prior to inversion, scattered data points with high error bars in apparent resistivity, phase, and tipper were masked in order ensure that unreliable points were not influencing the inversions. In some cases, this resulted in the complete removal of one of the modes of response. Both profile segments were inverted for $2 \mathrm{D}$ isotropic electrical structure along profiles perpendicular to the geo-electric strike roughly following the acquisition profiles ( $30 \mathrm{~W}$ of $\mathrm{N}$ for WLUA and E-W for ELUA). Electrical models were generated by simultaneously inverting transverse electric (TE) and transverse magnetic (TM) apparent resistivities and phases, as well as vertical magnetic components (tipper), using a 2D regularized inversion scheme [Rodi and Mackie, 2001], as implemented in the WinGLink software package. Static shift in the apparent resistivities was inverted for during modeling. Topography was not considered in inversions. Assigned error floors were $10 \%$ and $15 \%$ on TM and TE apparent resistivity, respectively, $5 \%$ on phases, and an absolute error floor of 0.1 for tipper. Smoothing parameters in the inversion algorithm control overall model smoothness (tau, the Tikhonov trade-off parameter), and smoothness of horizontal and vertical features (alpha and beta) to obtain the smoothest model that minimized data misfit and produce continuous horizontal features without unnecessary structure. Tau values were varied between 100 and 0.01 to produce an L-curve in order to assess overfitting and over smoothing of the data. Based on our variations of the smoothing parameters, the final tau, alpha, and beta values used for these data were $1,1.5$, and 1.7 respectively. The preferred 2D isotropic resistivity models for the WLUA and ELUA profiles were derived from an initial $100 \Omega \mathrm{m}$ half-space starting model. Features produced during inversions were tested for sensitivity to ensure that the data required all features present in the final models. After hundreds of iterations, the final normalized root-mean-squared (nRMS) misfit for the WLUA and ELUA 2D electrical models were 1.81 and 1.73, respectively (Fig. 6B and 6C). Total nRMS misfit for each station, as well as the misfit of the two modes and tipper, is plotted above the resistivity models. Misfit is greatest in the easternmost sites along both the WLUA and ELUA profile, with the highest misfits concentrated in the stations close to the Malawi Rift (Fig. 6B). 


\subsection{Results}

\subsubsection{Aeromagnetic Results}

Interpretation of the aeromagnetic data maps yields the following features: The Luangwa Rift Valley is represented by broad magnetic anomalies indicative of sedimentary fill of the rift. The Precambrian fabric is represented by short wavelength magnetic anomalies represented by alternation of low and high amplitudes in the vertical derivative image (Fig. 3A), and alternation of low and high degrees in the tilt (Fig. 3B), positive tilt (Fig. 3C) and negative tilt images (Fig. 3D). Both the Lufilian and the Irumide Orogenic Belts are dominated by roughly NE-trending magnetic fabric (Figs. 3A-D) that is obvious in the positive and negative tilt images (Fig. 3C and D). The boundary between the Lufilian and the Irumide Orogenic Belts is marked by a sharp contrast in the amplitudes of the vertical derivative aeromagnetic image (Fig. 4A), but this boundary is not obvious in the tilt derivative or the positive and negative tilt images (Fig. 4B-D). This suggests that this boundary separates domains of different composition, but that have similar structural trends. In the southwest, the Mwembeshi Shear Zone is represented by a sharp magnetic lineament obvious in all aeromagnetic images (Fig. 3A-D). This lineament juxtaposes a western domain dominated by a more northerly magnetic fabric with a domain in the east dominated by NE-trending fabric. It is possible that the difference in the orientation of the magnetic fabric is due to the presence of the Irumide Orogenic Belt west of the shear and the Southern Irumide Orogenic Belt to the east of it. To the east of the Mwembeshi Shear Zone, the magnetic fabric changes into E-W trending (Fig. 3A-D) and this is where the northern edge of the Niassa Craton is mapped (Fig. 1B). In the northeast, the magnetic fabric suggests the presence of terrains of complex folding on both sides of the Mwembeshi Shear Zone (Fig. 5AD).

\subsubsection{Magnetotelluric Results}

\section{Western profile (WLUA)}

The electrical model of the WLUA profile shows the following features:

(1) A highly resistive feature $\left(>10^{3} \Omega \mathrm{m}\right)$ throughout the Bangweulu Block in the western and central portion of the profile to depths of $\sim 250 \mathrm{~km}$. 
(2) Higher resistivity (100s to $>10^{3} \Omega \mathrm{m}$ ) mantle to depths of $180 \mathrm{~km}$ in the Lufilian Belt at the eastern edge of the profile.

(3) Deep asthenospheric resistivities beneath the region have values of $<300 \Omega \mathrm{m}$.

In order to test the resolution and robustness of the observed features in the WLUA model, we manually edited the model and then ran a forward model, as well as additional inversion sequences. Due to static shift effecting the apparent resistivity responses, we compare the phase responses of the forward model to the observed phases, and critique the misfit at individual sites. Differences in phase between the forward model and the observed data, as well as the final model and observed data, were calculated in pseudosections.

Our tests of each feature involved:

(1) Decreasing the resistivity at depth below the Bangweulu Block.

Thinning the resistive root beneath the Bangweulu Block to $180 \mathrm{~km}$ resulted in poor fit to the TE $\left(6\right.$ to $\left.10^{\circ}\right)$ and $\mathrm{TM}\left(3\right.$ to $\left.>10^{\circ}\right)$ phases at the longest periods in all sites. The preferred model TE and TM fit phases at all periods generally within $2^{\circ}$ in the region of the Bangweulu Block. The systematic misfit, particularly in the TM phases, indicates that a feature is required by data but is not being modeled if the resistivity below the Bangweulu Block is decreased. Thus, the resistive root is a robust feature.

(2) Increasing the depth of resistive mantle below the Lufilian Belt to $200 \mathrm{~km}$.

Forcing the mantle beneath the Lufilian Belt to be more resistive by extending the resistive root of the Bangweulu Block resulted in higher misfit in the TM phase $\left(>7^{\circ}\right)$ in the mid period range for sites W19 to W16 with highest misfit in the phase of site W16. The TE phase is less sensitive to the change in resistivity ( 3 to $7^{\circ}$ difference). Again, the preferred model TE and TM fit phases at all periods generally within $2^{\circ}$ beneath the Lufilian Belt. The increase in misfit of the phases indicates that the Lufilian SCLM does not extend to greater depths.

\section{Eastern profile (ELUA)}

The electrical model of the ELUA profile shows the following features: 
(1) Resistive mantle $\left(>10^{3} \Omega \mathrm{m}\right)$ that is $\sim 150 \mathrm{~km}$ thick in the Irumide Belt on the western end of the profile.

(2) A highly conductive crust and broad conductive feature $(<100 \Omega \mathrm{m})$ present throughout the mantle beneath sites E6-E8 within the Mwembeshi Shear Zone and dipping to the west beneath sites E10-E14.

(3) A resistive anomaly $\left(\sim 10^{3} \Omega \mathrm{m}\right)$ beneath the conductive crust of the Southern Irumide Belt that persists to depths of $250 \mathrm{~km}$.

(4) A highly conductive crust $(\sim 1 \Omega \mathrm{m})$ in the eastern end of the profile in Malawi.

(5) Crustal and asthenosphere resistivities are much lower throughout the ELUA profile than the WLUA profile.

Similar tests were conducted to investigate the extent of observed features in the ELUA model. Our tests of each feature involved:

(1) Manually editing the depth of high resistivity in the Irumide Belt mantle.

Increasing the depth of the SCLM of the Irumide Belt to $200 \mathrm{~km}$ resulted in poor fit to the observed TM phases $\left(>6^{\circ}\right)$ at the longest periods for sites E14 to E10. The TE phases were not sensitive to the change in resistivity. The preferred model TE and TM fit phases at all periods generally within $3^{\circ}$. The systematic misfit in the TM phases, particularly for site E10, shows that a dipping conductive feature beneath the Irumide Belt is required by data.

(2) Increasing crust and upper mantle resistivities between the Irumide and Southern Irumide Belts.

The high conductivities found in the crust beneath sites E5-E8 provide an electromagnetic shielding effect resulting in little to no resolution for the underlying mantle structure. Therefore, it is difficult to test if the broad conducting feature beneath sites E6-E8 is a required structural feature or simply a result of spatial smoothing of crustal conductivities during inversion. In order to test data sensitivity to such feature, we increased the lower crust and upper mantle resistivities to smooth the resistivities between sites E4 and E10. The TE and TM phase misfit for site E10 increased over all periods $\left(>6^{\circ}\right)$ as a result of the higher resistivities. The phases for sites E6-E8 were less sensitive to the change, with only a slight increase in TM phase misfit for the longest periods. The preferred model TE and TM fit phases at all periods generally within $5^{\circ}$. These observations might suggest that the upper mantle beneath sites E6-E8 could be more resistive 
than modeled. However, the high phase difference between the forward response and the observed data at site E10, in addition to the high misfit associated with increasing the mantle resistivity from test (1), show that the manually edited model lacks a dipping conductive feature required by the data. Therefore, the sites directly above the highly conductive crust are not the only constraints for the dipping conductive feature observed. This prompted further sensitivity tests of this feature including extensive inverse modeling with high tau smoothness values to produce the smoothest model, and inversions with high horizontal smoothing (alpha) to ensure that vertical smearing of the crustal conductor is not a contributor to the observed structure. We also conducted inversions that solved for the model closest to the starting model after manually increasing the lithospheric resistivities beneath sites E4-10. The dipping conductive feature was present in the final models of all additional sensitivity tests. We, therefore, find that a region of dipping moderate conductivity most likely extends throughout the entire mantle between the Irumide and Southern Irumide Belts.

(3) Decreasing the depth of high resistivities beneath the Southern Irumide Belt.

Thinning the resistive root beneath the Southern Irumide Belt at sites M2-E5 to $150 \mathrm{~km}$ resulted in poor fit to the TM phases $\left(>7^{\circ}\right)$ at the longest periods in sites E2-E4. The preferred model TE and TM fit phases at all periods generally within $5^{\circ}$ in the region. The systematic misfit, particularly in the TM phases, indicates that the resistive root is required by the MT data.

(4) Increasing crustal resistivities within Malawi.

Forcing higher resistivities sacrificed the misfit to the TE and TM phases at all periods $\left(>10^{\circ}\right)$ for sites M5-M9. The preferred model TE and TM fit phases at all periods generally within $3^{\circ}$ in the region. Therefore, the high conductivity upper crust is a robust feature in the model.

Subsequent inversions of each test for WLUA and ELUA removed the manual edits to each feature. Our sensitivity testing shows that all features in the WLUA and ELUA electrical conductivity models are supported by the data. 


\subsection{Discussion}

\subsubsection{WLUA Precambrian Lithospheric Structure}

Based on geological maps of the region, the WLUA profile traverses southeast from the border between Zambia and the Democratic Republic of Congo toward the Luangwa Rift Valley, with the majority of the profile crossing the Bangweulu Block and the remainder over the Lufilian Belt (Fig. 1B). O'Donnell et al. [2013] found that at a depth of $68 \mathrm{~km}$, the Bangweulu Block is seismically fast $\left(\mathrm{V}_{\mathrm{S}}>4.6 \mathrm{~km} \mathrm{~s}^{-1}\right)$ with slower shear velocities $\left(\mathrm{V}_{\mathrm{S}} \sim 4.4-4.5 \mathrm{~km} \mathrm{~s}^{-1}\right)$ in the Lufilian Belt. The fast shear velocity anomaly migrates SE with increasing depth until $140 \mathrm{~km}$ where shear wave speeds start to decrease to $\sim 4.5 \mathrm{~km} \mathrm{~s}^{-1}$. Based on these observations, O'Donnell et al. [2013] concluded that the lithosphere of the Bangweulu Block extends to a depth of $100 \mathrm{~km}$ in this region.

Our electrical model agrees well with the observed seismic structure, but provides a more detailed view of the Precambrian lithospheric structure (Fig. 6C and D). The majority of the profile shows a thick highly resistive block that reaches a maximum thickness of $\sim 250 \mathrm{~km}$ in the geographical extent of the Bangweulu Block. The resistivities of this feature range from 100s to well over 10,000 $\Omega \mathrm{m}$ requiring an anhydrous, cold SCLM. Our results suggest that the Bangweulu Block SCLM is significantly thicker than $100 \mathrm{~km}$ in this region and reaches lithospheric thicknesses rivaling that of the Tanzania Craton [Adams et al., 2012; O'Donnell et al., 2013, 140-200 km], Kaapvaal Craton [Muller et al., 2009, 200 km; Evans et al., 2011, 230 $\mathrm{km}$ ], and Zimbabwe Craton [Miensopust et al., 2011, 220 km]. Such thick SCLM supports the interpretation that the Bangweulu Block is a cratonic fragment.

On the eastern edge of the WLUA profile, the resistive mantle thins to $180 \mathrm{~km}$ depth, suggesting that the Lufilian Belt SCLM is thinner than the SCLM beneath the Bangweulu Block and is typical for the SCLM of an orogenic belt [Khoza et al., 2013; Miensopust et al., 2011; Muller et al., 2009]. The resistivities of this feature range from 100 s to well over $10,000 \Omega \mathrm{m}$ requiring an anhydrous, cold SCLM. Our electrical conductivity model would better agree with high shear wave velocities than observed in the Lufilian Belt [O'Donnell et al., 2013]. 


\subsubsection{ELUA Precambrian Lithospheric Structure}

The ELUA profile extends from the Irumide Belt in the NW, over the Luangwa Rift Valley and Mwembeshi Shear Zone, and into the Southern Irumide Belt ending at the western edge of the Malawi Rift (Fig. 1B). The shear wave velocity at $68 \mathrm{~km}$ depth in the O'Donnell et al. [2013] model for this region is slow $\left(\mathrm{V}_{\mathrm{S}} \sim 4.4-4.5 \mathrm{~km} \mathrm{~s}^{-1}\right)$ relative to the Bangweulu Block to the NW. Velocity increases at greater depths within Zambia until $200 \mathrm{~km}$, but remains relatively slow near the southern end of the Malawi Rift. This structure is interpreted to be a subsurface extension of the Bangweulu Block into eastern Zambia between 100 and $200 \mathrm{~km}$ depth [O'Donnell et al., 2013].

The $\sim 150 \mathrm{~km}$ thick resistive feature in the western end of the profile lies within the Irumide Belt. Resistivities of this feature range from $\sim 80 \Omega \mathrm{m}$ to over $10,000 \Omega \mathrm{m}$, but are generally greater than $5,000 \Omega \mathrm{m}$ indicative of cold, anhydrous SCLM. This lithospheric thickness is typical for orogenic belts [Khoza et al., 2013; Miensopust et al., 2011; Muller et al., 2009], which, taken by itself, supports the notion that the Irumide Belt formed entirely during the Irumide Orogeny of the late Mesoproterozoic - Neoproterozoic age. However, U-Pb geochronology on detrital zircons from the Irumide Belt shows that it is primarily Paleoproterozoic in age with signatures of Neoarchean crust components, similar to the Bangweulu Block [De Waele et al., 2009]. In fact, geochronological evidence suggests that the Bangweulu Block was once a larger craton, but multiple metacratonization events along its southern margin diminished its size and formed the Irumide Belt [De Waele et al., 2009; De Waele et al., 2006a; De Waele et al., 2006b]. With this in mind, the Irumide Belt may have had thicker cratonic lithosphere at one time, but it was partially delaminated [Liégeois et al., 2013] resulting in the lithospheric structure observed in our electrical model. Based on this interpretation, we identify the resistive feature in the western part of ELUA to be the Irumide Metacraton (Fig. 6D).

Just east of the Irumide Metacraton is a broad, moderately conductive feature of $\sim 80 \Omega \mathrm{m}$ dipping to the west beneath the Irumide Belt that persists throughout the lithosphere and into the asthenosphere. The near surface crust above the feature is highly conductive $(\sim 1 \Omega \mathrm{m})$. Similar crustal conductors have been observed along shear and suture zones. This feature coincides with the Mwembeshi Shear Zone and Luangwa Rift Valley that separates the Irumide and Southern 
Irumide Belts [Westerhof et al., 2008]. The Mwembeshi Shear Zone has a distinct magnetic fabric (ductile northeast-trending fabric) that is easily recognized on the vertical and tilt derivative maps and underlies stations E5-E7. These near surface conductive anomalies are generally interpreted as graphite and sulfides that experienced shear and metamorphism, such as during subduction [Bouzid et al., 2015; Jones et al., 2005; Wannamaker, 2005; Yang et al., 2015]. The extent of the Mwembeshi Shear Zone into the mantle (Fig. 6C and D) has never before been imaged, but similar mantle features have been observed in regions of ancient subduction [Yang et al., 2015]. Our electrical conductivity model testing show that the resistivity of the upper mantle directly beneath the near surface conductivity anomaly is less resolved. However, the longer periods of sites to the west require the dipping conductive feature at greater depths beneath the Irumide Metacraton. Therefore, based on our electrical conductivity model testing, the shear zone extends throughout the mantle and separates the lithosphere of the Irumide Metacraton from the lithosphere of the Southern Irumide Belt and most likely represents a suture zone. This interpretation is further supported by the variations in magnetic fabric observed in the aeromagnetic data over the Mwembeshi Shear Zone (Fig. 3). The suture zone most likely formed during the Irumide Orogeny in the Mesoproterozoic when the two lithospheric fragments collided as the oceanic slab subducted beneath the Irumide Belt [Johnson et al., 2006; Johnson et al., 2007]. The higher conductivity of the mantle in this feature may be due to conductive phases, such as carbon or sulfides, being carried to great depths during subduction [Yang et al., 2015], or as a result of mineral shearing [Pommier et al., 2015] during subduction in the Irumide Orogeny or during reworking in the Damara-Lufilian-Zambezi Orogeny. The presence of such a strong lithospheric discontinuity may have allowed for the percolation of fluids into the lithosphere resulting in metasomatization and assisting the delamination of the SCLM beneath the Irumide Belt, forming the Irumide Metacraton [Liégeois et al., 2013].

The Southern Irumide Belt is covered by the central portion of the ELUA profile (Fig. 1B). The electrical conductivity model shows a more conductive crust (resistivities as low as $1 \Omega \mathrm{m}$ ) of $\sim 40 \mathrm{~km}$ thickness than found within the Irumide Metacraton. Beneath the crust is a highly resistive anomaly ranging from 100 s to several $1000 \Omega \mathrm{m}$ that persists to depths of $250 \mathrm{~km}$ (Fig. $6 \mathrm{C}$ and D). As previously discussed, the Southern Irumide Belt is thought to have a cratonic 
nucleus that is "lost" beneath the surface sedimentary cover and episodes of rifting [Andreoli, 1984]. The resistive anomaly observed in our electrical conductivity model is similar in thickness to the Bangweulu Block in the northwest. The observed resistivity and thickness most likely represents a cold, anhydrous cratonic SCLM. A seismically fast shear wave feature was identified at approximately the same depths in southeastern Zambia as our resistive anomaly, and was interpreted to be a southern subsurface continuation of the Bangweulu Block [O'Donnell et $a l ., 2013]$. However, our conductivity model clearly shows a suture zone between the Irumide Metacraton and Southern Irumide Belt. We therefore believe that this resistive anomaly is a cratonic block separate from the Bangweulu Block and identify it to be the Niassa Craton. Arcuate shaped magnetic fabrics beneath stations E4-E1 on the vertical and tilt derivative maps are coincident with the edges of this craton at depth (Fig. 3). This interpretation does not match seismic results as well as for the WLUA profile, which may be a resolution issue. O'Donnell et al. [2013] greatly refined the Zambian lithospheric structure, but still focused on a broad area around the Tanzania Craton. Resolution tests of their data show that, at the depths of interest, features in eastern Zambia are significantly smeared. Therefore, as a result of the extent of their study region the seismic model may have smoothed the Niassa Craton such that it remained indistinguishable from the lithosphere of the Irumide and Bangweulu Block to the northwest.

In Malawi, the electrical model shows a very conductive shallow crust with resistivities around 1 $\Omega \mathrm{m}$ (Fig. 6C and D). Resistivities of the mantle below this feature cannot be resolved due to electromagnetic shielding and are instead defined by vertical smoothing during inversion [Jones, 1999]. The lower resistivities near the Malawi Rift are in agreement with the slower shear wave velocity observed in seismic results [O'Donnell et al., 2013], and may be related to rifting in the Western Branch of the EARS producing a much warmer lithosphere. However, our model misfit is highest in this region suggesting that resolution is limited.

The crustal layer continues throughout much of the ELUA model, but particularly in the Mwembeshi Suture Zone, Southern Irumide Belt (Niassa Craton), and Malawi Rift are characterized by sub-horizontal layers of conductive anomalies. It is possible that these represent fluids exploiting crustal scale detachment faults. This is in good agreement with S Johnson et al. 
[2006; 2007] who suggested that the Southern Irumide is composed of allochthonous continental margin terranes assembled during the Irumide Orogeny.

\subsection{Conclusions}

We have employed analysis of deep-probing magnetotelluric (MT) data and aeromagnetic data to gain insight into the lithospheric structure of the Precambrian entities of eastern Zambia and southern Malawi, which include the Archean-Paleoproterozoic cratonic Bangweulu Block, the Mesoproterozoic-Neoproterozoic Irumide and Southern Irumide Orogenic Belts, and the Neoproterozoic Lufilian Orogenic Belt. We find that the lithosphere beneath the Bangweulu Block is highly resistive to a depth of order $250 \mathrm{~km}$, consistent with lithospheric thicknesses of other cratonic blocks in southern Africa and worldwide. The Lufilian and Irumide Belt lithosphere reaches a depth of 150-180 km, typical of orogenic belts throughout southern Africa. The Irumide Belt is not as resistive as that of the Bangweulu Block suggesting partial SCLM modification. Using published geochronological data as constraints, we interpret the observed MT structure beneath the Irumide Belt as thinning of a cratonic SCLM, possibly through partial delamination by the Mwembeshi Shear Zone that is clearly identifiable by its distinct magnetic fabric. We propose to rename the Irumide Orogenic Belt the Irumide Metacraton. We find moderately resistive lithosphere beneath the Southern Irumide Belt extending to a depth of 250 $\mathrm{km}$. This corroborates the inferred presence of the Niassa Craton - a cratonic nucleus inferred from early surface geology studies. In addition, our models reveal a broad mantle discontinuity at the boundaries between the Irumide Metacraton and the Niassa Craton. We interpret this as SCLM modification along a lithospheric suture zone as a result of ancient subduction.

\subsection{Acknowledgements}

We thank the reviewers.... Funding for this research was provided by the National Science Foundation, grant number EAR-1010432 through the Continental Dynamics Program and EAR1255233. The results presented in this paper rely on data collected at magnetic observatories. We

thank the national institutes that support them and INTERMAGNET for promoting high standards of magnetic observatory practice (www.intermagnet.org). The aeromagnetic data used 
in this study can be obtained from the Geological Survey Department of Zambia. We thank Richard Sullivan, Trevor Harrison for MT instrument deployment, and the Geological Survey Department of Zambia for MT instrument deployment and aeromagnetic data collection. This is the Boone Pickens School of Geology contribution \#2017-xx. 


\subsection{References}

Abdelsalam, M. G., S. S. Gao, and J.-P. Liégeois (2011), Upper mantle structure of the Saharan Metacraton, Journal of African Earth Sciences, 60(5), 328-336, doi:10.1016/j.jafrearsci.2011.03.009.

Abdelsalam, M. G., J.-P. Liégeois, and R. J. Stern (2002), The saharan metacraton, Journal of African Earth Sciences, 34(3), 119-136, doi:10.1016/S0899-5362(02)00013-1.

Ackermann, E. (1950), Ein neuer Faltengürtel in Nordrhodesien und seine tektonische Stellung im afrikanischen Grundgebirge, Geologische Rundschau, 38(1), 24-39.

Ackermann, E. (1960), Strukturen im Untergrund eines interkratonischen Doppel-Orogens (Irumiden, Nordrhodesien), Geologische Rundschau, 50(1), 538-553, doi:10.1007/BF01786869.

Adams, A., A. Nyblade, and D. Weeraratne (2012), Upper mantle shear wave velocity structure beneath the East African plateau: evidence for a deep, plateauwide low velocity anomaly, Geophysical Journal International, 189(1), 123-142, doi:10.1111/j.1365246X.2012.05373.x.

Andersen, L., and R. Unrug (1984), Geodynamic evolution of the Bangweulu Block, northern Zambia, Precambrian Research, 25(1), 187-212, doi:10.1016/0301-9268(84)90032-9.

Andreoli, M. A. G. (1984), Petrochemistry, tectonic evolution and metasomatic mineralisations of Mozambique belt granulites from S. Malawi and Tete (Mozambique), Precambrian Research, 25, 161-186, doi:10.1016/0301-9268(84)90031-7.

Arndt, N., N. Coltice, H. Helmstaedt, and M. Gregoire (2009), Origin of Archean subcontinental lithospheric mantle: Some petrological constraints, Lithos, 109(1), 61-71, doi:10.1016/j.lithos.2008.10.019.

Artemieva, I. M., and W. D. Mooney (2001), Thermal thickness and evolution of Precambrian lithosphere: a global study, Journal of Geophysical Research: Solid Earth, 106(B8), $16387-$ 16414, doi:10.1029/2000JB900439.

Begg, G., W. Griffin, L. Natapov, S. Y. O'Reilly, S. Grand, C. O'Neill, J. Hronsky, Y. P. Djomani, C. Swain, and T. Deen (2009), The lithospheric architecture of Africa: Seismic tomography, mantle petrology, and tectonic evolution, Geosphere, 5(1), 23-50, doi:10.1130/GES00179.1.

Boniface, N., and V. Schenk (2012), Neoproterozoic eclogites in the Paleoproterozoic Ubendian Belt of Tanzania: evidence for a Pan-African suture between the Bangweulu Block and the Tanzania Craton, Precambrian Research, 208, 72-89, doi:10.1016/j.precamres.2012.03.014.

Bouzid, A., B. Bayou, J.-P. Liégeois, S. Bourouis, S. S. Bougchiche, A. Bendekken, A. Abtout, W. Boukhlouf, and A. Ouabadi (2015), Lithospheric structure of the Atakor metacratonic volcanic swell (Hoggar, Tuareg Shield, southern Algeria): Electrical constraints from 
magnetotelluric data, Geological Society of America Special Papers, 514, SPE514-515, doi:10.1130/2015.2514(15).

Caldwell, T. G., H. M. Bibby, and C. Brown (2004), The magnetotelluric phase tensor, Geophysical Journal International, 158(2), 457-469.

Daly, M. (1986), The intracratonic Irumide belt of Zambia and its bearing on collision orogeny during the Proterozoic of Africa, Geological Society, London, Special Publications, 19(1), 321-328.

De Waele, B., I. Fitzsimons, M. Wingate, F. Tembo, B. Mapani, and E. Belousova (2009), The geochronological framework of the Irumide Belt: a prolonged crustal history along the margin of the Bangweulu Craton, American Journal of Science, 309(2), 132-187, doi:10.2475/02.2009.03.

De Waele, B., A. Kampunzu, B. Mapani, and F. Tembo (2006a), The Mesoproterozoic Irumide belt of Zambia, Journal of African Earth Sciences, 46(1), 36-70, doi:10.1016/j.jafrearsci.2006.01.018.

De Waele, B., J.-P. Liégeois, A. A. Nemchin, and F. Tembo (2006b), Isotopic and geochemical evidence of Proterozoic episodic crustal reworking within the Irumide Belt of south-central Africa, the southern metacratonic boundary of an Archaean Bangweulu Craton, Precambrian Research, 148(3), 225-256, doi:10.1016/j.precamres.2006.05.006.

De Waele, B., M. T. Wingate, I. C. Fitzsimons, and B. S. Mapani (2003), Untying the Kibaran knot: A reassessment of Mesoproterozoic correlations in southern Africa based on SHRIMP $\mathrm{U}-\mathrm{Pb}$ data from the Irumide belt, Geology, 31(6), 509-512, doi:10.1130/0091-7613(2003) 031<0509:UTKKAR>2.0.CO;2.

Deen, T. J., W. Griffin, G. Begg, S. Y. O'Reilly, L. Natapov, and J. Hronsky (2006), Thermal and compositional structure of the subcontinental lithospheric mantle: Derivation from shear wave seismic tomography, Geochemistry, Geophysics, Geosystems, 7(7), doi:10.1029/2005GC001120.

Evans, R. L., et al. (2011), Electrical lithosphere beneath the Kaapvaal craton, southern Africa, Journal of Geophysical Research, 116(B4), doi:10.1029/2010jb007883.

Groom, R. W., and R. C. Bailey (1989), Decomposition of magnetotelluric impedance tensors in the presence of local three-dimensional galvanic distortion, Journal of Geophysical Research: Solid Earth, 94(B2), 1913-1925, doi:10.1029/JB094iB02p01913.

Hirth, G., R. L. Evans, and A. D. Chave (2000), Comparison of continental and oceanic mantle electrical conductivity: Is the Archean lithosphere dry?, Geochemistry, Geophysics, Geosystems, 1(12).

Irving, E., and G. Irving (1982), Apparent polar wander paths Carboniferous through Cenozoic and the assembly of Gondwana, Geophysical Surveys, 5(2), 141-188, doi:10.1007/BF01453983. 
Johnson, S., B. De Waele, and K. Liyungu (2006), U-Pb sensitive high-resolution ion microprobe (SHRIMP) zircon geochronology of granitoid rocks in eastern Zambia: Terrane subdivision of the Mesoproterozoic Southern Irumide Belt, Tectonics, 25(6), doi:10.1029/2006TC001977.

Johnson, S. P., B. De Waele, F. Tembo, C. Katongo, K. Tani, Q. Chang, T. Iizuka, and D. Dunkley (2007), Geochemistry, geochronology and isotopic evolution of the CheworeRufunsa Terrane, Southern Irumide Belt: a Mesoproterozoic continental margin arc, Journal of Petrology, doi:10.1093/petrology/egm025.

Johnson, S. P., T. Rivers, and B. De Waele (2005), A review of the Mesoproterozoic to early Palaeozoic magmatic and tectonothermal history of south-central Africa: implications for Rodinia and Gondwana, Journal of the Geological Society, 162(3), 433-450, doi:10.1144/0016-764904-028.

Jones, A. G. (1999), Imaging the continental upper mantle using electromagnetic methods, Lithos, 48(1), 57-80, doi:10.1016/S0024-4937(99)00022-5.

Jones, A. G., A. D. Chave, G. Egbert, D. Auld, and K. Bahr (1989), A comparison of techniques for magnetotelluric response function estimation, Journal of Geophysical Research, 94(B10), 14201, doi:10.1029/JB094iB10p14201.

Jones, A. G., and H. Jödicke (1984), Magnetotelluric transfer function estimation improvement by a coherence-based rejection technique, in SEG Technical Program Expanded Abstracts 1984, edited, pp. 51-55, Society of Exploration Geophysicists, doi:10.1190/1.1894081

Jones, A. G., J. Ledo, and I. J. Ferguson (2005), Electromagnetic images of the Trans-Hudson orogen: the North American Central Plains anomaly revealed, Canadian Journal of Earth Sciences, 42(4), 457-478, doi:10.1139/e05-018.

Katongo, C., F. Koller, U. Kloetzli, C. Koeberl, F. Tembo, and B. De Waele (2004), Petrography, geochemistry, and geochronology of granitoid rocks in the NeoproterozoicPaleozoic Lufilian-Zambezi belt, Zambia: Implications for tectonic setting and regional correlation, Journal of African Earth Sciences, 40(5), 219-244, doi:10.1016/j.jafrearsci.2004.12.007.

Khoza, D., A. Jones, M. Muller, R. Evans, S. Webb, and M. Miensopust (2013), Tectonic model of the Limpopo belt: Constraints from magnetotelluric data, Precambrian Research, 226, 143-156, doi:10.1016/j.precamres.2012.11.016.

Lebedev, S., J. Boonen, and J. Trampert (2009), Seismic structure of Precambrian lithosphere: New constraints from broad-band surface-wave dispersion, Lithos, 109(1), 96-111, doi:10.1016/j.lithos.2008.06.010.

Liégeois, J.-P., M. G. Abdelsalam, N. Ennih, and A. Ouabadi (2013), Metacraton: nature, genesis and behavior, Gondwana Research, 23(1), 220-237, doi:10.1016/j.gr.2012.02.016.

Liégeois, J. P., L. Latouche, M. Boughrara, J. Navez, and M. Guiraud (2003), The LATEA metacraton (Central Hoggar, Tuareg shield, Algeria): behaviour of an old passive margin 
during the Pan-African orogeny, Journal of African Earth Sciences, 37(3), 161-190, doi:10.1016/j.jafrearsci.2003.05.004.

Maruyama, S., and J. Liou (1998), Initiation of ultrahigh-pressure metamorphism and its significance on the Proterozoic-Phanerozoic boundary, Island Arc, 7(1-2), 6-35, doi:10.1046/j.1440-1738.1998.00181.x.

McConnell, R. (1972), Geological development of the rift system of eastern Africa, Geological Society of America Bulletin, 83(9), 2549-2572, doi:10.1130/00167606(1972)83[2549:GDOTRS]2.0.CO;2.

McNeice, G. W., and A. G. Jones (2001), Multisite, multifrequency tensor decomposition of magnetotelluric data, Geophysics, 66(1), 158-173, doi:10.1190/1.1444891.

Miensopust, M. P., A. G. Jones, M. R. Muller, X. Garcia, and R. L. Evans (2011), Lithospheric structures and Precambrian terrane boundaries in northeastern Botswana revealed through magnetotelluric profiling as part of the Southern African Magnetotelluric Experiment, Journal of Geophysical Research, 116(B2), doi:10.1029/2010jb007740.

Miller, H.G., and V. Singh, (1994), Potential field tilt - a new concept for location of potential field sources, Journal of Applied Geophysics 32, 213-217.

Muller, M. R., et al. (2009), Lithospheric structure, evolution and diamond prospectivity of the Rehoboth Terrane and western Kaapvaal Craton, southern Africa: Constraints from broadband magnetotellurics, Lithos, 112, 93-105, doi:10.1016/j.lithos.2009.06.023.

Nyblade, A. A., and R. A. Brazier (2002), Precambrian lithospheric controls on the development of the East African rift system, Geology, 30(8), 755-758, doi:10.1130/0091-7613(2002) 030<0755:PLCOTD $>2.0 . C O ; 2$.

O’Donnell, J., A. Adams, A. Nyblade, G. Mulibo, and F. Tugume (2013), The uppermost mantle shear wave velocity structure of eastern Africa from Rayleigh wave tomography: constraints on rift evolution, Geophysical Journal International, 194(2), 961-978, doi:10.1093/gji/ggt135.

Pasyanos, M. E. (2010), Lithospheric thickness modeled from long-period surface wave dispersion, Tectonophysics, 481(1), 38-50, doi:10.1016/j.tecto.2009.02.023.

Pasyanos, M. E., and A. A. Nyblade (2007), A top to bottom lithospheric study of Africa and Arabia, Tectonophysics, 444(1), 27-44, doi:10.1016/j.tecto.2007.07.008.

Peslier, A. H., A. B. Woodland, D. R. Bell, and M. Lazarov (2010), Olivine water contents in the continental lithosphere and the longevity of cratons, Nature, 467(7311), 78-81, doi:10.1038/nature09317.

Pollack, H. N. (1986), Cratonization and thermal evolution of the mantle, Earth and Planetary Science Letters, 80(1-2), 175-182, doi:/10.1016/0012-821X(86)90031-2. 
Pommier, A., K. Leinenweber, D. L. Kohlstedt, C. Qi, E. J. Garnero, S. J. Mackwell, and J. A. Tyburczy (2015), Experimental constraints on the electrical anisotropy of the lithosphereasthenosphere system, Nature, 522(7555), 202-206, doi:10.1038/nature14502.

Porada, H., and V. Berhorst (2000), Towards a new understanding of the Neoproterozoic-Early Palaeozoic Lufilian and northern Zambezi Belts in Zambia and the Democratic Republic of Congo, Journal of African Earth Sciences, 30(3), 727-771.

Ritsema, J., and H. van Heijst (2000), New seismic model of the upper mantle beneath Africa, Geology, 28(1), 63-66.

Rodi, W., and R. L. Mackie (2001), Nonlinear conjugate gradients algorithm for 2-D magnetotelluric inversion, Geophysics, 66(1), 174-187, doi:10.1190/1.1444893.

Rousseeuw, P. J. (1984), Least median of squares regression, Journal of the American Statistical Association, 79, 871-880.

Salem, A., S. Williams, D. Fairhead, R. Smith, and D. Ravat (2007), Interpretation of magnetic data using tilt-angle derivatives, Geophysics, 73(1), L1-L10, doi:10.1190/1.2799992.

Shapiro, N., and M. Ritzwoller (2002), Monte-Carlo inversion for a global shear-velocity model of the crust and upper mantle, Geophysical Journal International, 151(1), 88-105, doi:10.1046/j.1365-246X.2002.01742.x.

Smith, A. G., and A. Hallam (1970), The fit of the southern continents, doi:10.1038/225139a0.

Smith, R. S., and A. Salem (2005), Imaging depth, structure, and susceptibility from magnetic data: The advanced source-parameter imaging method, Geophysics, 70(4), L31-L38, doi:10.1190/1.1990219.

Stern, R. J. (2008), Neoproterozoic crustal growth: the solid Earth system during a critical episode of Earth history, Gondwana research, 14(1), 33-50, doi:10.1016/j.gr.2007.08.006.

Thébault, E., C. C. Finlay, C. D. Beggan, P. Alken, J. Aubert, O. Barrois, F. Bertrand, T. Bondar, A. Boness, L. Brocco, E. Canet, A. Chambodut, A. Chulliat, P. Coïsson, F. Civet, A. Du, A. Fournier, I. Fratter, N. Gillet, B. Hamilton, M. Hamoudi, G. Hulot, T. Jager, M. Korte, W. Kuang, X. Lalanne, B. Langlais, V. Léger, J. Lesur, F. J. Lowes, et al. (2015), International Geomagnetic Reference Field: the 12th generation. Earth, Planets and Space 2015, 67:79.

Thurston, J. B., and R. S. Smith (1997), Automatic conversion of magnetic data to depth, dip, and susceptibility contrast using the SPI (TM) method, Geophysics, 62(3), 807-813, doi:10.1190/1.1444190.

Verduzco, B., J. D. Fairhead, C. M. Green, and C. MacKenzie (2004), New insights into magnetic derivatives for structural mapping, The Leading Edge, 23(2), 116-119, doi:10.1190/1.1651454.

Wannamaker, P. E. (2005), Anisotropy Versus Heterogeneity in Continental Solid Earth Electromagnetic Studies: Fundamental Response Characteristics and Implications for 
Physicochemical State, Surveys in Geophysics, 26(6), 733-765, doi:10.1007/s10712-0051832-1.

Westerhof, A. P., M. I. Lehtonen, H. Mäkitie, T. Manninen, Y. Pekkala, B. Gustafsson, and A. Tahon (2008), The Tete-Chipata Belt: A new multiple terrane element from western Mozambique and southern Zambia, Geological Survey of Finland Special Paper, 48, 145166.

Yang, B., G. D. Egbert, A. Kelbert, and N. M. Meqbel (2015), Three-dimensional electrical resistivity of the north-central USA from EarthScope long period magnetotelluric data, Earth and Planetary Science Letters, 422, 87-93, doi:10.1016/j.eps1.2015.04.006. 


\subsection{Figures}

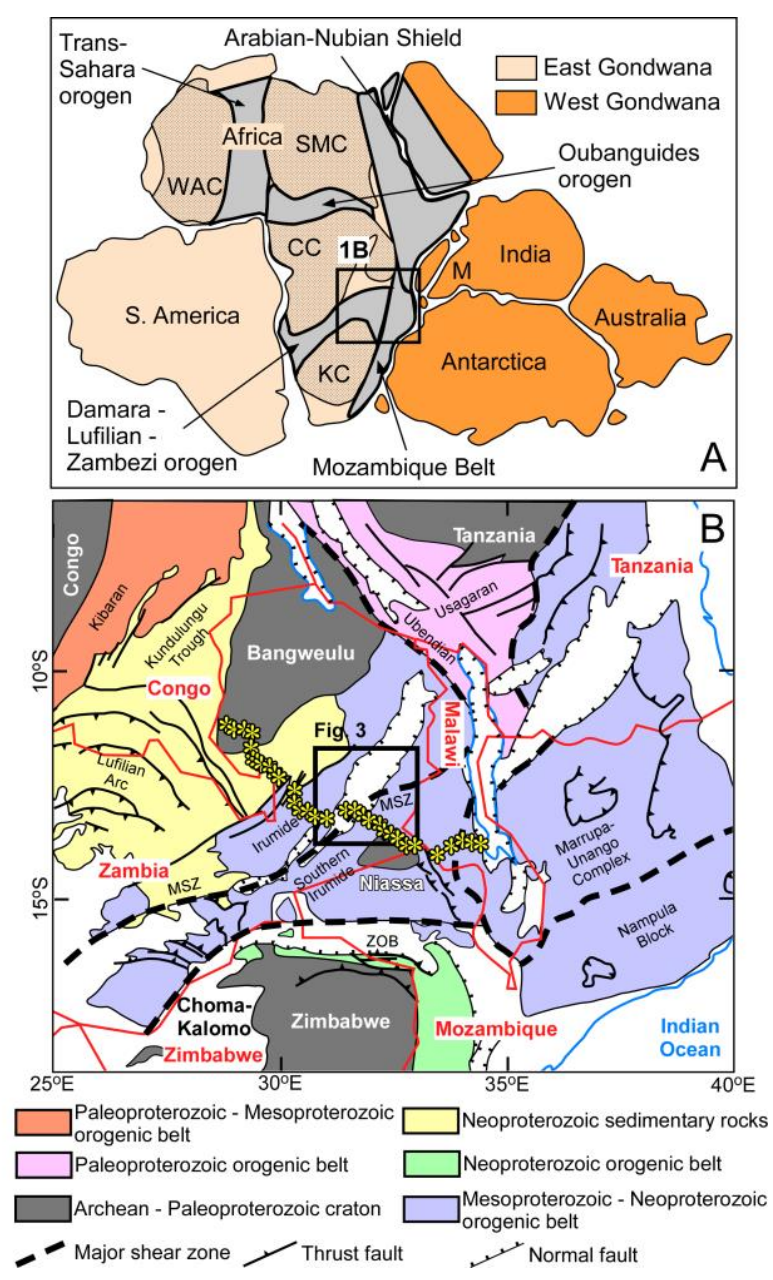

Fig. 1

(A) A reconstruction of Gondwana with the major tectonic elements of Africa identified from geological mapping, geochemical and geochronological studies, and seismic tomography. WAC: West African Craton; SMC: Saharan Metacraton; CC: Congo Craton; KC: Kalahari Craton. The black box indicates the region of interest in this study as shown in Fig. 1B. (B) A simplified geological map showing the tectonic framework of Zambia and the surrounding region. Modified after Westerhof et al. [2008]. Yellow stars show MT station locations. Red lines show political boundaries. The black box highlights the area where high resolution aeromagnetic data was collected as shown in Fig. 3. MSZ: Mwembeshi Shear Zone; ZOB: Zambezi Orogenic Belt. 

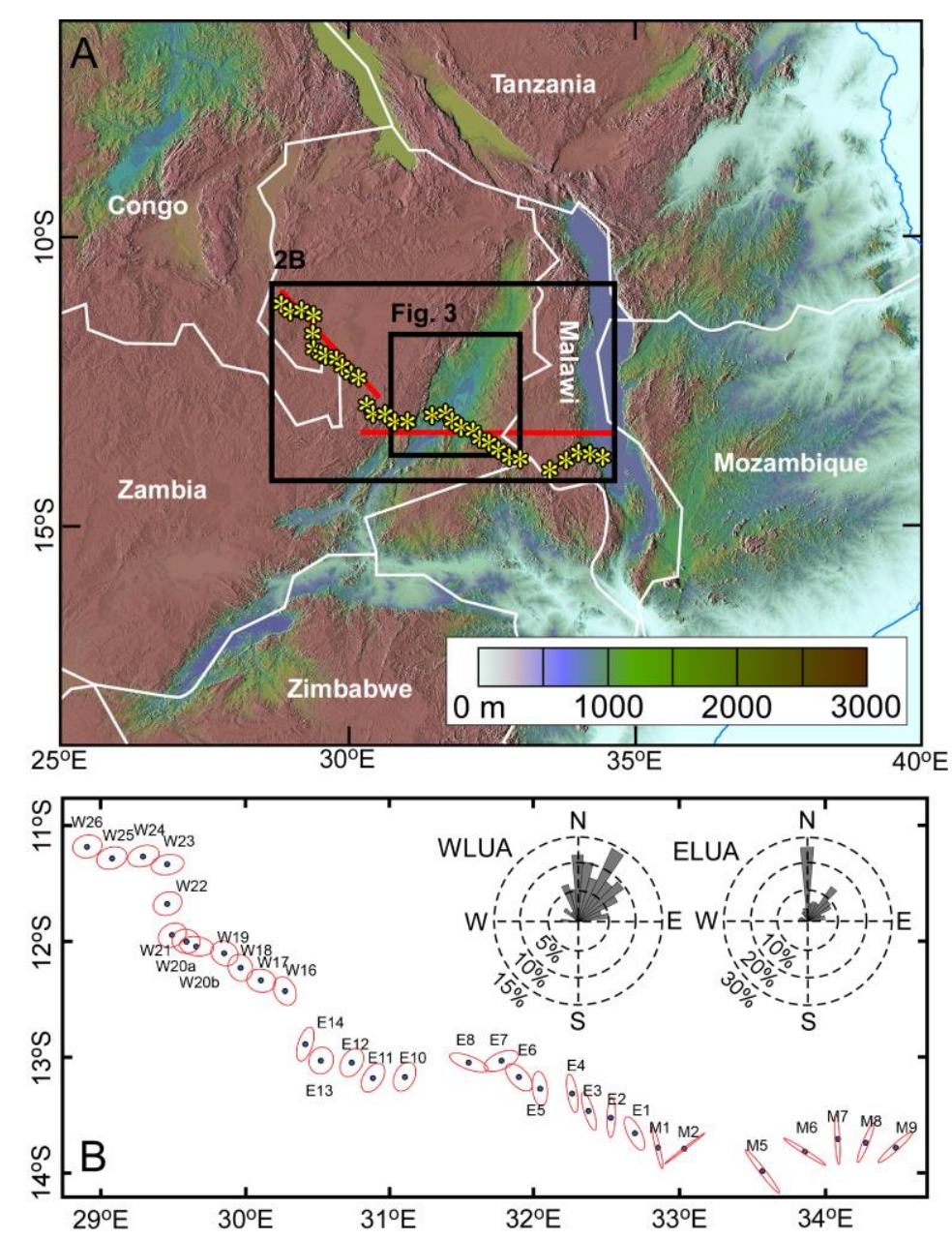

Fig. 2

(A) Shuttle Radar Topography Mission (SRTM) Digital Elevation Model (DEM) courtesy NASA/JPL-Caltech of the region of Fig. 1B. Yellow stars indicate MT station locations. Stations traverse from eastern Zambia into southern Malawi. Red traces show the WLUA and ELUA profiles, and their orientations, used during inverse modeling of MT data. The black box highlights the area where high resolution aeromagnetic data was collected as shown in Fig. 3. White lines show political boundaries. (B) The MT phase tensor for each station determined over the entire period range. Stations labeled with a "W" lie on the WLUA profile. Stations labeled with an "E" lie on the ELUA profile within Zambia. Stations labeled with a "M" lie on the ELUA profile within Malawi. 


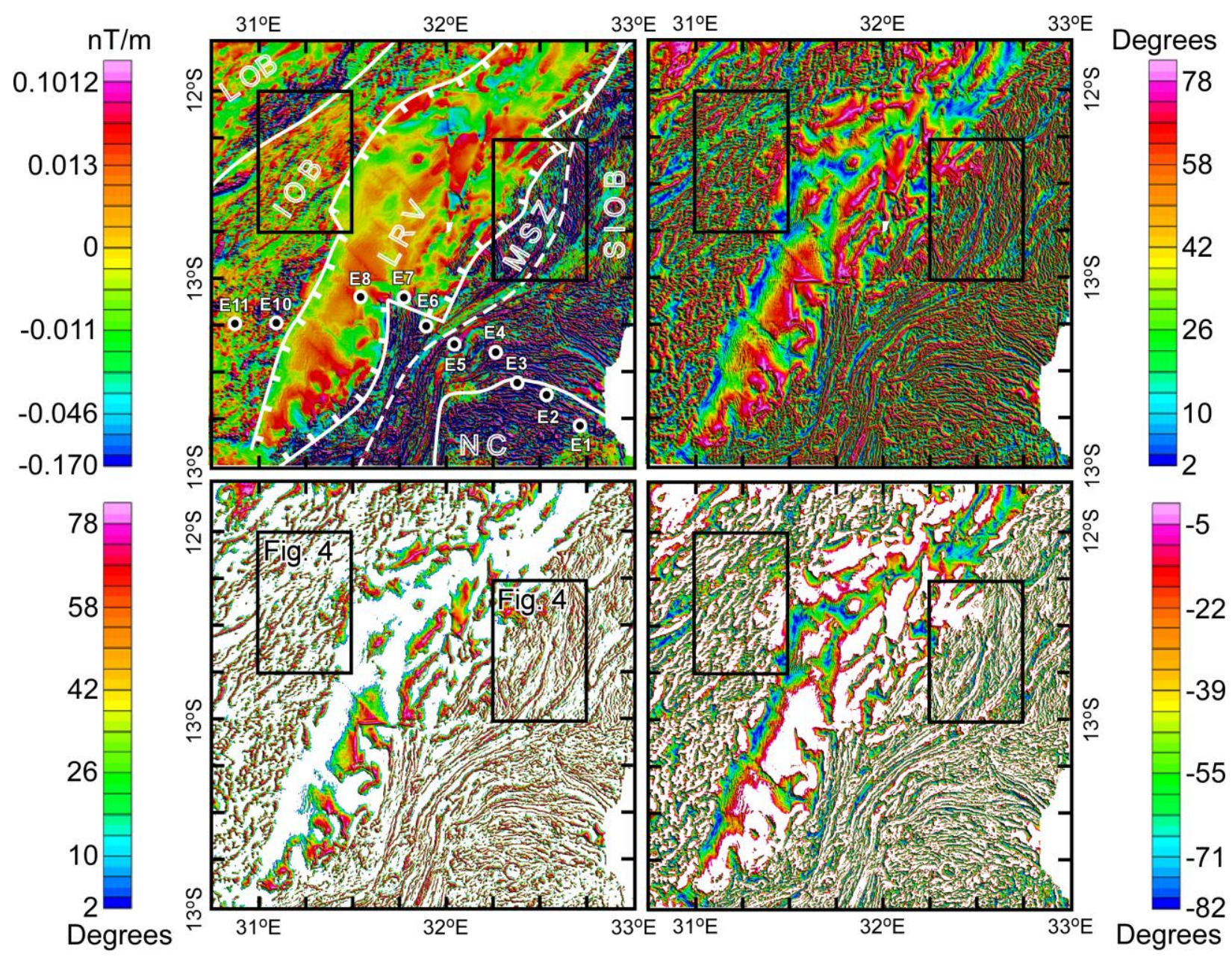

Fig. 3

Aeromagnetic images showing the shallow crustal structures of portions of the Lufilian Orogenic Belt (LOB), Irumide Orogenic Belt (IOB), Southern Irumide Orogenic Belt (SIOB), Niassa Craton (NC), Mwembeshi Shear Zone (MSZ), and Luangwa Rift Valley (LRV). (A) Vertical derivative map from the total magnetic field data. (B) Tilt derivative image derived from ratioing of the vertical and horizontal derivatives of the total magnetic field. (C) Positive tilt image. (D) Negative tilt image. 

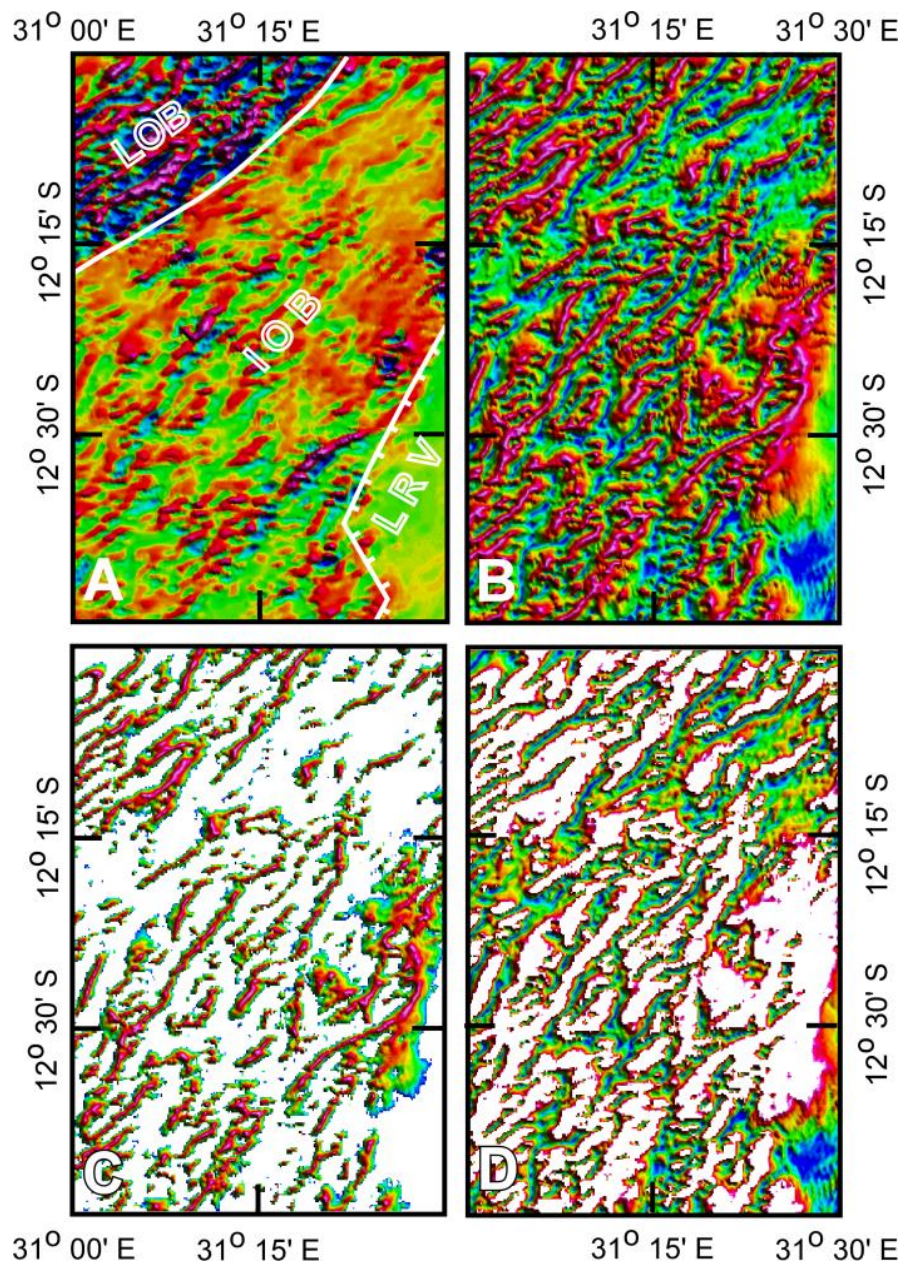

Fig. 4

(A) The vertical derivative map generated from the total magnetic field data, (B) tilt derivative image derived from ratioing of the vertical and horizontal derivatives of the total magnetic field, (C) positive tilt image, and (D) negative tilt image of portions of the Lufilian and Irumide Orogenic Belt (LOB and IOB), and Luangwa Rift Velley (LRV). See Fig. 3 for location. 

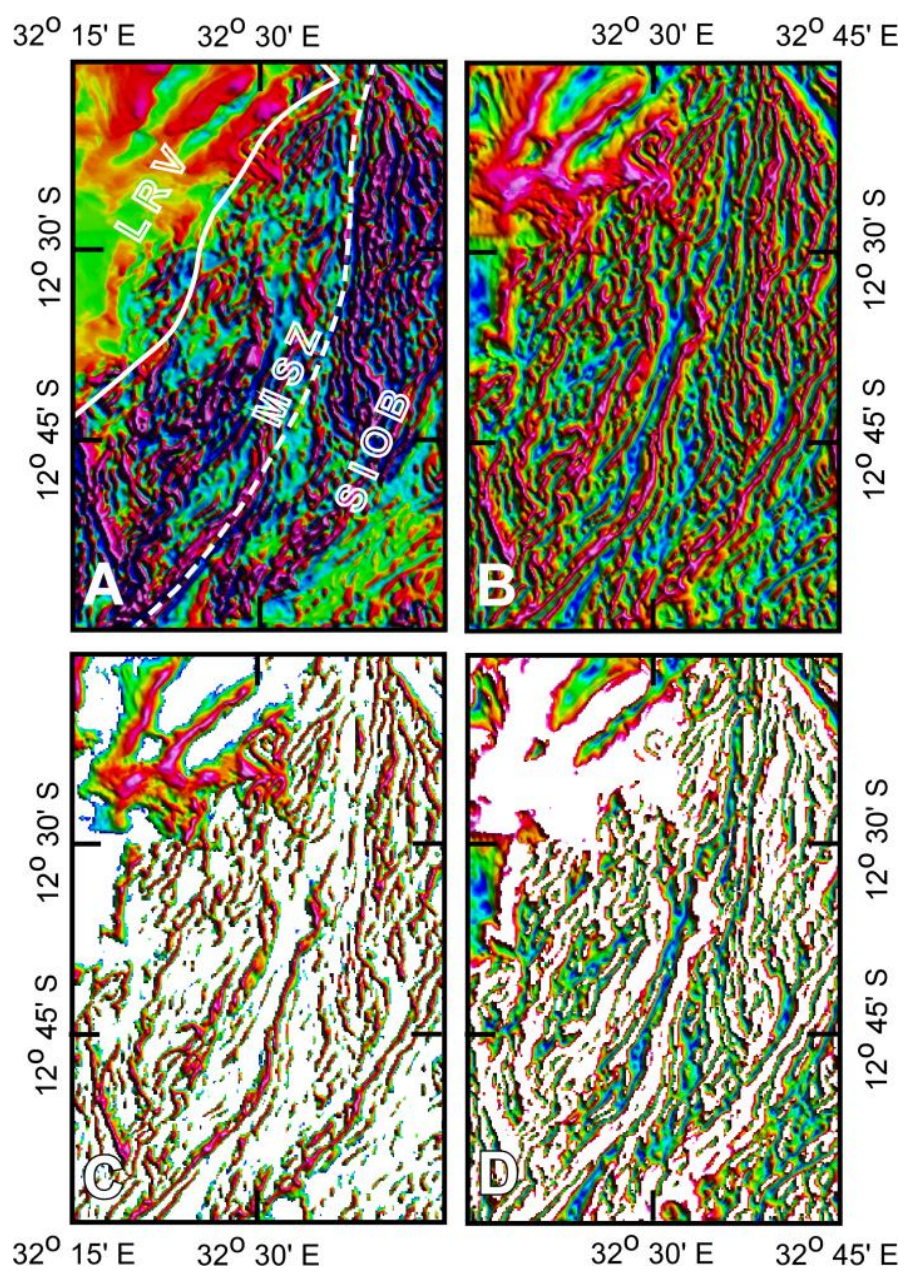

Fig. 5

(A) The vertical derivative map generated from the total magnetic field data, (B) tilt derivative image derived from ratioing the vertical and horizontal derivatives of the total magnetic field, (C) positive tilt image, and (D) negative tilt image of portions of the Luangwa Rift Valley (LRV), Mwembeshi Shear Zone (MBZ), and Southern Irumide Orogenic Belt (SIOB). See Fig. 3 for location. 

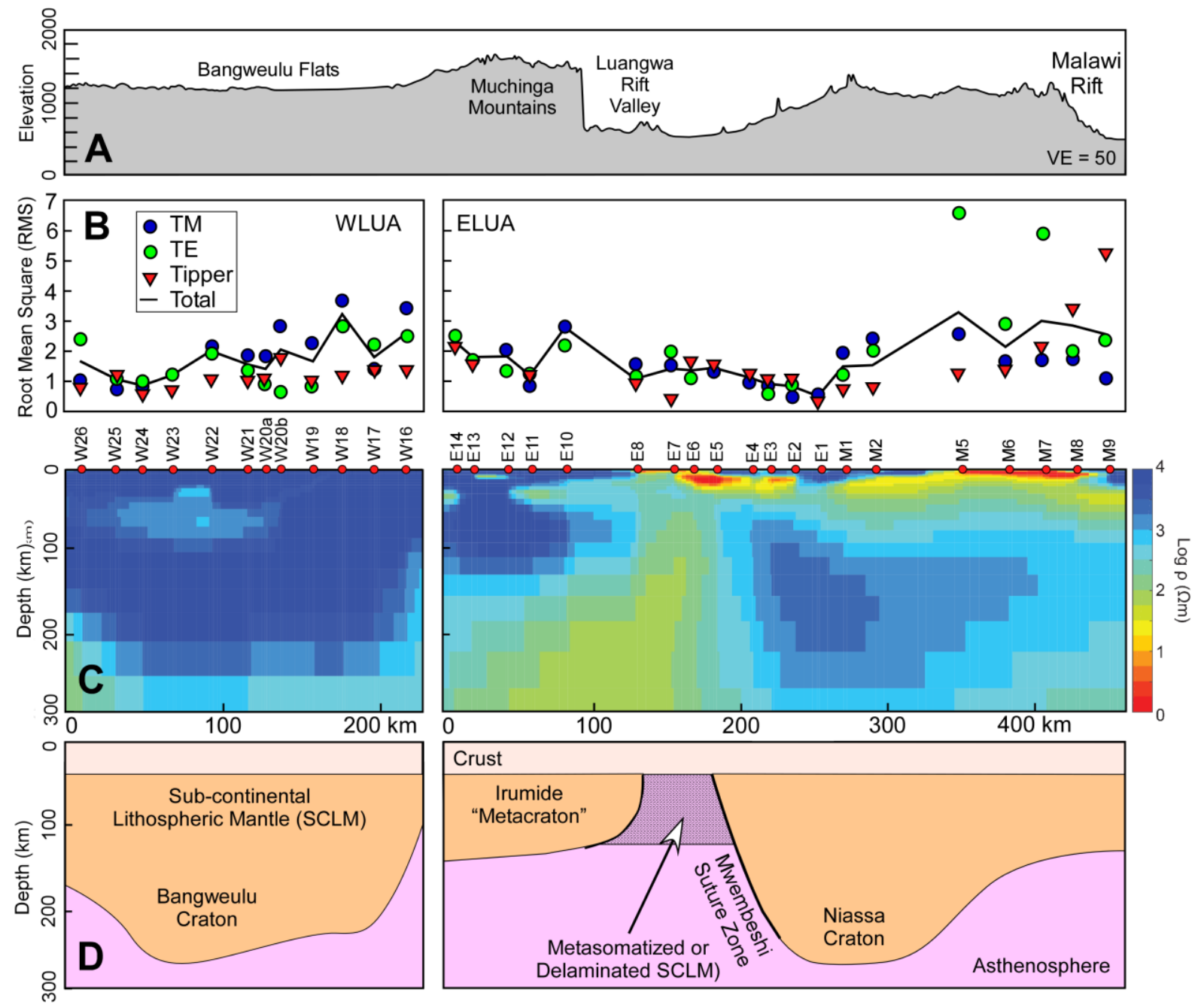

Fig. 6

(A) Topographic profile extracted from Shuttle Radar Topography Mission (SRTM) Digital Elevation Model (DEM) courtesy NASA/JPL-Caltech along the same trace of MT stations. (B) The TE and TM mode, tipper, and total root-mean-squared (RMS) misfit for each station. (C) The preferred 2D isotropic resistivity models for the WLUA and ELUA profiles with station locations. Warm colors indicate less resistive (more conductive) regions and cool colors indicate more resisitive regions. (D) Our interpretation of the upper mantle structure beneath the WLUA and ELUA profiles based on MT and aeromagnetic observations. 


\section{Appendix A}

\section{Supplementary materials for Chapter 2}

\section{A.1 Materials and Methods}

\section{A.1.1. Experimental Design}

\section{Starting Materials}

The starting material was synthesized from a mixture of high-purity oxides, Ca-metasilicate $\left(\mathrm{CaSiO}_{3}\right)$, synthetic fayalite, Amelia albite and natural orthoclase. The synthetic peridotite was modeled after the DMM composition from Workman and Hart [2005] excluding $\mathrm{P}_{2} \mathrm{O}_{5}$. Individual components were dehydrated to remove adsorbed $\mathrm{H}_{2} \mathrm{O}$ before being weighed (see Table S1), then ground in an agate mortar and pestle under ethanol for 6 hours to form a homogeneous powder. The synthetic DMM mixture was then reacted for 72 hours in a vertical gas mixing furnace with the fugacity of oxygen controlled at the fayalite-magnetite-quartz (FMQ) buffer by mixing $\mathrm{CO}_{2}$ and $\mathrm{CO}$ gases. Following the reaction step, the mix was re-ground to a fine powder. San Carlos olivine spheres 250-500 $\mu \mathrm{m}$ in diameter were fabricated from large single crystals of San Carlos olivine. The olivine spheres were mixed with the synthetic peridotite in $\sim 5: 95$ proportions by weight. The completed mix (olivine spheres + synthetic peridotite) was stored under vacuum at $120{ }^{\circ} \mathrm{C}$ to minimize $\mathrm{H}_{2} \mathrm{O}$ adsorption.

\section{Experimental Methods}

Prior to each experiment, an aliquot of the starting material was packed into a $10 \mathrm{~mm}$ long $\mathrm{Au}_{80} \mathrm{Pd}_{20}$ capsule that had been pre-conditioned to minimize Fe loss, and then dried for up to 96 $\mathrm{h}$ in a vacuum oven at $120^{\circ} \mathrm{C}$. After drying, the top of the experimental capsule was immediately welded shut to ensure that the experimental powder was exposed to minimal atmospheric $\mathrm{H}_{2} \mathrm{O}$. The sealed capsule was then inserted into a crushable $\mathrm{MgO}$ sleeve, and centered in a graphite furnace using crushable $\mathrm{MgO}$ spacers. All $\mathrm{MgO}$ spacers were dried at $1000^{\circ} \mathrm{C}$ in a muffle furnace for at least 24 hours prior to assembly. The pressure medium consisted of a sintered $\mathrm{CaF}_{2}$ sleeve. 
Melting experiments, spaced $20^{\circ} \mathrm{C}$ apart, were performed from 1250 to $1430{ }^{\circ} \mathrm{C}$ at $1.5 \mathrm{GPa}$ for $24 \mathrm{~h}$ in an end-loaded piston cylinder device [Boyd and England, 1960] with $12.7 \mathrm{~mm}$ assemblies using the cold-piston-in technique [Johannes et al., 1971] (Table S2). The friction correction was determined at 1.2 to $1.4 \mathrm{GPa}$ and $1300{ }^{\circ} \mathrm{C}$ using the breakdown of CaTschermakite to the assemblage anorthite, gehlenite, and corundum [Hays, 1966] and is within the pressure uncertainty $( \pm 50 \mathrm{MPa})$. Therefore, no friction correction was applied to reported pressures. The temperature was measured and controlled using $\mathrm{W}_{97} \mathrm{Re}_{3}-\mathrm{W}_{75} \mathrm{Re}_{25}$ thermocouples with no correction for the effect of pressure on thermocouple EMF. The accuracy for pressure is within $\pm 50 \mathrm{MPa}$ and for temperature is within $\pm 10^{\circ} \mathrm{C}$. After $24 \mathrm{~h}$, experiments were quenched to room temperature by shutting off the power. Capsules were mounted in epoxy, sectioned longitudinally, and polished using $\mathrm{SiC}$ and water based diamond suspensions down to $0.25 \mu \mathrm{m}$.

\section{Diffusive equilibration of San Carlos Olivine spheres}

The San Carlos olivine spheres added to the peridotite mixture act as hygrometers because volume diffusion of $\mathrm{H}$ in olivine is rapid enough to allow for equilibration of the spheres to the experimental $\mathrm{H}_{2} \mathrm{O}$ fugacity during runs [Kohlstedt and Mackwell, 1998; Demouchy and Mackwell, 2006]. At our experimental temperatures, $\mathrm{H}$ diffusion in San Carlos olivine is rate limited by diffusion of octahedral metal vacancies, of which the slowest diffusion rate occurs along the [100] and [010] axes following the diffusion law

$$
\mathrm{D}_{\mathrm{H}[100],[010]}=10^{-4.5 \pm 4.1} \exp [-(204 \pm 94) / \mathrm{RT}]
$$

and the fastest diffusion rate occurs along the [001] axis following

$$
\mathrm{D}_{\mathrm{H}[001]}=10^{-1.4 \pm 0.5} \exp [-(258 \pm 11) / \mathrm{RT}]
$$

where $\mathrm{D}_{\mathrm{H}}$ is $\mathrm{H}$ diffusivity in $\mathrm{m}^{2} \mathrm{~s}^{-1}$ in the specified orientations, $\mathrm{R}$ is the gas constant in $\mathrm{kJ} \mathrm{mol}^{-1}$ $\mathrm{K}^{-1}$, and $\mathrm{T}$ is the temperature in $\mathrm{K}$ [Demouchy and Mackwell, 2006]. The time required for diffusive equilibration of $\mathrm{H}$ in the San Carlos olivine spheres can be calculated for the lowest experimental temperature of $1250^{\circ} \mathrm{C}$, a $500 \mu \mathrm{m}$ diameter San Carlos olivine sphere, an initial sphere $\mathrm{H}_{2} \mathrm{O}$ content of $5 \mu \mathrm{g} / \mathrm{g}$, and a constant boundary condition of $33 \mu \mathrm{g} / \mathrm{g} \mathrm{H}_{2} \mathrm{O}$ (the average $\mathrm{H}_{2} \mathrm{O}$ content of San Carlos olivine spheres in subsolidus experiments). Figure S1 shows that the time for equilibration of the spheres with the imposed $\mathrm{H}_{2} \mathrm{O}$ fugacity is less than 6 hours. This is 
the maximum amount of time necessary for equilibration because higher run temperatures and smaller olivine spheres decrease the amount of time needed.

\section{A.1.2. Analytical Methods}

\section{Sample Preparation}

Sectioned and polished experiments were pressed in indium metal along with three secondary reference materials: 1) a low $\mathrm{H}_{2} \mathrm{O}$ reference to monitor machine background (Suprasil 3002 pure $\mathrm{SiO}_{2}$ glass, $1 \mu \mathrm{g} / \mathrm{g} \mathrm{H}_{2} \mathrm{O}$ provided by Heraeus Quarzglas, Switzerland), 2) a mid $\mathrm{H}_{2} \mathrm{O}$ reference to monitor reproducibility (Herasil 102 pure $\mathrm{SiO}_{2}$ glass, $55 \mu \mathrm{g} / \mathrm{g} \mathrm{H}_{2} \mathrm{O}$ provided by Heraeus Quarzglas, Switzerland), and 3) a high $\mathrm{H}_{2} \mathrm{O}$ reference to monitor instrumental drift (ALV 519-4$1 \mathrm{mid}$ ocean ridge basalt glass, $1700 \mu \mathrm{g} / \mathrm{g} \mathrm{H}_{2} \mathrm{O}$ ).

\section{Scanning Electron Microscope (SEM)}

Polished experimental charges were analyzed using the Hitachi TM3000 scanning electron microscope (SEM) with an attached energy dispersive x-ray spectrometer (EDS) at the Woods Hole Oceanographic Institution. The SEM allowed for the visual inspection of the San Carlos olivine grains to ensure that the hygrometers survived the experimental run with little alteration. Every experiment contained run-produced, subhedral grains of olivine, orthopyroxene, clinopyroxene, and spinel \pm glass in addition to the San Carlos olivine grains (see Table S2).

\section{Electron Probe Micro-analyzer (EPMA)}

The major element compositions mineral phases were analyzed in select experiments using the JEOL JXA-8200 electron microprobe at the Massachusetts Institute of Technology. We used an accelerating potential of $15 \mathrm{kV}$ and a beam current of $10 \mathrm{nA}$. Mineral phases were analyzed using a focused beam. San Carlos olivines and run produced olivine were analyzed for the elements $\mathrm{Mg}, \mathrm{Al}, \mathrm{Si}, \mathrm{Ca}, \mathrm{Ti}, \mathrm{Mn}, \mathrm{Fe}$, and $\mathrm{Ni}$, orthopyroxene and clinopyroxene for $\mathrm{Na}, \mathrm{Mg}, \mathrm{Al}$, $\mathrm{Si}, \mathrm{K}, \mathrm{Ca}, \mathrm{Ti}, \mathrm{Cr}, \mathrm{Mn}$, and Fe, and spinel for $\mathrm{Mg}, \mathrm{Al}, \mathrm{Si}, \mathrm{Ca}, \mathrm{Ti}, \mathrm{Cr}, \mathrm{Mn}, \mathrm{Fe}, \mathrm{Ni}$, and Zn. In house natural and synthetic standards were used for calibration. Mineral analyses with totals below 98\% and above $102 \%$ were discarded (Table S4)

Secondary Ion Mass Specrometry (SIMS) 
We conducted SIMS measurements on the olivine hygrometers within the experimental charges using the Cameca IMS 6F or NanoSIMS 50L ion microprobes at the Carnegie Institution of Washington, Department of Terrestrial Magnetism following previously established methods [O'Leary et al., 2010; Hauri et al., 2002]. Prior to analysis, reference materials and experimental mounts were gold coated and held in an airlock attached to the sample chamber of the ion microprobe and allowed to degas until the pressure was ca. $10^{-6} \mathrm{~Pa}\left(10^{-8}\right.$ Torr $)$. Then the mounts were inserted into the sample chamber to further degas until the sample chamber pressure was below $10^{-7} \mathrm{~Pa}\left(10^{-9}\right.$ Torr). The quality of the vacuum inside the sample chamber allows for low $\mathrm{H}_{2} \mathrm{O}$ background, thus keeping detection limits low [Hauri et al., 2002]. When experimental mounts were not in either the airlock or sample chamber, they were held in a $50{ }^{\circ} \mathrm{C}$ vacuum oven to aid degassing.

During measurements, a focused $\mathrm{Cs}^{+}$primary beam, $\sim 15 \mathrm{nA}$ (6f) and $\sim 10 \mathrm{nA}$ (NanoSIMS), was rastered over a $20 \mu \mathrm{m} \times 20 \mu \mathrm{m}$ (6f) or $15 \mu \mathrm{m} \times 15 \mu \mathrm{m}$ (NanoSIMS) area. In addition, a field aperture (6f) and beam blanking (NanoSIMS) was used to measure only those ions generated from the central $10 \mu \mathrm{m} \times 10 \mu \mathrm{m}$ (6f) or $4 \mu \mathrm{m} \times 4 \mu \mathrm{m}$ (NanoSIMS) of the crater ensuring a low volatile background and eliminating crater edge effects [Hauri et al., 2006]. Mass resolving power $\left(\mathrm{M} / \Delta \mathrm{M}\right.$ at $10 \%$ peak height) was $\sim 4500$, sufficient to separate ${ }^{16} \mathrm{OH}$ from ${ }^{17} \mathrm{O}$. The masses ${ }^{12} \mathrm{C},{ }^{16} \mathrm{O}^{1} \mathrm{H},{ }^{19} \mathrm{~F},{ }^{31} \mathrm{P},{ }^{30} \mathrm{Si},{ }^{32} \mathrm{~S},{ }^{35} \mathrm{Cl}(6 \mathrm{f})$ and ${ }^{12} \mathrm{C},{ }^{16} \mathrm{O}{ }^{1} \mathrm{H},{ }^{19} \mathrm{~F}, \pm{ }^{31} \mathrm{P},{ }^{30} \mathrm{Si}, \pm{ }^{32} \mathrm{~S},{ }^{35} \mathrm{Cl}$ (NanoSIMS), were measured, using ${ }^{30} \mathrm{Si}$ as the normalizing mass. Each measurement consisted of a 300 second pre-sputter period followed by a ca. 3 minute acquisition time. ${ }^{12} \mathrm{C}$ ion imaging was used to identify small cracks or contamination within the craters, which were observed to have elevated ${ }^{12} \mathrm{C}$ signal.

Our target during analysis of the experimental mounts was the olivine hygrometers within each experiment because the groundmass was too fine-grained for the beam size (see text and Fig 1). We measured 4 San Carlos olivine grains per experiment with 2 spots per olivine totaling 8 analyses per experimental capsule. Secondary standards were measured before and after each experimental capsule in order to monitor the detection limits $\left(<5 \mu \mathrm{g} / \mathrm{g} \mathrm{H}_{2} \mathrm{O}\right)$ and instrumental drift throughout the analyses. 
Abundances for $\mathrm{H}_{2} \mathrm{O}$ in San Carlos olivine were calculated from the calibrations performed on the reference olivines and orthopyroxenes [Hauri et al., 2002] and corrected for machine background and instrumental drift. After the initial calculation, $\mathrm{H}_{2} \mathrm{O}$ contents from each measurement within each experiment were averaged. The average San Carlos olivine sphere $\mathrm{H}_{2} \mathrm{O}$ content in each experiment was then averaged between sessions for the reported value (Table S2).

\section{A.2 Mass balance calculation}

The major element concentrations of the phases in each subsolidus experiment measured by EPMA were used to calculate the phase proportions by minimizing the error between the measured oxide abundances and the known bulk oxide abundances of the synthetic mixture [Workman and Hart, 2005]. In subsolidus experiments, the phase proportions of the run products (excluding the San Carlos olivine spheres) are roughly $61 \%$ olivine, $22 \%$ orthopyroxene, $15 \%$ clinopyroxene, and 2\% spinel. Given the calculated phase proportions and the measured San Carlos olivine sphere $\mathrm{H}_{2} \mathrm{O}$ contents, we were able to calculate the $\mathrm{H}_{2} \mathrm{O}$ content of each experiment using experimentally determined partition coefficients [Hirschmann et al., 2009; Aubaud et al., 2004; Hauri et al., 2006; O'Leary et al., 2010]. The run produced olivine $\mathrm{H}_{2} \mathrm{O}$ content was assumed to be the same as that measured in the San Carlos olivine. The orthopyroxene-olivine and clinopyroxene-olivine partition coefficients were calculated for each experiment using the methods of O'Leary et al. [2010], and the spinel-olivine partition coefficient was assumed to be 0 . An example calculation is shown in Table S3.

\section{A.3 Solidus crossing calculations}

We used the nominally anhydrous solidus as described in [Hirschmann, 2000] and performed a cryoscopic calculation to obtain the $200 \mu \mathrm{g} / \mathrm{g} \mathrm{H}_{2} \mathrm{O}$ solidus following the methods of [Hirschmann et al., 2009] with

$$
\mathrm{T}_{\text {hydr }}=\mathrm{T}_{\text {anhydr }} /\left[1-(\mathrm{R} / \mathrm{M} \Delta \mathrm{S}) \ln \left(1-\mathrm{X}_{\mathrm{OH}}\right)\right]
$$

where $\mathrm{T}_{\text {hydr }}$ is the hydrated solidus temperature, $\mathrm{T}_{\text {anhydr }}$ is the anhydrous solidus temperature, $\mathrm{R}$ is the gas constant, $\mathrm{M}$ is the number of grams in one mole of silicate $\left(59 \mathrm{~g} \mathrm{~mol}^{-1}\right), \Delta \mathrm{S}$ is the entropy 
of fusion per unit mass $\left(0.4 \mathrm{~J} \mathrm{~K}^{-1} \mathrm{~g}^{-1}\right)$, and $\mathrm{X}_{\mathrm{OH}}$ is the mole fraction of dissolved $\mathrm{H}_{2} \mathrm{O}$ in the melt as dissociated hydroxyl. We calculated the truly anhydrous $\left(0 \mu \mathrm{g} / \mathrm{g} \mathrm{H} \mathrm{H}_{2} \mathrm{O}\right)$ solidus on the basis of our experimental results, and the subsequent 200 and $450 \mu \mathrm{g} / \mathrm{g} \mathrm{H}_{2} \mathrm{O}$ solidus using the same equation.

Mantle adiabats were calculated for a potential temperature of 1350 and $1410{ }^{\circ} \mathrm{C}$ using a thermal expansivity of $3 \times 10^{-5} \mathrm{~K}^{-1}$ and a heat capacity of $1 \mathrm{~kJ} \mathrm{~kg}^{-1} \mathrm{~K}^{-1}$. The relationship between pressure $(\mathrm{P})$, in $\mathrm{GPa}$, and depth $(\mathrm{z})$, in $\mathrm{km}$, was assumed to be: $\mathrm{z}=30.2 \mathrm{P}+5$. 


\section{A.4 Figures and Tables}

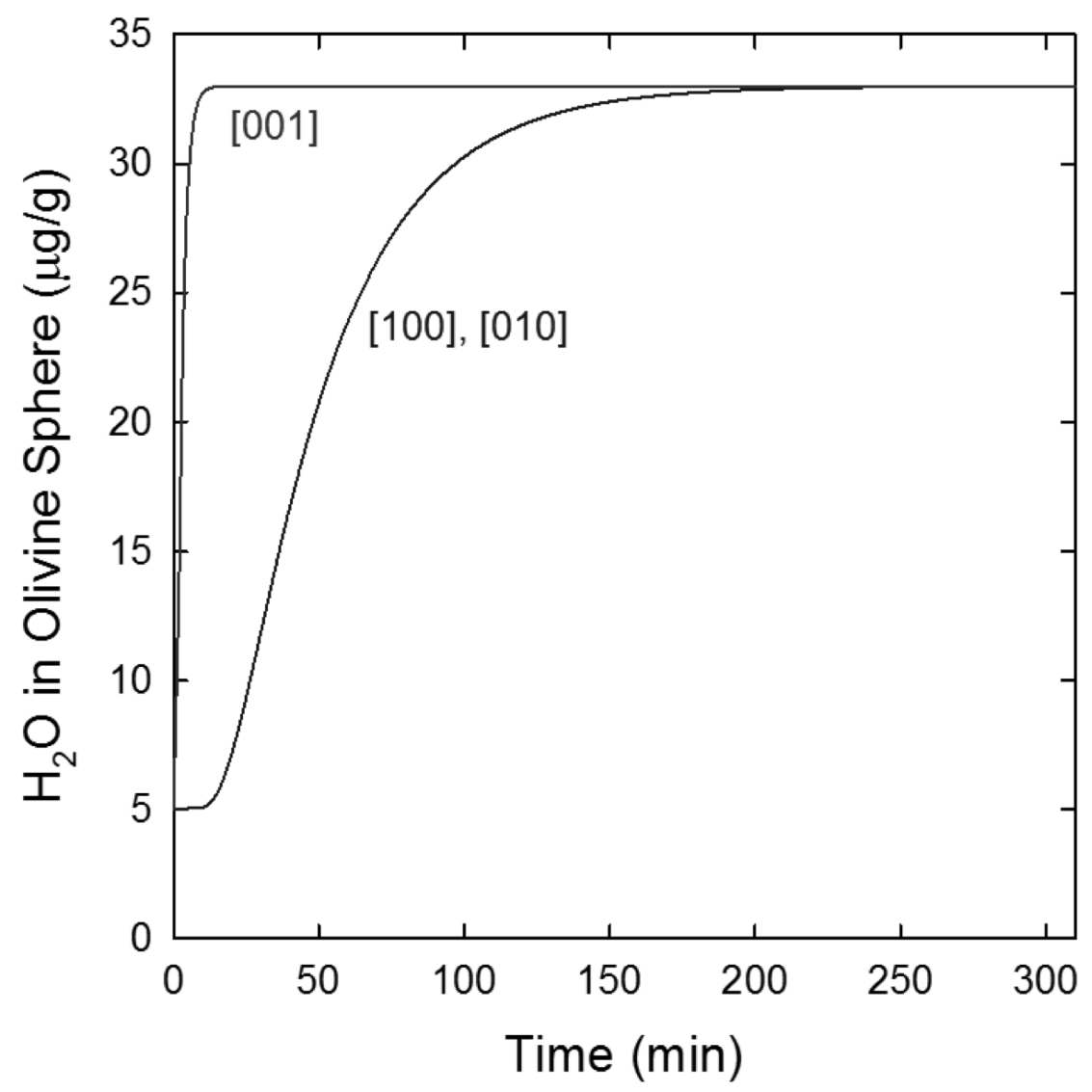

Fig. S1.

Time for diffusive equilibration of $\mathrm{H}$ in the San Carlos olivine spheres. 


\section{Table S1.}

Oxides and corresponding weight for synthetic DMM composition

\begin{tabular}{lc}
\hline Oxide & $\begin{array}{c}\text { Peridotite Mixture } \\
(\text { wt } \%)\end{array}$ \\
\hline $\mathrm{SiO}_{2}$ & 43.58 \\
$\mathrm{Al}_{2} \mathrm{O}_{3}$ & 3.89 \\
$\mathrm{FeO}^{\text {b }}$ & 7.98 \\
$\mathrm{MnO}$ & 0.14 \\
$\mathrm{MgO}$ & 40.07 \\
$\mathrm{CaO}$ & 3.10 \\
$\mathrm{Na} 2 \mathrm{O}$ & 0.28 \\
$\mathrm{Cr}_{2} \mathrm{O}_{3}$ & 0.57 \\
$\mathrm{TiO}_{2}$ & 0.14 \\
$\mathrm{NiO}_{\mathrm{K}} \mathrm{O}$ & 0.24 \\
$\mathrm{H}_{2} \mathrm{O}$ & 0.01 \\
$\mathrm{Total}^{2}$ & 0.00 \\
h. Based on Workman and Hart [2005] & 100.00 \\
i. Total Fe as FeO
\end{tabular}




\section{Table S2.}

Run conditions, average San Carlos olivine H2O content and number of SIMS analyses, and experimental run products.

\begin{tabular}{|c|c|c|c|c|c|c|c|}
\hline Experiment & $\begin{array}{l}\text { Drying } \\
\text { Time } \\
\text { (h) }\end{array}$ & $\begin{array}{c}\mathrm{P} \\
(\mathrm{GPa})\end{array}$ & $\begin{array}{c}\mathrm{T} \\
\left({ }^{\circ} \mathrm{C}\right)\end{array}$ & $\begin{array}{l}\text { Duration } \\
\text { (h) }\end{array}$ & $\begin{array}{c}\text { Average San } \\
\text { Carlos } \mathrm{H}_{2} \mathrm{O} \\
\text { Content }^{\mathrm{a}} \\
(\mu \mathrm{g} / \mathrm{g})\end{array}$ & $\begin{array}{c}\text { \# of } \\
\text { Analyses }\end{array}$ & Run products $^{\mathrm{b}}$ \\
\hline ETDMM18 & 96 & 1.5 & 1250 & 24 & $32(3)$ & 17 & $\begin{array}{c}\mathrm{Ol}+\mathrm{Opx}+\mathrm{Cpx}+ \\
\mathrm{Sp}\end{array}$ \\
\hline ETDMM24 & 0 & 1.5 & 1270 & 24 & $29(2)$ & 13 & $\begin{array}{c}\mathrm{O}+\mathrm{Opx}+\mathrm{Cpx}+ \\
\mathrm{Sp}\end{array}$ \\
\hline ETDMM32 & 12 & 1.5 & 1270 & 24 & $38(2)$ & 14 & $\begin{array}{c}\mathrm{O} 1+\mathrm{Opx}+\mathrm{Cpx}+ \\
\mathrm{Sp}\end{array}$ \\
\hline ETDMM23 & 48 & 1.5 & 1270 & 24 & $28(2)$ & 10 & $\begin{array}{c}\mathrm{O}+\mathrm{Opx}+\mathrm{Cpx}+ \\
\mathrm{Sp}\end{array}$ \\
\hline ETDMM30 & 24 & 1.5 & 1290 & 24 & $36(2)$ & 15 & $\begin{array}{c}\mathrm{O} 1+\mathrm{Opx}+\mathrm{Cpx}+ \\
\mathrm{Sp}\end{array}$ \\
\hline ETDMM19 & 96 & 1.5 & 1290 & 24 & $28(4)$ & 20 & $\begin{array}{c}\mathrm{O} 1+\mathrm{Opx}+\mathrm{Cpx}+ \\
\mathrm{Sp}\end{array}$ \\
\hline ETDMM20 & 96 & 1.5 & 1310 & 24 & $33(3)$ & 15 & $\begin{array}{c}\mathrm{O} 1+\mathrm{Opx}+\mathrm{Cpx}+ \\
\mathrm{Sp}\end{array}$ \\
\hline ETDMM21 & 96 & 1.5 & 1330 & 24 & $36(3)$ & 25 & $\begin{array}{c}\mathrm{O}+\mathrm{Opx}+\mathrm{Cpx}+ \\
\mathrm{Sp}+\mathrm{Gl}\end{array}$ \\
\hline ETDMM31 & 12 & 1.5 & 1350 & 24 & $25(1)$ & 16 & $\begin{array}{c}\mathrm{O} 1+\mathrm{Opx}+\mathrm{Cpx}+ \\
\mathrm{Sp}+\mathrm{Gl}\end{array}$ \\
\hline ETDMM22 & 96 & 1.5 & 1350 & 24 & $31(2)$ & 15 & $\begin{array}{c}\mathrm{O} 1+\mathrm{Opx}+\mathrm{Cpx}+ \\
\mathrm{Sp}+\mathrm{Gl}\end{array}$ \\
\hline ETDMM25 & 96 & 1.5 & 1370 & 24 & $23(1)$ & 18 & $\begin{array}{c}\mathrm{Ol}+\mathrm{Opx}+\mathrm{Cpx}+ \\
\mathrm{Sp}+\mathrm{Gl}\end{array}$ \\
\hline ETDMM26 & 24 & 1.5 & 1390 & 24 & $28(1)$ & 6 & $\begin{array}{c}\mathrm{O} 1+\mathrm{Opx}+\mathrm{Cpx}+ \\
\mathrm{Sp}+\mathrm{Gl}\end{array}$ \\
\hline ETDMM27 & 24 & 1.5 & 1410 & 24 & $19(1)$ & 7 & $\begin{array}{c}\mathrm{O}+\mathrm{Opx}+\mathrm{Cpx}+ \\
\mathrm{Sp}+\mathrm{Gl}\end{array}$ \\
\hline ETDMM28 & 24 & 1.5 & 1430 & 24 & $13(1)$ & 8 & $\begin{array}{l}\mathrm{Ol}+\mathrm{Opx} \\
+\mathrm{Sp}+\mathrm{Gl}\end{array}$ \\
\hline
\end{tabular}

d. Number in parentheses are 2 standard error uncertainties.

e. Run products are olivine (ol), orthopyroxene (opx), clinopyroxene (cpx), spinel (sp), and optically identified glass (gl). All experiments also included San Carlos olivine spheres. 


\section{Table S3.}

Mass balance calculation for experiment ETDMM18: $\mathrm{T}=1250^{\circ} \mathrm{C}$.

\begin{tabular}{lccc}
\hline \multicolumn{1}{c}{ Phase } & $\begin{array}{c}\text { Phase proportion } \\
(\%)\end{array}$ & $\begin{array}{c}\text { Phase } \mathrm{H}_{2} \mathrm{O} \\
\text { content }\end{array}$ & $\begin{array}{c}\text { Total DMM } \mathrm{H}_{2} \mathrm{O} \\
\text { content }\end{array}$ \\
& 5 & $(\mu \mathrm{g} / \mathrm{g})$ & $(\mu \mathrm{g} / \mathrm{g})$ \\
\hline San Carlos olivine & 56 & 32 & 2 \\
Olivine & 21 & 32 & 18 \\
Orthopyroxene & 15 & 351 & 74 \\
Clinopyroxene & 3 & 309 & 45 \\
Spinel & & 0 & 0 \\
& 100 & - & 139 \\
Total & & & \\
\end{tabular}

a. Phase proportions were recalculated assuming 5\% San Carlos olivine and 95\% run produced minerals. 


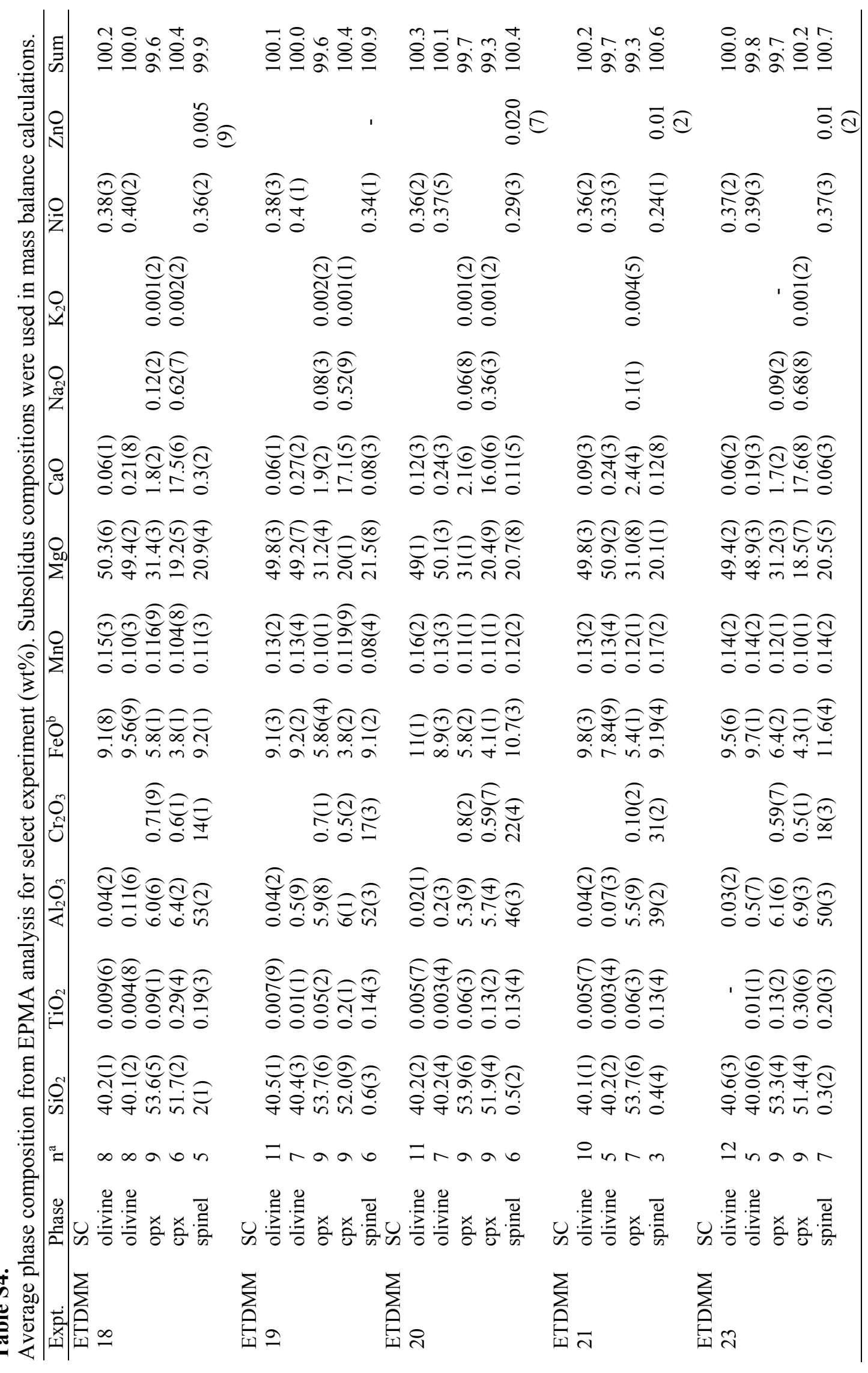




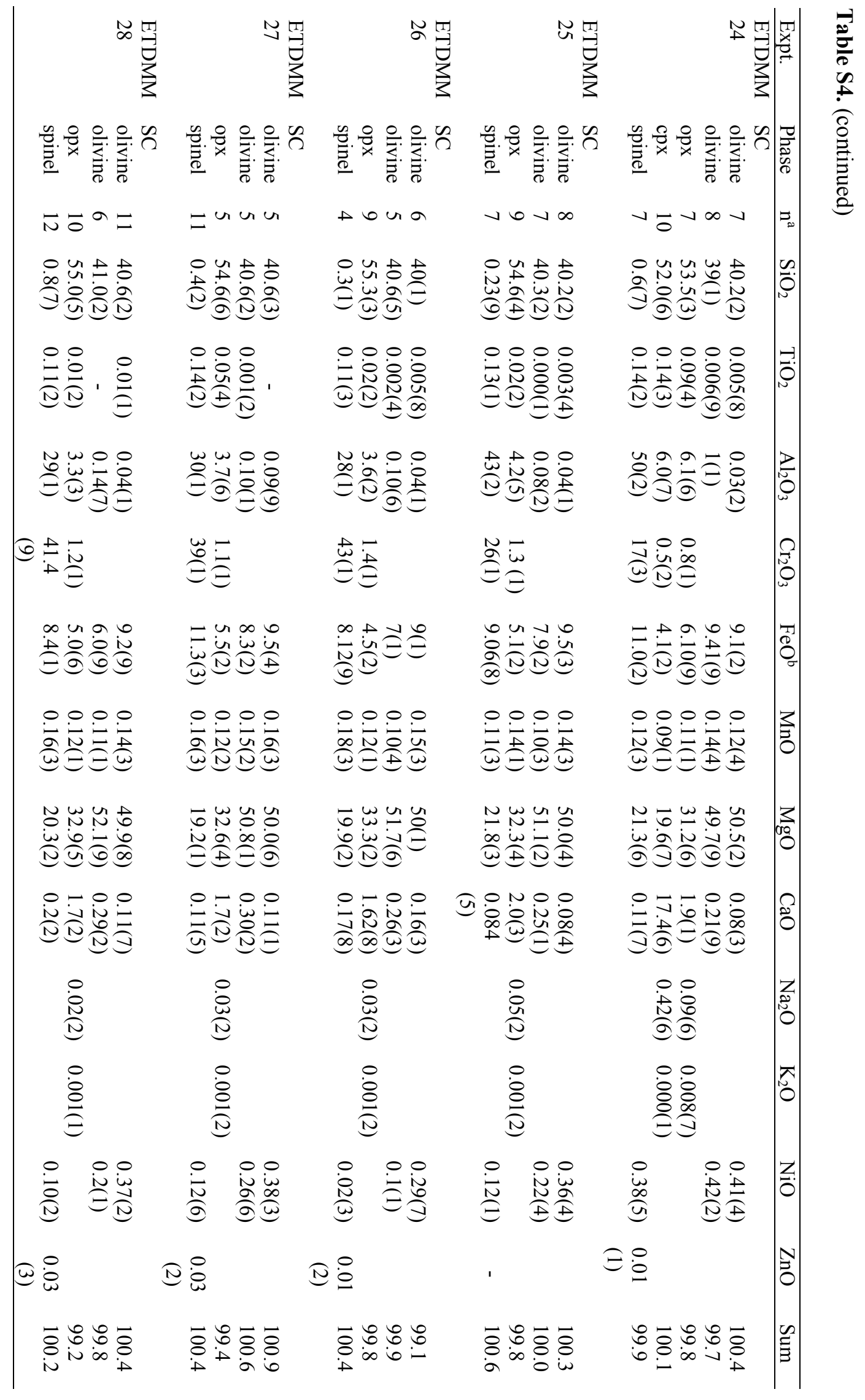




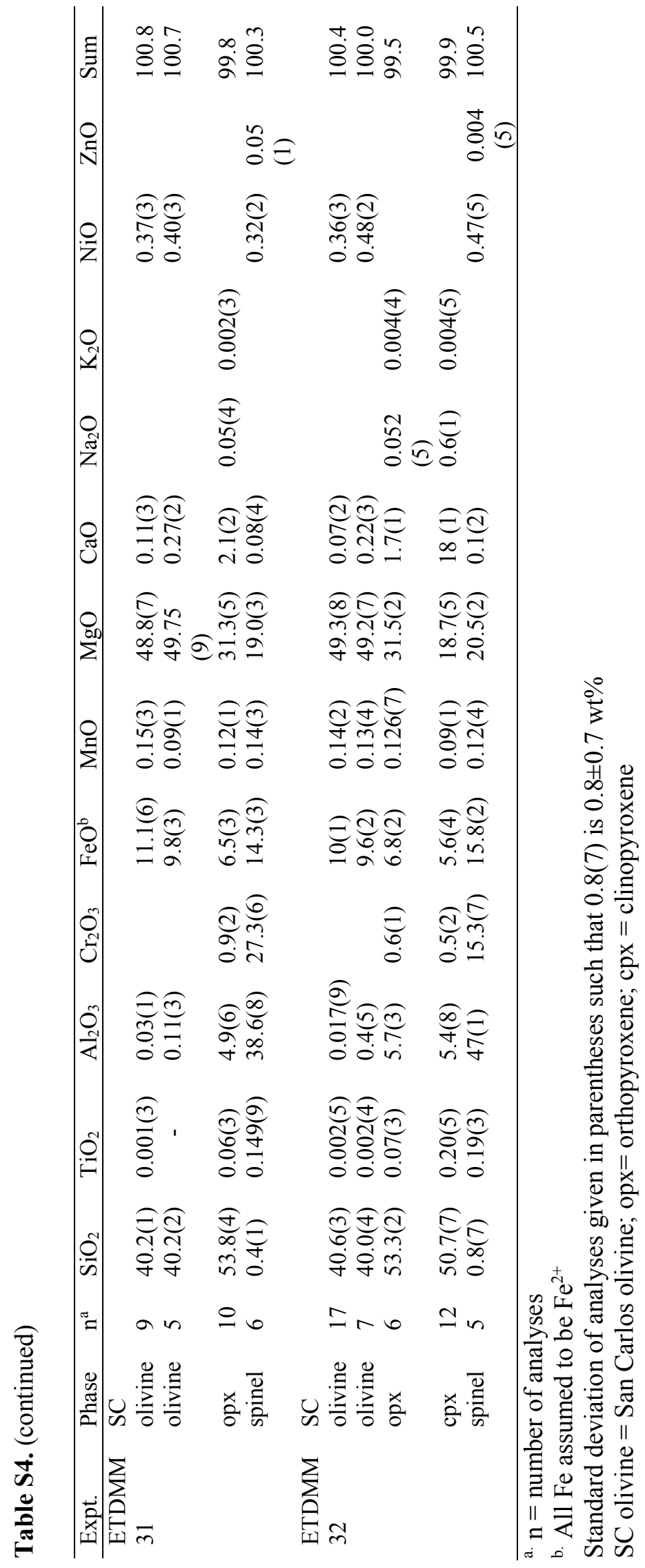




\section{Appendix B}

\section{Supplementary materials for Chapter 3}

\section{B.1 Materials and Methods Check List}

\section{Synthetic Peridotite Mixture}

Table 1 lists the oxides and the corresponding normalized weight percent, the components used to produce the starting mixture with the respective drying conditions, and weights of each component.

1. Weigh $20 \%$ more than the desired amount of $\mathrm{MgO}$ and dry at listed conditions. $\mathrm{MgO}$ is known to adsorb a lot of water very quickly, so in order to ensure there is enough $\mathrm{MgO}$ post drying to form the starting mixture we weigh $20 \%$ more than desired. The goal is to have a $\sim 10$ g supply of peridotite.

2. Once $\mathrm{MgO}$ is dried, quickly weigh the amount of $\mathrm{MgO}$ (must be quick to minimize water adsorption). Store the dried $\mathrm{MgO}$ in a clean vessel in the desiccator. Adjust the desired weights of the other components to the weight of dried $\mathrm{MgO}$ in order to maintain the same weight percentages (Table 1).

3. Dry all other components at listed conditions and be sure to dry excess of the desired (and $\mathrm{MgO}$ adjusted) weight. Once dried, quickly weigh out the desired amount of the component and store in a clean vessel in the desiccator.

4. Grind individual components under ethanol for 6 hours in an automated agate mortar and pestle to ensure the components are homogeneous. To do this: the automated grinder will run for 1 hour, then the component must be completely dried down and hand crushed into a powder before covering in ethanol and ground again (repeat this 6 times). When adding the ethanol, be sure to check that there is not so much that the slurry will spill over the sides of the mortar.

5. After all components are dried, weighed, and homogenized, the peridotite mixture can be synthesized. A $10 \mathrm{~g}$ synthetic peridotite mix is formed by combining the weighed and homogenized components and grinding the combined components under ethanol for 
another 6 hours in order to obtain the desired homogeneous starting material. Follow the directions in step 4 for grinding.

6. Store the complete synthetic peridotite mixture at standard pressure and temperature conditions in a clean vessel with a lid in a desiccator.

\section{San Carlos Olivine Spheres}

1. Obtain an air abrasion chamber such as used to generate zircon spheres, olivine shards $250-500 \mu \mathrm{m}$ in diameter, pyrite $150-250 \mu \mathrm{m}$ in diameter, and 400 mesh nylon abrasion paper.

2. Hand pick the cleanest, most spherical, inclusion free olivine shards under binoculars.

3. Clean the abrasion chamber by taking apart the apparatus and submerging all pieces in ethanol. Place submerged apparatus parts in an ultrasonic bath for $5-10$ minutes. Do this step often throughout use to maintain the apparatus and avoid clogging the air passage.

4. Cut a circle of 400 mesh paper, $4 \mathrm{~cm}$ in diameter, to cover the holes of the air abrasion chamber, but does not hang over the abrasion top (trim if necessary). An inner circle must be cut in the mesh paper, $1.6 \mathrm{~cm}$ in diameter, to allow for the air inlet. Reassemble the top of the apparatus with the mesh in place and screw on the inlet cap. Make sure not to fold or crinkle mesh as this will increase the possibility of tearing during sphere making.

5. In air abrasion chamber base, use a small spatula to measure two scoops of pyrite and one scoop of hand-picked olivine shards. Make sure that all material is within the "track" and not in the center of the chamber so that the chamber will close completely.

6. Place the assembled top of the chamber on the base. Place and tighten the outer ring to close the chamber. Cover the chamber with an old plastic Tupperware to minimize pyrite dust spreading throughout the lab.

7. Attach the air supply to the top of the chamber and turn on the air (should be set to 2.25 PSI).

8. Run for 15 hours.

9. Empty pyrite and olivine spheres into a clean vessel and fill vessel with distilled water. Allow the spheres to soak at least 24 hours in water (preferably warm if you can manage) to ensure easy cleaning of pyrite dust from the olivine spheres. 
10. Place vessel with olivine spheres and pyrite in an ultrasonic bath to clean pyrite from olivine spheres. This may require up to 1 hour, but frequently check the spheres to ensure they are clean of pyrite dust. It is helpful to use a pipette to remove the cloudy pyrite water (but not the olivine spheres) and fill the vessel with clean distilled water between ultrasonic sessions.

11. Once spheres are clean, transfer spheres onto a clean dish and hand pick the best olivine spheres.

\section{Conditioning the Synthetic Peridotite Mixture}

1. Set the Deltech furnace to $1050{ }^{\circ} \mathrm{C}$ and QFM. Remove the bottom plug to maintain the flow of gases.

2. Weigh a $\sim 700 \mathrm{mg}$ aliquot of the synthetic peridotite mixture and load in a large nickel bucket

3. Once the Deltech is at temperature and the correct buffer, hang the full large nickel bucket from the tower.

4. Slowly lower the tower and nickel bucket into the Deltech and tightly close the top of the Deltech.

5. Keep the mix in the Deltech at the same conditions for 3 or more days and monitor the oxygen fugacity and temperature.

6. Slowly remove the tower from the Deltech with full nickel bucket still attached. Allow tower and bucket to cool before handling.

7. Remove nickel bucket from tower and empty the contents onto weigh paper (the starting mixture should form a solid cylinder). Weigh the contents.

8. Place the synthetic peridotite mixture cylinder/large chucks into a clean Wig-L-Bug container and add the large glass crushing sphere.

9. Set up the Wig-L-Bug with the container full of the peridotite and run for $\sim 5$ minutes. The peridotite should be a fine powder. If not, run the Wig-L-Bug again.

10. Weigh the final powdered peridotite mixture. Store in a clean vessel covered with aluminum foil in a $120^{\circ} \mathrm{C}$ vacuum oven.

11. Calculate the weight of San Carlos olivine spheres needed (5\% of the weight of the synthetic peridotite mixture). 


\section{Making the Final Starting Mixture}

Complete this step only after the synthetic peridotite mixture is conditioned and enough olivine spheres have been made and completely cleaned of pyrite (at least $5 \%$ of the weight of the synthetic peridotite mixture).

1. Weigh out the correct amount of San Carlos olivine spheres.

2. Remove powered, conditioned synthetic peridotite mixture from the vacuum oven and place in a clean Wig-L-Bug container. Do NOT add the glass crushing sphere.

3. Add the San Carlos olivine spheres to the Wig-L-Bug container with the conditioned peridotite powder.

4. Run the Wig-L-Bug for 5-10 minutes.

5. Store the final starting mixture in a clean vessel covered with aluminum foil in a $120{ }^{\circ} \mathrm{C}$ vacuum oven.

\section{Conditioning the AuPd Capsules}

1. Set the Deltech furnace to $1250^{\circ} \mathrm{C}$ and QFM-1. Remove the bottom plug to maintain the flow of gases.

2. Make $3 \mathrm{Au}_{80} \mathrm{Pd}_{20}$ capsules $10 \mathrm{~mm}$ in length. Triple crimp and weld one end of each capsule. Clean in ethanol and ultrasonic bath.

3. Pack $3 \mathrm{Au}_{80} \mathrm{Pd}_{20}$ capsules with basalt (sample: AII 92 29-1). The basalt will saturate the capsules with $\mathrm{Fe}$ so there is no Fe loss during experiment.

4. Place 3 filled capsules in pyrophyllite capsule holder.

5. Once the Deltech is at temperature and the correct buffer, hang the full pyrophyllite capsule holder from the tower.

6. Move the hanger up or down so that the center of the pyrophyllite holder is aligned with the thermocouple and oxygen fugacity monitor. Mark this height at the top of the hanger (above the cooling head) and then raise the hanger to the top of the tower.

7. Slowly lower the tower with raised hanger into the Deltech and tightly close the top of the Deltech.

8. Very slowly lower the hanger into the Deltech by twisting. After 2 hours, the hanger should be lowered such that the marked height is situated above the cooling head as it 
was when the pyrophyllite contained was aligned with the thermocouple and oxygen sensor. This step must be done slowly to ensure that the powdered basalt does not overflow from the $\mathrm{Au}_{80} \mathrm{Pd}_{20}$ capsules when lowering.

9. Keep the packed capsules in the Deltech at the same conditions for $\sim 2$ days and monitor the oxygen fugacity and temperature.

10. Slowly remove the tower from the Deltech with pyrophyllite holder still attached. Allow tower and pyrophyllite to cool before handling.

11. Remove pyrophyllite holder from tower and empty the contents onto weigh paper. The basalt in the capsules should be glassed. Remove the glass by lightly squeezing the sides of the capsules with needle nosed pliers. The glass should crack and fall out in chunks. Clean the capsules well enough that you can see the triple crimped bottom of the capsule. No large pieces of basalt should remain.

12. Place the glass-free capsules in a screw top Teflon container. Safely add enough HF acid and Nitric acid (in $\sim 50: 50$ proportion) so that the capsules are completely submerged in acid. Screw the lid of the Teflon container on and seal the lid with parafilm.

13. Fill with distilled water and heat ultrasonic bath. Fill Teflon beaker with distilled water and place Teflon container with capsules and acid inside. Once ultrasonic bath is heated, place Teflon beaker with container in the ultrasonic bath and turn on sonicator.

14. Run warm ultrasonic bath for 24 hours. Then turn off and let cool for 24 hours.

15. Once cooled, remove Teflon container and Teflon beaker. Empty contents of beaker into waste container. Empty liquid contents of container into beaker (keep capsules in the container). Rinse container with distilled water 3 times - empty liquid contents into beaker between each rinse. Empty contents of beaker into waste container as necessary and then rinse beaker into waste container.

16. Use tweezers to remove cleaned $\mathrm{Au}_{80} \mathrm{Pd}_{20}$ capsules from cleaned Teflon container. The capsules should be perfectly clean of basalt and other residue. Place capsules in pyrex beaker and cover with ethanol. Clean capsules in ultrasonic bath (unheated) for $\sim 10$ minutes.

17. Dry cleaned capsules and store for use.

Experimental Materials 
1. Make $\mathrm{CaF}_{2}$ sleeves following written instructions in lab.

2. Drill appropriate sized $\mathrm{MgO}$ insulating sleeve from $\mathrm{MgO}$ thermocouple sleeve.

3. Cut $11.7 \mathrm{~mm} \mathrm{MgO}$ thermocouple sleeve, $1 \mathrm{~mm} \mathrm{MgO}$ solid spacer, $10 \mathrm{~mm} \mathrm{MgO}$ insulating sleeve (for experiment), and $9.1 \mathrm{~mm} \mathrm{MgO}$ solid spacer.

4. Place $\mathrm{MgO}$ spacers in muffle furnace at $1000^{\circ} \mathrm{C}$ for 24 hours to dry.

5. Cut $\mathrm{Pb}$ pieces for assembly.

6. Punch insulating sheets.

7. Fill conditioned $\mathrm{Au}_{80} \mathrm{Pd}_{20}$ capsule $\sim 2 / 3$ full with final starting mixture from vacuum oven. Triple crimp and cut top of the capsule, but do not weld shut. Store capsule in vacuum oven for 24 hours.

8. Once all experimental materials are made and ready for set up, remove packed capsule from vacuum oven and weld shut. Assemble the experimental furnace using a $\mathrm{CaF}_{2}$ sleeve with an inner graphite furnace, and $\mathrm{MgO}$ spacers as shown in Figure $\mathrm{S} 1$. This assemblage ensured that the experimental temperature was measured robustly. Assemble piston cylinder.

9. Run experiment.

\section{Polishing}

1. Quench experiment to room temperature.

2. Unload experimental capsule, cut open length-wise using slow speed saw, and mount in epoxy.

3. Once cut, you should be able to identify how many San Carlos olivine spheres are exposed.

4. Set polishers to force 5 and speed 20 .

5. Polish on 240 grit $\mathrm{SiC}$ for 5 minutes (or longer if not enough spheres are exposed), 320 grit $\mathrm{SiC}$ for 10 minutes, 400 grit $\mathrm{SiC}$ for 15 minutes, and 600 grit $\mathrm{SiC}$ for 20 minutes. Check number of spheres exposed. If not enough, start back on 240 grit and repeat.

6. Polish on $6 \mu \mathrm{m}$ diamond suspension for 60 minutes, $1 \mu \mathrm{m}$ diamond suspension for 90 minutes, $0.25 \mu \mathrm{m}$ diamond suspension for 90 minutes, and colloidal silica for 30 minutes. 


\section{B.2 Figures and Tables}

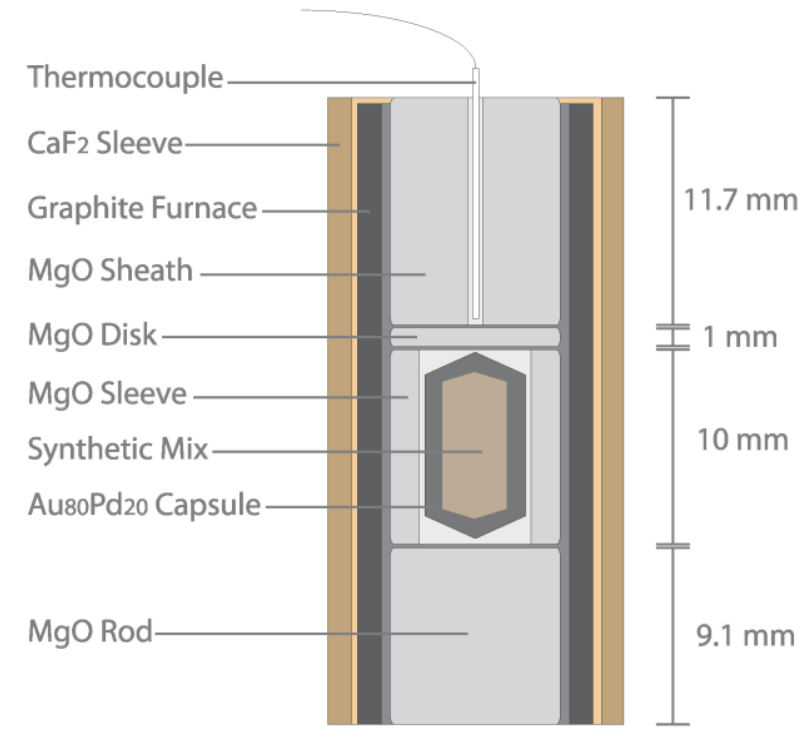

Fig. S1

Schematic of furnace assembly. 


\section{Fig. S2}

Photomicrograph of experiment ETDMM102. Red circles highlight olivine spheres.

\section{Pressure: 1.0 GPa}

Temperature: $1210^{\circ} \mathrm{C}$ 


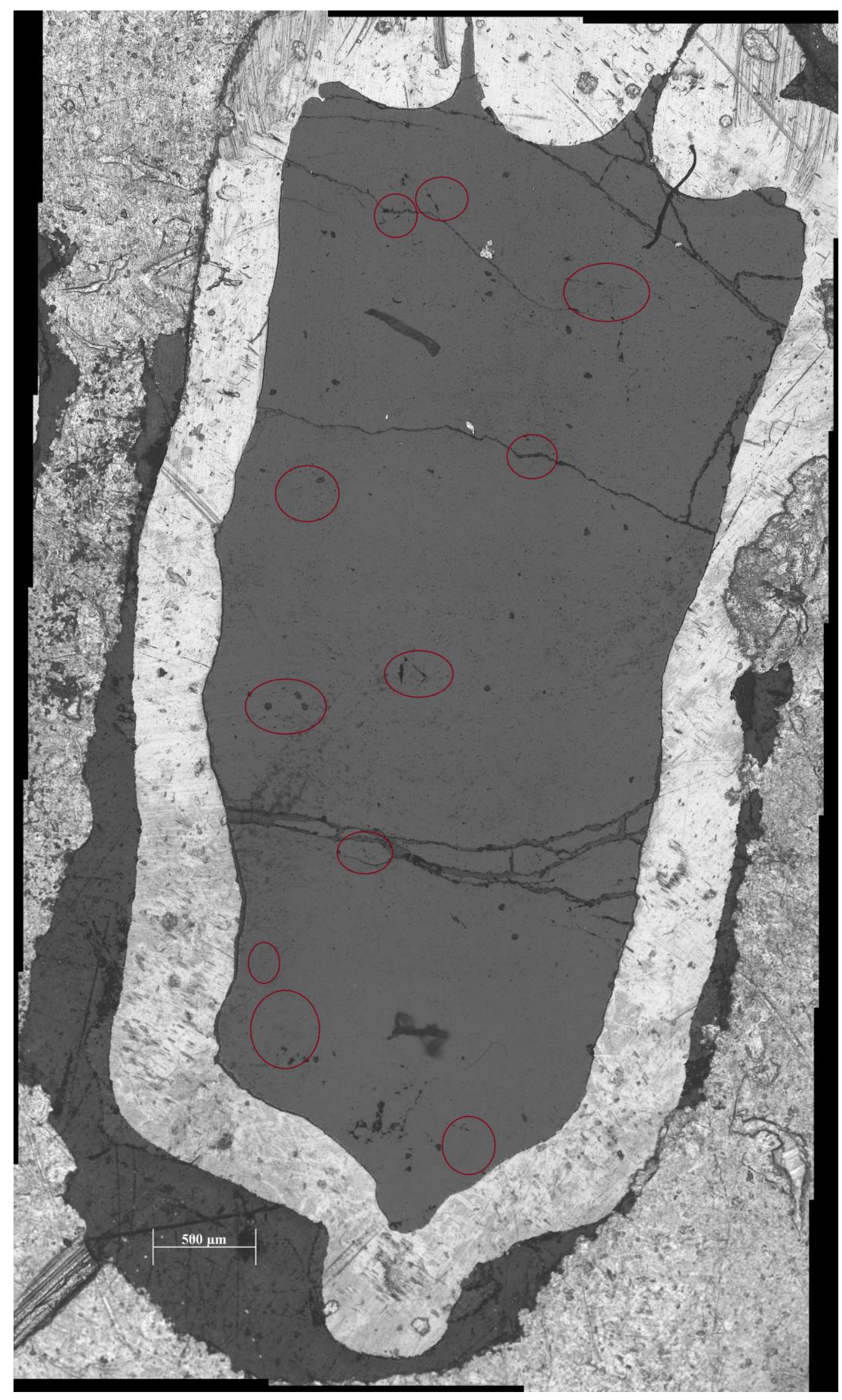


Fig. S3

Photomicrograph of experiment ETDMM108. Red circles highlight olivine spheres.

Pressure: 1.0 GPa

Temperature: $1330{ }^{\circ} \mathrm{C}$ 


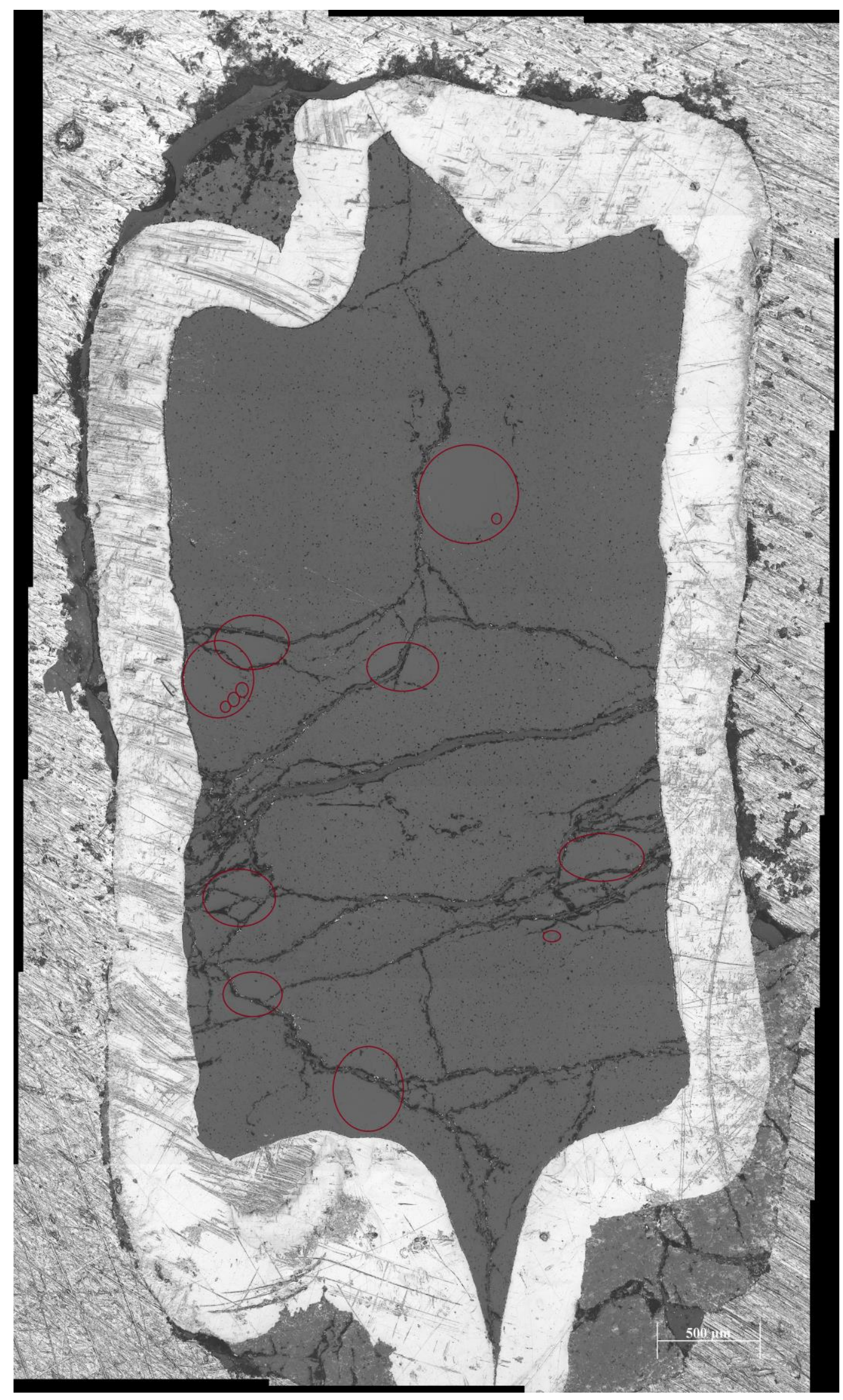




\section{Fig. $\mathbf{S 4}$}

Photomicrograph of experiment ETDMM18. Black squares highlight olivine spheres.

\section{Pressure: 1.5 GPa}

Temperature: $1250{ }^{\circ} \mathrm{C}$ 


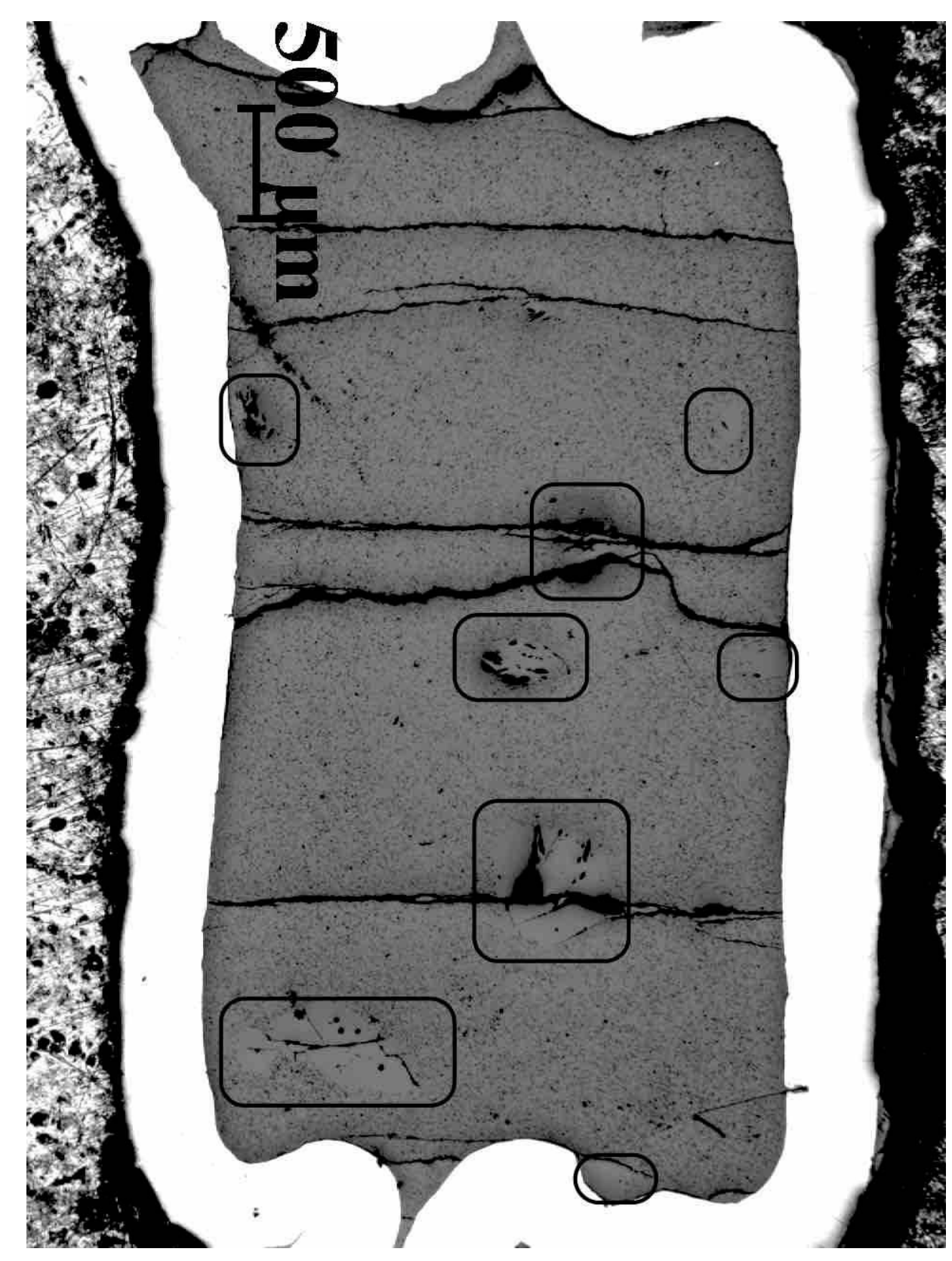


Fig. S5

Photomicrograph of experiment ETDMM28. Black squares highlight olivine spheres.

Pressure: $1.5 \mathrm{GPa}$

Temperature: $1430{ }^{\circ} \mathrm{C}$ 


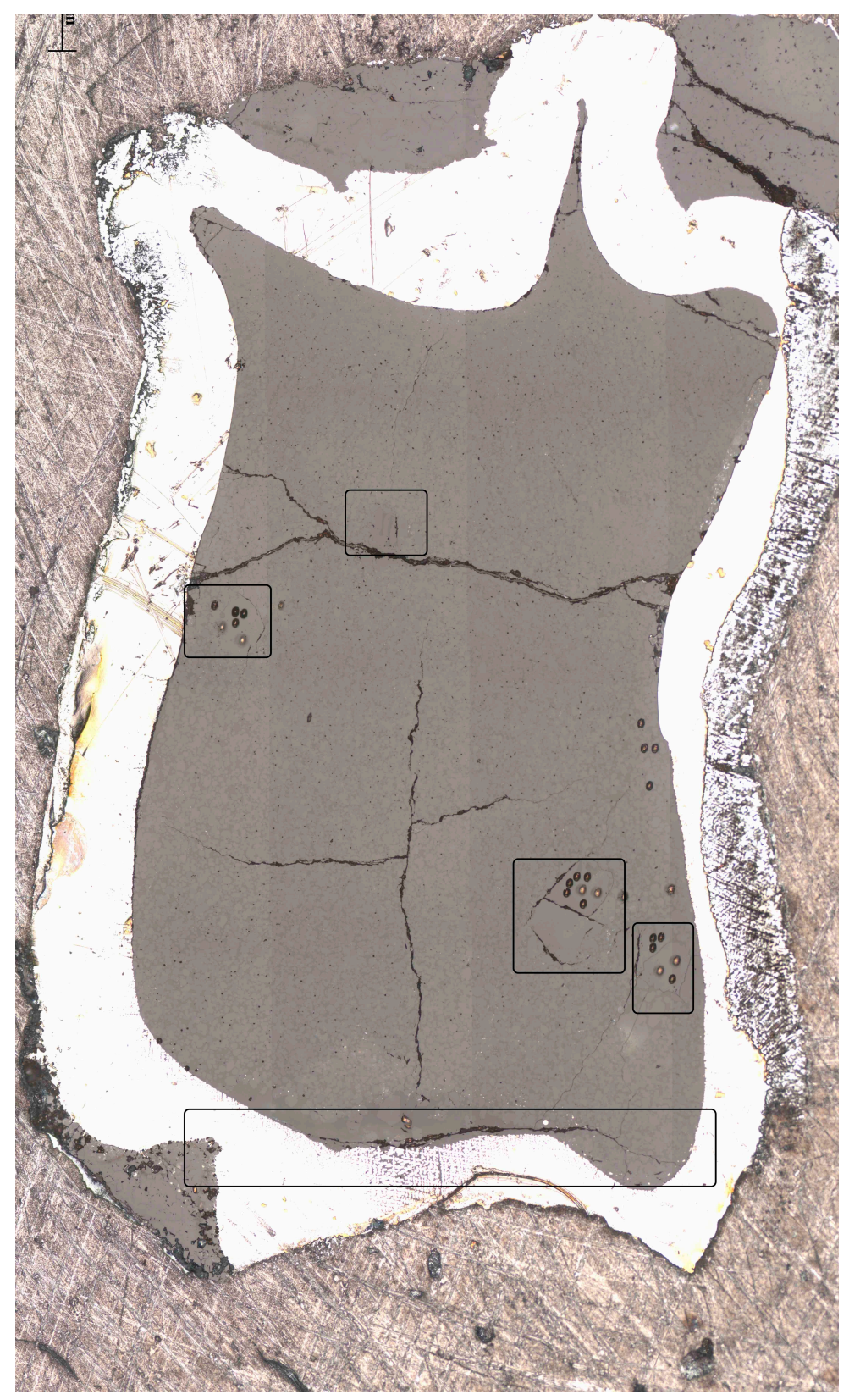




\section{Fig. S6}

Photomicrograph of experiment ETDMM201. Red circles highlight olivine spheres.

\section{Pressure: 2.0 GPa}

Temperature: $1310^{\circ} \mathrm{C}$ 


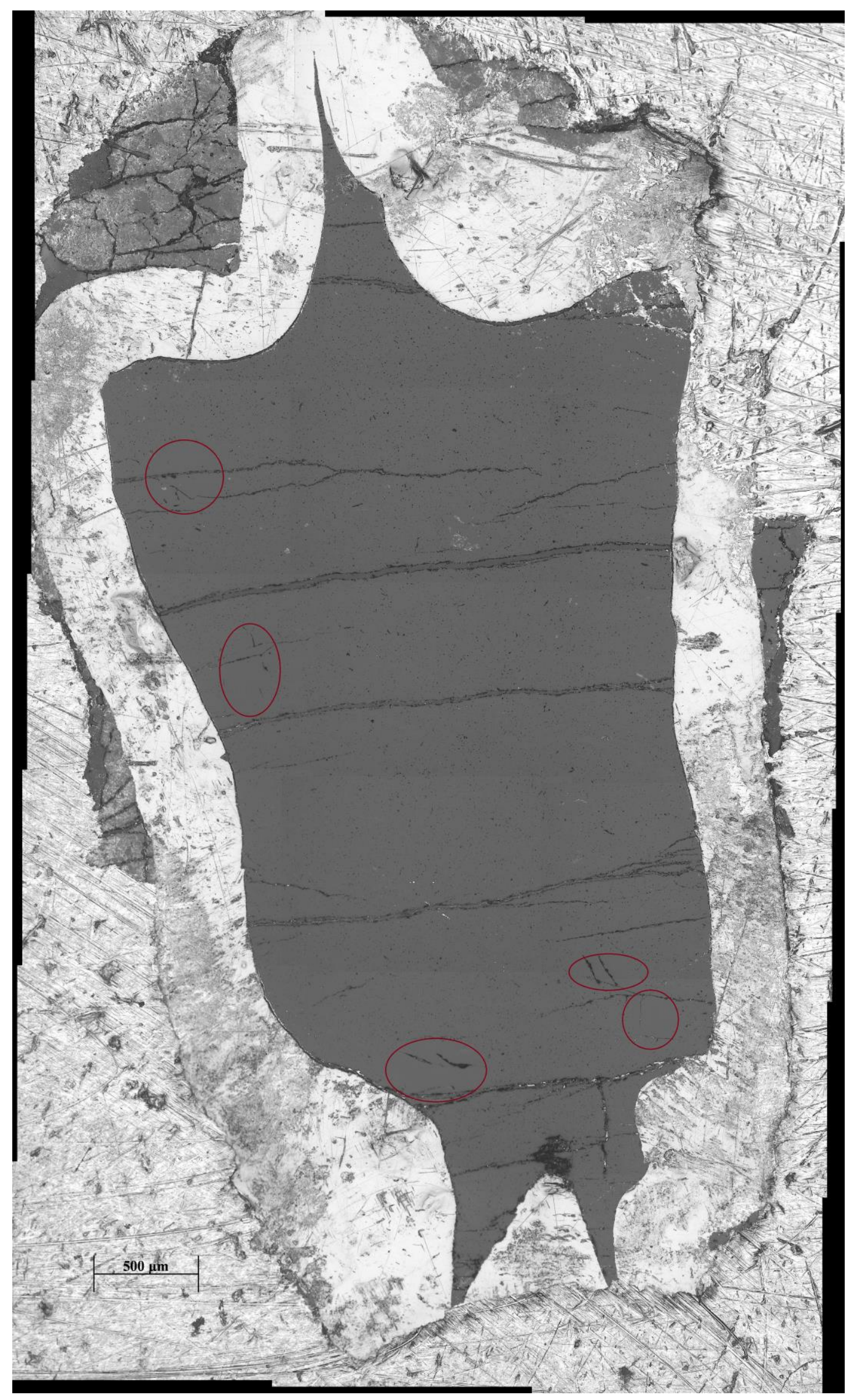




\section{Fig. S7}

Photomicrograph of experiment ETDMM208. Red circles highlight olivine spheres.

\section{Pressure: $2.0 \mathrm{GPa}$}

Temperature: $1450{ }^{\circ} \mathrm{C}$ 


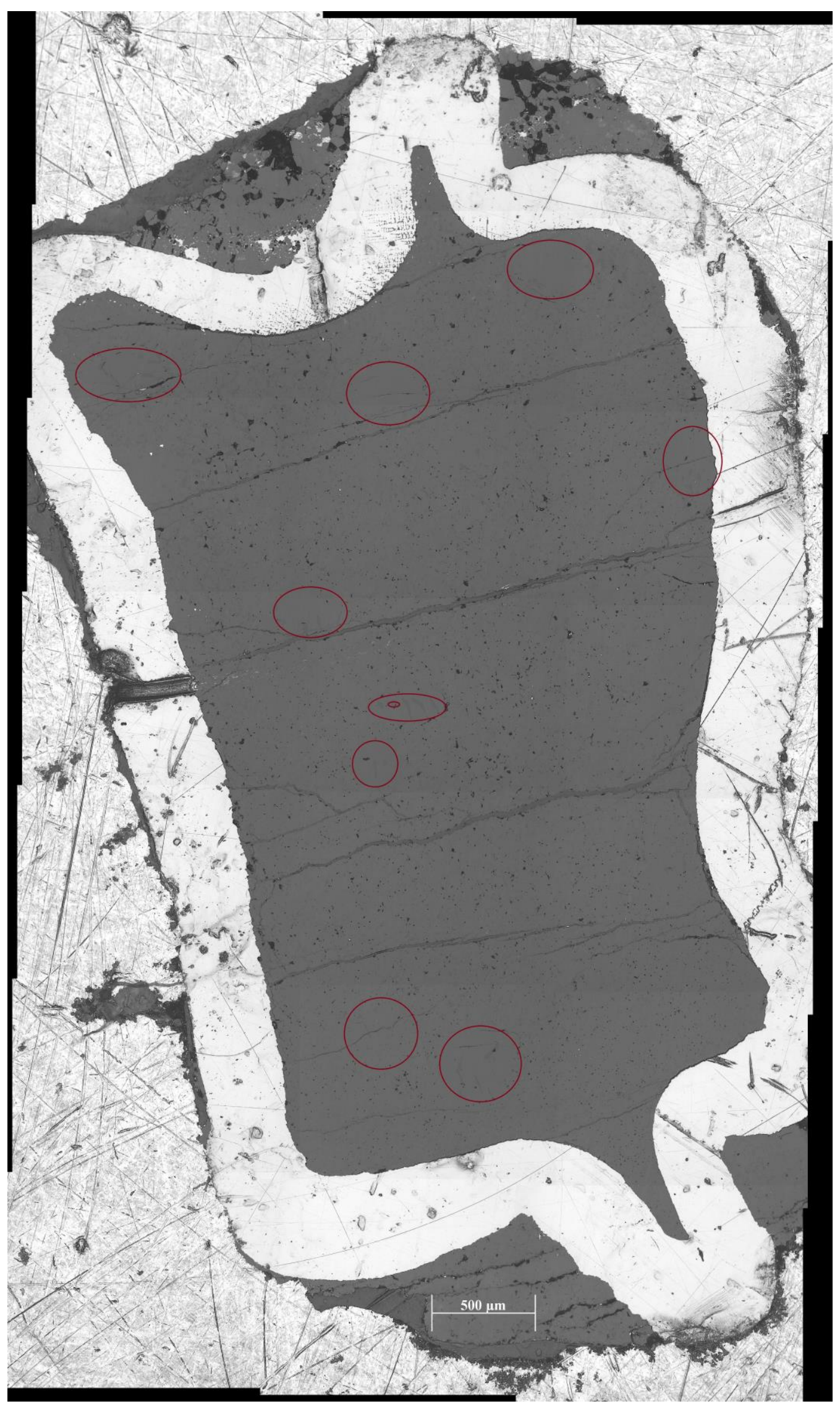




\section{Fig. S8}

Photomicrograph of experiment ETDMM259. Red circles highlight olivine spheres.

\section{Pressure: $2.5 \mathrm{GPa}$}

Temperature: $1350{ }^{\circ} \mathrm{C}$ 


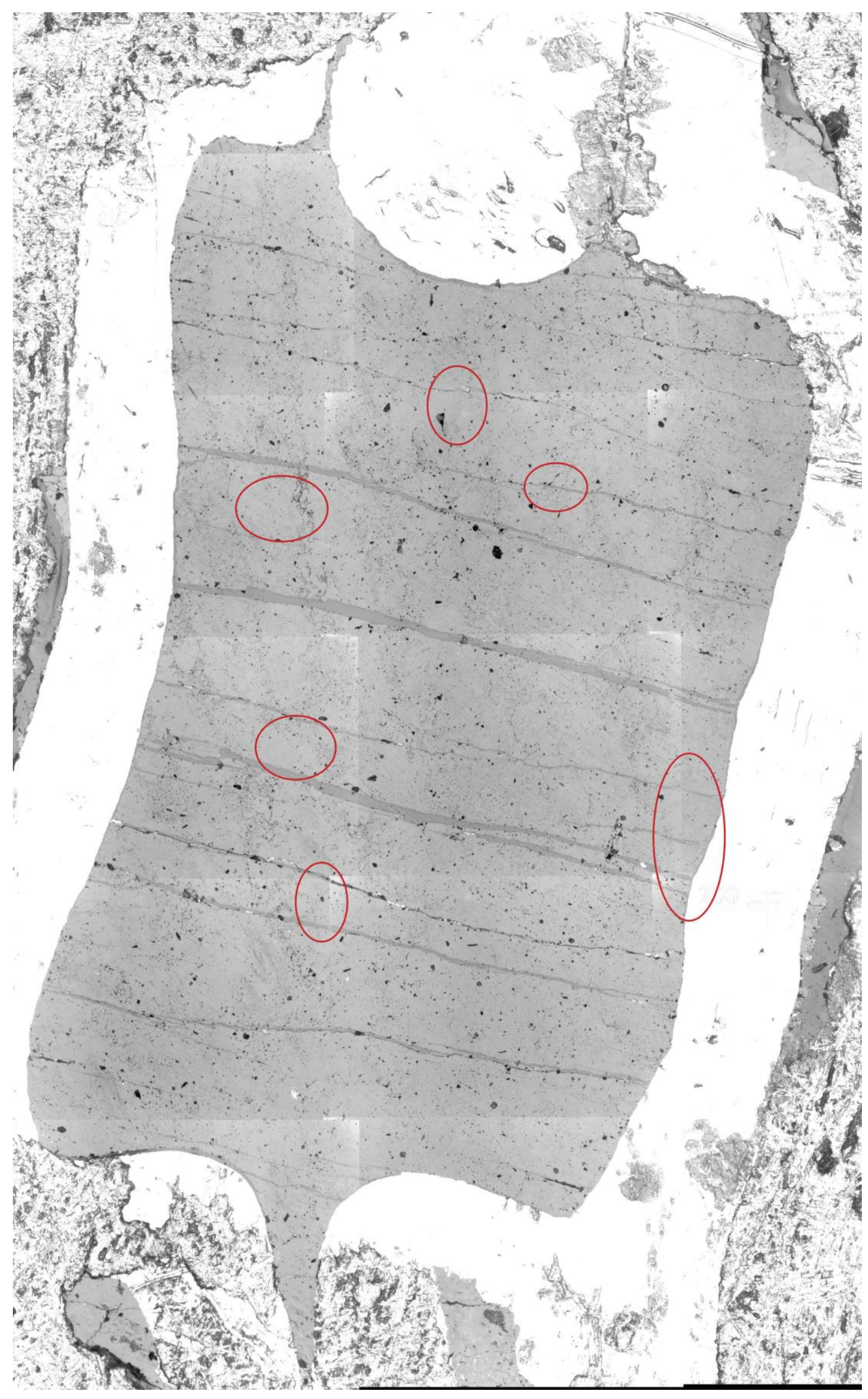




\section{Fig. S9}

Photomicrograph of experiment ETDMM256. Red circles highlight olivine spheres.

\section{Pressure: 2.5 GPa}

Temperature: $1490{ }^{\circ} \mathrm{C}$ 


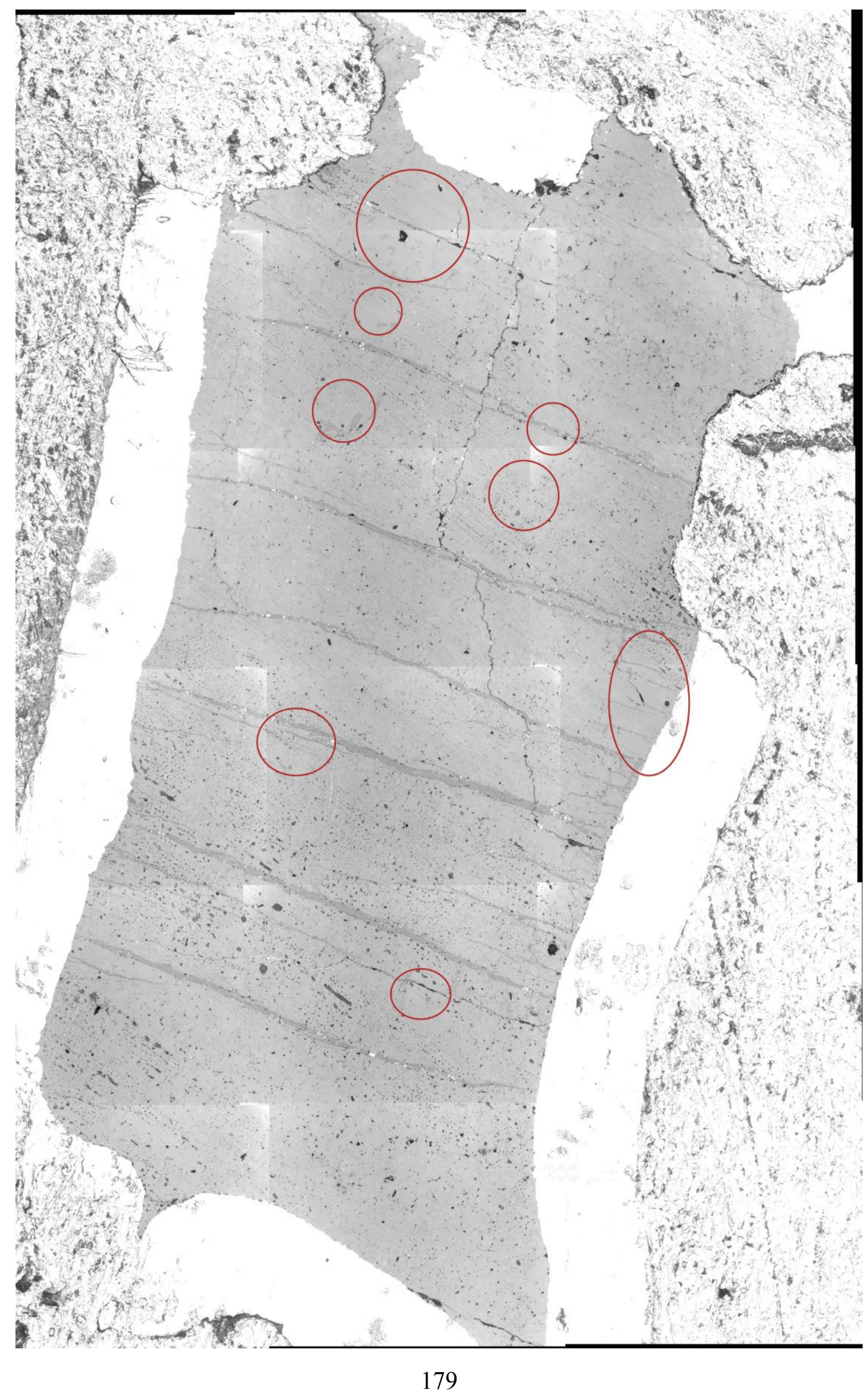




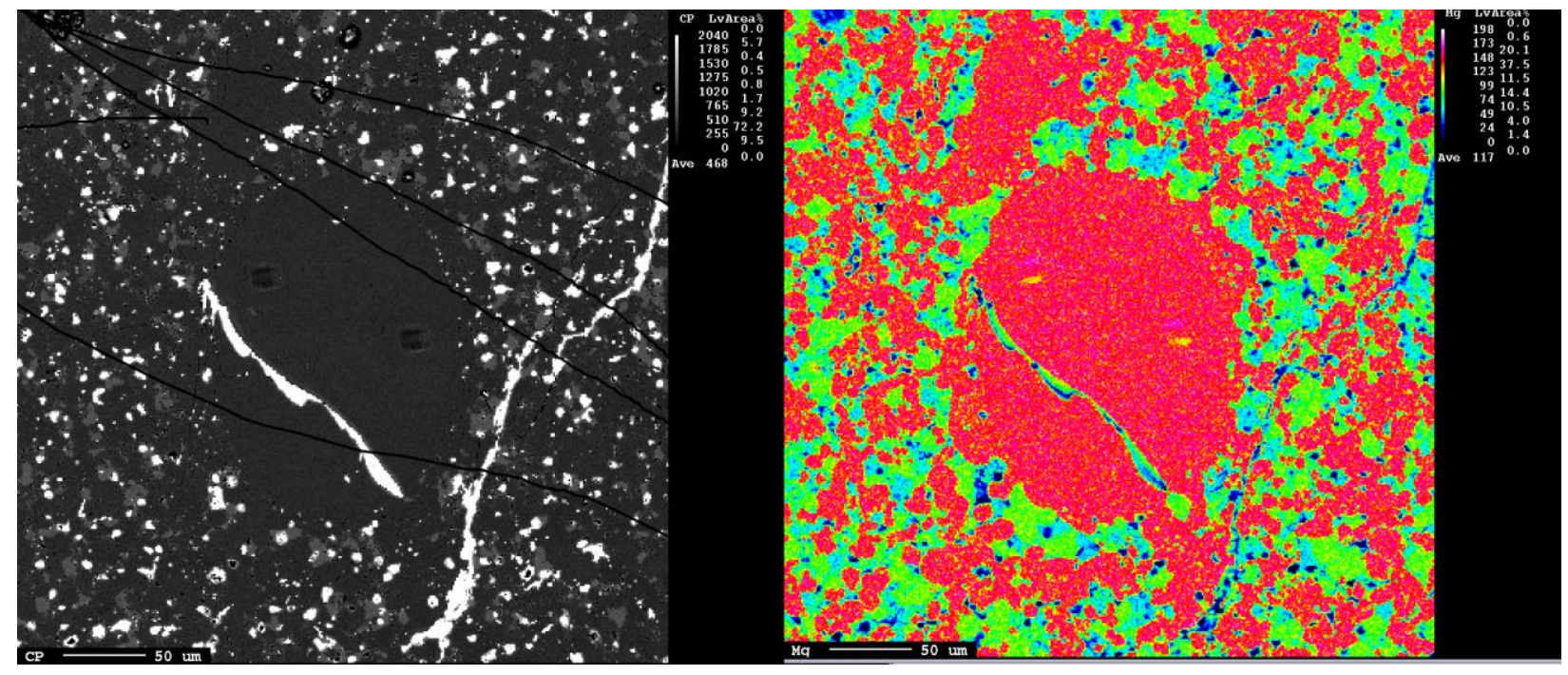

\section{Fig. S10}

A backscattered electron image of the run-produced peridotite mineral grains and an embedded San Carlos olivine sphere (left). Two 6f SIMS analyses are visible in the San Carlos olivine spheres. A map of $\mathrm{Mg}$ content over the same region (right). Warm colors indicate high $\mathrm{Mg}$ in olivine, yellow/green colors indicate intermediate $\mathrm{Mg}$ in pyroxene, and cool colors indicate low $\mathrm{Mg}$ in high-Ca pyroxene and spinel. 
Fig. S11

Phase map of experiment ETDMM28.

Pressure: 1.5 GPa

Temperature: $1430{ }^{\circ} \mathrm{C}$ 


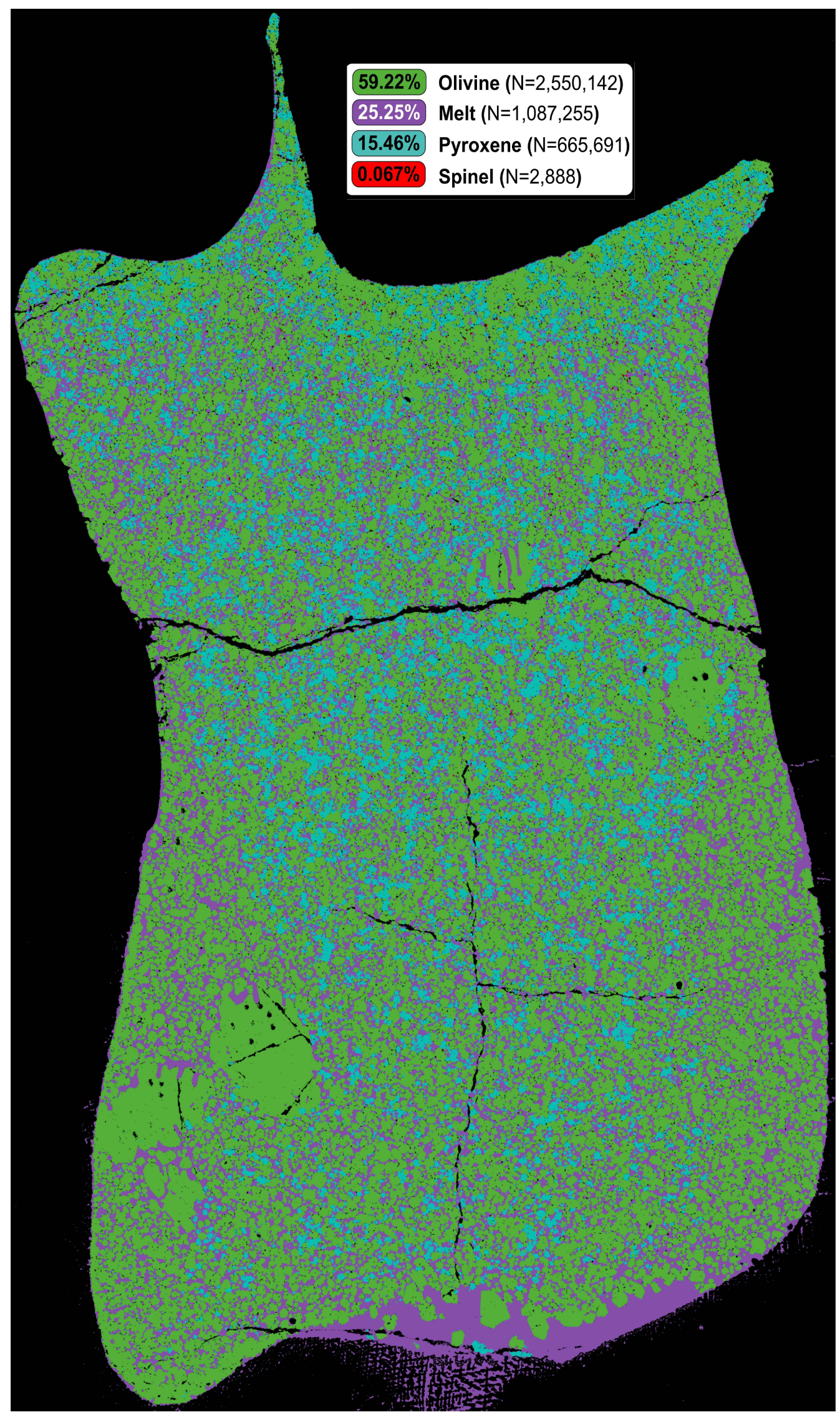




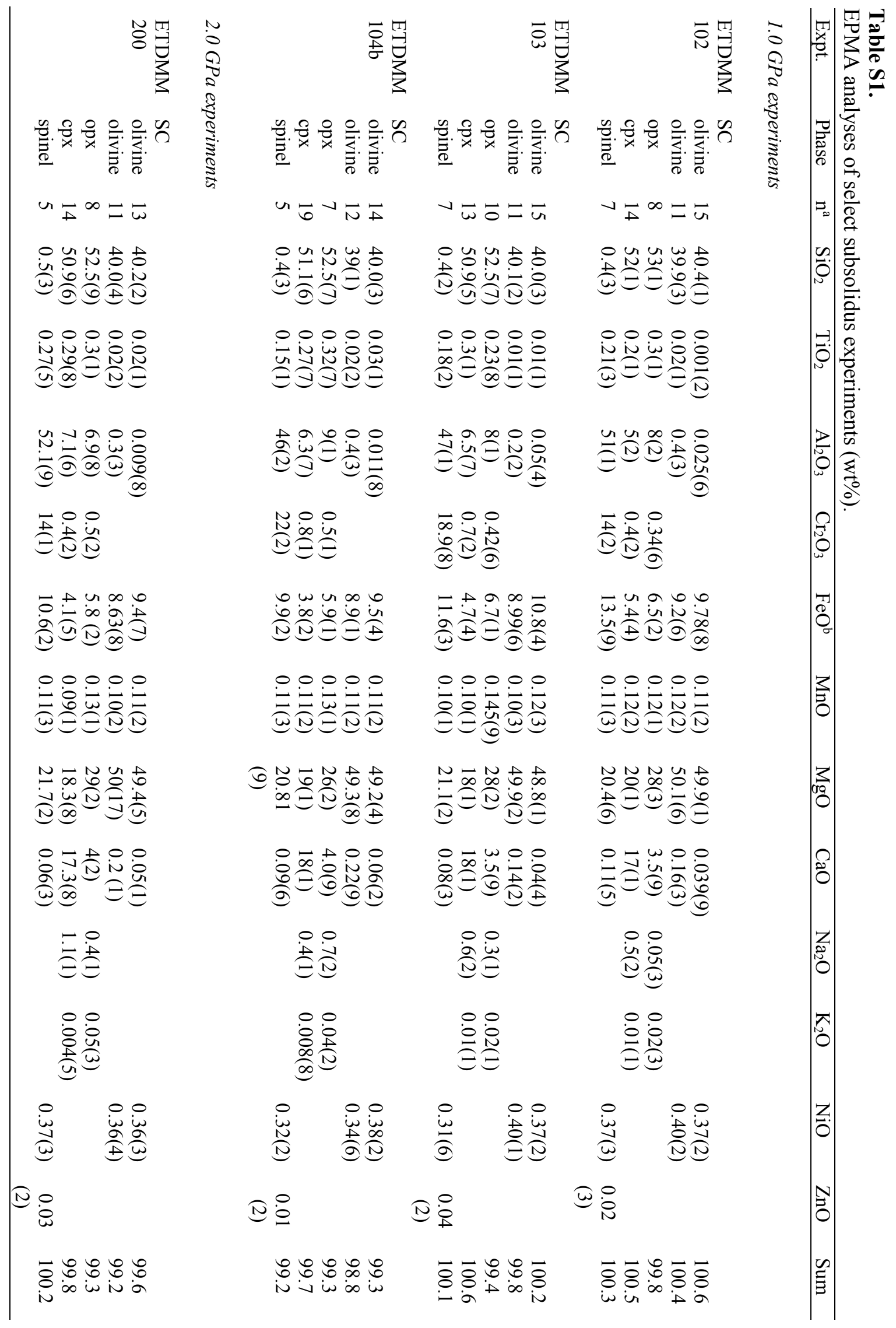




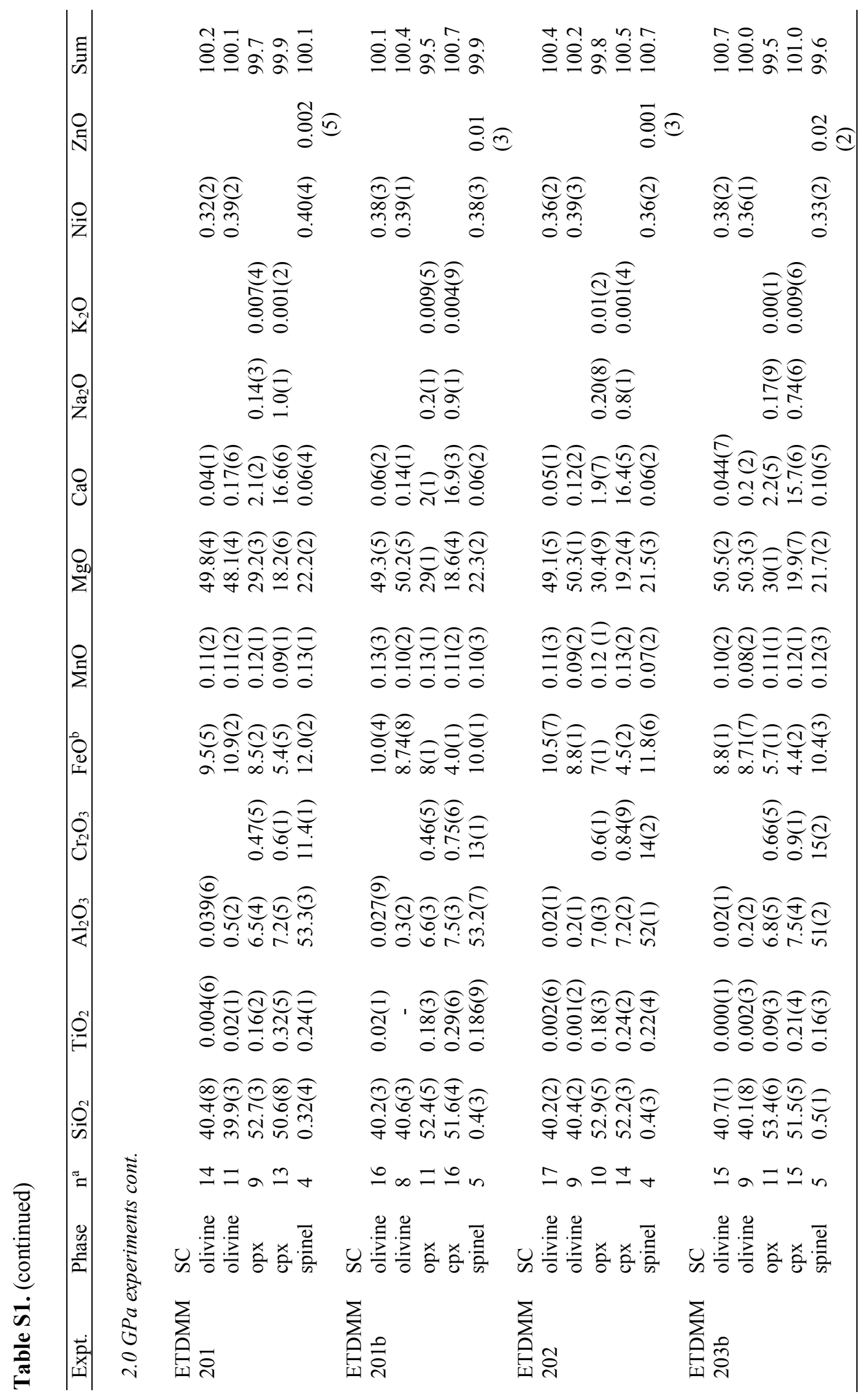




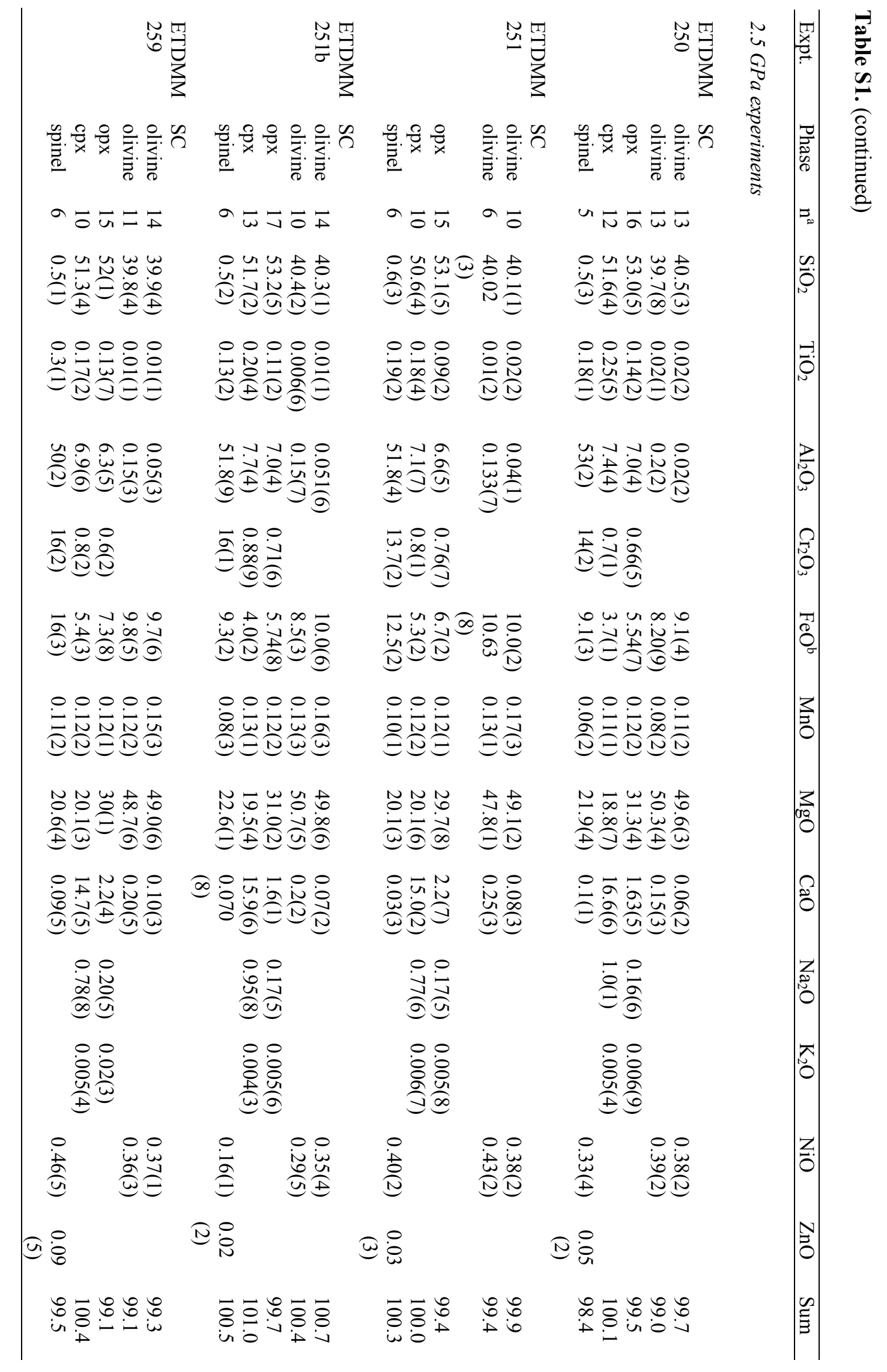




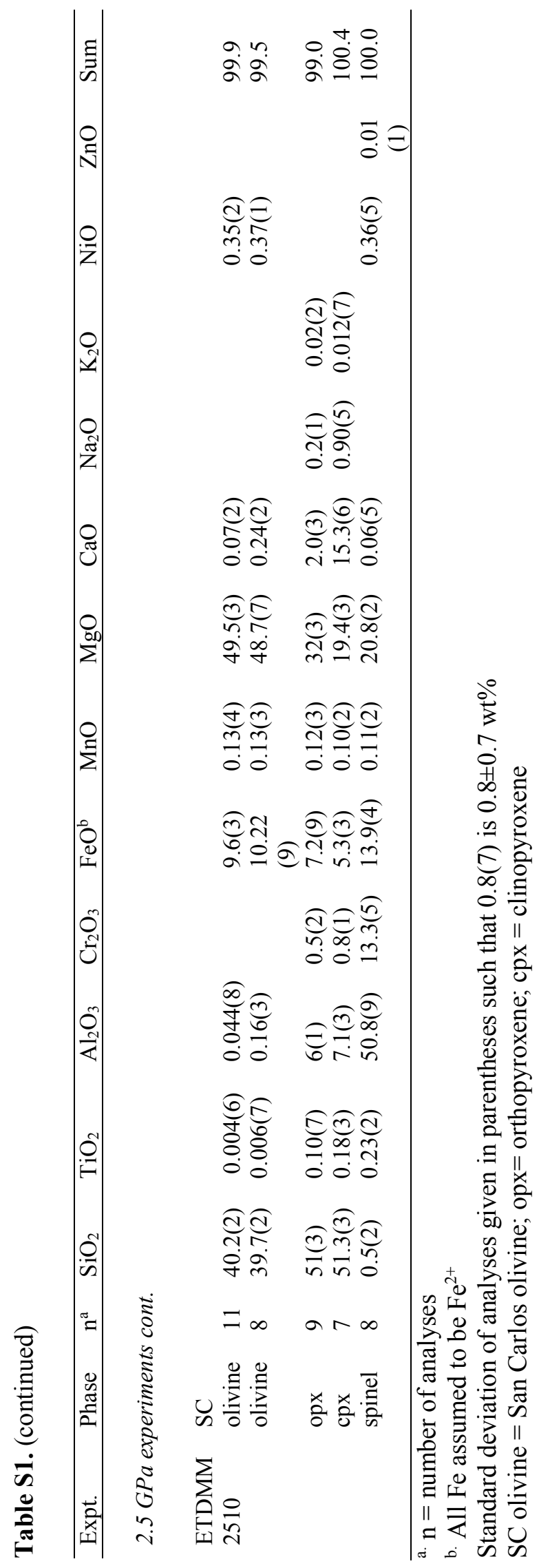

